\title{
ALSTOM
}

\section{Field Demonstration of Enhanced Sorbent Injection for Mercury Control}

\section{Final Report}

\author{
Submitted By \\ Alstom Power Inc. \\ 2000 Day Hill Road \\ Windsor, Connecticut 06095 \\ Shin Kang \\ Robert Schrecengost
}

Prepared For

NETL AAD Document Control Bldg. 921

US Department of Energy

National Energy Technology Laboratory

P.O. Box 10940

Pittsburgh, Pennsylvania 15236-0940

(Cooperative Agreement No. DE-FC26-04NT42306)

Final Report Submittal Date: November 12, 2008

Performance Period: October 1, 2004 - September 30, 2007 


\section{Disclaimer}

This report was prepared as an account of work sponsored by an agency of the United States Government. Neither the United States Government nor any agency thereof, nor any of their employees, makes any warranty, express or implied, or assumes any legal liability or responsibility for the accuracy, completeness, or usefulness of any information, apparatus, product, or process disclosed, or represent that its use would not infringe privately owned rights. Reference herein to any specific commercial product, process, or service by trade name, trademark, manufacturer, or otherwise does not necessarily constitute or imply its endorsement, recommendation, or favoring by the United States Government or any agency thereof. The views and opinions of authors expressed herein do not necessarily state or reflect those of the United States Government or any agency thereof. 


\section{Acknowledgements}

Any work of this scope requires the effort and cooperation of many individuals and groups. First of all, Alstom would like to thank the USDOE National Energy Technology Laboratory for their support of this work. The organizations providing co-funding for this program include:

- Basin Electric Power Cooperative

- North Dakota Industrial Commission (NDIC)

- PacifiCorp

- Reliant Energy

- Alstom Power Inc.

The support of Alstom management was invaluable in getting resources necessary to complete the projects. Key contributors include John Marion, Vice President of Alstom Boiler Technology; Dave O’Neill, General Manager for Alstom EBR - Windsor; and Kevin Taugher, R\&D and Technology Director for Alstom EBR.

Key contributions to the project management and accomplishments were made by Dr Shin G. Kang, Prinicipal Investigator and later Program Manager for this work, and by Dr. Srivats Srinivasachar, Program Manager for the first two host sites for this work. Key members of the project team who supported field testing at the various host sites include:

Basin Electric

- Les Allery

- Robert Eriksen

- Rita Stalter

Pacificorp

- Gregory Betenson

- Heather Bleile

- Bob Bilger (ISG contractor on site for ash testing)

Reliant Energy

- Rich Cresko

- Ray Himes

- Eric Lieb

- Eric Roland

- David Yosh

UND-EERC

- Steve Benson

- John Kay

- Don McCollor

- Richard Schulz

- Don Toman

- Mike Wuitshick 
Alstom Power, Inc.

- Stanley Bohdanowicz

- Ray Cournoyer

- Kurt Johnson

- Ray MacWhinnie

- Ken Petersen 


\section{Public Abstract}

Alstom Power Inc. has conducted a DOE/NETL-sponsored program (under DOE Cooperative Agreement No. DE-FC26-04NT42306) to demonstrate Mer-Cure ${ }^{\mathrm{TM}}$, one of Alstom's mercury control technologies for coal-fired boilers. Mer-Cure ${ }^{\mathrm{TM}}$ utilizes a small amount of Mer-Clean ${ }^{\mathrm{TM}}$ sorbent that is injected into the flue gas stream for oxidation and adsorption of gaseous mercury. Mer-Clean ${ }^{\mathrm{TM}}$ sorbents are carbon-based and prepared with chemical additives that promote oxidation and capture of mercury. Mer-Cure ${ }^{\mathrm{TM}}$ is unique in that the sorbent is injected into an environment where the mercury capture kinetics is accelerated.

This full-scale demonstration program was comprised of three seven-week long test campaigns at three host sites including PacifiCorp's 240-MWe Dave Johnston Unit \#3 burning a Powder River Basin (PRB) coal, Basin Electric's 220-MWe Leland Olds Unit \#1 burning a North Dakota lignite, and Reliant Energy's 170-MWe Portland Unit \#1 burning an Eastern bituminous coal. All three boilers are equipped with electrostatic precipitators.

The goals for this Round 2 program, established by DOE/NETL under the original solicitation, were to reduce the uncontrolled mercury emissions by 50 to $70 \%$ at a cost 25 to $50 \%$ lower than the previous target of $\$ 60,000 / \mathrm{lb}$ mercury removed. The results for all three host sites indicated that Mer-Cure ${ }^{\mathrm{TM}}$ technology could achieve mercury removal of $90 \%$. The estimated mercury removal costs were $25-92 \%$ lower than the benchmark of $\$ 60,000 /$ lb mercury removed. The estimated costs for control, at sorbent cost of $\$ 1.25$ to $\$ 2.00 /$ lb respectively, are as follows:

- Dave Johnston Unit \#3 - \$2,650 to $\$ 4,328 / \mathrm{lb}$ Hg removed ( $92.8 \%$ less than $\$ 60 \mathrm{k} / \mathrm{lb}$ ),

- Leland Olds Unit \#1 - \$8,680 to $\$ 13,860 / \mathrm{lb} \mathrm{Hg}$ removed (76.7\% less than $\$ 60 \mathrm{k} / \mathrm{lb}$ ),

- Portland Unit \#1 - $\$ 28,540$ to $\$ 45,065 / \mathrm{lb}$ Hg removed (24.9\% less than $\$ 60 \mathrm{k} / \mathrm{lb})$,

In summary, the results from demonstration testing at all three host sites show that the goals established by DOE/NETL were exceeded during this test program. Mercury removal performance of greater than $90 \%$ reduction was above the $50-70 \%$ reduction goal, and mercury removal cost of 25 $92 \%$ lower than the benchmark was above the 25 to $50 \%$ cost reduction goal. 


\section{Table of Contents}

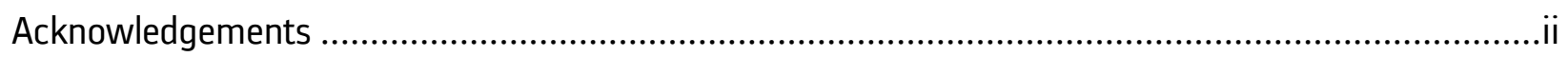

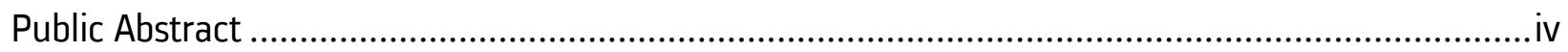

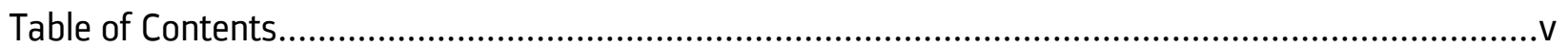

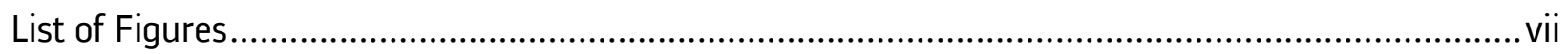

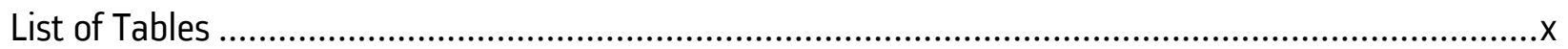

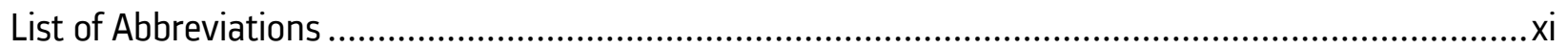

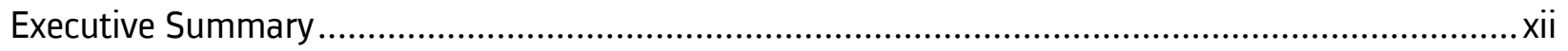

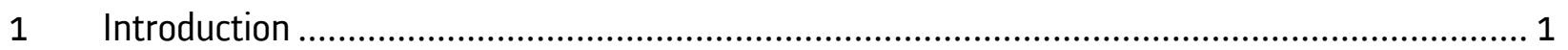

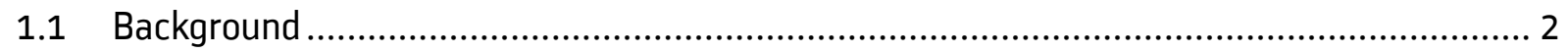

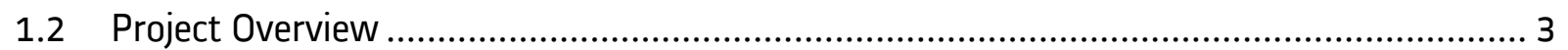

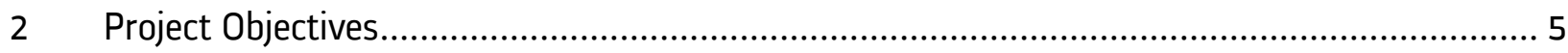

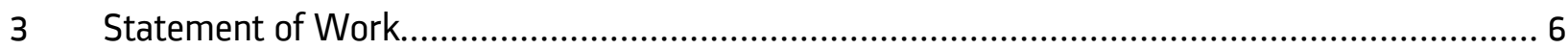

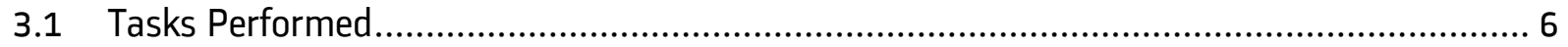

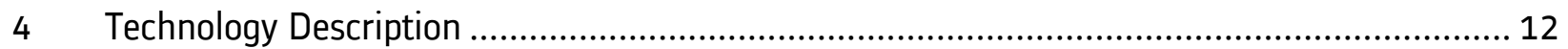

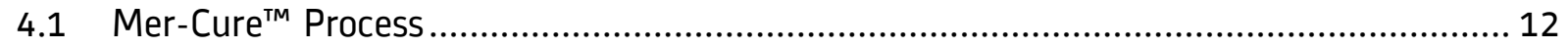

4.2 Mobile Mer-Cure ${ }^{\mathrm{TM}}$ Demonstration System ............................................................... 13

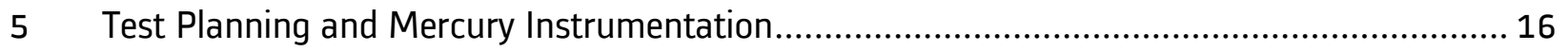

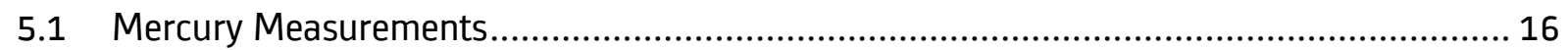

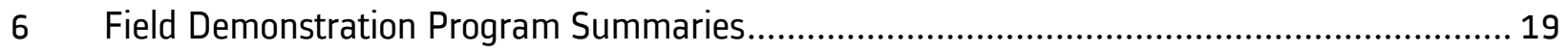

6.1 Dave Johnson Unit \#3.......................................................................................... 19

6.1.1 Pre-test Mercury Measurement at Dave Johnston Units ..................................... 19

6.1.2 Site Description and Test Preparation................................................................ 21

6.1.3 Baseline Testing Results ............................................................................... 27

6.1.4 Parametric Testing Results ......................................................................... 28

6.1.5 Long-Term Testing Results ............................................................................ 31

6.1.6 Balance of Plant Impacts........................................................................... 34

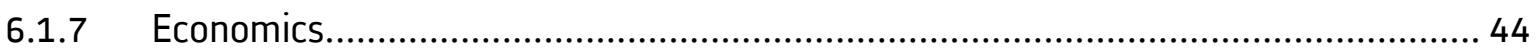

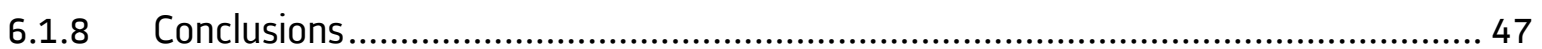

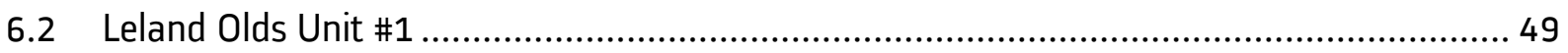

6.2.1 Site Description and Test Preparation............................................................... 49

6.2.2 Baseline Testing Results ............................................................................... 55

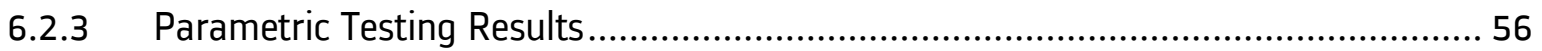

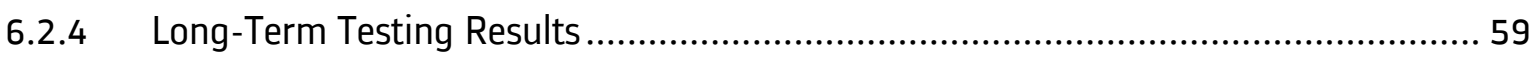

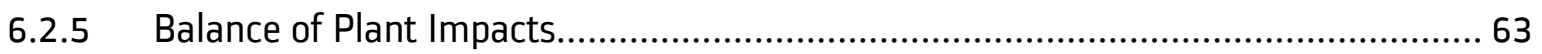

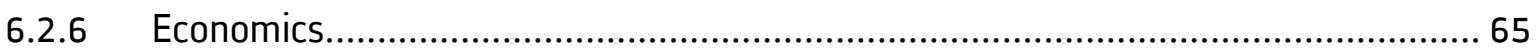

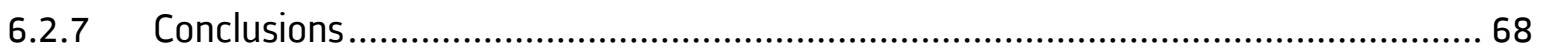

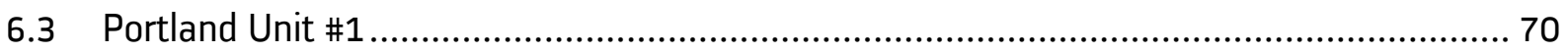

6.3.1 Site Description and Test Preparation................................................................. 70

6.3.2 Baseline Testing Results ........................................................................... 77 


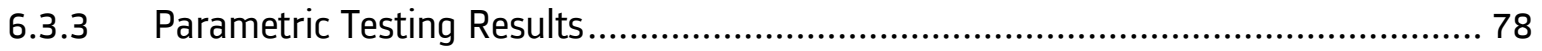

6.3.4 Long-Term Testing Results ........................................................................ 79

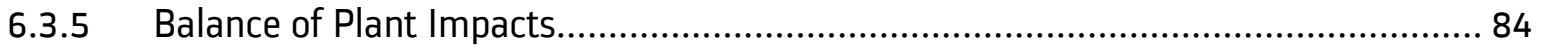

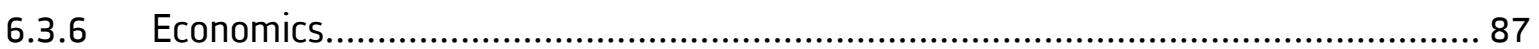

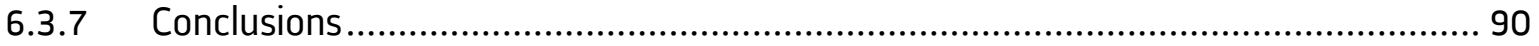

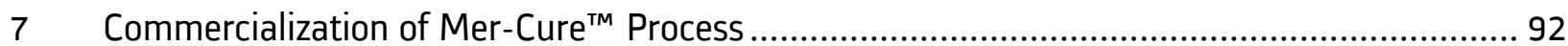

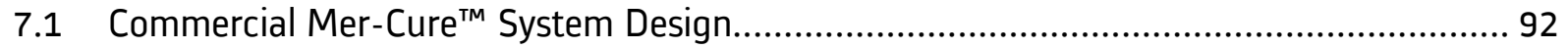

7.2 Status of Mer-Cure ${ }^{\mathrm{TM}}$ Commercialization Efforts ....................................................... 93

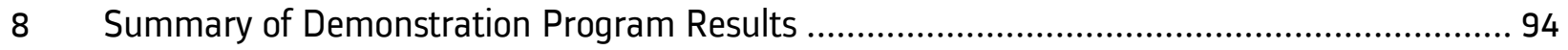

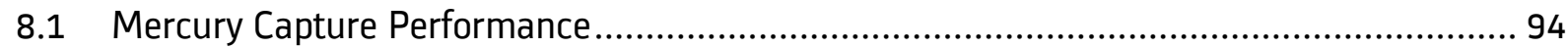

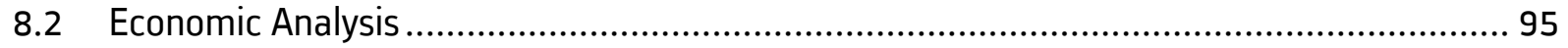

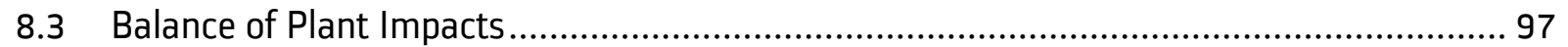

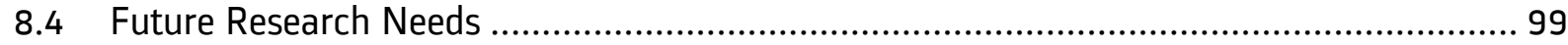

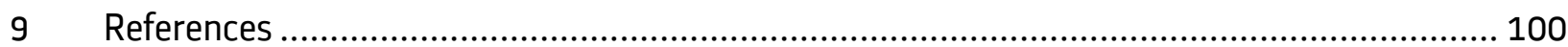




\section{List of Figures}

Figure i-1 Mercury Capture Results for Demonstration Project Host Sites .................................... xiv

Figure i-2 Mercury Removal Costs for Demonstration Project Host Sites .......................................xv

Figure 4.1-1 Alstom's Mer-Cure ${ }^{\mathrm{TM}}$ Technology for Mercury Capture ............................................ 12

Figure 4.2-1 Mobile Mer-Cure ${ }^{\mathrm{TM}}$ Demonstration Trailer Schematic .............................................. 13

Figure 4.2-2 On Site Assembly of Mobile Mer-Cure ${ }^{\mathrm{TM}}$ Demonstration Trailer................................. 14

Figure 5.1-1 Inertial Separation Probe at Air Preheater inlet CMM Location ................................ 17

Figure 5.1-2 Ontario Hydro Sample Train Schematic ................................................................ 18

Figure 6.1-1 Sorbent Injection Between Economizer and Air Heater for Dave Johnston Unit \#3...... 22

Figure 6.1-2 Flow Distribution Contours in the Back-Pass of Dave Johnston Unit \#3 ..................... 23

Figure 6.1-3 Flue Gas Flow Distribution at Sorbent Injection Location of Dave Johnston Unit \#3 .... 23

Figure 6.1-4 Sorbent Distribution System....................................................................... 24

Figure 6.1-5 Sorbent Injection Lances .................................................................................. 24

Figure 6.1-6 Injection and Sampling Locations, Dave Johnston Unit \#3 ...................................... 25

Figure 6.1-7 Baseline Mercury Levels at Air Preheater Inlet and Stack........................................ 27

Figure 6.1-8 CMM Response to Mer-Cure ${ }^{\mathrm{TM}}$ System On/Off Operation ........................................ 28

Figure 6.1-9 Mercury Emission Rate Parametric Results for Mer-Clean ${ }^{\mathrm{TM}}$ 2, 4, 6 and 8 ............... 30

Figure 6.1-10 Mercury Removal Efficiency Parametric Results for Mer-Clean ${ }^{\mathrm{TM}}$ 2, 4, 6 and 8 ........ 30

Figure 6.1-11 APH Inlet and Stack Mercury Emission Rate Results During Long-Term Demonstration

Figure 6.1-12 Mercury Removal Performance Based on Ontario Hydro Measurements at APH Inlet and Stack.

Figure 6.1-13 Comparison between Ontario Hydro and CMM measurements at DJ3 APH Inlet and

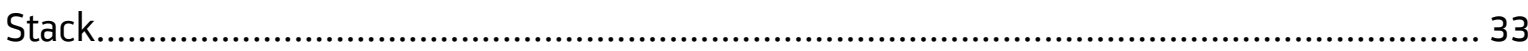

Figure 6.1-14 Mercury speciation at DJ3 Air Preheater Inlet and Stack....................................... 34

Figure 6.1-15 Opacity Change During Long-Term Testing at DJ3 ................................................ 35

Figure 6.1-16 Change in LOI of Bulk Fly Ash Samples During Long-Term Testing at DJ3 ............... 36

Figure 6.1-17 Carbon Content (Percent in ash) in ESP Hopper Ash Samples During Long-Term

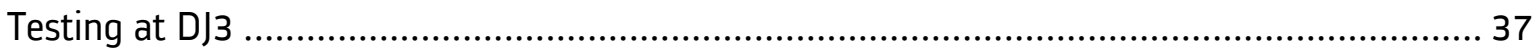

Figure 6.1-18 Mercury Content (ppb in ash) in ESP Hopper Ash Samples During Long-Term Testing at DJ3.

Figure 6.1-19 Mercury Content (ppb in carbon) in ESP Hopper Ash Samples During Long-Term

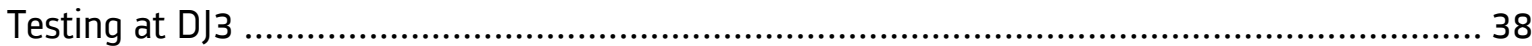

Figure 6.1-20 Particle Size Distributions for Hopper Ash Samples Collected on August 18, 2005 .... 39

Figure 6.1-21 APH Outlet Temperature versus Plant MW $\mathrm{W}_{\mathrm{e}}$ During Long-Term Testing at DJ3 ......... 40

Figure 6.1-22 $\mathrm{NO}_{\mathrm{x}}$ and $\mathrm{SO}_{2}$ Emissions Before, During and After Long-Term Testing at DJ3............ 43

Figure 6.1-23 Effect of Sorbent Cost on Operating Cost of Mer-Cure ${ }^{\mathrm{TM}}$ System at DJ3 ................... 46

Figure 6.1-24 Effect of Mercury Control Level on Mer-Cure ${ }^{\mathrm{TM}}$ System Operating Cost at DJ3

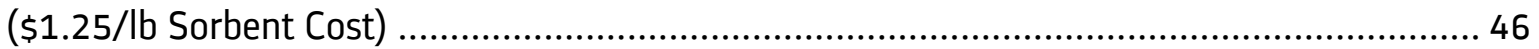

Figure 6.2-1 CFD Results for LOS1 Sorbent Injection Location .............................................. 51 
Figure 6.2-2 Flow Distribution Results for LOS1 Sorbent Injection Location 51

Figure 6.2-3 Vertical Flow Distribution Measured by a Pitot Tube at the Center of the Injection

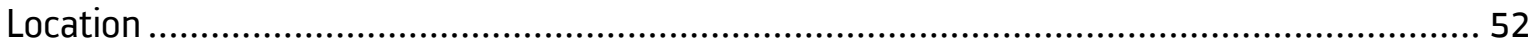

Figure 6.2-4 Sorbent Injection Lances Installed Upstream of the Air Heater.................................. 52

Figure 6.2-5 Mer-Cure ${ }^{\mathrm{TM}}$ System After Installation............................................................... 53

Figure 6.2-6 Sorbent Treatment and Sampling Locations, Leland Olds Unit \#1 ........................... 53

Figure 6.2-7 Baseline Mercury Measurement at Leland Olds Unit \#1 ......................................... 55

Figure 6.2-8 CMM Response to Mer-Cure ${ }^{\mathrm{TM}}$ System On/Off Operation ....................................... 56

Figure 6.2-9 Mer-Cure ${ }^{\mathrm{TM}}$ Performance Curve from Parametric Testing at Leland Olds Unit \#1 ........ 58

Figure 6.2-10 Effect of Processor Operation on Sorbent Performance at Leland Olds Station ......... 59

Figure 6.2-11 Mercury Capture and Stack Mercury Emission Results from CMMs During Long-Term

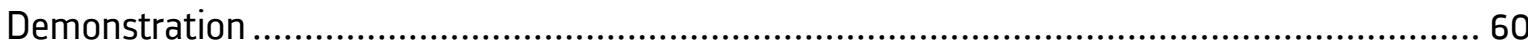

Figure 6.2-12 Mercury Capture and Stack Emission Results from Ontario Hydro Tests During Long-

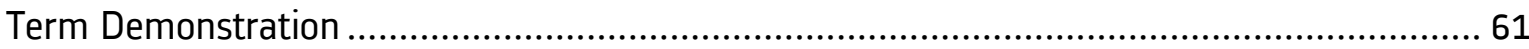

Figure 6.2-13 Comparison of CMM Measurements with Ontario Hydro Measurements at the Air

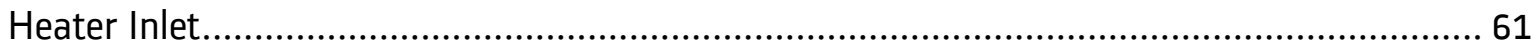

Figure 6.2-14 Comparison of CMM Measurements with Ontario Hydro Measurements at the ESP

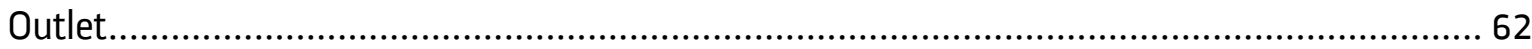

Figure 6.2-15 Mercury Speciation at the Air Heater linlet and the ESP Outlet............................. 63

Figure 6.2-16 Opacity Change During Long-Term Testing at LOS1 .......................................... 64

Figure 6.2-17 Change in Unburned Carbon of Bulk Fly Ash Samples During Long-Term Testing at

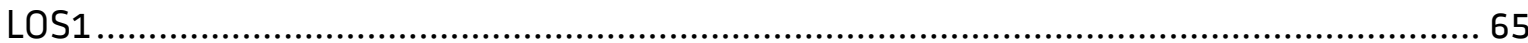

Figure 6.2-18 Sensitivity analysis: Effect of Sorbent Unit Cost and Mercury Removal Required on Operating Cost for Mercury Control for Basin Electric Leland Olds Unit \#1 using Mer-Cure ${ }^{\mathrm{TM}}$

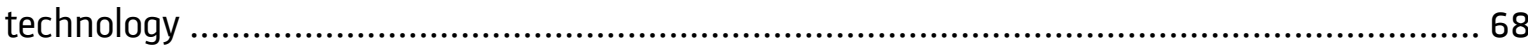

Figure 6.3-1 Modeled Injection Region for Portland Unit \#1 ............................................. 71

Figure 6.3-2 Flow Distribution Results for Portland Unit \#1 Sorbent Injection Location ................. 72

Figure 6.3-3 Sorbent Distribution and Injection System at the Economizer Outlet ....................... 73

Figure 6.3-4 Mer-Cure ${ }^{\mathrm{TM}}$ System After Installation................................................................. 73

Figure 6.3-5 Sorbent Treatment and Sampling Locations, Portland Unit \#1................................ 74

Figure 6.3-6 Daily Composite Sample Variation in Mercury and Sulfur Content in Coal from Portland

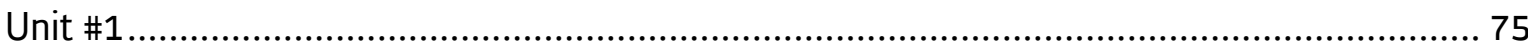

Figure 6.3-7 Gaseous Mercury Measurements at the ESP Outlet (navy blue) and Air Heater Inlet

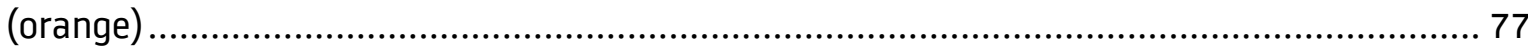

Figure 6.3-8 CMM Measurements at the Air Heater Inlet and ESP Outlet During Parametric Testing

Figure 6.3-9 Full Load Parametric Test Summary of Mer-Cure ${ }^{\mathrm{TM}}$ System with Various Mer-Clean ${ }^{\mathrm{TM}}$ Sorbents.

Figure 6.3-10 Long-term Demonstration Performance of Mer-Cure ${ }^{\top M}$ with Non-Ozone Season Operation 
Figure 6.3-11 $\mathrm{SO}_{3}$ Concentrations at the Air Heater Outlet and ESP Outlet with Non-Ozone Season Operation

Figure 6.3-12 Long-term Demonstration Performance of Mer-Cure ${ }^{\mathrm{TM}}$ with Ozone Season Operation

Figure 6.3-13 Long-term Demonstration Performance of Mer-Cure ${ }^{\mathrm{TM}}$ with Ozone Season Operation

Figure 6.3-14 Validation of Long-Term Performance of Mer-Cure ${ }^{\mathrm{TM}}$ System by Ontario Hydro Method

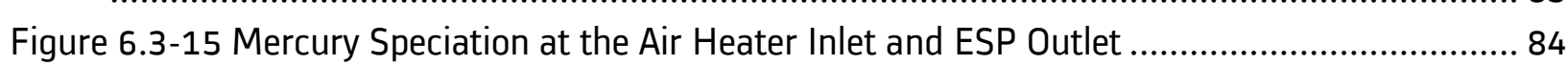

Figure 6.3-16 Stack Opacity Change During Sorbent Injection............................................... 85

Figure 6.3-17 Change in Unburned Carbon of Bulk Fly Ash Samples at Portland Unit \#1 ............... 87

Figure 6.3-18 Sensitivity analysis: Effect of Sorbent Unit Cost and Mercury Removal Required on Operating Cost for Mercury Control for Typical 170-MWe Unit Firing Eastern Bituminous Coal

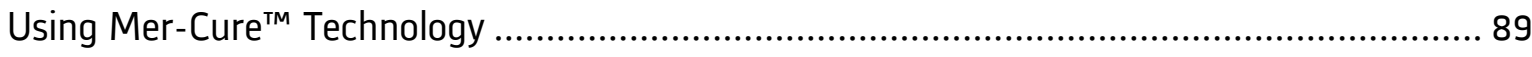

Figure 8.1-1 Mercury Capture Results for Low Rank Coal Sites ............................................... 94

Figure 8.1-2 Mercury Capture Results for Bituminous Coal Site.............................................. 95

Figure 8.2-1 Mercury Removal Costs for Demonstration Project Host Sites................................ 96

Figure 8.2-2 Levelized Annual Operating Costs for Demonstration Project Host Sites .................... 97 


\section{List of Tables}

Table 1.2-1 Host site, Coal and Emission Data for the Field Demonstration Program ..................... 3

Table 1.2-2 Overall Program Schedule .................................................................................. 4

Table 3.1-1 Summary of Test Plan for Each Site ...................................................................... 9

Table 3.1-2 Preliminary Test Matrix for Parametric testing ......................................................... 9

Table 6.1-1 Comparison between PacifiCorp's Dave Johnston Unit \#1 and Unit \#3 ........................ 20

Table 6.1-2 Dave Johnson Unit \#3 Average Coal Properties......................................................... 26

Table 6.1-3 PacifiCorp Test Campaign Timeline ............................................................................ 26

Table 6.1-4 Capital, Operating and Maintenance Cost Estimates for Alstom's Mer-Cure ${ }^{\mathrm{TM}}$ Technology

Implantation at PacifiCorp's Dave Johnston Unit \#3 ......................................................... 44

Table 6.1-5 Sorbent Consumption Rates as a function of Mercury Removal Level for Alstom's Mer-

Cure $^{\mathrm{TM}}$ Technology Implementation at PacifiCorp's Dave Johnston Unit \#3 .......................... 45

Table 6.2-1 Leland Olds Unit \#1 Average Coal Properties.............................................................. 54

Table 6.2-2 Basin Electric Test Campaign Timeline .................................................................... 55

Table 6.2-3 Capital, Operating and Maintenance Cost Estimate for Alstom's Mer-Cure ${ }^{\mathrm{TM}}$ Technology

Implementation at Leland Olds Unit \#1 for 90 Percent Mercury Reduction ........................... 66

Table 6.2-4 Sorbent Consumption Rates as a Function of Mercury Removal Level for Mer-Cure ${ }^{\mathrm{TM}}$

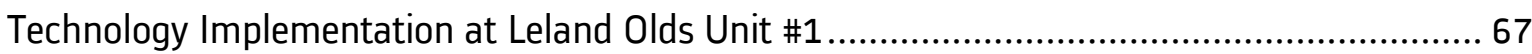

Table 6.3-1 Reliant Energy Fuel Properties (Average) ............................................................ 75

Table 6.3-2 Reliant Energy Test Campaign Timeline ................................................................. 76

Table 6.3-3 Summary of Portland Unit \#1 Particulate Matter Testing ......................................... 86

Table 6.3-4 Sorbent Consumption Rates for Mer-Cure ${ }^{\mathrm{TM}}$ Technology for Typical 179-MW $\mathrm{W}_{\mathrm{e}}$ Unit Firing

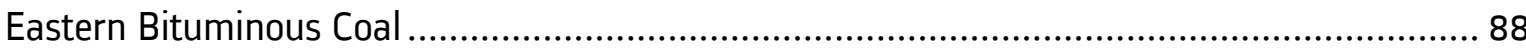

Table 6.3-5 Capital, Operating and Maintenance Cost Estimate for Alstom's Mer-Cure ${ }^{\mathrm{TM}}$ Technology Implementation (90 percent mercury reduction) ........................................................... 88 


\section{List of Abbreviations}

$\begin{array}{ll}\text { BOP } & \text { balance of plant } \\ \text { CFD } & \text { computational fluid dynamics } \\ \text { CMM } & \text { continuous mercury monitor } \\ \text { DOE } & \text { U.S. Department of Energy } \\ \text { UND EERC } & \text { University of North Dakota Energy and Environmental Research Center } \\ \text { ESP } & \text { electrostatic precipitator } \\ \text { LOI } & \text { loss on ignition } \\ \text { NETL } & \text { National Energy Technology Laboratory } \\ \text { OH } & \text { Ontario Hydro } \\ \text { PAC } & \text { powdered activated carbon } \\ \text { PC } & \text { pulverized coal } \\ \text { PRB } & \text { Powder River Basin } \\ \text { PSA } & \text { PS Analytical } \\ \text { QA } & \text { quality assurance } \\ \text { QC } & \text { quality control } \\ \text { SCA } & \text { specific collection area } \\ \text { UBC } & \text { unburned carbon }\end{array}$




\section{Executive Summary}

Alstom was awarded a DOE/NETL-sponsored project (DOE Cooperative Agreement No. DE-FC2604NT42306) to perform full-scale demonstration of its Mer-Cure ${ }^{\mathrm{TM}}$ technology in three coal-fired boilers burning coals of various ranks. These host sites include PacifiCorp's 240-MW $\mathrm{e}_{\mathrm{e}}$ Dave Johnston Unit \#3 (DJ3) burning a PRB coal, Basin Electric's 220-MWe Leland Olds Unit \#1 (LOS1) burning a North Dakota lignite, and Reliant Energy's 170-MW Portland Unit \#1 (Port1) burning an Eastern bituminous coal. Each of these boilers is equipped with a cold-side electrostatic precipitator (ESP) for particulate control. This report gives a summary of the demonstration testing at all three sites. Mer-Cure ${ }^{\mathrm{TM}}$ is a treated sorbent-based mercury control technology. This technology has been developed based on a mechanistic understanding of the critical areas that need to be augmented for mercury oxidation and capture. The technology was originally conceived and tested in the laboratory environment and scaled up for a short-term demonstration on a $220 \mathrm{MW}_{\mathrm{e}}$ pulverized coal-fired boiler.

In Alstom's Mer-Cure ${ }^{\mathrm{TM}}$ mercury control technology, a small amount of sorbent is injected into the flue gas stream for oxidation and adsorption of gaseous mercury. The sorbents are activated carbonbased and prepared with chemical additives that promote oxidation and capture of elemental mercury. The technology is unique in that the sorbent is injected into a high temperature (above $700^{\circ} \mathrm{F}$ ) environment where the mercury oxidation/removal kinetics are accelerated.

The report concludes that Mer-Cure ${ }^{T M}$ technology, using Mer-Clean ${ }^{T M}$ sorbent(s), is both a cost and performance effective means of controlling mercury emissions. Mer-Cure ${ }^{\mathrm{TM}}$ technology has also been successfully applied to alternative commercially available sorbent products.

\section{Background}

This field demonstration program had three host sites for full-scale demonstration to obtain the required information for assessing the technical feasibility and determining the mercury capture performance and costs of controlling mercury in coal-fired utility plants using Mer-Cure ${ }^{\mathrm{TM}}$ technology. The three sites were selected to represent boilers burning coals of various ranks.

The goals for this Round 2 program, established by DOE/NETL in the original solicitation, were to reduce the uncontrolled mercury emissions by 50 to $70 \%$ at a cost 25 to $50 \%$ lower than the previous target of $\$ 60,000 /$ lb mercury removed.

The technical objectives of the proposed project are to:

- Demonstrate Alstom-PPL's mercury control technology in three full-scale, coal-fired boilers for bituminous, sub-bituminous and lignite coals for mercury oxidation and capture;

- Obtain the performance data of the technology for economic evaluation, and engineering design; and

- Determine the operational, BOP and environmental impact of the technology. 


\section{Work Scope}

A technical approach was utilized to effectively demonstrate and evaluate Alstom-PPL mercury control technology. Three seven-week long, full-scale test campaigns were conducted as part of the demonstration program. The work required for the test campaigns can be broken down to the following tasks:

- Task 1. Design, Engineering and Fabrication of the Mercury Control System (three sites)

- Subtask 1.1 Design and Engineering of System Architecture

- Subtask 1.2 Component Fabrication and Testing

- Subtask 1.3 System Assembly

- Task 2. Field Demonstration (three sites)

- Subtask 2.1 Project Planning

- Subtask 2.2 Installation, Checkout and Commissioning

- Subtask 2.3 Parametric and Long-Term Testing

- Subtask 2.4 System Removal

- Subtask 2.5 Data Analysis and Site Report

- Task 3. Technology Transfer

- Task 4. Program Management and Reporting.

The Tasks 1 and 2 were repeated for the three host sites. Alstom-PPL engineers at Alstom-PPL's Windsor site performed most of the Task 1 work. Alstom-PPL engineers performed Task 2 with the assistance of host site personnel and EERC measurement crew. The three seven-week test campaigns took place over the performance period, with the first one in June-August 2005 followed by the second in September-November 2005, and the last in April-June 2006.

\section{Field Demonstration Mercury Capture Results}

The mercury capture results for the low rank coal sites are shown in Figure i-1. DJ3 fired a PRB coal and LOS1 fired lignite. At these two test sites, four Mer-Clean ${ }^{\mathrm{TM}}$ formulations were tested (\# 2, 4, 6, and 8). These formulations differed from each other in terms of the added halogen compound, amounts of the added halogen, and manufacturing process. Mer-Clean ${ }^{\mathrm{TM}} 8$ showed the best mercury capture results in both cases, and it was chosen for the long term testing portion of the demonstration program. Figure i-1 includes parametric results for the sorbent used for long term tests only.

Long term tests were conducted at DJ3 injecting Mer-Clean ${ }^{T M} 8$ at $52 \mathrm{lb} / \mathrm{h}$ (or $0.94 \mathrm{lb} / \mathrm{MMacf}$ ) to achieve $94 \%$ removal of baseline stack mercury based on CMM readings. The sorbent injection rate was then decreased to $35 \mathrm{lb} / \mathrm{h}$ (or $0.63 \mathrm{lb} / \mathrm{MMacf}$ ) to achieve $90 \%$ mercury removal. Mer-Clean ${ }^{\mathrm{TM}} 2$ was then injected at $59 \mathrm{lb} / \mathrm{h}(1.06 \mathrm{lb} / \mathrm{MMacf})$ for the rest of the test program to achieve $90 \%$ mercury removal.

Long term tests were conducted at LOS1 injecting Mer-Clean ${ }^{\mathrm{TM}} 8$ at $26 \mathrm{lb} / \mathrm{h}$ (or $0.9 \mathrm{lb} / \mathrm{MMacf}$ ) for the first five days to achieve $75 \%$ mercury removal. This testing was then followed injection of Mer- 
Clean $^{\mathrm{TM}} 8$ at $40 \mathrm{lb} / \mathrm{h}$ (or $1.4 \mathrm{lb} / \mathrm{MMacf}$ ) for the remainder of long term testing to achieve $90 \%$ mercury removal.

At Portland Unit \#1, Mer-Clean ${ }^{\mathrm{TM}}$ 8-21 (a processing temperature variation of Mer-Clean ${ }^{\mathrm{TM}} 8$ ) showed the best mercury capture results, and it was chosen for the long term testing portion of the demonstration program. During ozone season long term tests, the sorbent injection rate was 330 $\mathrm{lb} / \mathrm{hr}$ (approximately $8.5 \mathrm{lb} / \mathrm{MMacf}$ ) to achieve $90 \%$ mercury removal at minimum.

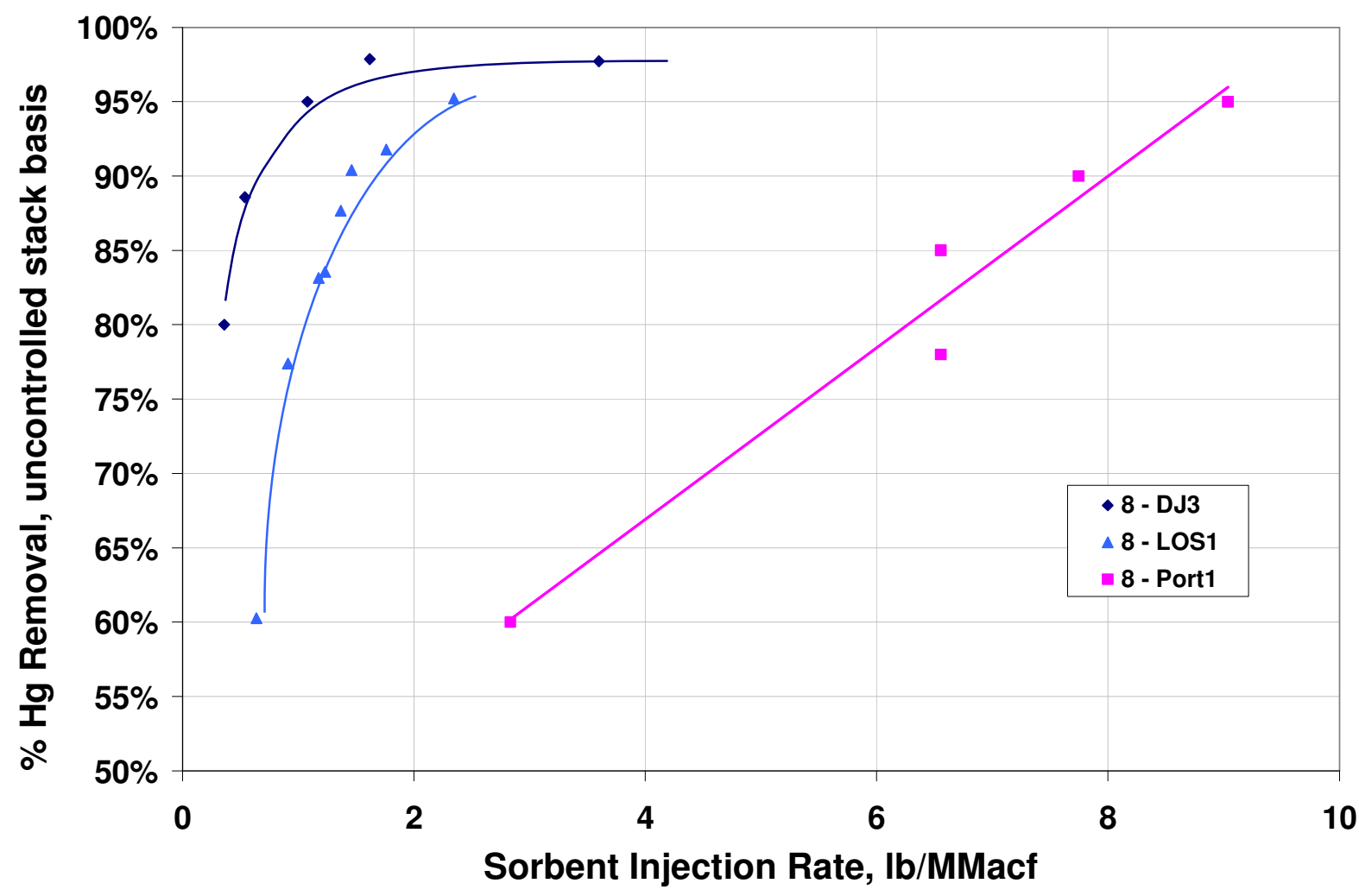

Figure i-1 Mercury Capture Results for Demonstration Project Host Sites

Note that mercury reductions above $90 \%$ were demonstrated at all three host sites, well in excess of the original project goals.

\section{Engineering System Analysis and Economics}

The goals for this Round 2 program, established by DOE/NETL in the original solicitation, were to reduce the uncontrolled mercury emissions by 50 to $70 \%$ at a cost 25 to $50 \%$ lower than the previous target of $\$ 60,000 / \mathrm{lb}$ mercury removed. The mercury removal costs in $\$ / \mathrm{lb} \mathrm{Hg}$ removed are summarized for all three test sites in Figure i-2. This figures shows that the goals of the test program were exceeded at all three sites. Mercury reduction rates of $75 \%$ and $90 \%$ were demonstrated at all three host sites. Mercury removal costs were below the goal at both DJ3 and LOS1. At Port1, mercury removal costs were at or below the goal with one exception. The removal cost at a $90 \%$ reduction rate $\$ 45,065 / \mathrm{lb} \mathrm{Hg}$ removed, which was just above the minimum goal of a $25 \%$ reduction in removal cost. 


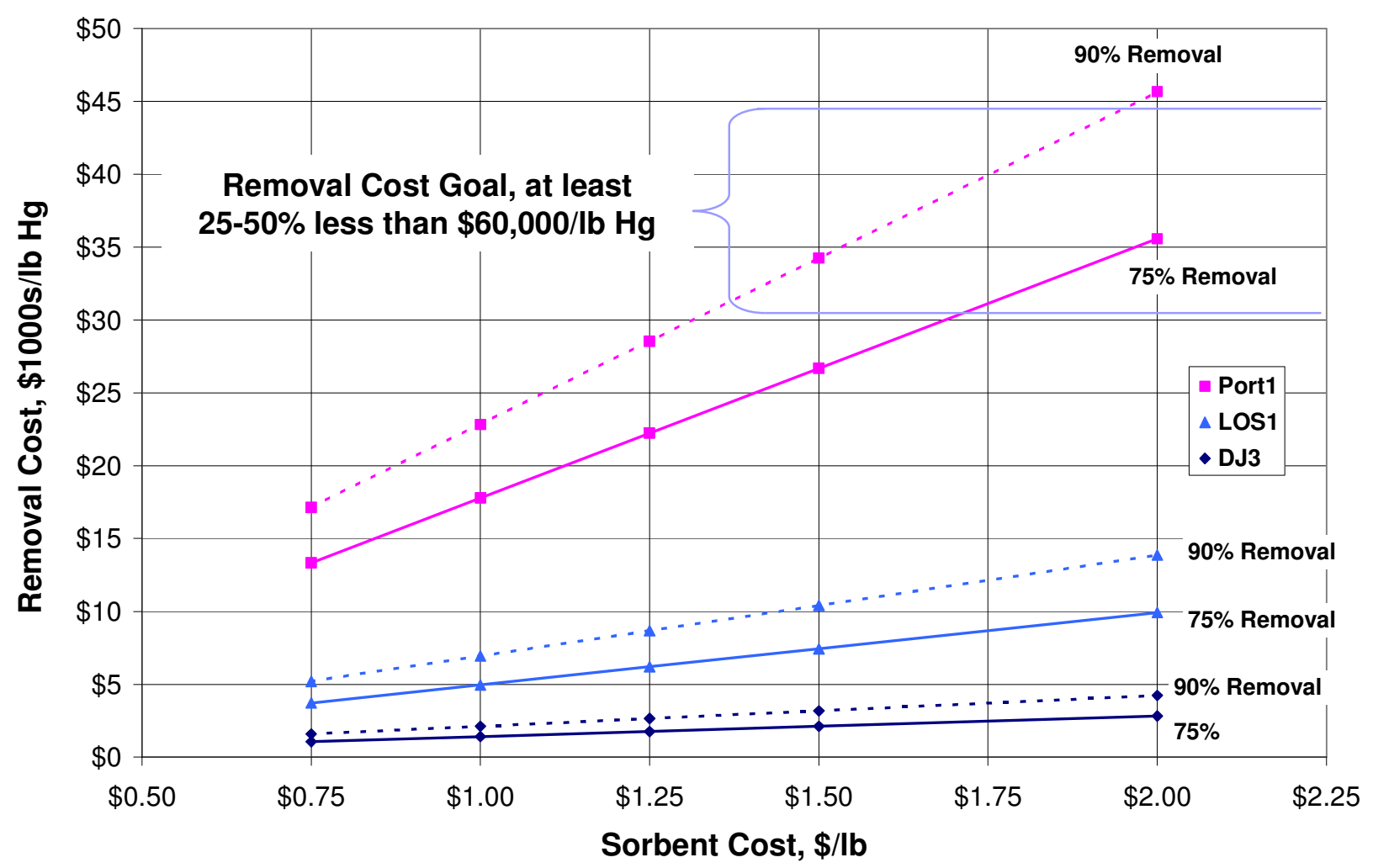

Figure i-2 Mercury Removal Costs for Demonstration Project Host Sites

\section{Balance of Plant Impacts}

Observations throughout the long-term testing suggest that injection of Mer-Clean ${ }^{\mathrm{TM}}$ sorbent did not increase the stack opacity during long-term testing. $\mathrm{NO}_{\mathrm{x}}$ and $\mathrm{SO}_{2}$ emissions were documented during mercury sorbent injection. As expected, no change in $\mathrm{NO}_{\mathrm{x}}$ and $\mathrm{SO}_{2}$ emissions levels was observed as a result of continuous sorbent injection. Particulate emissions rates were also documented at Portland Unit \#1. At Port1, the total PM measured was $0.046 \mathrm{lb} / \mathrm{MMBtu}$ during normal boiler operation and $0.034 \mathrm{lb} / \mathrm{MMBtu}$ while the Mer-Cure ${ }^{\mathrm{TM}}$ system was running. The measured total PM was less than the permit limit of $0.10 \mathrm{lb} / \mathrm{MMBtu}$ and did not increase with sorbent injection.

The unburned carbon in the fly ash increased at all three test sites, and the increase was related to the amount of sorbent injected. The unburned carbon showed a slight increase from $0.95 \%$ to $1.03 \%$ at DJ3. After testing, the unburned carbon recovered the baseline level. The unburned carbon increase of $0.08 \%$ points at DJ3 is attributed to the injection of sorbent. The unburned carbon showed a slight increase from $0.58 \%$ without sorbent injection to $0.87 \%$ with sorbent injection on average at LOS1. The unburned carbon increase of $0.29 \%$ points at LOS1 is attributed to the injection of sorbent. Both of these low rank coal sites had low sorbent feed rates (35-59 lb/hr). 
At Port1, the unburned carbon showed an increase from $6.2 \%$ without sorbent injection to $8.3 \%$ (long term tests) under non-ozone season operation and with sorbent injection on average. The unburned carbon increase of $2.1 \%$ points between baseline and long term non-ozone tests is attributed to the injection of sorbent. This increase was higher than the other two sites because of the higher sorbent feed rates required with bituminous coal (302-330 lb/hr).

A related concern would be the impact on the fly ash saleability for concrete applications due to sorbent injection with the Mer-Cure ${ }^{\mathrm{TM}}$ technology. Fly ash with low unburned carbon content is often sold as a replacement for Portland cement in ready-mix concrete. However, fly ashes with elevated levels of carbon are unsuitable for concrete mixtures because they require increased amounts of costly air-entraining agents (AEA) to achieve a given level of air entrainment.

Fly ash containing less than 1-3\% carbon is well within the specification for use as a concrete additive, but a Foam Index Test (or other air entrainment measure) would be needed on the specific ash from a given unit to determine if ash containing the tested level of Mer-Clean ${ }^{\text {TM }}$ sorbent is suitable for concrete applications. Basin Electric sells ash from LOS1 for mine reclamation, and the ash carbon levels documented in this project do not affect use of fly ash for that purpose. 


\section{Introduction}

Mercury $(\mathrm{Hg})$ is contained in trace amounts in coal and is emitted in the flue gas, mainly in the elemental form $\mathrm{Hg}^{0}$. A portion of the $\mathrm{Hg}$ escapes into the atmosphere and can end up in the food chain. A number of human health and environmental impacts are associated with exposure to mercury. Mercury is released into the air in very low levels, but is known to bio-accumulate in fish and animal tissue in its most toxic form, methyl mercury. Human exposure to methyl mercury has been associated with serious neurological and developmental effects. Adverse effects of mercury on fish, birds, and mammals include reduced reproductive success, impaired growth, behavioral abnormalities, and even death.

In the majority of States in the USA, Hg levels in fresh water fish are above the EPA recommended levels for pregnant women. Phased regulation of $\mathrm{Hg}$ on a national level is being introduced in the near future and new plants are already subjected to strong regulation on an individual state level. For example, some new PC plants are looking for mercury reductions of $80-90 \%$. Even existing plants, with uncertain future regulations, are subject to environmental pressures and will need reductions of $50 \%-70 \%$ by 2010 .

Various methods for mercury control in coal-fired power plants are being developed and demonstrated to meet current and impending mercury emission regulations. ${ }^{1,2}$ These technologies range from powdered activated carbon (PAC) injection, coal and flue gas additives, catalytic and electro-catalytic mercury oxidation with subsequent capture in scrubbers, and in-situ mercury sorbent generation from coal. Among these, PAC injection is one of the more mature technologies for mercury control.

In previous Round 1 demonstration projects, it was observed that very high injection rates (6-15 $\mathrm{Ib} / \mathrm{MMacf})^{1}$ of plain AC were needed to achieve reasonable levels of mercury removal, particularly for low-chlorine containing sub-bituminous (Powder River Basin-PRB) and lignite coals. The low removal levels could be ascribed to a high proportion of elemental mercury in the flue gas when firing these coals. Researchers and technology developers have since used halogenated carbon sorbents to address this problem, with improved performance compared to plain AC (3.3 to 6 $\mathrm{lb} /$ MMacf injection rate for $90 \%$ removal). ${ }^{1,2}$

Recent test results indicate that for medium- to high-sulfur bituminous coals, carbon sorbents lose effectiveness due to the presence of high $\mathrm{SO}_{3}$ concentration in the flue gas stream. ${ }^{3,4,5}$ In the presence of $\mathrm{SO}_{3}$, the sorbent active sites may be bound more preferably by $\mathrm{SO}_{3}$ than by mercury. Also, $\mathrm{SO}_{3}$ is believed to replace captured mercury in the active sites, resulting in re-release of mercury into flue gas stream.

Alstom was awarded a DOE/NETL-sponsored project (DOE Cooperative Agreement No. DE-FC2604NT42306) to perform full-scale demonstration of its Mer-Cure ${ }^{\mathrm{TM}}$ technology in three coal-fired boilers burning coals of various ranks. These host sites include PacifiCorp's 240-MWe Dave Johnston Unit \#3 (DJ3) burning a PRB coal, Basin Electric's 220-MWe Leland Olds Unit \#1 (LOS1) burning a North Dakota lignite, and Reliant Energy's 170-MWe Portland Unit \#1 (Port1) burning an Eastern 
bituminous coal. Each of these boilers is equipped with a cold-side electrostatic precipitator (ESP) for particulate control. This report gives a summary of the demonstration testing at all three sites.

Mer-Cure ${ }^{T M}$ is a treated sorbent-based mercury control technology. This technology has been developed based on a mechanistic understanding of the critical areas that need to be augmented for mercury oxidation and capture and scaled up from well-controlled laboratory-scale testing, pilotscale testing, and through a short-term demonstration at a $220 \mathrm{MW}_{\mathrm{e}}$ pulverized coal-fired boiler. Alstom is also developing other technologies for mercury control in coal-fired boilers, including coal additives $\left(\mathrm{KNX}^{\mathrm{TM}}\right)$ and polishing fabric filters. ${ }^{6}$

\subsection{Background}

In Alstom's Mer-Cure ${ }^{\mathrm{TM}}$ mercury control technology, a small amount of sorbent is injected into the flue gas stream for oxidation and adsorption of gaseous mercury. The sorbents are activated carbonbased and prepared with chemical additives that promote oxidation and capture of elemental mercury. The technology is unique in that the sorbent is injected into a high temperature (above $700^{\circ} \mathrm{F}$ ) environment where the mercury oxidation/removal kinetics are accelerated.

Mer-Cure ${ }^{\mathrm{TM}}$ mercury control technology applied to coal-fired power generation has the potential to be a cost-effective mercury control technology for the entire range of coals (bituminous, subbituminous, and lignite). As the technology is based on oxidation and adsorption of mercury, it is also applicable to all air pollution control configurations including wet scrubber and spray dryerESP/baghouse units. The main focus of this project, however, is with a cold-side ESP as the particulate control device. Cold-side ESPs represent over $70 \%$ of the coal-fired boilers in the United States. The mercury control technology has low-capital costs $\left(\$ 5-10 / \mathrm{kW}_{\mathrm{e}}\right)$. It also requires a very small amount of low-cost additives for treatment, which results in low operating costs (0.5-0.75 mills/kWh) and minimal balance-of-plant (BOP) impact.

Mer-Cure ${ }^{T M}$ takes advantage of mechanistic understanding of mercury oxidation and capture to identify the critical areas that need to be augmented to maximize mercury oxidation and capture. The approach for enhanced mercury capture is:

- Pre-treatment of activated carbon (AC)-based sorbent with proprietary additive and its injection into the high temperature region $\left(400\right.$ to $\left.800^{\circ} \mathrm{F}\right)$. This activates the additive on the carbon and makes it reactive with elemental mercury;

- Accelerated reaction (due to the high temperature) of adsorbed mercury with the activated additive to an oxidized product and its retention; and

- Injection methodology that ensures dispersion and uniform distribution of sorbent in the flue gas and minimizes mixing limitation;

- Capture of sorbent particle with adsorbed mercury in an ESP or fabric filter.

Mer-Clean ${ }^{T M}$ is a carbon-based sorbent with a proprietary additive that accelerates mercury oxidation by providing the oxidation reaction partner in high concentrations on the carbonaceous particle. MerCure $^{\mathrm{TM}}$ technology has also been successfully applied to alternative commercially available sorbent products. 
More importantly, Mer-Cure ${ }^{T M}$ involves injection at an "ideal" temperature location, which allows contact with the elemental mercury to begin as early as it can be effective. This is typically in the duct leading to the air heater. Higher temperature also increases reaction rates exponentially. This enables maximum utilization of the entire effective temperature range for oxidation with the added sorbent. In contrast to Mer-Cure ${ }^{T M}$, current practice involves the injection of carbon sorbents at low temperatures downstream an air heater, where typical temperatures are between 250 and $350^{\circ} \mathrm{F}$. In this case, the contact time between the sorbent and the mercury in the flue gas is significantly shorter and the added benefit of accelerated kinetics at a higher temperature is not available.

In connection with injection at higher temperatures is the unique and proprietary nature of MerClean $^{\mathrm{TM}}$. Careful selection of the additive and method by which it is administered to the sorbent ensures that the sorbent-additive combination becomes active and retains its integrity through the high temperature range. Nevertheless, Mer-Cure ${ }^{\mathrm{TM}}$ technology has also been successfully applied to alternative commercially available sorbent products.

Finally, detailed computational flow modeling of the injection region is performed to match the injection system to local flow conditions. In this manner, uniform distribution of sorbent is achieved before the flue gases enter the air heater. Sorbent distribution is critical to minimize the amount of sorbent required for a given performance level.

\subsection{Project Overview}

This field demonstration program had three host sites for full-scale demonstration to obtain the required information for assessing the technical feasibility and determining the mercury capture performance and costs of controlling mercury in coal-fired utility plants using Mer-Cure ${ }^{\mathrm{TM}}$ technology. The three sites were selected to represent boilers burning coals of various ranks. The host sites include PacifiCorp's 240-MWe Dave Johnston Unit 3 (DJ3) burning a PRB coal, Basin Electric's 220-MW eland Olds Unit 1 (LOS1) burning North Dakota lignite, and Reliant Energy's $170-\mathrm{MW}_{\mathrm{e}}$ Portland Unit 1 (Port1) burning an Eastern bituminous coal. These boilers are each equipped with an ESP. Table 1.2-1 provides a summary of the operating parameters, coal and emission data for each site. Table 1.2-2 shows the overall program schedule.

Table 1.2-1 Host site, Coal and Emission Data for the Field Demonstration Program

\begin{tabular}{|c|c|c|c|}
\hline & PacifiCorp & Basin Electric & Reliant Energy \\
\hline Unit & Dave Johnston 3 & Leland Olds 1 & Portland 1 \\
\hline Capacity (MW e Gross) & 240 & 220 & 172 \\
\hline Operation & Base-loaded & Base-loaded & Cycling \\
\hline $\mathrm{NO}_{x}$ and $\mathrm{SO}_{2}$ control & $\begin{array}{l}\text { No low- } \mathrm{NO}_{\mathrm{x}} \\
\text { Low sulfur coal }\end{array}$ & $\begin{array}{c}\text { No low } \mathrm{NO}_{\mathrm{x}} \\
\text { Low sulfur coal }\end{array}$ & $\begin{array}{l}\text { Low } \mathrm{NO}_{\mathrm{x}}-\mathrm{LNCFS}^{\mathrm{TM}} \\
\text { No sulfur control }\end{array}$ \\
\hline Air Heater & Two Ljungstrom $^{\mathrm{TM}}$ & Ljungstrom $^{\mathrm{TM}}+$ Tubular & Ljungstrom $^{\mathrm{TM}}$ \\
\hline $\begin{array}{l}\text { Particulate control } \\
\left.\text { (SCA in } \mathrm{ft}^{2} / \mathrm{kacfm}\right)\end{array}$ & $\begin{array}{l}\text { CS-ESP } \\
(629)\end{array}$ & $\begin{array}{l}\text { CS-ESP } \\
(320)\end{array}$ & $\begin{array}{c}\text { CS-ESP } \\
(284)\end{array}$ \\
\hline
\end{tabular}




\begin{tabular}{|r|c|c|c|}
\hline & PacifiCorp & Basin Electric & Reliant Energy \\
\hline Ash utilization & Mine reclamation & Disposal & Disposal \\
\hline $\begin{array}{r}\text { Higher Heating Value } \\
\text { As-received (Btu/lb) }\end{array}$ & Wyodak (PRB) & ND lignite & E. Bituminous \\
\hline S in coal (\%) & 0.94 & 6617 & $12,800-13,100$ \\
\hline Ash (\%) & 10.09 & 0.63 & $2-2.5$ \\
\hline Cl in coal (ppmwd)-dry & $<50$ & 9.86 & $6-8$ \\
\hline Hg in coal (ppmwd) & 0.071 & & $\sim 1,500$ \\
\hline As-fired Hg level from Coal & $7-9$ & $6-057-0.099$ & $0.1-0.16$ \\
\hline ( $\left.\mu \mathrm{g} / \mathrm{Nm}^{3}\right)$ & & & $10-16$ \\
\hline Inlet Hg $\left(\mu \mathrm{g} / \mathrm{m}^{3}\right)$ & $10-12$ & $8-9$ & $11-13$ \\
\hline Stack $\left(\mu \mathrm{g} / \mathrm{m}^{3}\right)$ & $9-11$ & $7-8$ & $11-13$ \\
\hline Removal Efficiency $(\%)$ & $0-20$ & 10 & 0 \\
\hline Carbon-in-ash $(\%)$ & $0.6-1.4$ & $<0.2$ & $10-12$ \\
\hline Flue gas temp (ESP InletF) & $330-360^{\circ} \mathrm{F}$ & $375^{\circ} \mathrm{F}$ & $277^{\circ} \mathrm{F}$ at full load \\
\hline
\end{tabular}

Table 1.2-2 Overall Program Schedule

\begin{tabular}{|c|c|c|c|c|c|c|c|c|c|c|c|c|c|c|c|c|c|c|}
\hline \multirow{2}{*}{ Site } & \multicolumn{12}{|c|}{2005} & \multicolumn{6}{|c|}{2006} \\
\hline & J & $F$ & $M$ & A & $M$ & 1 & $J$ & $A$ & $\mathrm{~S}$ & 0 & $\mathrm{~N}$ & $\mathrm{D}$ & $J$ & $\mathrm{~F}$ & $M$ & A & $M$ & 1 \\
\hline \multicolumn{19}{|l|}{ Dave Johnston Unit \#3 } \\
\hline \multicolumn{19}{|l|}{ Leland Olds Unit \#1 } \\
\hline Portland Unit \#1 & & & & & & & & & & & & & & & & & & \\
\hline
\end{tabular}

The goals for this Round 2 program, established by DOE/NETL, were to reduce the uncontrolled mercury emissions by 50 to $70 \%$ at a cost 25 to $50 \%$ lower than the previous target of $\$ 60,000 / \mathrm{lb}$ mercury removed. These technical objectives are accomplished by following the series of tasks listed below. A detailed description of the statement of work is included for completeness in Section 3.

- Design, engineering and fabrication of a mobile sorbent handling and injection system for mercury control

- Design and installation of site-specific equipment

- Baseline measurements

- Parametric testing with sorbent injection

- Long-term testing of Mer-Cure ${ }^{T M}$ technology

- Sample analysis

- Data analysis

- Economic evaluation

- Reporting and technology transfer. 


\section{Project Objectives}

The overall objective of the proposed work is to develop a mercury control technology in coal-fired boilers that can achieve more than 90\% mercury capture. In Alstom-PPL's mercury control technology, sorbents with chemical additives that promote oxidation and capture of elemental mercury are injected into an environment where the kinetics are favorable. Installation of AlstomPPL mercury control technology has low-capital costs $\left(\$ 5-10 / \mathrm{kW}_{\mathrm{e}}\right)$. The mercury control technology also requires a very small amount of additives, which results in low operating costs (0.5-0.75 mills/kWh) and minimal impact on BOP aspect.

The goals for this Round 2 program, established by DOE/NETL in the original solicitation, were to reduce the uncontrolled mercury emissions by 50 to $70 \%$ at a cost 25 to $50 \%$ lower than the previous target of $\$ 60,000 / \mathrm{lb}$ mercury removed.

The technical objectives of the proposed project are to:

- Demonstrate Alstom-PPL's mercury control technology in three full-scale, coal-fired boilers for bituminous, sub-bituminous and lignite coals for mercury oxidation and capture;

- Obtain the performance data of the technology for economic evaluation, and engineering design; and

- Determine the operational, BOP and environmental impact of the technology.

Alstom-PPL is committed to offer the most economically viable mercury control solution to our utility customers while minimizing the impact on the overall power plant economics. A successful completion of the proposed demonstration project will expedite Alstom-PPL's commercialization efforts of the mercury control technology. 


\section{Statement of Work}

In order to accomplish the technical objectives, a technical approach was utilized to effectively demonstrate and evaluate Alstom-PPL mercury control technology. Three seven-week long, fullscale test campaigns were conducted as part of the demonstration program. The work required for the test campaigns can be broken down to the following tasks:

- Task 1. Design, Engineering and Fabrication of the Mercury Control System (three sites)

- Subtask 1.1 Design and Engineering of System Architecture

- Subtask 1.2 Component Fabrication and Testing

- Subtask 1.3 System Assembly

- Task 2. Field Demonstration (three sites)

- Subtask 2.1 Project Planning

- Subtask 2.2 Installation, Checkout and Commissioning

- Subtask 2.3 Parametric and Long-Term Testing

- Subtask 2.4 System Removal

- Subtask 2.5 Data Analysis and Site Report

- Task 3. Technology Transfer

- Task 4. Program Management and Reporting.

The Tasks 1 and 2 were repeated for the three host sites. Alstom-PPL engineers at Alstom-PPL's Windsor site performed most of the Task 1 work. Alstom-PPL engineers performed Task 2 with the assistance of host site personnel and EERC measurement crew. The three seven-week test campaigns took place over the performance period of September 2004 through March 2007, with the first in June-August 2005 followed by the second in September-November 2005, and the last in April-June 2006. Tasks 3 and 4 were performed by Alstom-PPL throughout the performance period to support the entire demonstration program. The EERC and the participating utility companies also provided input to the tasks.

\subsection{Tasks Performed}

Detailed description of the tasks and subtasks listed in Section 3 are presented in the following paragraphs.

\section{Task 1.0 Design, Engineering and Fabrication}

In preparation for the seven-week field testing, the mercury control system were designed, fabricated and tested before shipping to the field sites. This task was broken down to the following three subtasks.

Subtask 1.1 Design and Engineering of System Architecture

Alstom-PPL's mercury control technology requires injection of chemical additives adsorbed onto carbonaceous material into the flue gas stream where the flue gas environment can significantly accelerate additive-mercury interaction. The mercury control system is composed of three 
components: a sorbent storage system, a sorbent delivery system, and a sorbent distribution system. These components were sized and designed specifically for each of the host sites.

The subtask began with an initial visit to the host sites for preliminary site evaluation. At the sites, Alstom-PPL engineers and site personnel thoroughly reviewed plant arrangements, site operations, baseline mercury emission levels and other plant data available. At this early stage, any additional mercury measurement data was obtained as needed. This initial review of site-specific information was aimed at optimized design of the mercury control system, the test matrix/program, and at ensuring adequacy and integrity of the planned test campaigns at the specified sites.

Uniform distribution of sorbents into the flue gas stream is very important for good contact between the sorbents and the mercury in the flue gas stream. Alstom-PPL carried out additional detailed computational flow modeling calculations to identify injection points for each of the three boilers to design the piping system. These flow-modeling studies allowed us to better determine the number of injection lances and their specific design for each of the host sites. Flow modeling ensured that (i) uniform distribution of the injected material is achieved in the flue gas and that (ii) there is no dropout in the piping and injection lance system.

\section{Subtask 1.2 Component Fabrication and Testing}

The components designed in Subtask 1.1 were fabricated to the portable test system. The components were made modular so that any removal or replacement of parts during the testing, either for maintenance or for test purposes, could be made without significantly interrupting the testing schedule.

Once the components were fabricated, the delivery and distribution systems were tested in AlstomPPL's facility before shipping to the demonstration sites. This testing included measurements of pressure distributions over components such as injection lances.

\section{Subtask 1.3 System Assembly}

The components thus fabricated and tested were shipped to the host site for on-site assembly. The portable demonstration system was interfaced with the delivery and distribution systems at the host sites. Utilities such as electrical power, pneumatic transport air supply, etc., were connected to the assembled system before testing.

\section{Task 2.0 Field Demonstration}

The seven-week field test program was carried out at the three demonstration sites. One week of baseline measurement was followed by two weeks of parametric testing and four weeks of longterm testing. The testing program was broken down to the following five (5) subtasks.

\section{Subtask 2.1 Project Planning}

The success of the project was very much dependent on close and smooth coordination with various team members throughout the performance period. In the planning stage, Alstom-PPL communicated closely with the plant personnel of the host sites and the mercury measurement crew of the EERC of University of North Dakota in order to clearly identify the roles and scopes of each of 
the project team members for the demonstration program. Alstom-PPL held meetings with plant and corporate personnel to design and discuss the overall program. In these meetings, any potential operational issues of the plant and plant equipment were thoroughly discussed. Also, plant data acquisition was coordinated with the operational crew. Alstom-PPL worked with the environmental personnel to help obtain permits for the testing from the State Department of Environmental Protection as required.

Alstom-PPL also communicated closely with EERC on measurement plans. The EERC provided personnel and measurement equipment to obtain continuous mercury concentrations using two CMMs and $\mathrm{OH}$ measurements at the ESP outlet/before stack. Alstom-PPL and the project team members developed the QA/QC plan on the overall test program.

\section{Subtask 2.2 Installation, Checkout and Commissioning}

Most of the Alstom-PPL mercury control system was assembled in the host site before the testing. Plant personnel installed the injection ports during a previous outage in anticipation of the demonstration. A sorbent distribution system was assembled by inserting injection lances into the flue gas duct through injection ports and tying them to the distribution manifolds. The sorbent distribution system was then connected to the sorbent delivery system, which in turn was connected to the sorbent storage system. The electrical and mechanical connections were completed. Plant personnel provided some of the services for installation of the test equipment. Each of the systems were checked out and finally commissioned by Alstom-PPL test crew before the testing.

\section{Subtask 2.3 Field Testing and Measurement}

Once the systems were set up, the project team carried out a seven week test (one week for baseline, two weeks for parametric and four weeks for long-term) under various conditions. The technical objectives of the test program were (i) to investigate the speciation of mercury under various fuel compositions, (ii) to demonstrate Alstom-PPL mercury control technology for oxidation and capture of over $90 \%$ of the total mercury released during combustion, and (iii) to obtain extensive engineering, environmental and operational data for evaluation of the technology.

In order to achieve these objectives, a test program was constructed as listed in Table 3.1-1. During the first week, the uncontrolled, baseline mercury levels were established. The next two weeks were dedicated to testing of the technology under various conditions. Table 3.1-2 lists a preliminary test matrix for parametric testing. Testing was carried out at three different feed rates $(1,2$, and 5 Ib/MMacf) for the four enhanced sorbents (sorbent $A, B, C$ and $D$ ) while burning two different coals (a PRB and a blend). The test conditions factored in variation in boiler load and flue gas flow. Some of the test conditions were repeated towards the end of the testing for data quality control and assurance. The sorbent feed rates were varied during the tests in order to construct a complete sorbent consumption-mercury removal curve. These data were used later to determine the required consumption rate and operating cost for a given removal target. 
Table 3.1-1 Summary of Test Plan for Each Site

\begin{tabular}{|c|c|c|c|c|c|}
\hline Week & Activity & Sorbent Injection & $\begin{array}{c}\text { CMM } \\
\text { Measurements }\end{array}$ & $\begin{array}{c}\text { OH } \\
\text { Measurements }\end{array}$ & $\begin{array}{c}\text { Coal and Ash } \\
\text { Sampling }\end{array}$ \\
\hline 1 & Baseline Testing & & $\mathrm{X}$ & $\mathrm{X}$ & $\mathrm{X}$ \\
\hline 2 & Parametric Testing & $\mathrm{X}$ & $\mathrm{X}$ & $\mathrm{X}$ & $\mathrm{X}$ \\
\hline 3 & Parametric Testing & $\mathrm{X}$ & $\mathrm{X}$ & $\mathrm{X}$ & $\mathrm{X}$ \\
\hline 4 & Long-Term Testing & $\mathrm{X}$ & $\mathrm{X}$ & $\mathrm{X}$ & $\mathrm{X}$ \\
\hline 5 & Long-Term Testing & $\mathrm{X}$ & $\mathrm{X}$ & & $\mathrm{X}$ \\
\hline 6 & Long-Term Testing & $\mathrm{X}$ & $\mathrm{X}$ & $\mathrm{X}$ & $\mathrm{X}$ \\
\hline 7 & Long-Term Testing & $\mathrm{X}$ & $\mathrm{X}$ & & $\mathrm{X}$ \\
\hline
\end{tabular}

During parametric testing for a given test condition, sorbent injection was performed over 8-12 hour period, and the mercury concentrations from the unit allowed to recover for the subsequent 12-16 hours before the next test condition. Based on our previous testing and measurement experience and the measurement data available in the literature, 12 to 16 hours is a long enough time to allow a full-scale boiler system to recover from previous mercury test conditions.

Table 3.1-2 Preliminary Test Matrix for Parametric testing

\begin{tabular}{|c|c|c|c|}
\hline Day & $\begin{array}{c}\text { Sorbent } \\
\text { type }\end{array}$ & Injection system mode & Sorbent feed rate (lb/MMacf) \\
\hline 1 & None & Off & N/A \\
\hline 2 & Sorbent A & On & 5 \\
\hline 3 & Sorbent B & On & 1 \\
\hline 4 & Sorbent B & On & 2 \\
\hline 5 & Sorbent B & On & 5 \\
\hline 6 & Sorbent B & On & 1 \\
\hline 7 & Sorbent C & On & 2 \\
\hline 8 & Sorbent C & On & 5 \\
\hline 9 & Sorbent C & On & 2 \\
\hline 10 & Sorbent D & On & 5 \\
\hline 11 & Sorbent D & On & On \\
\hline 12 & Sorbent D & Repeat of selected conditions \\
\hline $13-14$ & \multicolumn{2}{|c|}{}
\end{tabular}

Basin Electric fires mainly ND lignite and occasionally a PRB-lignite blend. This allowed an opportunity to investigate the effect of coal blending on the overall mercury emission level and its speciation. Continuous measurement of mercury was also made during transition between coals in order to obtain this information. During the transition, the $\mathrm{SO}_{2}$ level was simultaneously monitored to determine the blending ratio at a given point in time. Also, Portland Unit 1 of Reliant Energy 
cycles between 75 and $172 \mathrm{MW}_{\mathrm{e}}$ and allowed study of the impact of load cycling on Alstom-PPL's mercury control technology.

As mentioned above, two CMMs were installed, one for measurement upstream of sorbent injection and the other after particulate control. They allowed rapid measurements of various test conditions. $\mathrm{OH}$ measurements for mercury concentration and speciation were performed for selected conditions before sorbent injection and at ESP outlet to substantiate the mercury CMM data.

Solid samples (coal and ESP ash) were collected by plant personnel as directed by Alstom. Representative 5-gal bucket samples were taken from the ESP over the course of the test campaigns. These include three buckets from baseline testing, three buckets from selected parametric test conditions and three buckets from long-term testing. At DOE/NETL's directions, these were sent out to DOE contractors for by-product characterization. Independent analysis was also carried out by Alstom-PPL for selected samples. The analysis on collected samples included ultimate and proximate analysis, mercury content, LOI, TCLP (Toxic Characteristic Leaching Procedure) and foam index tests. The plant operation data was obtained from the plant personnel. These included the temperature profile, oxygen concentration profile, sootblowing history, ESP rapping history, $\mathrm{SO}_{2}, \mathrm{NO}_{x}$, and stack opacity at the exit of the ESP.

Throughout the testing, the test crew adhered to procedures that ensured tight QC and QA. For example, the CMM system was calibrated before and after tests with zero and span drift checks. EERC provided $\mathrm{OH}$ measurement services for selected test conditions to ensure QA/QC.

\section{Subtask 2.4 System Removal}

After the seven weeks of testing, the installed mercury control system and any testing related items were removed and disassembled by Alstom-PPL personnel. Rental equipment was returned to vendors or moved to the next test site.

\section{Subtask 2.5 Data Analysis and Site Report}

Data analysis was carried out at the completion of the testing. Coal and ash samples were analyzed for determination of chemical composition. Complete fuel analyses were carried out on selected fuel samples including the mercury, sulfur and chlorine contents in the fuels. The carbon content (LOI) and the mercury content in ash samples were also analyzed. Byproduct characterization was carried out by employing such standard test procedures as TCLP (Toxic Characteristic Leaching Procedure) and foam index tests.

The data collected during and after the testing was used to assess the extent of mercury oxidation under various conditions, to obtain the technical performance data of Alstom-PPL mercury control technology, and to evaluate the technology from economic, operational, and environmental points of view. Based on the data and findings, a summary report was written for each host site.

Task 3.0 Technology Transfer

A number of utility companies have shown great interests in Alstom-PPL mercury control technology so far because of its potential as a low capital and operating cost option for mercury control. In 
addition, it has delivered high performance with respect to one of the most difficult configurations: lignite-fired coal and ESP. Therefore, this shows promise to other fuels as well, including PRB subbituminous and bituminous coals. The ESP configuration also represents the majority of the units in the industry and is much more difficult of a category compared to fabric filters for mercury control. Utilities are interested in better understanding the performance of the mercury control technology and its performance in full-scale boilers. As soon as the project results and findings were available, Alstom-PPL disseminated them to the power generation industry by attending and making presentations in relevant technical conferences such as DOE/NETL sponsored meetings. Technical papers were written and presented at multiple industry conferences and trade shows.

\section{Task 4.0 Project Management and Reporting}

Throughout the project, the project manager of Alstom-PPL closely communicated with the team members. The project team also obtained feedback from each host site to ensure the project addresses the utility perspective. Alstom-PPL was in close contact with the DOE project manager to report any progresses or issues as well as to inquire feedback and overall directions.

Project deliverables include quarterly progress reports, host site summary reports and this final report. Presentations on the project results were made at several conferences, including the AWMA 2006 Mega Symposium, DOE 2006 Mercury Conference, Clearwater 2007 Coal Conference, Electric Power 2007, and EUEC 2007 Mercury Control Meeting. 


\section{Technology Description}

\subsection{Mer-Cure ${ }^{\mathrm{TM}}$ Process}

Alstom's Mer-Cure ${ }^{\mathrm{TM}}$ technology (Figure 4.1-1) employs a patented sorbent preparation and injection system that has several unique features to enhance its mercury control performance. First, sorbent injection is at an "ideal" temperature location (600-800 ${ }^{\circ} \mathrm{F}$ ), which allows contact with the elemental mercury to begin as early as it can be effective. Unlike more conventional AC injection systems, the Mer-Cure ${ }^{\mathrm{TM}}$ system injects the sorbent into the duct upstream of the air heater as shown in Figure 4.1-1. This enables maximum utilization of the entire effective temperature range for oxidation with the added sorbent. In current practice, carbon sorbents are injected at low temperatures, such as downstream an air heater (typically between 250 and $350^{\circ} \mathrm{F}$ ), where oxidation kinetics are significantly slower. Also, the sorbent-mercury contact time becomes significantly shorter.

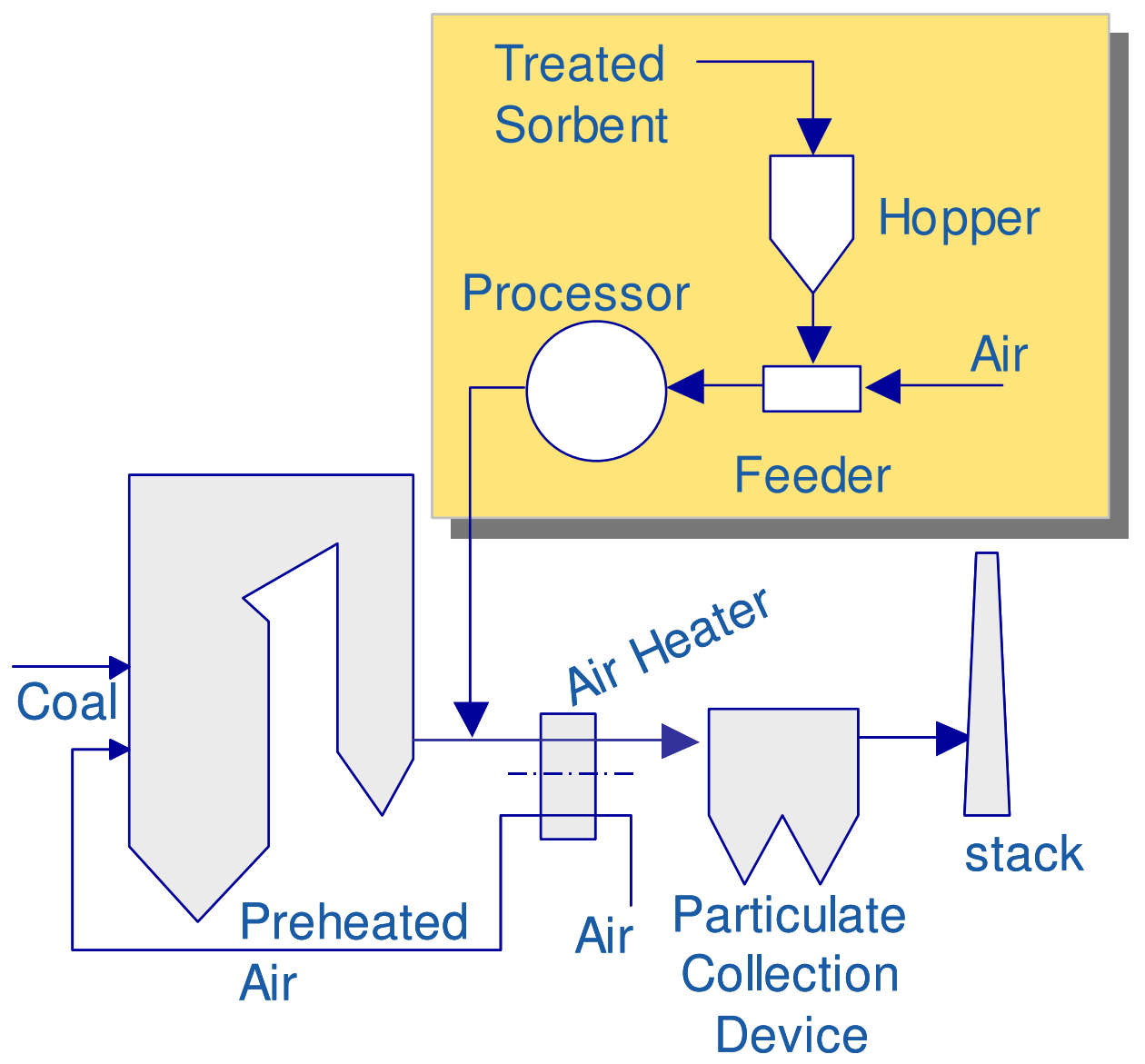

Figure 4.1-1 Alstom's Mer-Cure ${ }^{T M}$ Technology for Mercury Capture

Second, the Mer-Cure ${ }^{\mathrm{TM}}$ system utilizes a carbon-based sorbent (called Mer-Clean ${ }^{\mathrm{TM}}$ ) with a proprietary additive that has been designed to accelerate mercury oxidation. Carefully designing the additive and its impregnation method to the sorbent ensures that the Mer-Clean ${ }^{\mathrm{TM}}$ sorbent is active and retains its integrity throughout the temperature range. Additionally, Mer-Cure ${ }^{\mathrm{TM}}$ technology has been successfully applied to alternative commercially available sorbent products. 
A third distinct feature of the Mer-Cure ${ }^{\mathrm{TM}}$ is the unique injection methodology. The system is designed to remove any mass transfer limitations of mercury vapor to sorbent by de-agglomerating the sorbent into individual particles and uniformly distributing them to flue gas flow based on local flow conditions. Computational fluid dynamics (CFD) tools are employed to guide optimum design of the injection system, as sorbent distribution is critical to minimize its consumption for a given performance level.

\subsection{Mobile Mer-Cure ${ }^{\mathrm{TM}}$ Demonstration System}

As part of the test program, Alstom designed and fabricated a mobile Mer-Cure ${ }^{\top M}$ system. The mobile Mer-Cure ${ }^{T M}$ demonstration system (Figure 4.2-1) is composed of three components mounted on a 48-foot trailer: a sorbent storage system, a sorbent processing/delivery system, and a sorbent distribution system.

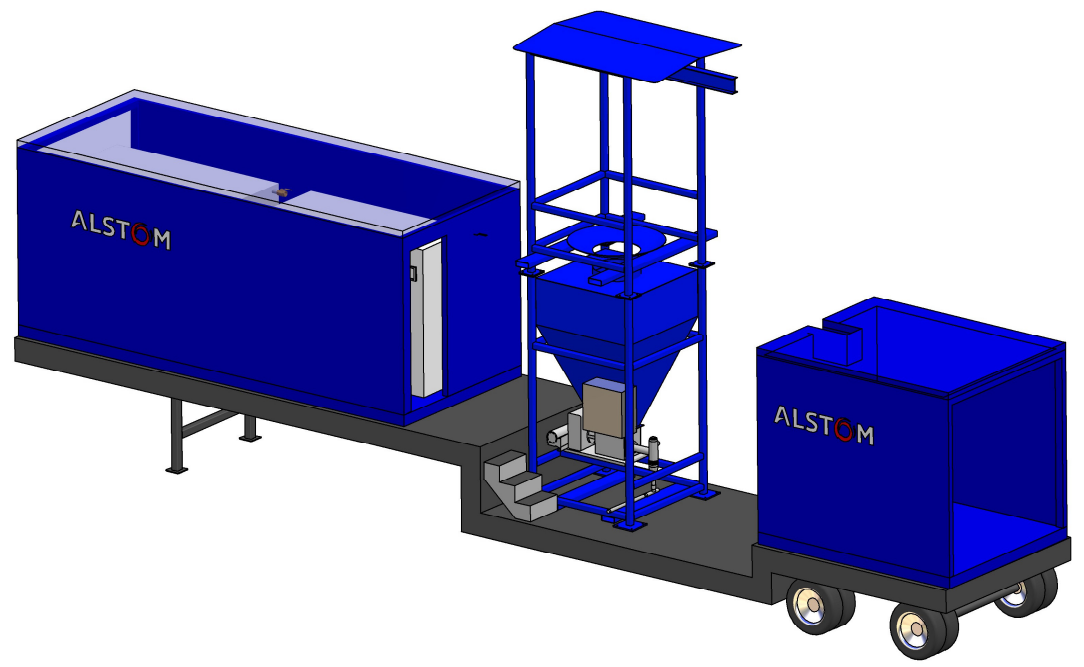

Figure 4.2-1 Mobile Mer-Cure ${ }^{T M}$ Demonstration Trailer Schematic

The sorbent storage system is a portable two-piece silo, which can be easily assembled and requires a relatively small footprint. The sorbent storage system, when assembled, is capable of loading powdered material of up to three 900-lb super-sack bags at the same time and will allow uninterrupted operation for 24 hours at a typical injection rate. Due to height limitations of the trailer during transportation, the storage system is delivered unassembled. The top piece of the twopiece storage system is attached to the base piece at the test site, as shown in Figure 4.2-2.

The sorbent processing/delivery system consists of a variable screw feeder for metering the sorbent and an eductor for its pneumatic transport, a processor that de-agglomerates sorbent particles, and a compressed air system that supplies dry air for pneumatic transport. This system is mounted next to the storage system and is completely connected to the other subsystems.

The sorbent distribution system consists of flexible hoses, interconnecting pipes, distribution manifolds and injection lances. The injection lances designed based on CFD analysis of the duct flow 
conditions. They typically are $1 \frac{1}{4}$-inch pipes with multiple nozzles for even sorbent distribution throughout the duct cross-section.

The process equipment trailer is also equipped with control and data acquisition systems for the Mer-Cure ${ }^{\mathrm{TM}}$ system. The control system allows remote monitoring of operating conditions of the

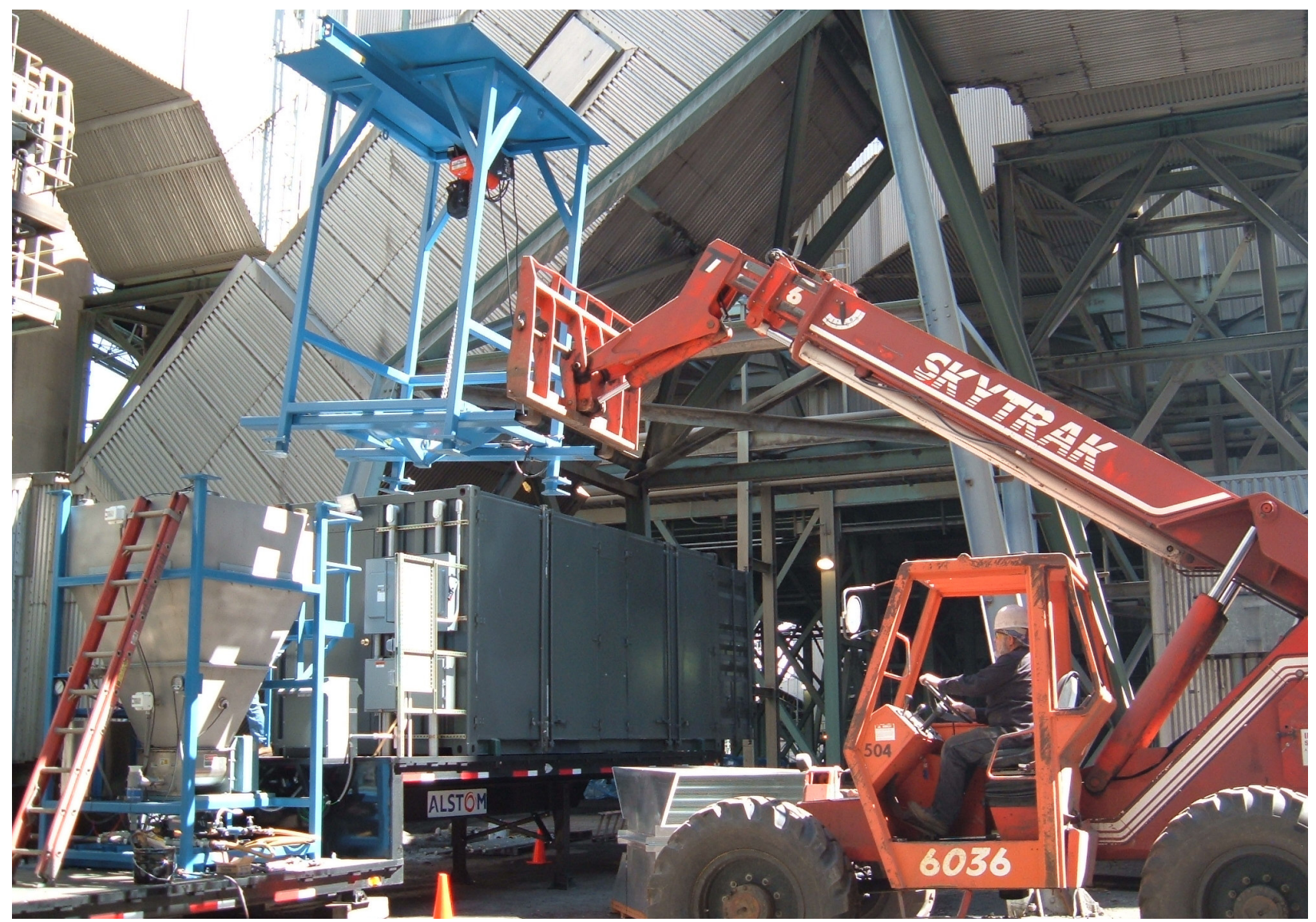

Figure 4.2-2 On Site Assembly of Mobile Mer-Cure ${ }^{\mathrm{TM}}$ Demonstration Trailer

three Mer-Cure ${ }^{\mathrm{TM}}$ subsystems. It also automatically shuts down the system in case of a boiler trip or internal system failure. The control system is designed to receive load signals from the boiler and to vary sorbent injection rate as a function of boiler load. The data acquisition system stores system operating data such as injection rates, pressure levels of various sections of the sorbent delivery, processing and injections systems, and temperatures.

Appropriate distribution of sorbent into the flue gas stream is critical for maximum contact between the sorbent and the mercury in the flue gas stream. Flow modeling studies using Fluent CFD package were conducted using specific boiler design data to better determine the location and the number of injection lances.

Based on calculated flow distributions, the number of injection ports, diameter and length of injection lances, and the number, orientation and size of injection lance nozzles were determined. The injection system was designed to proportionally distribute sorbent with flue gas volumetric flow. 
The completed mobile Mer-Cure ${ }^{\mathrm{TM}}$ demonstration trailer and custom fabricated injection system was shipped to each site. The sorbent storage and delivery system was assembled at the site; the sorbent processing system was placed close to the sorbent injection system and was connected to the storage system by 4-inch flexible hoses. The sorbent distribution system was installed at the sorbent injection location and connected to the delivery system by $1 \frac{1}{4}$-inch flexible hoses. 


\section{Test Planning and Mercury Instrumentation}

In general, the test program at each site consisted of three major components: baseline testing, parametric testing and long-term testing. During baseline testing, the existing mercury emissions were characterized for the unit, and the extent of native mercury capture was documented. During parametric testing, the sorbents to be evaluated were injected at a constant rate for 8-16 hours. For a given sorbent, several sorbent flow rates were tested to develop a parametric curve of sorbent injection rate versus mercury capture performance. For example, a sorbent could be injected for 12 hours each at $0.5,1.0,1.5$ and $2.0 \mathrm{lb} / \mathrm{MMacf}$ injection rate. That set of tests would constitute a parametric test run for a given sorbent. After roughly 12 hours without sorbent injection to allow the boiler to recover and return to its baseline condition, a parametric test run was performed on a second sorbent. At each host site, up to five different sorbent formulations were tested parametrically.

For long-term testing, the sorbent/injection rate combination that performed best during parametric testing was typically chosen. This sorbent was then injected at a constant rate while the boiler went through its normal operation. In addition to documenting $70 \%$ mercury capture, all of the participating utilities wanted to determine the injection rate required for $90 \%$ mercury capture. Each long-term test program was customized to achieve both the project goals and the desired goals of the host utility.

\subsection{Mercury Measurements}

Mercury concentrations in the flue gas (including speciation) were determined using CMMs and the $\mathrm{OH}$ method at (i) the air heater inlet, upstream of sorbent injection and (ii) the stack, downstream of the ESP after the particulate has been removed from the flue gas. Limited mercury concentration measurements were also performed in the duct between the air pre-heater and the ESP. The concentration of the mercury species in the flue gas upstream sorbent injection is used as the basis to calculate the percentage mercury removal with sorbent injection.

The University of North Dakota - Energy and Environmental Research Center (UND-EERC) used PS Analytical and Tekran CMMs to perform the on-line mercury concentration measurements. In this set-up, the flue gas is sampled through an inertial separation probe (Figure 5.1-1) to remove any suspended particulate matter, before it is directed to a wet conditioning system and subsequently to a mercury analyzer.

The inertial separation probe enables a particle-free stream to be sampled from the dust-laden flue gas, while minimizing the contact of the flue gas with suspended particulate during the sampling process. This is particularly important at the inlet sampling location where a high concentration of ash is present compared to the stack where a relatively dust-free flue gas is present. Ash components and unburned carbon in the ash can modify the chemical speciation of mercury or adsorb mercury species during the sampling process upon intimate contact with the sampled gas. Such contact would occur, for example, when the sampled gas passes through a layer of ash collected on filters within the sampling system. 
The mercury analyzer consists of a cold-vapor atomic adsorption spectrometer (CVAAS) coupled with a gold amalgamation system. The system is calibrated using vapor phase elemental mercury. The analyzers are capable of measuring both vapor-phase elemental and total mercury. The analyzer determines total vapor-phase mercury concentrations by reducing all of the oxidized mercury to the elemental form in the wet conditioning system. To measure elemental mercury, the oxidized mercury species are removed in the conditioning system, while allowing the elemental mercury to pass through.

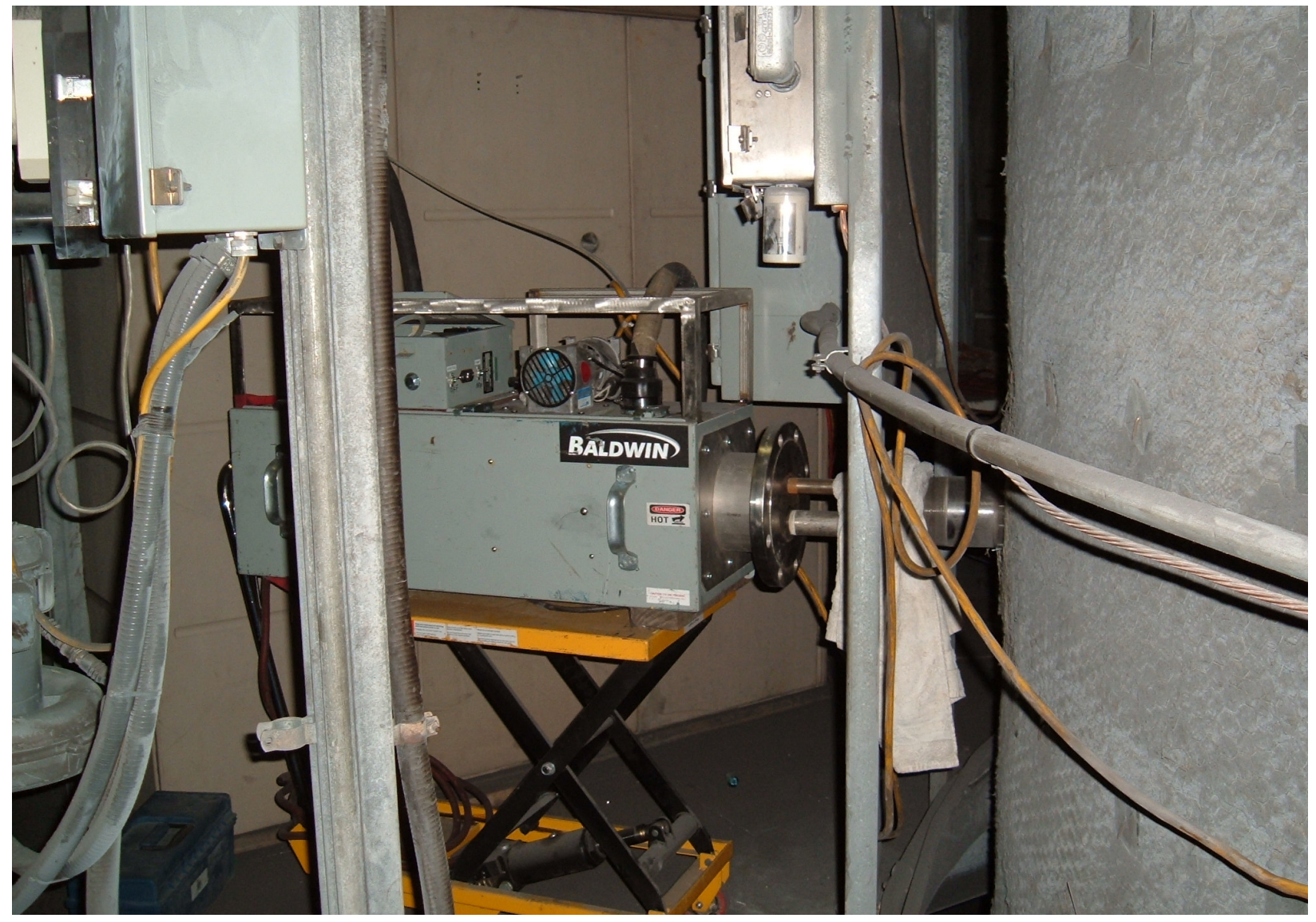

Figure 5.1-1 Inertial Separation Probe at Air Preheater inlet CMM Location

The results of the CMMs were validated by selective measurements using the $\mathrm{OH}$ method performed at the same location. With the $\mathrm{OH}$ method, flue gas is sampled through a filter (to capture particulate) and an impinger train that is designed to capture oxidized mercury in the first three impingers, followed by a blank impinger, then to capture elemental mercury in the last three impingers, followed by a moisture removal impinger (Figure 5.1-2). Analysis of the filter and the impinger solutions provides speciated mercury concentration data. 


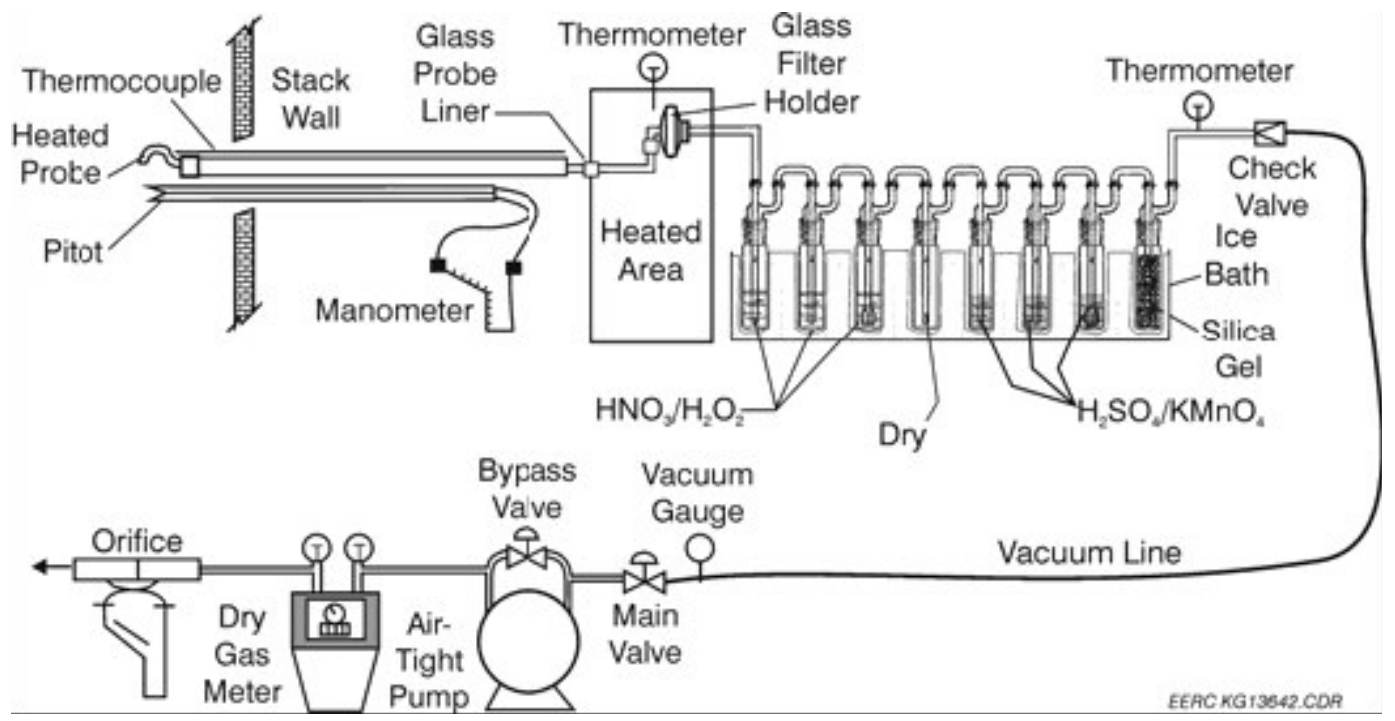

Figure 5.1-2 Ontario Hydro Sample Train Schematic

In addition to sampling for mercury concentrations using $\mathrm{CMM}$ and $\mathrm{OH}$ methods, samples of coal (from the feeders) and fly ash (from ESP hoppers) were obtained on a regular basis. The coal samples were analyzed for mercury and chlorine content in addition to obtaining their proximate and ultimate analysis. Ash samples were analyzed for mercury content and loss-on-ignition (LOI). Boiler operation data, including load, excess air, ESP operation and air heater outlet flue gas temperature were also collected throughout the test period. 


\section{Field Demonstration Program Summaries}

This section gives a detailed summary of the field demonstration program at each host site. The test program at each unit is documented completely in a separate host site report, including raw data and operating logs for the entire test program.

\subsection{Dave Johnson Unit \#3}

The goals for this Round 2 program, established by DOE/NETL, were to reduce the uncontrolled mercury emissions by 50 to $70 \%$ at a cost 25 to $50 \%$ lower than the previous target of $\$ 60,000 / \mathrm{lb}$ mercury removed. The enhanced performance desired by PacifiCorp and Alstom was to demonstrate greater than $90 \%$ capture of the gaseous mercury in the flue gas by injection of tailored sorbent at a feed rate significantly lower than standard (untreated) activated carbon.

\subsubsection{Pre-test Mercury Measurement at Dave Johnston Units}

The original proposal had identified Unit \#1 as the host unit for the demonstration testing. Limited measurements by the host utility, outside of this program, indicated that the emission levels of mercury from this unit were low. Alstom wanted to confirm the stack mercury concentrations for Unit \#1 before making the decision to proceed with this particular unit. Measurements were also carried out at Unit \#3 as an alternative test site.

Measurements of uncontrolled mercury level from PacifiCorp's Dave Johnston Unit \#1 and Unit \#3 were performed in January 2005. Both units are base-loaded units with electrostatic precipitators for particulate emission control. No other pollution control equipment is installed on these units. The units are each equipped with two Ljungstrom ${ }^{\mathrm{TM}}$ air heaters in parallel. Dave Johnston Unit \#1 burns Cordero Rojo coal while Unit \#3 burns Wyodak coal. Both coals are PRB coals with low chlorine content. These coals are not blended but are supplied separately to each unit.

Sampling was carried out at the stacks of Unit \#1 and Unit \#3. The flue gas temperature at the sampling location was approximately $290-320^{\circ} \mathrm{F}$. Baseline mercury measurements were carried out using Frontier GeoSciences' FAMS (Flue gas Adsorbent Mercury Speciation) method.

The FAMS method relies on sequential selective capture to separate and quantify three mercury species: particulate mercury, $\mathrm{Hg}^{p}$, gaseous oxidized mercury, $\mathrm{Hg}^{+2}$, and gaseous elemental mercury, $\mathrm{Hg}^{0}$. A known volume of flue gas is pulled through the FAMS sorbent train using standard sampling equipment including quartz probe liner, heated probe, silica-gel water trap, mass flow meter and pump. The $\mathrm{Hg}^{p}$ is captured on a quartz-fiber filter with the gas phase $\mathrm{Hg}^{+2}$ and $\mathrm{Hg}^{0}$ separated selectively on specialized solid sorbent traps. The temperature of the FAMS sorbent train is kept at $95 \pm 5^{\circ} \mathrm{C}$ during sampling to avoid water condensation in the trap. The adsorbed $\mathrm{Hg}^{0}$ on the $\mathrm{Hg}^{0}$ solid sorbent section of the speciation trap and $\mathrm{Hg}^{\mathrm{p}}$ on the quartz filter is leached out in a clean lab using hot-refluxing, oxidizing acid, and then reduced with a reducing agent solution. The adsorbed $\mathrm{Hg}^{+2}$ on the $\mathrm{Hg}^{+2}$ solid sorbent section of the speciation trap is dissolved in a reduction solution. Aliquots of all three $\mathrm{Hg}$ species digests are then analyzed using cold vapor atomic fluorescence spectroscopy (CVAFS). 
The measured mercury levels along with coal data are listed in Table 6.1-1. The total mercury level from the Unit \#1 was between 1.6 and $1.9 \mu \mathrm{g} / \mathrm{m}^{3}$, whereas that from the Unit \#3 was between 5.6 and $8.7 \mu \mathrm{g} / \mathrm{m}^{3}$. Despite fuels for both units being PRB coals, Unit \#1 had roughly $25-35 \%$ lower coal mercury content but $70-80 \%$ lower mercury stack emissions rates than Unit \#3, indicating that significantly more inherent removal takes place in Unit \#1 in comparison to Unit \#3.

Table 6.1-1 Comparison between PacifiCorp's Dave Johnston Unit \#1 and Unit \#3

\begin{tabular}{|c|c|c|}
\hline Unit & Dave Johnston Unit \#1 & Dave Johnston Unit \#3 \\
\hline Capacity $\left(\mathrm{MW}_{\mathrm{e}} \mathrm{Net}\right)$ & 110 & 220 \\
\hline Operation & Base-loaded & Base-loaded \\
\hline $\mathrm{NO}_{x}$ control & No low- $\mathrm{NO}_{\mathrm{x}}$ & No low- $\mathrm{NO}_{\mathrm{x}}$ \\
\hline $\mathrm{SO}_{2}$ control & Low sulfur coal & Low sulfur coal \\
\hline Air Heater & 2 - Ljungstrom ${ }^{\mathrm{TM}}$ & 2 - Ljungstrom ${ }^{\mathrm{TM}}$ \\
\hline $\begin{array}{l}\text { Particulate control } \\
\left(\mathrm{SCA} \text { in } \mathrm{ft}^{2} / \mathrm{kacfm}\right)\end{array}$ & $\begin{array}{l}\text { Cold Side-ESP } \\
\text { (706) }\end{array}$ & $\begin{array}{l}\text { Cold Side-ESP } \\
(629)\end{array}$ \\
\hline Ash utilization & Disposal & Sold for mine reclamation \\
\hline Coal & Cordero (PRB) & Wyodak (PRB) \\
\hline \multicolumn{3}{|l|}{ Proximate analysis } \\
\hline Moisture (\%) & 29.79 & 30.73 \\
\hline Ash (\%) & 5.49 & 7 \\
\hline Vol.matter. + fixed carbon (\%) & 64.72 & 62.27 \\
\hline HHV (Btu/lb) & 8,421 & 8060 \\
\hline \multicolumn{3}{|l|}{ Ultimate analysis (dry basis) } \\
\hline Hydrogen (\%) & 4.8 & 4.92 \\
\hline Carbon (\%) & 68.46 & 67.75 \\
\hline Sulfur (\%) & 0.43 & 0.94 \\
\hline Nitrogen (\%) & 1.07 & 0.94 \\
\hline Oxygen (\%) & 17.77 & 15.44 \\
\hline Ash (\%) & 7.49 & 10.09 \\
\hline $\mathrm{Cl}$ in coal (ppmw dry) & $101-327$ & $<50$ \\
\hline $\mathrm{Hg}$ in coal (ppmw dry) & $0.038-0.094$ & $0.06-0.12$ \\
\hline Stack Hg Data $\left(\mu \mathrm{g} / \mathrm{m}^{3}\right)$ & Dave Johnston Unit \#1 & Dave Johnston Unit \#3 \\
\hline Particulate $\mathrm{Hg}$ & $0.12-0.37$ & $0.01-0.04$ \\
\hline Elemental $\mathrm{Hg}$ & $0.4-0.6$ & $2.4-4.35$ \\
\hline Oxidized $\mathrm{Hg}$ & $0.93-1.21$ & $3.1-4.35$ \\
\hline Total $\mathrm{Hg}$ & $1.61-1.93$ & $5.55-8.71$ \\
\hline
\end{tabular}

About $60 \%$ of the total mercury emitted was in the oxidized form for both the units. Some of the reasons for such a low mercury emission level for Unit \#1 may include: 
- Boiler operation - Unit \#1 runs at a higher CO emission level (approximately 500 ppm) than Unit \#3 (approximately 90 ppm), suggesting less efficient combustion, and, therefore, higher carbon-in-ash;

- Chlorine content of coal - the coal of Unit \#1 (Cordero Rojo) has higher chlorine levels than that of Unit \#3 (Wyodak);

- Flue gas temperature at the ESP inlet - Unit \#1 has about $280^{\circ} \mathrm{F}$ whereas Unit \#3 has about $320^{\circ} \mathrm{F}$.

The three factors mentioned above are likely to have contributed to higher native capture and lower stack mercury emissions level in Unit \#1. The mercury level of 1.6-1.9 $\mu \mathrm{g} / \mathrm{m}^{3}$ is low enough to cause significant mercury measurement errors, and led to re-evaluation of the test program at Dave Johnston Unit \#1. After discussions with PacifiCorp and DOE/NETL, a decision was made to carry out the demonstration program at Unit \#3.

\subsubsection{Site Description and Test Preparation}

Dave Johnston Unit \#3 of PacifiCorp is a $220 \mathrm{MW}_{\mathrm{e}}$ wall-fired, pulverized coal (PC) boiler firing subbituminous coal (PRB) and equipped with an ESP as a particulate emission control device. The specific collection area (SCA) of the ESP is $640 \mathrm{ft}^{2} / \mathrm{kacfm}$. Table 1.2-1 previously showed the unit configuration and coal and emissions data for DJ3. The back-pass section of the unit has a transition section, following the economizer, with dropout hoppers that serve as mechanical collectors for large ash particle/deposits leaving the economizer or upstream sections. Downstream of the transition section are two Ljungstrom ${ }^{T M}$ air pre-heaters located in parallel followed by a large electrostatic precipitator. Because the ductwork came together after the air pre-heaters, it was not possible to treat only one portion of the flue gas and the entire gas path had to be treated for mercury control. The temperatures at the inlet of the air pre-heater ranged between 800 and $870^{\circ} \mathrm{F}$, higher than normally expected for a typical pulverized coal-fired boiler. The air pre-heater outlet/ESP inlet temperatures ranged from 330 to $360^{\circ} \mathrm{F}$, also higher than typical operation. The loss-on-ignition (LOI) of the fly ash collected in the ESP hoppers varied between 0.6 to $1.4 \%$. The plant is fully equipped to provide the operational data including flue gas composition, stack opacity, and air heater flue gas temperatures.

Dave Johnston Unit \#3 was chosen for this evaluation because it fires a sub-bituminous Powder River Basin (PRB) coal and is configured with a cold-side ESP.

A PRB coal-fired boiler with a cold-side ESP has emerged as a preferred combination in the US utility industry for several reasons. Utilities are switching to these lower sulfur Western coals to lower $\mathrm{SO}_{2}$ emissions. Second, when the boilers are operated in a low- $\mathrm{NO}_{x}$ configuration (air staging), very low emissions can be achieved with these coals ( $<0.1 \mathrm{lb} / \mathrm{MMBtu}$ ), particularly with tangentially-fired boilers. Fuel cost, which is the predominant operating cost for coal-fired power plants, is also lower with the use of PRB coals. These coals are low cost because they are typically surface mined with low mining costs.

Previous tests at plants with PRB coal and a cold-side ESP using plain activated carbon sorbents indicated that the mercury removal was limited to about 70 percent. For example, in a Round 1 
mercury control technology demonstration sponsored by US DOE, testing was conducted at We Energies Pleasant Prairie power plant, also a PRB-fired unit equipped with a cold-side ESP. The average mercury control efficiency ranged from 46 percent at an injection rate of $1.0 \mathrm{lb} / \mathrm{MMacf}$ to 50-55 percent at an injection rate of $5.0 \mathrm{lb} / \mathrm{MMacf}$. Increasing the injection rate to $10 \mathrm{lb} / \mathrm{MMacf}$ increased mercury capture across the ESP to 60-65 percent. Almost no further increase was observed at higher injection rates. ${ }^{1,2}$

Several technical risks associated with the Mer-Cure ${ }^{T M}$ technology would be addressed by the demonstration testing at DJ3. These include:

- Sorbent survivability and activity retention upon exposure to the high temperature flue gas upstream of the air heater

- Long-term and continuous operation of the sorbent processing, distribution and injection system

- Potential for increased opacity due to slip of the fine sorbent particles through the ESP

- Potential for increased air pre-heater fouling Appropriate distribution of sorbent into the flue gas stream is critical for maximum contact between the sorbent and the mercury in the flue gas stream. Flow modeling studies using Fluent CFD package were conducted using specific boiler design data to better determine the location and the number of injection lances. Figure 6.1-1 shows a photo of the modeled injection location at DJ3.

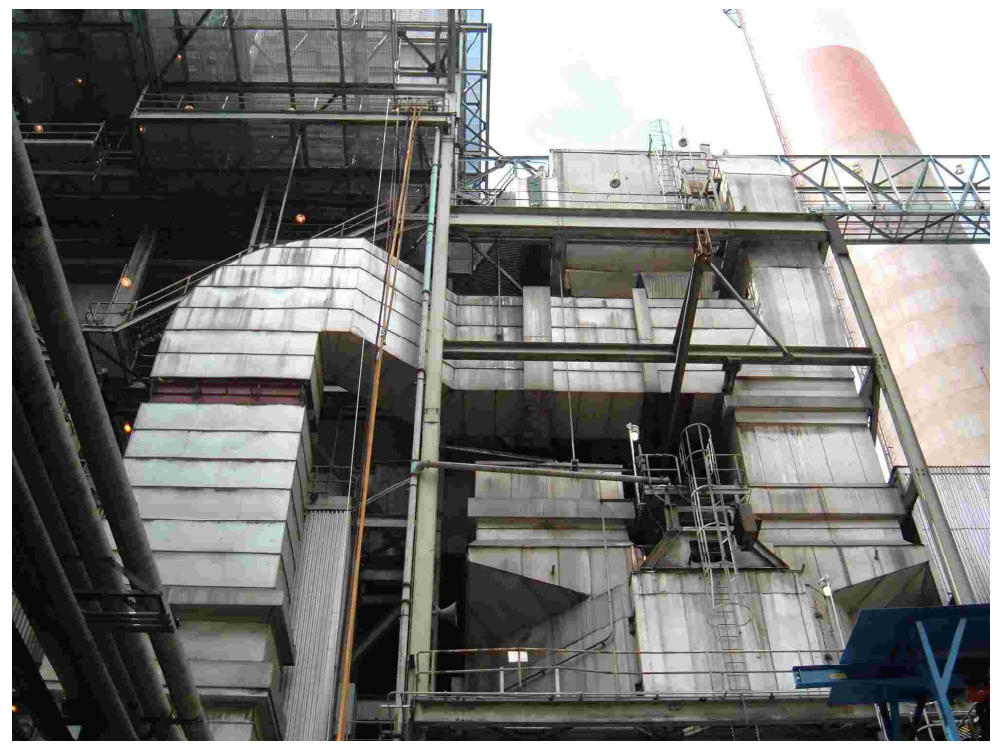

Figure 6.1-1 Sorbent Injection Between Economizer and Air Heater for Dave Johnston Unit \#3

Figure 6.1-2 and Figure 6.1-3 show some of the results from the DJ3 back-pass CFD study. The unit has two horizontal ducts out of the economizer section as shown in the $x-y$ plane sectional view in Figure 6.1-2. The dimensions of these ducts expand in horizontal direction and slightly reduce in vertical direction.

As shown in Figure 6.1-3, the flow profile in the $x-y$ plane (the horizontal plane along the flow direction) from the CFD study suggests that the flue gas flow out of the economizer section is 


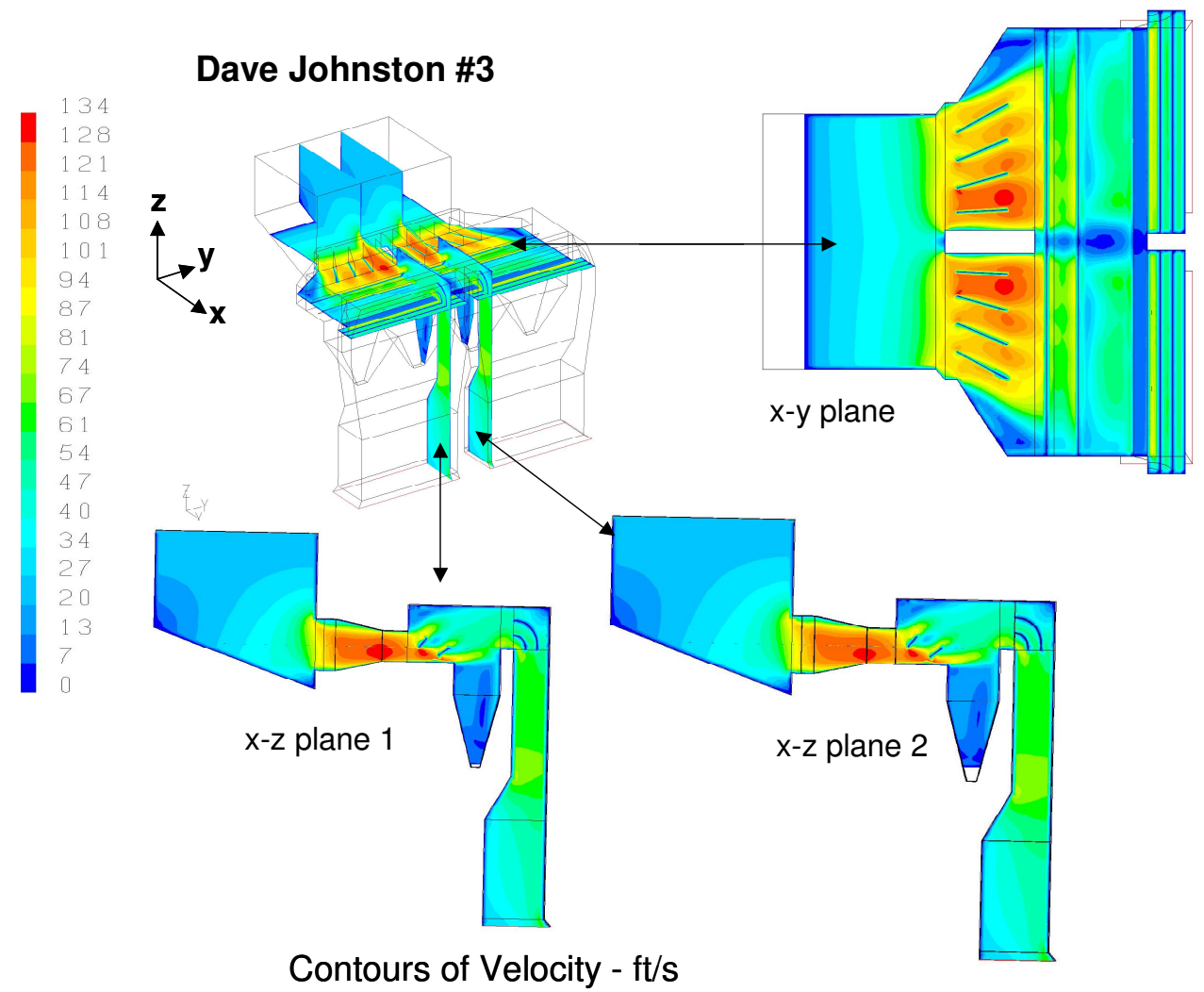

Figure 6.1-2 Flow Distribution Contours in the Back-Pass of Dave Johnston Unit \#3

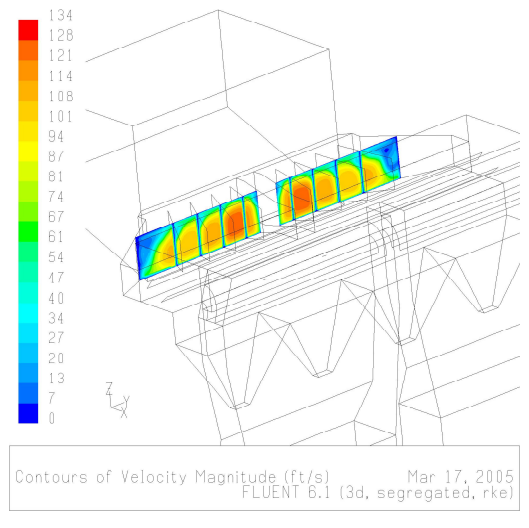

\begin{tabular}{|rrr} 
& \multicolumn{1}{c}{$\%$} & $\begin{array}{c}\text { Normalized } \\
\text { to lowest flow }\end{array}$ \\
\hline a & $8.92 \%$ & 1.31 \\
b & $10.27 \%$ & 1.51 \\
c $11.04 \%$ & 1.63 \\
d $13.01 \%$ & 1.91 \\
e & $6.79 \%$ & 1.00 \\
\hline & & \\
f & $6.83 \%$ & 1.01 \\
g $13.08 \%$ & 1.93 \\
h $10.86 \%$ & 1.60 \\
I $10.31 \%$ & 1.52 \\
j & $8.89 \%$ & 1.31
\end{tabular}
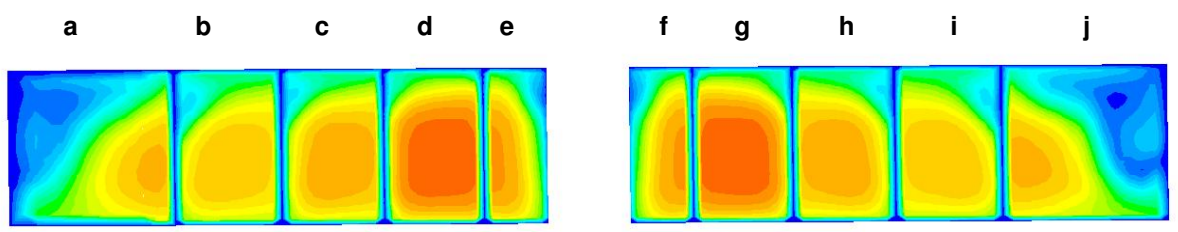

Figure 6.1-3 Flue Gas Flow Distribution at Sorbent Injection Location of Dave Johnston Unit \#3 
concentrated mostly in the center of the duct. Despite turning vanes at the transition ducts, most of the flue gas flow stays in the middle of the cross section (sections " $d$ " and " $g$ " of Figure 6.1-3). Also, some recirculation of flue gases is observed on both ends of the duct cross section (sections "a" and "j" of Figure 6.1-3). On the other hand, the flow profile in the $x-z$ plane (the vertical plane along the flow direction) shows relatively even vertical distribution in the duct. Based on the calculated flow distributions, the numbers of injection ports, injection lances and their nozzles were determined.

Based on the CFD results, a lance injection system was designed for DJ3 targeting proportional distribution of sorbent with the flue gas volumetric flow.

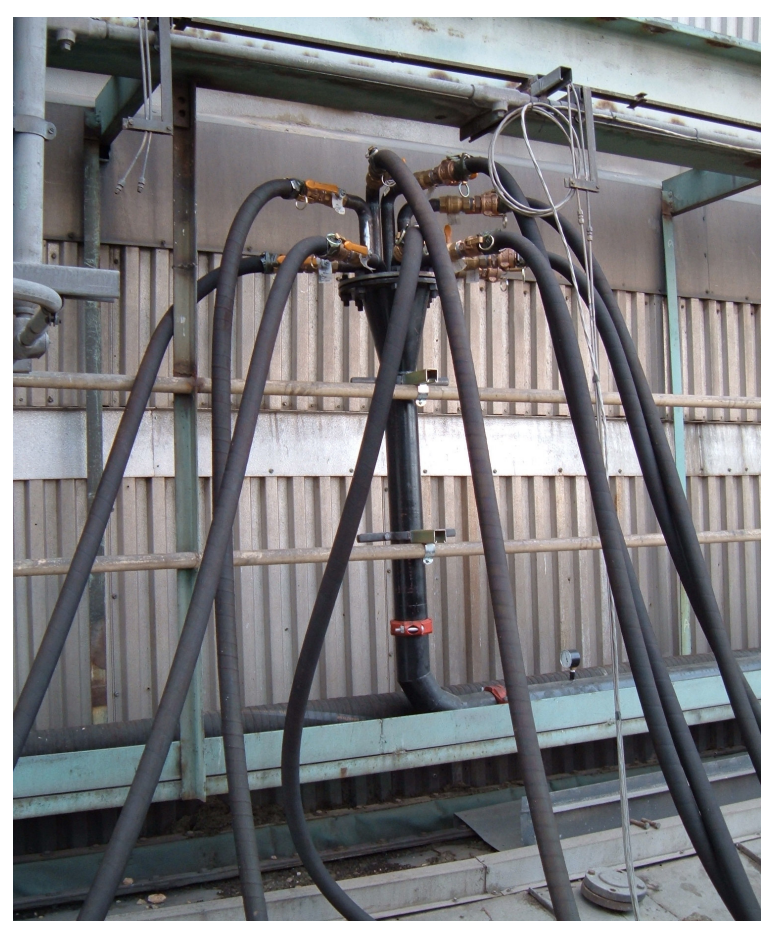

Figure 6.1-4 Sorbent Distribution System
The completed mobile Mer-Cure ${ }^{\mathrm{TM}}$ demonstration trailer was shipped to PacifiCorp in June 2005. The Mer-Cure ${ }^{\mathrm{TM}}$ system was placed on the east side of the DJ3 boiler. The sorbent storage and delivery system was assembled at the site; the sorbent processing system was placed close to the sorbent injection system and was connected to the storage system by 4 -inch flexible hoses. The sorbent distribution system was installed at the sorbent injection location as shown in Figure 6.1-4 and connected to the delivery system by 1.25 -inch flexible hoses. The injection and distribution systems were secured to the boiler structure. The sorbent delivery system is shown in Figure 6.1-5.

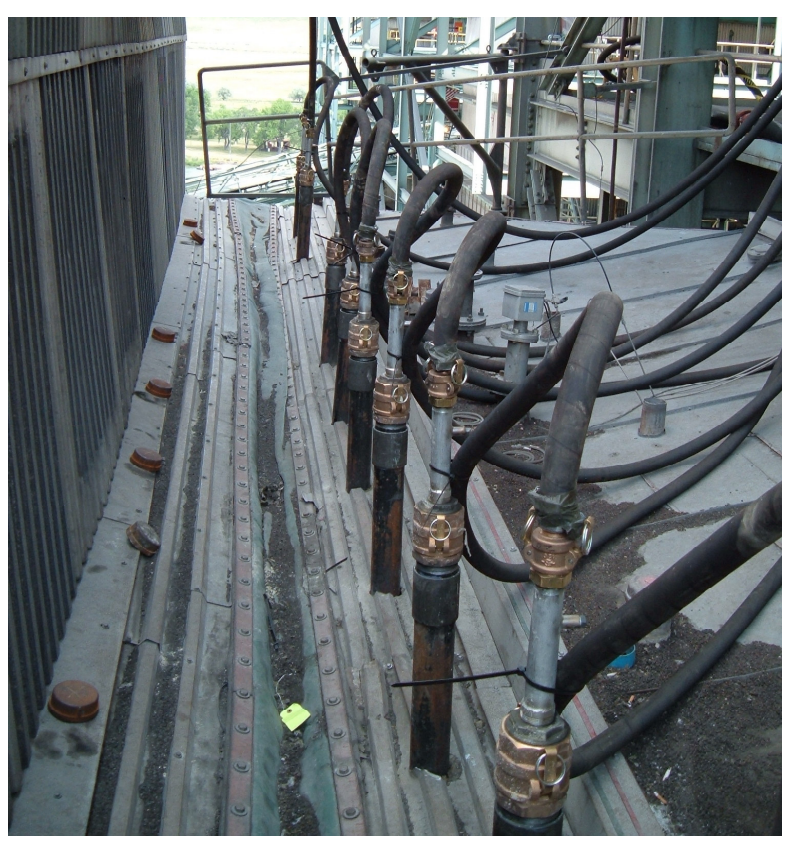

Figure 6.1-5 Sorbent Injection Lances 
Figure 6.1-6 shows a schematic diagram of the Dave Johnston Unit \#3 plant layout showing various sampling locations. Coal samples were collected from the mills and composite samples prepared. Ash samples were collected from the ESP hoppers and the ash silo on a regular basis.

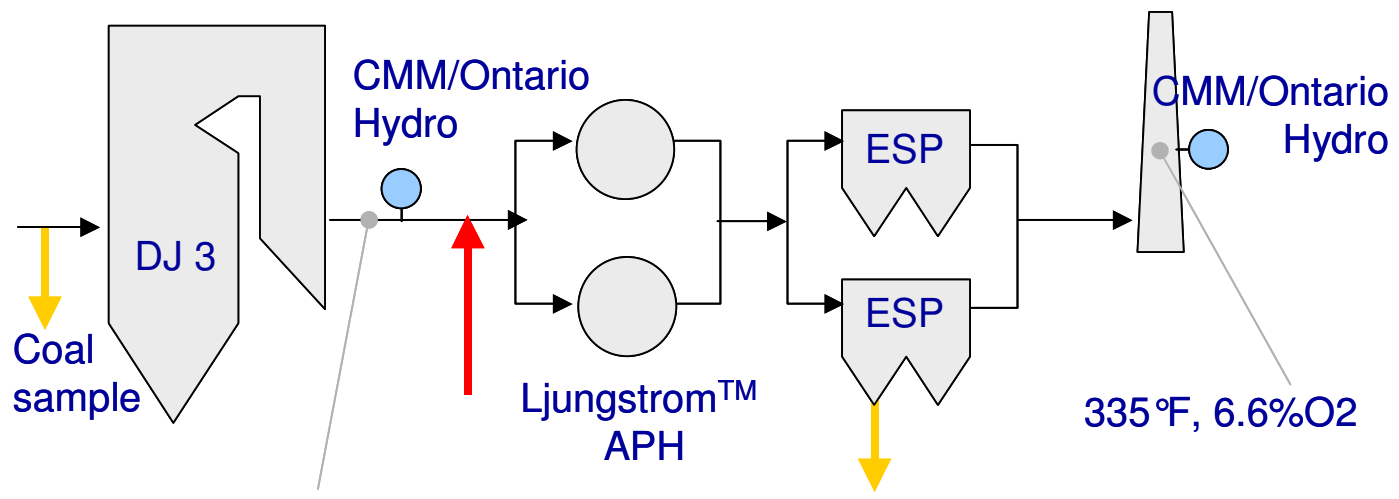

$770^{\circ} \mathrm{F}, 4.4 \% \mathrm{O} 2$

Fly Ash

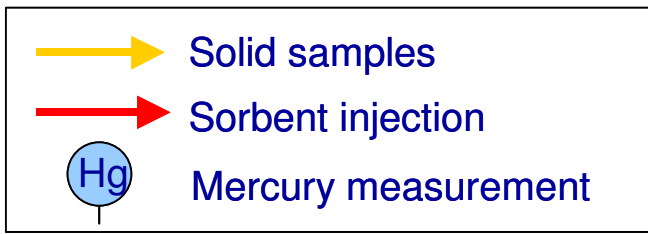

Figure 6.1-6 Injection and Sampling Locations, Dave Johnston Unit \#3

One of the unique aspects of Alstom's Mer-Cure ${ }^{T M}$ technology is that the sorbent injection is performed between the economizer and the air heater. In typical utility boilers, temperatures at this location are around 600 to $800^{\circ} \mathrm{F}$. The sorbents used in the Mer-Cure ${ }^{\mathrm{TM}}$ technology are activated carbon-based. Different halogenated components are added to the activated carbon and the material processed to make the final sorbent. During this test program, four such formulations were tested (\# 2, 4, 6, and 8). These formulations differed from each other in terms of the added components, amounts of the added components, and manufacturing process conditions. One of the challenges in the preparation of these sorbents is that the added components must not be altered as they pass through the high temperature region upstream and within the air heater. A rigorous bench-scale study performed earlier by Alstom identified the most promising formulations that were stable under the process conditions they would be exposed to once injected into the flue gas.

The coal fired at Dave Johnston Unit \#3 was a sub-bituminous PRB coal from the Wyodak mine. Table 6.1-2 lists the average coal properties determined by analysis of coal composite samples. A total of ten (10) composite coal samples were collected and prepared from the four mills of DJ3 during test campaign. From these composite samples, the average mercury content of the coal and its standard deviation have been determined to be $0.09 \mu \mathrm{g} / \mathrm{g}$ dry coal, and $0.023 \mu \mathrm{g} / \mathrm{g}$ dry coal, respectively. The chlorine content of the coal was $49.2 \mathrm{ppm}$ with a standard deviation of $13.4 \mathrm{ppm}$ on a dry basis. 
Table 6.1-2 Dave Johnson Unit \#3 Average Coal Properties

\begin{tabular}{|r|r|r|}
\hline Proximate analysis & As received & Dry basis \\
\hline Total moisture (\%) & 29.50 & $\mathrm{~N} / \mathrm{A}$ \\
\hline Volatile matter (\%) & 30.75 & 43.63 \\
\hline Fixed Carbon (\%) & 34.37 & 48.75 \\
\hline Ash (\%) & 5.37 & 7.62 \\
\hline HHV (BTU/lb) & 8,165 & 11,582 \\
\hline Ultimate analysis & As received & Dry basis \\
\hline $\mathrm{C}$ & 47.52 & 67.40 \\
\hline $\mathrm{H}$ & 3.32 & 4.71 \\
\hline $\mathrm{O}$ & 13.27 & 18.82 \\
\hline $\mathrm{S}$ & 0.60 & 0.86 \\
\hline $\mathrm{Cl}$ & 0.41 & 0.58 \\
\hline Ash & $35 \mathrm{ppm}$ & $50 \mathrm{ppm}$ \\
\hline Total & 5.37 & 7.62 \\
\hline $\mathrm{Hg}(\mu \mathrm{g} / \mathrm{g}$ dry coal) & 100.00 & 100.00 \\
\hline $\mathrm{Hg}(\mathrm{lb} / \mathrm{TBTU})$ & $7.77 \pm 1.99$ & $7.77 \pm 1.99$ \\
\hline
\end{tabular}

The minimum and maximum mercury contents in the samples analyzed were $0.03 \mathrm{ppm}$ and 0.16 ppm, respectively, indicating a wide variation in the quantity of mercury entering the boiler with the coal.

Table 6.1-3 lists the tasks carried out to complete the PacifiCorp test campaign and their associated timeline. Long-term testing had originally been planned to start in the 4th week of July; however, tube leaks at DJ3 and subsequent boiler start-up issues at the plant delayed the testing.

Table 6.1-3 PacifiCorp Test Campaign Timeline

\begin{tabular}{|c|c|}
\hline Tasks & Timeline \\
\hline Baseline measurement & June $19-26,2005$ \\
\hline Parametric Testing & June $27-$ July 2, 2005 \\
\hline Long-term testing & August 4 - September 4, 2005 \\
\hline System removal & September 6 - 9, 2005 \\
\hline
\end{tabular}

Baseline measurements of mercury concentration in the flue gas were performed at the air heater inlet (pre-sorbent injection) and precipitator outlet. Validation data using the $\mathrm{OH}$ method was also obtained for the baseline condition. Subsequent to the baseline testing, approximately one week of parametric testing was conducted. Tests included four enhanced activated carbon sorbents.

In the parametric tests, Mer-Clean ${ }^{T M} 8$ gave the best mercury removal performance. Mer-Clean ${ }^{T M} 8$ ( $\mathrm{H}$ in schedule table) was chosen for the first half of the long-term testing. 
Following the baseline and parametric testing in June, the long-term testing was scheduled for the middle of July. Due to a forced outage and subsequent operational difficulties such as tube leaks in DJ3, the start of the long-term testing was delayed until early August. Despite the delay, the fourweek field demonstration was completed early September, in time for the next scheduled test campaign at Basin Electric.

During the first half of the long-term tests, the sorbent injection rate was initially maintained at approximately $52 \mathrm{lb} / \mathrm{hr}$ for one week. In the second week, the injection rate was lowered to $35 \mathrm{lb} / \mathrm{hr}$. During the last two weeks of long-term testing, Mer-Clean ${ }^{\mathrm{TM}} 2$ (B in schedule table) was used, which required slightly higher injection rates to achieve similar levels of mercury removal as Mer-Clean ${ }^{\mathrm{TM}} 8$. Injection rates during these two weeks of testing were maintained at $59 \mathrm{lb} / \mathrm{hr}$.

\subsubsection{Baseline Testing Results}

Figure 6.1-7 shows typical variations of speciated mercury levels at the stack and total mercury at the pre-injection location. These measured mercury levels are uncorrected vapor phase concentrations. During measurements, the economizer outlet excess oxygen level was maintained around 3\% $\mathrm{O}_{2}$ and the boiler load (gross) was kept around $225 \mathrm{MW}_{\mathrm{e}}$. The total vapor phase mercury level at the air heater inlet varied between 10 and $12 \mu \mathrm{g} / \mathrm{m}^{3}$, while that at the stack was between 9 and $11 \mu \mathrm{g} / \mathrm{m}^{3}$. Up to 50 percent of the stack mercury was elemental, with an average value 5.5 $\mu \mathrm{g} / \mathrm{m}^{3}$. According to the obtained CMM data, the inherent mercury capture between the two sampling locations was between 0 and 20 percent during this measurement.

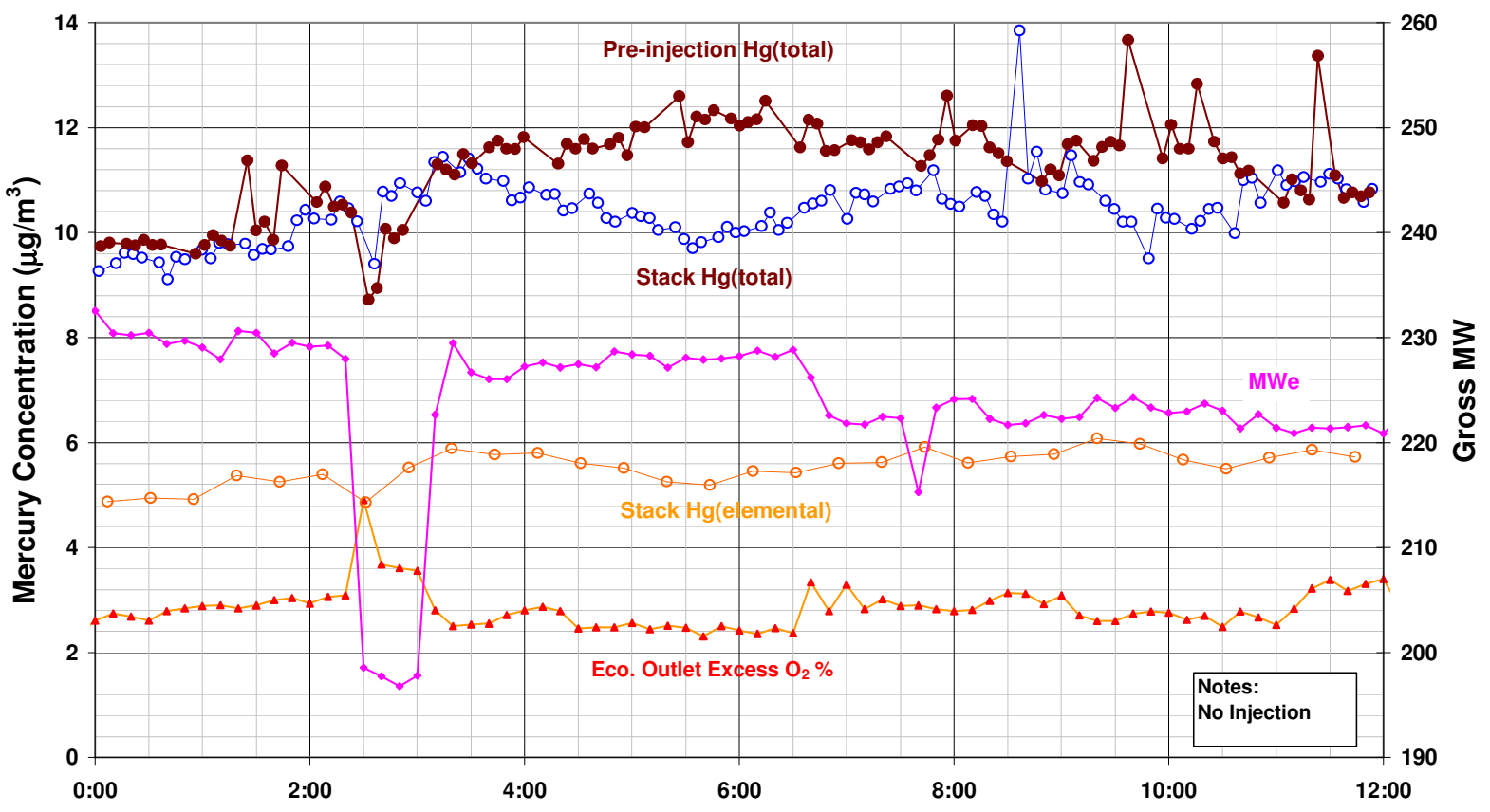

Figure 6.1-7 Baseline Mercury Levels at Air Preheater Inlet and Stack 


\subsubsection{Parametric Testing Results}

Figure 6.1-8 shows a typical response of the mercury levels from DJ3 when a Mer-Clean ${ }^{\mathrm{TM}}$ sorbent is injected. These reported mercury levels are vapor phase mercury levels corrected to $3 \% \mathrm{O}_{2}$ and $68^{\circ} \mathrm{F}$. The uncontrolled mercury level before the injection testing gradually increased from $10 \mu \mathrm{g} / \mathrm{m}^{3}$ to 12 $\mu \mathrm{g} / \mathrm{m}^{3}$. This may be due to variation in mercury content in coal. Although the levels changed with time, the air heater inlet mercury and the stack mercury were of the same level at any given point in time before injection (between 0:00 and 14:00), suggesting no inherent mercury removal between the air heater inlet and the stack. This also suggests that the measured air heater inlet mercury can be used as an indicator for "uncontrolled" mercury level at the stack on this unit.

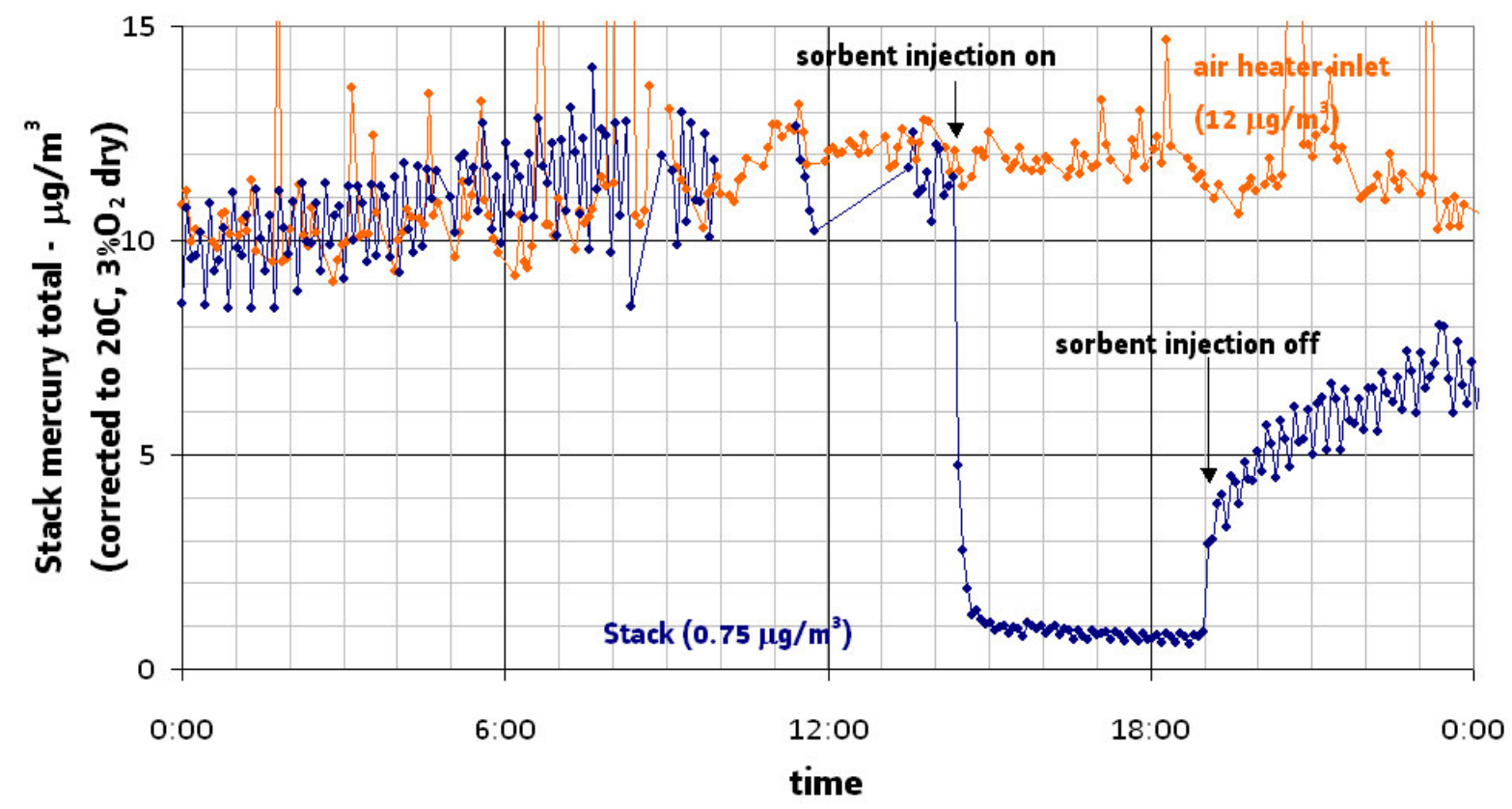

Figure 6.1-8 CMM Response to Mer-Cure ${ }^{\mathrm{TM}}$ System On/Off Operation

The Mer-Cure ${ }^{T M}$ system was turned on at 14:20 and the Mer-Clean ${ }^{T M}$ sorbent was injected to the back-pass of the DJ3. The mercury level dropped in two steps: (i) instantaneous drop to $1 \mu \mathrm{g} / \mathrm{m}^{3}$ in 20 minutes and (ii) slow reduction eventually reached a steady state level of $0.75 \mu \mathrm{g} / \mathrm{m}^{3}$ over a twohour period. The mercury level at the air heater inlet during injection was relatively constant between 11 and $12 \mu \mathrm{g} / \mathrm{m}^{3}$ during this period. The mercury removal efficiency based on the uncontrolled mercury level, i.e., air heater inlet mercury level, was approximately $94 \%$. The test was continued under this condition for five hours.

When the sorbent injection was turned off at 19:00, the mercury level at the stack started recovering to the baseline level. The recovery occurred in two stages: (1) instantaneous initial recovery over 10 minute period, followed by (2) slow recovery. This recovery pattern has been observed for every test condition during parametric testing. This behavior has also been observed in previous testing 
conducted in our laboratory scale experiments, as well as in other field testing conducted in previous DOE-sponsored field demonstration programs.

These two-step reduction and recovery patterns may be explained by how sorbent particles would behave differently as they are injected into the flue gas stream. As sorbent particles are injected, they are entrained by flue gas and travel through various devices (air heaters, SCRs, ductwork, scrubbers, etc.) until they are collected by particulate control devices (an electrostatic precipitator in case of DJ3). Some of these "in-flight" particles, however, are deposited onto internal surfaces (air heater elements, turning vanes, duct surfaces, regions of high turbulence, etc,) even before they arrive at the electrostatic precipitators. The residence time of "in-flight" sorbent particles in the ductwork is on the order of a second, whereas that of the wall-deposited particles may be orders of magnitude longer.

As the Mer-Cure ${ }^{\mathrm{TM}}$ system is turned on, sorbent particles interact with mercury in the flue gas and reduce the mercury level to $1 \mu \mathrm{g} / \mathrm{m}^{3}$. Some of these injected sorbent particles start "coating" most of the internal surfaces, providing additional mercury adsorption surface area. Depending on the duct design, sorbent particle size distribution, degree of turbulence, etc., it may take time for the internal surfaces to be completely covered by some of these in-flight particles. This is observed in the slow decrease of stack mercury level over a two-hour period.

The in-flight and wall effects may be decoupled as the recovery pattern is further analyzed. During injection (14:00 through 19:00 in Figure 6.1-8), mercury reduction is achieved both by the in-flight particles and by the wall particles. A relatively constant population of in-flight particles will be maintained between the injection point and the electrostatic precipitators. As soon as the injection system has been turned off, the in-flight sorbent particles quickly disappear, leaving only the walldeposited particles in the back-pass for mercury capture. The immediate recovery to $4 \mu \mathrm{g} / \mathrm{m}^{3}$ is mainly attributed to the absence of the in-flight particles. Those wall-deposited particles continue to adsorb mercury until their adsorption capacity is depleted or they are covered by incoming fly ash particles. This is observed in an asymptotic recovery pattern towards the baseline mercury level.

This simple analysis of the recovery pattern shows that the in-flight contributions to the overall mercury capture, i.e., immediate recovery, are approximately $29 \%$. Roughly $70 \%$ of the total mercury capture is, in other words, due to the wall effect. This further emphasizes the significance of injecting sorbent particles as far upstream of the particulate collection devices as possible, maximizing conversion of internally available surface area into reactive surfaces. This is achieved in Mer-Cure ${ }^{\mathrm{TM}}$ system by selecting the air heater inlet as the sorbent injection point.

Figure 6.1-9 shows the stack mercury emission level as a function of sorbent feed rate for a family of Mer-Clean ${ }^{\mathrm{TM}}$ sorbents. The stack mercury level decreases exponentially as the sorbent injection rate is increased. At an injection rate of $1.0 \mathrm{lb} / \mathrm{MMacf}$, the stack mercury level reached below $0.5 \mu \mathrm{g} / \mathrm{m}^{3}$. The incremental reduction with further increase in injection rate rapidly diminishes.

Figure 6.1-10 shows the performance curves of various Mer-Clean ${ }^{\mathrm{TM}}$ sorbents when injected upstream of air heaters using the Mer-Cure ${ }^{\mathrm{TM}}$ hardware system. Each of the data points was obtained while running the Mer-Cure ${ }^{\mathrm{TM}}$ system for at least four hours at a relatively constant boiler 


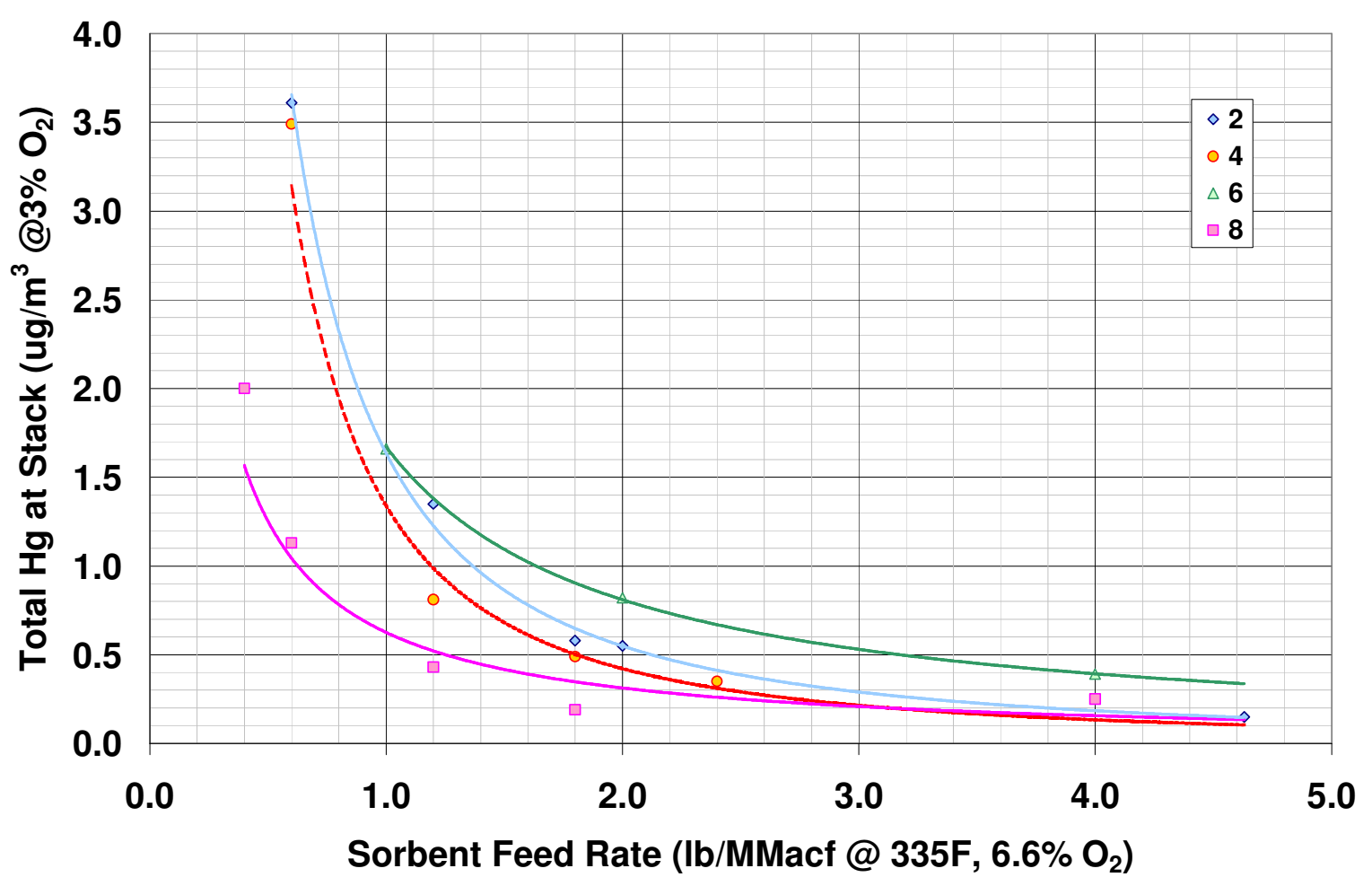

Figure 6.1-9 Mercury Emission Rate Parametric Results for Mer-Clean ${ }^{\mathrm{TM}}$ 2, 4, 6 and 8

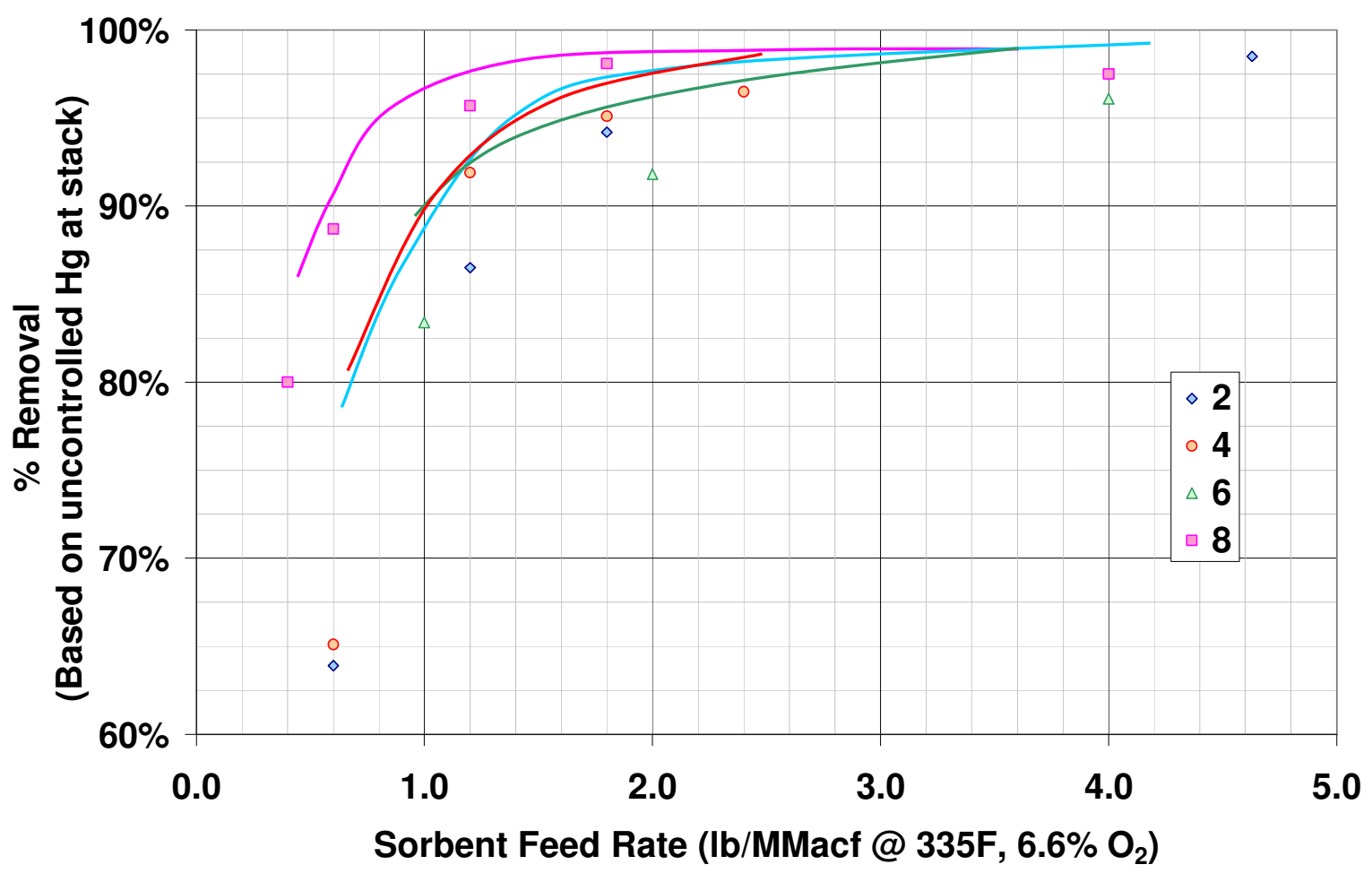

Figure 6.1-10 Mercury Removal Efficiency Parametric Results for Mer-Clean ${ }^{\mathrm{TM}}$ 2, 4, 6 and 8 
load. The removal efficiency has been calculated based on the "uncontrolled" stack emission levels measured during baseline testing. Four Mer-Clean ${ }^{T M}$ sorbents - labeled Mer-Clean ${ }^{T M}$ 2, 4, 6, and 8 were tested during parametric testing. With some variations in performance among sorbents, all of the Mer-Clean ${ }^{\mathrm{TM}}$ sorbents could achieve greater than $90 \%$ removal at a relatively low injection rate. Among the four sorbents tested, Mer-Clean 8 performed the best, achieving $90 \%$ at approximately $0.7 \mathrm{lb} /$ MMacf. At $1.6 \mathrm{lb} / \mathrm{MMacf}$, nearly $98 \%$ removal could be achieved.

Although this excellent performance may be partly attributed to the size of the electrostatic precipitator and the relatively long ductwork leading to the electrostatic precipitator, it is mostly due to the three-pronged approach being taken in the Mer-Cure ${ }^{T M}$ system, i.e., (1) uniform dispersion of sorbent particles in the flue gas stream, (2) process chemistry enhancement from carefully selected injection location, and (3) use of proprietary sorbent additives.

\subsubsection{Long-Term Testing Results}

Figure 6.1-11 shows the total mercury levels measured at the air heater inlet and the stack over the entire long-term demonstration period. The reported mercury levels are total gaseous mercury, i.e., both elemental and oxidized, corrected to $3 \% \mathrm{O}_{2}$ and reported in micrograms per dry standard cubic meter. PS Analytical mercury systems were used for the measurements. For measurements at the air heater inlet, a solids-free flue gas was sampled by an inertial separation probe (ISP) in order to minimize solids-flue gas interaction during sampling.

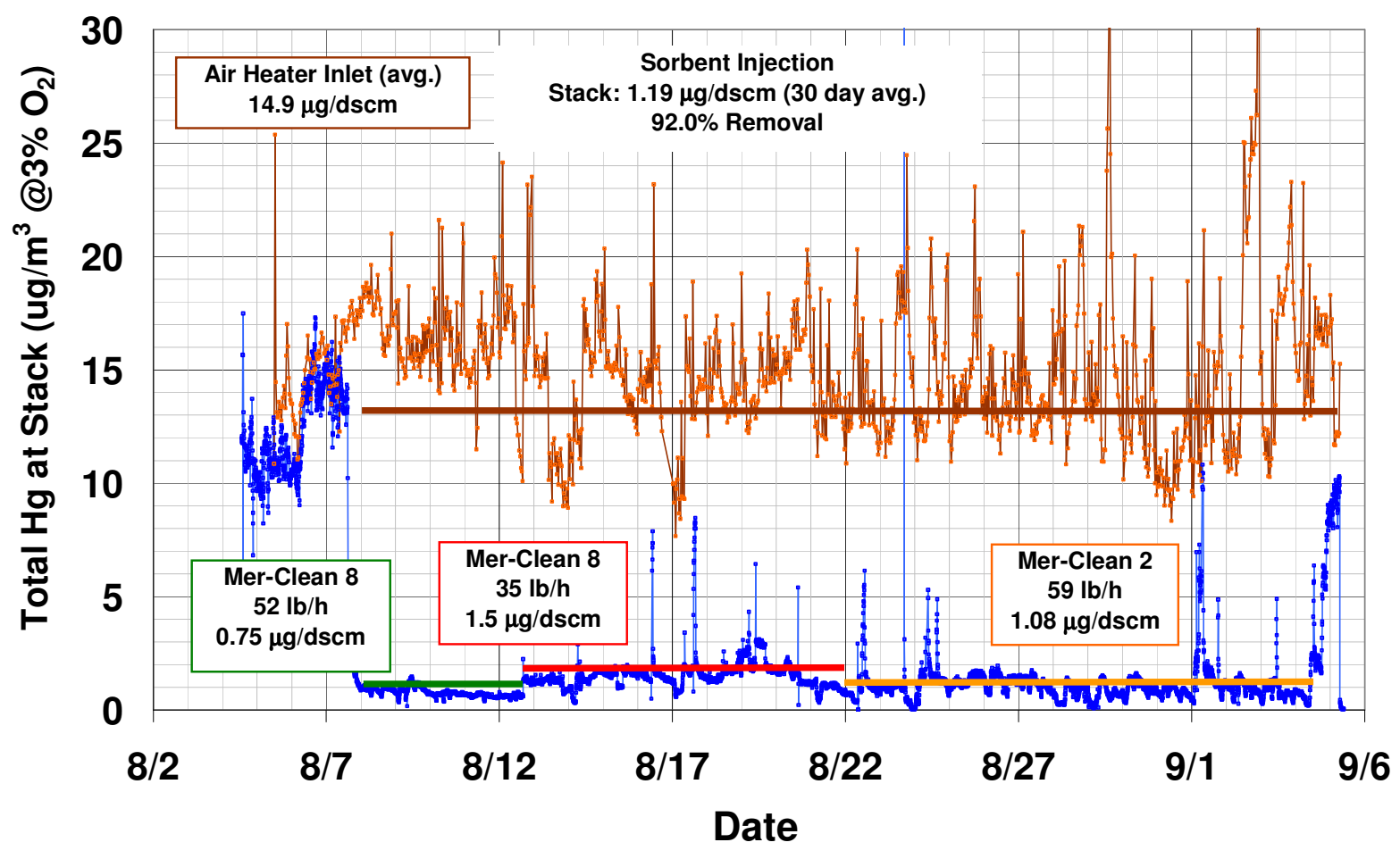

Figure 6.1-11 APH Inlet and Stack Mercury Emission Rate Results During Long-Term Demonstration

For the first three days of the testing, mercury levels were measured at the air heater inlet and stack without operating the Mer-Cure ${ }^{\mathrm{TM}}$ system. This allowed re-establishment of the baseline mercury 
level before any long-term Mer-Clean ${ }^{\mathrm{TM}}$ sorbent injection. The baseline stack level was $12.6 \mu \mathrm{g} / \mathrm{m}^{3}$. The two mercury levels observed during this initial three-day period showed $11.6 \%$ native removal of mercury between air heater inlet and stack, in agreement with the previous baseline measurements.

The total mercury at the air heater inlet fluctuated widely between $8 \mu \mathrm{g} / \mathrm{m}^{3}$ and $25 \mu \mathrm{g} / \mathrm{m}^{3}$ and its average over the 32-day period was $14.9 \mu \mathrm{g} / \mathrm{m}^{3}$. The long-term sorbent injection testing started with Mer-Clean ${ }^{\mathrm{TM}} 8$ sorbent at $52 \mathrm{lb} / \mathrm{h}$ (or $0.94 \mathrm{lb} /$ MMacf, where the "actual" condition refers to the actual stack condition, i.e., $335^{\circ} \mathrm{F}$ and $6.6 \% \mathrm{O}_{2}$ ). Within an hour from the start of sorbent injection, the mercury level reached a steady state level of $0.75 \mu \mathrm{g} / \mathrm{m}^{3}$, showing $95 \%$ removal of air heater inlet mercury (or $94 \%$ removal of baseline stack mercury) based on CMM readings. This test condition was maintained for five days.

The sorbent injection rate was then decreased until just 90\% removal was achieved. At $35 \mathrm{lb} / \mathrm{h}$ (or $0.63 \mathrm{lb} / \mathrm{MMacf}$ ), the steady state stack mercury level reached $1.5 \mu \mathrm{g} / \mathrm{m}^{3}$ giving $90 \%$ removal, again based on $\mathrm{AH}$ inlet and stack CMM readings. Mer-Clean ${ }^{\mathrm{TM}} 2$, a variation of Mer-Clean ${ }^{\mathrm{TM}} 8$, was then used at $59 \mathrm{lb} / \mathrm{h}$ (1.06 lb/MMacf) for the rest of the test program to achieve $1.08 \mu \mathrm{g} / \mathrm{m}^{3}$, or $93 \%$ removal of air heater inlet mercury. The 30-day average stack mercury level with injection of MerClean ${ }^{\mathrm{TM}}$ sorbents at various rates was $1.19 \mu \mathrm{g} / \mathrm{m}^{3}$, giving $92 \%$ removal of air heater inlet mercury, or $91 \%$ reduction of uncontrolled stack mercury based on stack CMM readings.

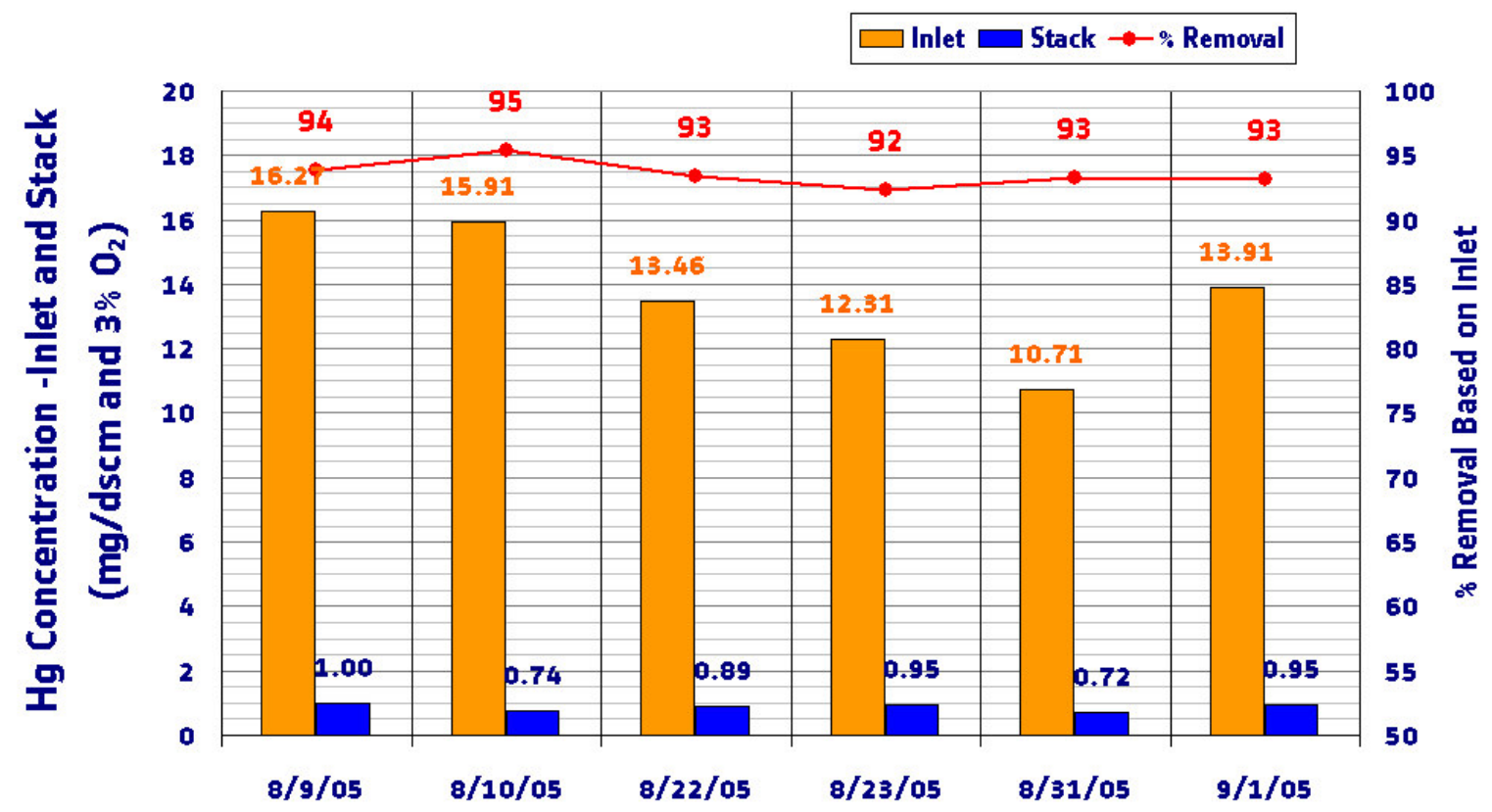

Figure 6.1-12 Mercury Removal Performance Based on Ontario Hydro Measurements at APH Inlet and Stack

Figure 6.1-12 shows six sets of $\mathrm{OH}$ data measured simultaneously at the air heater inlet and the stack over the long-term testing period. The $\mathrm{OH}$ measurements were made while sampling flue gas for 90 minutes. The $\mathrm{OH}$ data thus obtained verifies the long-term performance of Mer-Cure ${ }^{\mathrm{TM}}$ system measured by $\mathrm{CMMs}$ and discussed above. The $\mathrm{OH}$ measurements at the air heater inlet varied from $10.8 \mu \mathrm{g} / \mathrm{m}^{3}$ to $16.2 \mu \mathrm{g} / \mathrm{m}^{3}$, and those at the stack ranged from $0.75 \mu \mathrm{g} / \mathrm{m}^{3}$ to 1.0 
$\mu \mathrm{g} / \mathrm{m}^{3}$. The mercury removal efficiency calculated by $\mathrm{OH}$ measurement results and based on the air heater inlet level was consistently between $92 \%$ and $95 \%$.

Figure 6.1-13 shows comparison between $\mathrm{OH}$ measurement data and CMM data. The CMM measurements at the stack are typically higher than $\mathrm{OH}$ measurements (in 6 of 7 tests). On the other hand, the air heater inlet measurements do not show any such trend. The average absolute errors for the stack and the air heater inlet measurements are $24.8 \%$ and $9.2 \%$, respectively.
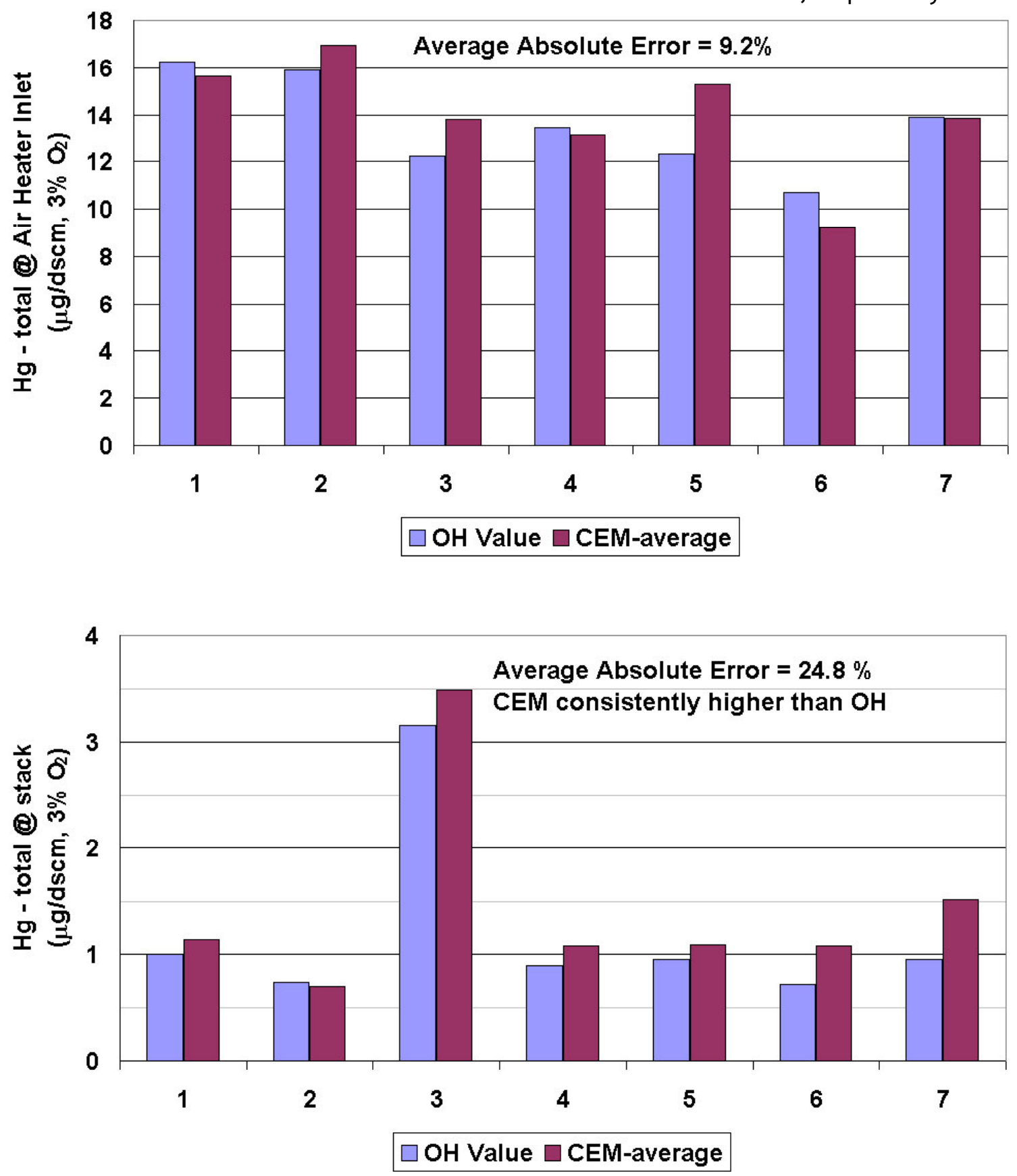

Figure 6.1-13 Comparison between Ontario Hydro and CMM measurements at DJ3 APH Inlet and Stack 
Figure 6.1-14 shows comparison of mercury speciation between air heater inlet and stack as determined by $\mathrm{OH}$ measurements. At the air heater inlet, the amount of oxidized mercury was only $5.3 \%$ of the total gaseous mercury and the rest was elemental mercury. (The air heater inlet temperature at $\mathrm{DJ} 3$ was around $770^{\circ} \mathrm{F}$.) This is not surprising given that the PRB coal fired at DJ3 has under 50 ppm of chlorine and no detectable amount of bromine.

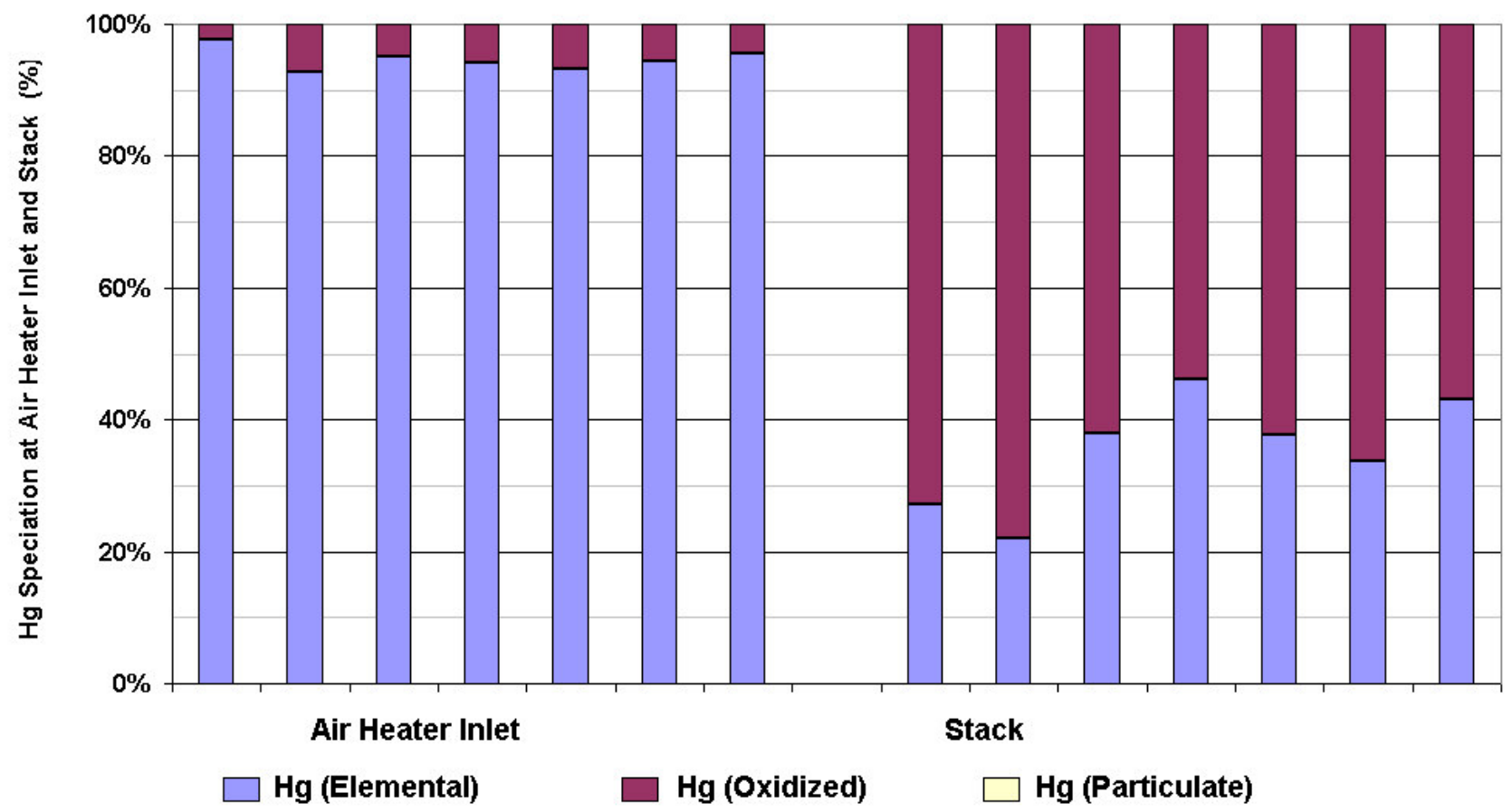

Figure 6.1-14 Mercury speciation at DJ3 Air Preheater Inlet and Stack

In the presence of sorbent in the flue gas, Figure $6.1-14$ shows that about $65 \%$ of the mercury leaving the stack was in the oxidized form and therefore readily condensable. Its practical implication is that a boiler with a wet scrubber will often be able to remove most of this incoming oxidized mercury and potentially result in even higher mercury reduction at the stack.

This increase in oxidized mercury capture due to wet scrubbing for $\mathrm{SO}_{2}$ can sometimes be limited by re-emission of oxidized mercury from the scrubber. Some wet scrubbed units have experienced higher levels of elemental mercury leaving the scrubber than exist entering the scrubber, indicating that some oxidized mercury has been reduced back to elemental within the wet scrubber. Data from several demonstration projects at units with wet scrubbers indicate that re-emission sometimes occurs and can limit mercury capture performance. ${ }^{1,2}$

\subsubsection{Balance of Plant Impacts}

In the previous section, performance data have been presented to demonstrate that Mer-Cure ${ }^{\mathrm{TM}}$ technology offers a solution to effectively control mercury emissions from coal-fired boilers. Sorbent 
injection into the economizer outlet, however, may be of technical and operational concern to boiler operators. In this section, the impact of sorbent injection on boiler operation is discussed.

Figure 6.1-15 shows opacity before and during long-term sorbent injection testing. The stack opacity is directly related to the performance of electrostatic precipitators, which is in turn closely related to the flue gas temperature entering electrostatic precipitators. The data shows a strong correlation between the stack opacity and the air heater outlet temperature. The opacity fluctuated between 1 and $5 \%$ while the air heater outlet temperature (B side) varied between $310^{\circ} \mathrm{F}$ and $375^{\circ} \mathrm{F}$. Before injection testing, the stack opacity was approximately $3.3 \%$ at $350^{\circ} \mathrm{F}$ of air heater outlet temperature (side B). When injection of the Mer-Clean ${ }^{\mathrm{TM}}$ sorbent started, the stack opacity decreased over threeday period to $1.5 \%$. The stack opacity was $1.4 \%$ at its corresponding air heater outlet temperature of $350^{\circ} \mathrm{F}$. There was no appreciable change in opacity when sorbent injection was stopped.

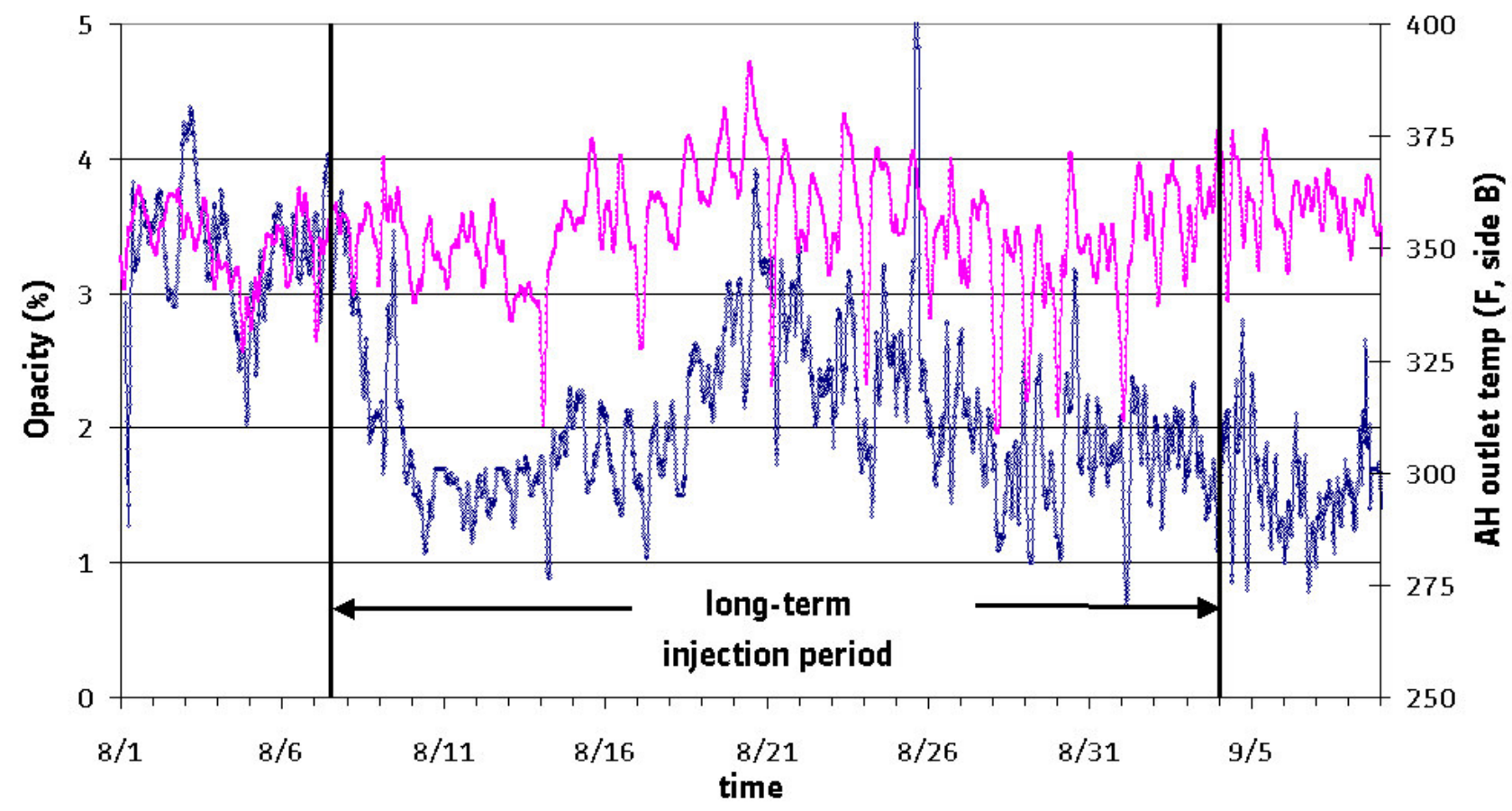

Figure 6.1-15 Opacity Change During Long-Term Testing at DJ3

(blue line $\mathbf{3} \mathbf{~ h r}$ average opacity data, purple line $=\mathrm{AH}$ outlet temperature)

Observations throughout the long-term testing suggest that injection of Mer-Clean ${ }^{\mathrm{TM}}$ sorbent did not increase the stack opacity during long-term testing. If anything, sorbent injection decreased the opacity, although the reduction in opacity was maintained for five days after sorbent injection was stopped. This data clearly show no increase in opacity with sorbent injection, but the data set is too limited to conclude that opacity definitely decreased with sorbent injection.

Figure 6.1-16 shows loss on ignition (LOI) measured for bulk flyash samples collected during longterm testing. The LOI showed a slight increase from $0.95 \%$ to $1.03 \%$. After testing, the LOI recovered to the baseline LOI level. The LOI increase of $0.08 \%$ points are attributed to the injection of sorbent. 


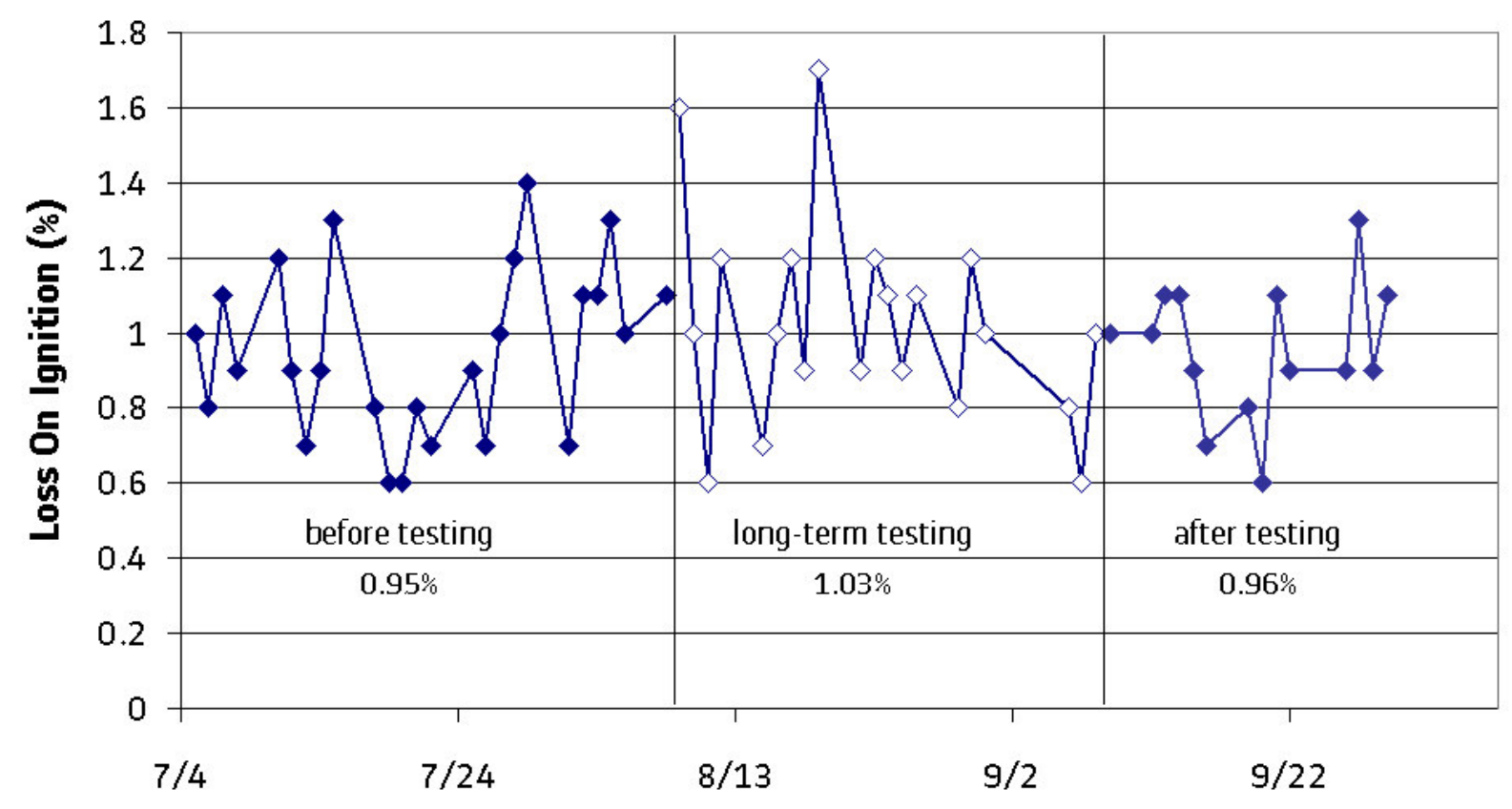

Figure 6.1-16 Change in LOI of Bulk Fly Ash Samples During Long-Term Testing at DJ3

Mercury and carbon analyses have been carried out for hopper ash samples collected from six middle-row ESP hoppers along the flue gas flow direction (A through $F, F$ being closest to the stack). The results are shown in Figure 6.1-17 and Figure 6.1-18 for mercury and carbon contents, respectively.

Figure 6.1-17 shows the carbon contents of the ash hopper samples during baseline and long-term injection test periods. The baseline ash samples show that more unburned carbon is found in the ash from the first hopper than from downstream hoppers. The downstream hopper ash samples show a bell-curve distribution, with more carbon in hopper $D$ than in others. Samples collected during injection testing also shows the same overall trend.

During injection testing, the carbon content fluctuated more for samples from the first hopper than those from subsequent hoppers. Samples from hoppers $E$ and $F$ had more carbon content during injection than during baseline. Samples from hoppers $B, C, D, E$, and $F$ during injection had average carbon contents of $0.63 \%, 0.64 \%, 1.02 \%, 0.66 \%$, and $0.65 \%$, respectively.

Figure 6.1-18 shows a plot of the amount of mercury collected per gram of ash (ppb $\mathrm{Hg}$ in ash) for each of the ESP hopper samples collected during continuous injection testing. The mercury contents in the ash for baseline hopper samples show a bell-curve distribution. Among the hopper samples collected during baseline, the hopper D sample has the highest mercury content of $3.3 \mu \mathrm{g} \mathrm{Hg} / \mathrm{g}$ ash. The hopper samples during continuous injection, on the other hand, show a distribution with the mercury content of $0.16 \mu \mathrm{g} / \mathrm{g}$ ash for hopper A, gradually increasing to approximately $3 \mu \mathrm{g} / \mathrm{g}$ ash for hoppers D, E, and F. 


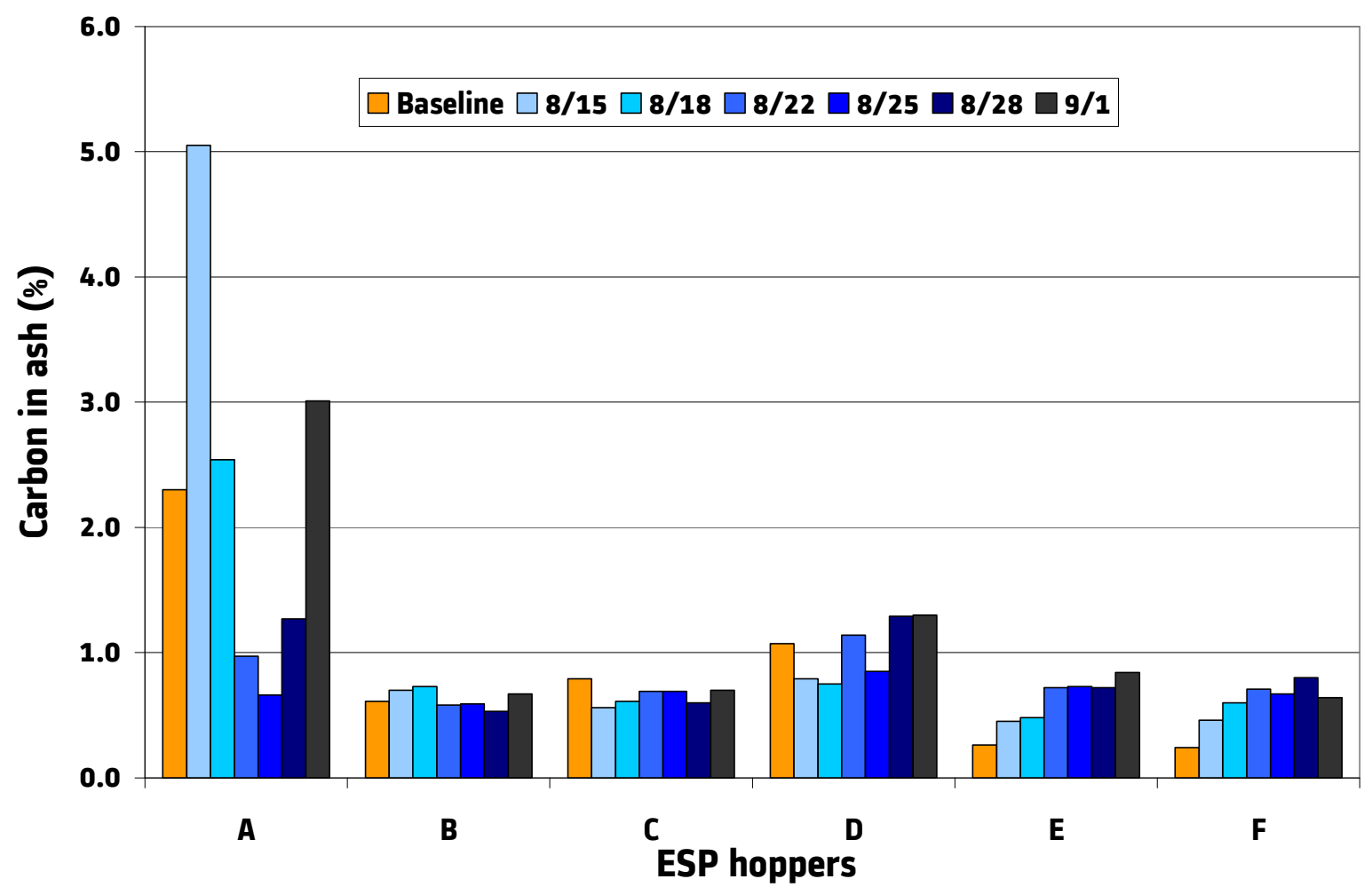

Figure 6.1-17 Carbon Content (Percent in ash) in ESP Hopper Ash Samples During Long-Term Testing at DJ3

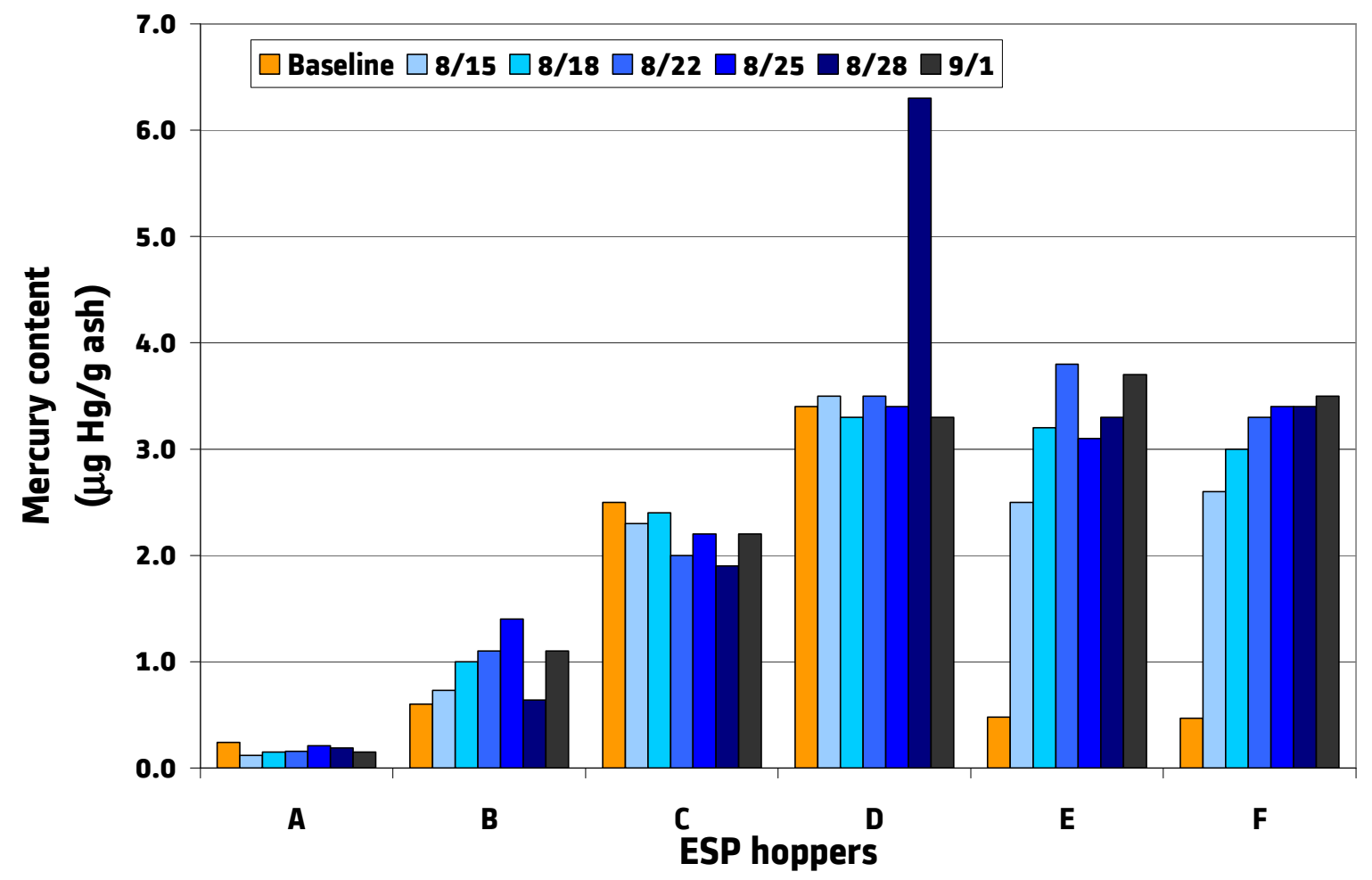

Figure 6.1-18 Mercury Content (ppb in ash) in ESP Hopper Ash Samples During Long-Term Testing at DJ3 
Comparing mercury content distributions, a clear difference is observed for ash samples from hoppers $E$ and $F$. Baseline ash samples from these two hoppers do not contain as much mercury as those collected during injection testing. Mercury is more effectively captured by ash collected in the last two hoppers during injection testing. This may be due to the very fine sorbent particles being collected mostly in the last two (or three) hoppers during continuous injection testing.

The difference in mercury content for ash samples from hoppers $E$ and $F$ is more apparent as the captured mercury results are presented on a carbon-in-ash basis. Figure 6.1-19 shows a plot of the amount of mercury collected per gram of carbon ( $\mathrm{ppb} \mathrm{Hg}$ in carbon) for each of the ESP hopper samples collected during continuous injection testing.

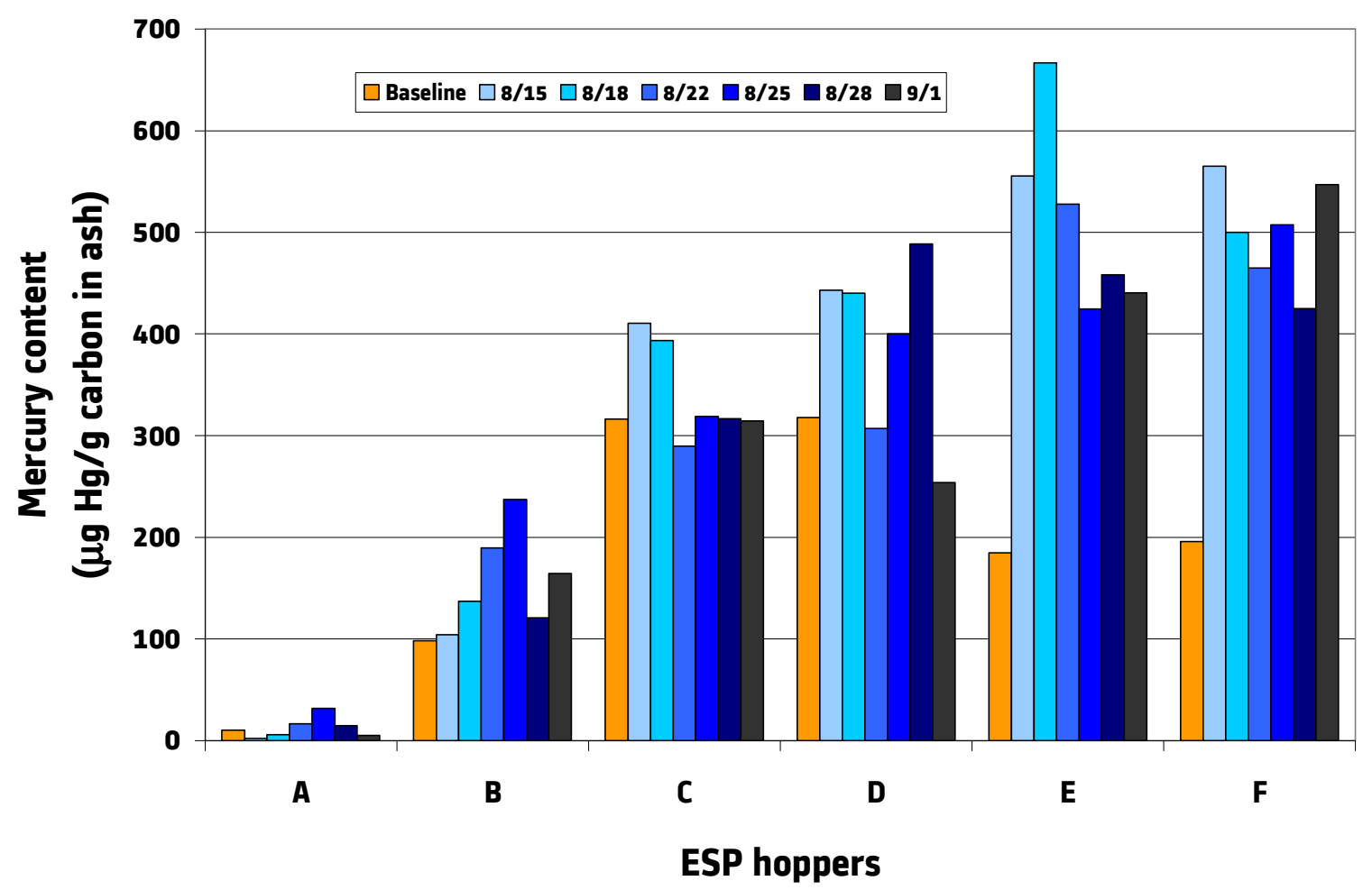

Figure 6.1-19 Mercury Content (ppb in carbon) in ESP Hopper Ash Samples During Long-Term Testing at DJ3

Figure 6.1-20 shows particle size distributions of hopper ash samples collected during continuous injection testing (on August 18, 2005). The mean sizes (d50) of samples from hoppers $A, B, C, D, E$, and $\mathrm{F}$ were $71 \mathrm{~mm}, 18 \mathrm{~mm}, 4 \mathrm{~mm}, 2 \mathrm{~mm}, 2.2 \mathrm{~mm}$, and $1.8 \mathrm{~mm}$, respectively. The ash samples with high specific mercury content, i.e., those from hoppers $D, E$, and $F$, all have $d 50$ of approximately $2 \mathrm{~mm}$ and d90 of less than $7 \mathrm{~mm}$, indicating the importance of the particle size on mercury control. 


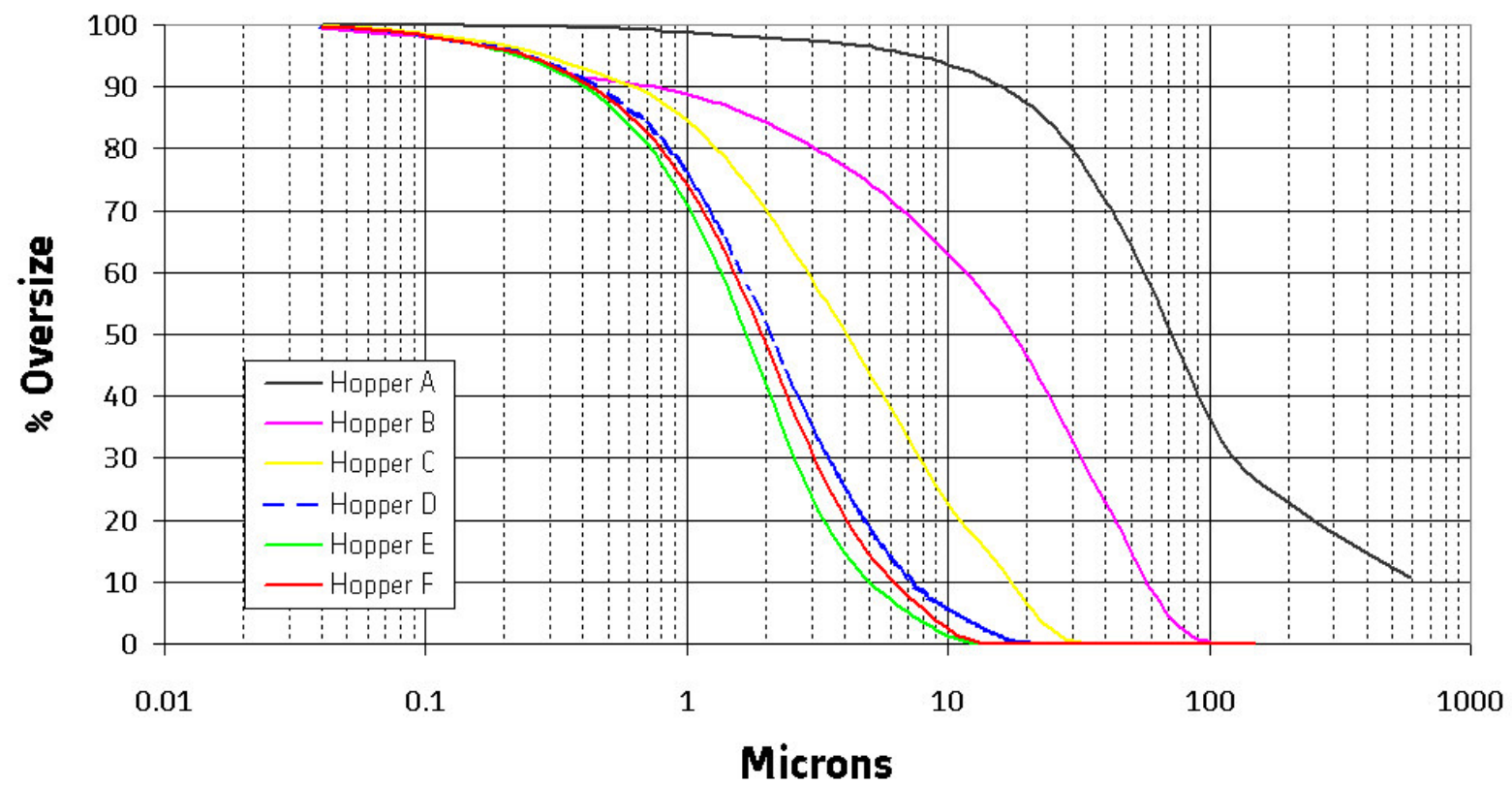

Figure 6.1-20 Particle Size Distributions for Hopper Ash Samples Collected on August 18, 2005

Another concern would be the impact on the air heater due to sorbent injection with the Mer-Cure ${ }^{\mathrm{TM}}$ technology. Thermo-gravimetric analysis of the sorbent material with respect to its combustibility shows it has similar characteristics as unburned carbon in fly ash. Several factors contribute to the relative inertness - the oxygen content in the flue gas at the point of injection is typically around 3 percent, and at these low flue gas oxygen concentrations, the activated carbon particles have a lower propensity to react than with pure air. Second, the activated carbon material is relatively volatilefree. This also contributes to its low propensity for ignition and combustion. Third, the chemical additive that makes up the sorbent formulation is a halogen compound, a flame retardant. (Halogen compounds, when subjected to a combustion temperature, dissociate to form halogen radicals. These radicals scavenge any $\mathrm{OH}$ radicals retarding combustion.) Fourth, the flue gas temperature around which the activated carbon sorbent is injected (approximately $650-800^{\circ} \mathrm{F}$ ) is still below the value where any significant reactivity was observed. Fifth, the residence time that the activated carbon particles spend in the flue gas is in the order of several seconds - too short for any reaction to proceed to any extent given the other process conditions. Lastly, even if the all of the sorbent were completely burnt, the estimated temperature rise in the flue gas would only be around $3^{\circ} \mathrm{F}$.

Figure 6.1-21 shows air heater outlet temperatures (both sides) measured at Dave Johnston Unit \#3 during the test program. There was about $40^{\circ} \mathrm{F}$ difference in air heater outlet temperatures between duct $A$ and duct $\mathrm{B}$, and the $\mathrm{B} \mathrm{AH}$ had the higher gas outlet temperature. As expected, the air heater outlet temperatures varied with the unit load change. No change was observed due to injection of sorbent upstream of the air heaters. 


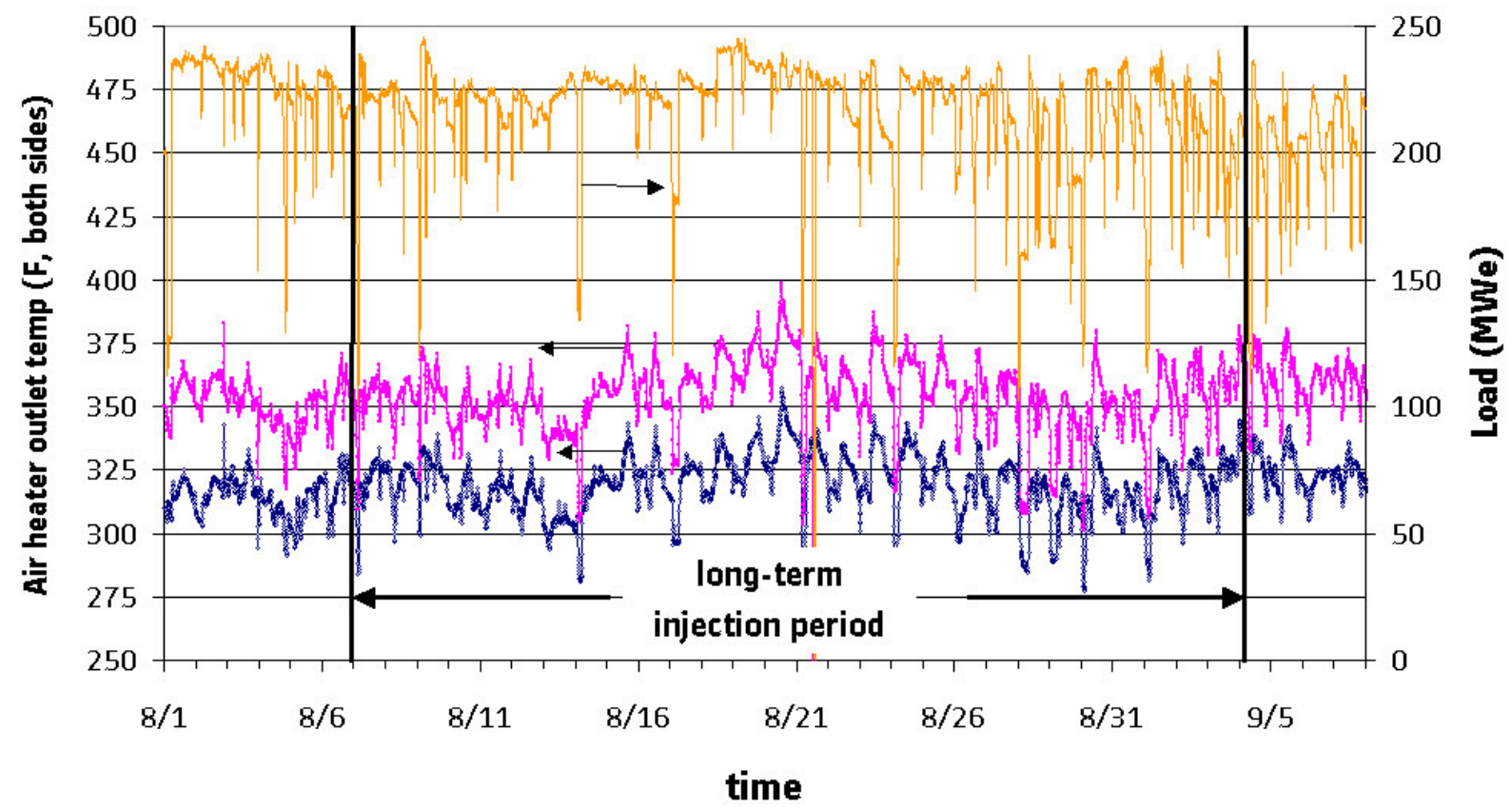

Figure 6.1-21 APH Outlet Temperature versus Plant $\mathrm{MW}_{\mathrm{e}}$ During Long-Term Testing at DJ3 (yellow line= load data, blue line= A AH outlet temperature, purple line = B AH outlet temperature)

The impact of the additive used with the sorbent is also very small. Typical additive concentrations are below 10 percent of the sorbent. These sorbents are prepared by a method that exposes them to temperatures and residence times higher than what they would be expected to experience in the flue gas. Testing at the operating temperatures with the sorbent additive combination has shown that it is tightly bound to the carbon. Even if the additive were released to any significant extent, it would be too small a quantity to cause any fouling or corrosion of the air heater or downstream ducts.

Another concern would be the impact on the fly ash saleability for concrete applications due to sorbent injection with the Mer-Cure ${ }^{\mathrm{TM}}$ technology. Fly ash with low unburned carbon content is often sold as a replacement for Portland cement in ready-mix concrete. However, fly ashes with elevated levels of carbon are unsuitable for concrete mixtures. One of the reasons given is that concrete mixtures containing such ashes require increased amounts of costly air-entraining agents (AEA) to achieve a given level of air entrainment. ${ }^{7}$

It has been suggested that the reason for an increase in the AEA requirement is due to AEA adsorption by the unburned carbon. ${ }^{8,9}$ The Foam Index Test is a rapid means to determine the relative levels of AEA needed for concrete containing fly ash and other materials that affect air entrainment in concrete. Because of the presumed influence of unburned carbon on AEA adsorption, the Foam Index Test has also been used as a measure of the degree of interaction between an AEA and fly ash or carbon. ${ }^{8,9}$

The Foam Index Test is a laboratory titration procedure that determines the AEA adsorption on fly ash or fly ash and cement mixtures. An AEA is titrated into a fly ash and cement suspension and the 
suspension is shaken. The added AEA leads to foam formation on top of the liquid surface, which initially behaves in an unstable manner. At the endpoint of the test, the AEA adsorption sites are "saturated" and the AEA contributes to foam formation on the top of the mixture. The amount of AEA required to obtain stable foam depends on fly ash quality, fly ash-cement interactions, and characteristics of the AEA.

We could expect the ash (with the sorbent) in the ESP would be unsuitable for concrete applications, due to interaction of the carbonaceous sorbent and the air-entraining additives. Most of the ash (greater than 75 percent) from coal-fired boilers in the US is currently land-filled, and, in this case, would not be expected to be impacted by carbonaceous sorbent that is added in small amounts to the flue gas with our technology.

Previous studies have shown that the mercury captured on activated carbon has very low leachability. ${ }^{10,11}$ A number of leaching test procedures have been developed in the US over the last two decades. Two of these that are commonly employed are the Toxicity Characteristic Leaching Procedure (TCLP) and Synthetic Precipitation Leaching Procedure (SPLP). Both methods were used to determine the leachable components in the sorbent-fly ash mixture collected in the ESP hoppers during long-term sorbent injection tests.

The leaching data for Dave Johnson Unit \#3 show that the only leachable component that can be detected in the aforementioned tests is barium. The regulatory limit for barium is $100 \mathrm{mg} / \mathrm{l}$ (RCRA limit for a material defined as being hazardous waste). The values obtained in this testing were significantly lower than the regulatory limit. Furthermore, the addition of the sorbent is not likely to have any impact on increased leachability of barium. The values would correspond to what would be those from the native ash resulting from the combustion of the PRB coal. The methodology used for the two leaching procedures is described in the next two paragraphs.

TCLP (US EPA Method 1311) is designed to simulate the leaching a waste will undergo if disposed in an unlined sanitary landfill. It is based on a co-disposal scenario of 95 percent municipal waste and 5 percent industrial waste. The method is an agitated extraction test using leaching fluid that is a function of the alkalinity of the solid phase of the waste. Either a sodium acetate buffer solution having a pH of $4.93 \pm 0.05$ or an acetic acid solution having a pH of $2.88 \pm 0.05$ is used. The procedure requires particle size reduction to less than $9.5 \mathrm{~mm}$. The TCLP is designed to determine the mobility of 40 toxicity characteristic (TC) constituents in liquid, solid, and multiphase wastes. The TC constituents include both inorganic and organic species. Leachability of volatile organic compounds is determined using a zero-headspace extractor and the sodium acetate buffer solution. The TCLP was developed in 1984 under the Hazardous and Solid Waste Amendments to the Resource Conservation and Recovery Act (RCRA 1984) and is the US EPA regulatory method for classifying wastes as hazardous or non-hazardous based on toxicity. If the TCLP extract contains any one of the TC constituents in an amount equal to or greater than the concentration specified in the 40 CFR 261.24 (1992), the waste possesses the characteristic of toxicity and is a hazardous waste. 
ALPHA ANALYTICAL LABORATORIES

CERTIFICATE OF ANALYSIS

MA:M-MA086 NH:200301-A CT:PH-0574 ME:MA086 RI:65 NY:11148 NJ:MA935 Army:USACE

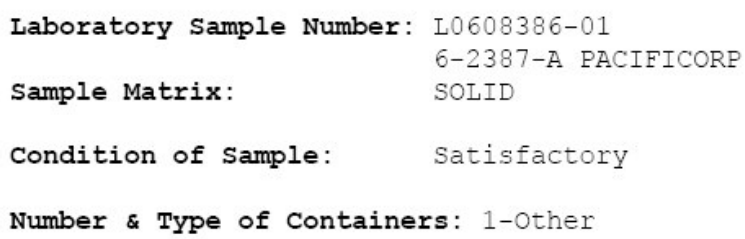

11311

$\mathrm{mg} / \mathrm{l}$

$\mathrm{mg} / \mathrm{l}$

$\mathrm{mg} / 1$

Barium, TCLP

Cadmium, TCLP

Chromium, TCLP

Lead, TCLP

Mercury, TCLP

Selenium, TCLP

Silver, TCLP

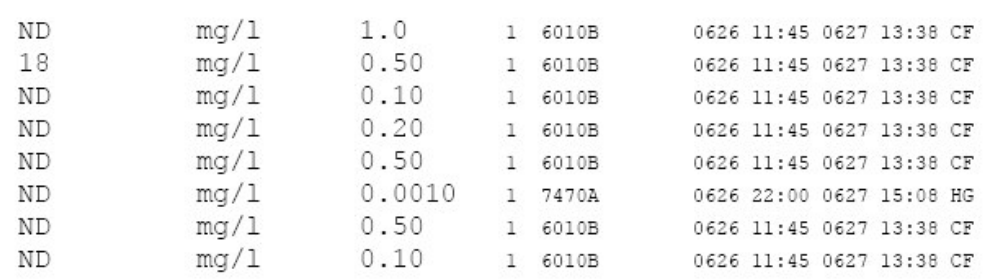

SPLP (US EPA Method 1312), also an agitated extraction test, was developed by the EPA in 1988 for use in evaluating the impact that contaminated soils may have on ground water. The procedure calls for use of simulated acid rain or reagent water as the extraction fluid, depending on the constituents of interest. The extraction fluid used to determine the leachability of soil from a site that is east of the Mississippi River is a solution of sulfuric and nitric acids in reagent water having a pH of $4.2 \pm$ 0.05. This extraction fluid is also used to extract waste or wastewater using the procedure. The extraction fluid used to determine the leachability of soil from a site that is west of the Mississippi River is a solution of sulfuric and nitric acid in reagent water having a pH of $5.0 \pm 0.05$. When the leachability of organic compounds or cyanide is being evaluated, reagent water is used as the extraction fluid. The procedure required particle size reduction to less than $9.5 \mathrm{~mm}$, and as with the TCLP, extraction for volatile constituents is performed in a zero-headspace extractor. 
ALPHA ANALYTICAL LABORATORIES

CERTIFICATE OF ANALYSIS

MA:M-MA086 NH:200301-A CT:PH-0574 ME:MA086 RI:65 NY:11148 NJ:MA935 Army:USACE

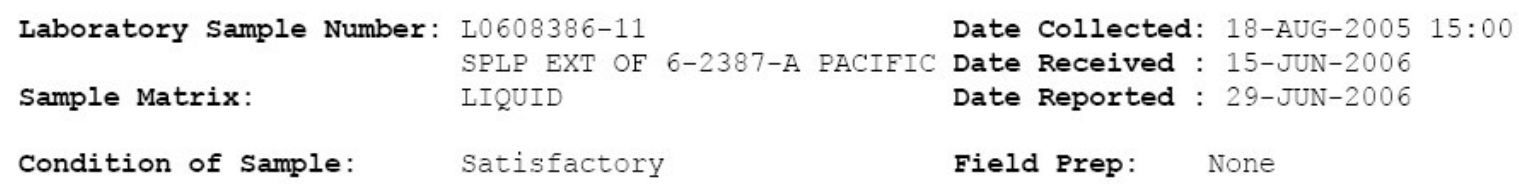

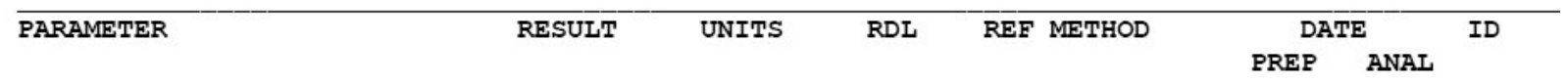

\section{Total Metals}

\section{Arsenic, Total}

Barium, Total

Cadmium, Total

Chromium, Total

Lead, Total

Mercury, Total

Selenium, Total

Silver, Total

$\begin{array}{lllll}\mathrm{ND} & \mathrm{mg} / 1 & 0.005 & 1 & 6010 \mathrm{~B} \\ 27 & \mathrm{mg} / 1 & 0.01 & 1 & 6010 \mathrm{~B} \\ \mathrm{ND} & \mathrm{mg} / 1 & 0.005 & 1 & 6010 \mathrm{~B} \\ \mathrm{ND} & \mathrm{mg} / 1 & 0.01 & 1 & 6010 \mathrm{~B} \\ \mathrm{ND} & \mathrm{mg} / 1 & 0.010 & 1 & 6010 \mathrm{~B} \\ \mathrm{ND} & \mathrm{mg} / 1 & 0.0010 & 1 & 7470 \mathrm{~A} \\ \mathrm{ND} & \mathrm{mg} / \mathrm{I} & 0.005 & 1 & 6010 \mathrm{~B} \\ \mathrm{ND} & \mathrm{mg} / 1 & 0.007 & 1 & 6010 \mathrm{~B}\end{array}$

$\begin{array}{lllll}0622 & 19: 00 & 0623 & 11: 49 & \mathrm{CF} \\ 0622 & 19: 00 & 0623 & 11: 49 \mathrm{CF} \\ 0622 & 19: 00 & 0623 & 11: 49 \mathrm{CF} \\ 0622 & 19: 00 & 0623 & 11: 49 & \mathrm{CF} \\ 0622 & 19: 00 & 0623 & 11: 49 & \mathrm{CF} \\ 0622 & 17: 35 & 0623 & 11: 06 \mathrm{DM} \\ 0622 & 19: 00 & 0623 & 11: 49 \mathrm{CF} \\ 0622 & 19: 00 & 0623 & 11: 49 \mathrm{CF}\end{array}$

Figure 6.1-22 shows $\mathrm{NO}_{x}$ and $\mathrm{SO}_{2}$ emissions during mercury sorbent injection. As expected, no change in emissions levels was observed as a result of continuous sorbent injection.

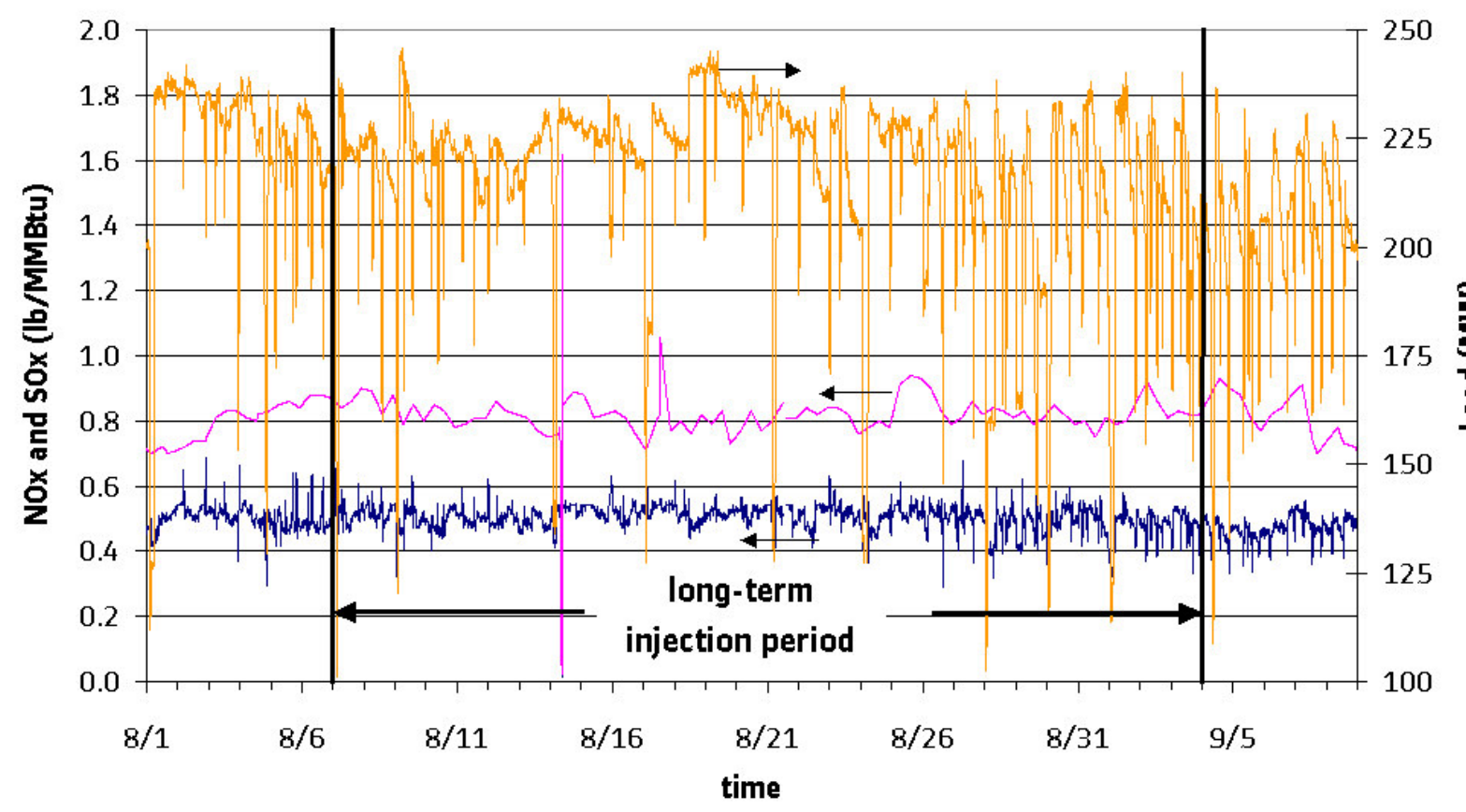

Figure 6.1-22 $\mathrm{NO}_{\mathrm{x}}$ and $\mathrm{SO}_{2}$ Emissions Before, During and After Long-Term Testing at DJ3 (yellow line $=$ load data, blue line $=\mathbf{N O}_{\mathbf{x}}$ emissions, purple line $=\mathrm{SO}_{2}$ emissions) 


\subsubsection{Economics}

Capital and operating costs for the installation and operation of a Mer-Cure ${ }^{\mathrm{TM}}$ system for Dave Johnston Unit \#3 are presented below in Table 6.1-4. Capital costs include those for sorbent storage, sorbent processing and injection equipment, and were determined from vendor quotes in early 2006. Equipment costs including all piping, materials and controls are estimated to be $\$ 1.1$ million. Installation, including site integration, is estimated around $\$ 500,000$. Adding in start-up support and a contingency of 10 percent of capital costs, the overall capital cost of the Mer-Cure ${ }^{\mathrm{TM}}$ system is estimated to be about $\$ 1.8$ million or about $\$ 8.0 / \mathrm{kW}_{\mathrm{e}}$.

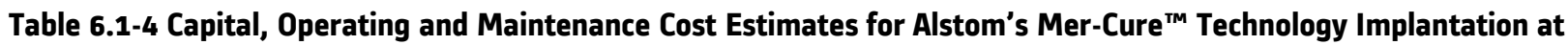
PacifiCorp's Dave Johnston Unit \#3

\begin{tabular}{|c|c|}
\hline \multicolumn{2}{|l|}{ Capital Costs Summary } \\
\hline Equipment & $\$ 1,110,000$ \\
\hline Installation including site integration (materials and labor) & $\$ 518,000$ \\
\hline Start-up support & $\$ 18,000$ \\
\hline Contingency & $\$ 163,000$ \\
\hline Total Capital Required (2006) & $\$ 1,799,000$ \\
\hline$\$ / k W\left(240 \mathrm{MW}_{\mathrm{e}}\right.$ gross) & 8.00 \\
\hline \multicolumn{2}{|l|}{ Operating and Maintenance Costs Summary } \\
\hline Sorbent (\$1.25/lb, 90\% reduction, $38 \mathrm{lb} / \mathrm{h}, 7500$ hours) & $\$ 356,250$ \\
\hline Power, Labor and Maintenance & $\$ 115,000$ \\
\hline Waste Disposal & $\$ 0$ \\
\hline Annual $0 \& M$ cost (2006 costs) & $\$ 471,250$ \\
\hline Levelized - 20 year $0 \& M$ cost $(\$ / \mathrm{kW})$ & $\$ 1.96$ \\
\hline \$/MWh & 0.30 \\
\hline
\end{tabular}

Notes:
a) Unit is assumed to be base loaded
b) Ash is not utilized or still available for use after carbon injection
c) Installation is with union labor
d) Contingency is calculated at 10 percent of capital cost
e) Levelized costs are calculated assuming 3\% increase per year
f) $240 \mathrm{MW}_{\mathrm{e}}$ gross capacity with 7,500 hours operation per year

The predominant component of the operating cost is the sorbent cost. Costs were estimated based on a long-term custom-enhanced activated carbon injection rate conservatively assumed to be 0.65 $\mathrm{lb} / \mathrm{MMacf}$ or $38 \mathrm{lbs} / \mathrm{hr}$. Unit operation is assumed at 85 percent capacity factor. With these assumptions, the annual sorbent costs are $\$ 356,250$, assuming a delivered sorbent cost of $\$ 1.25 / \mathrm{lb}$. There is a significant uncertainty in the cost for the sorbent because of anti-dumping tariffs being imposed on imported (Chinese) activated carbon. The tariff amounts are expected to be around 
$\$ 0.25$ to $\$ 0.30 / \mathrm{lb}$. This almost doubles the cost of imported Chinese activated carbon which is currently around $\$ 0.3-0.4 / \mathrm{lb}$ and may increase the custom-enhanced sorbent costs by a similar amount.

The other component of the operating cost is parasitic power, labor and maintenance and this is estimated to be $\$ 115,000$ annually. The overall operating cost for DJ3 for 90 percent mercury control is $\$ 470,536$ or $\$ 0.30 / \mathrm{MWh}$, as shown in Table 6.1-4.

If a wet scrubber is installed at DJ3, then a portion of the oxidized mercury that escapes the cold-side ESP can be removed in the wet scrubber. It is estimated that about 65 percent (Figure 6.1-14) of the mercury leaving the ESP is in the oxidized form. Assuming 50 percent removal of the oxidized mercury in the scrubber, we can use Figure 6.1-10 to estimate the amount of reduction that we can expect in the sorbent needed if removal occurs both in the ESP and the wet scrubber. This is estimated to be 85 percent mercury removal in the ESP, plus 50 percent removal in the wet scrubber of the 65 percent oxidized mercury leaving the ESP, or a reduction in the amount of sorbent needed to $31 \mathrm{lb} / \mathrm{hr}$. This implies that the overall operating cost if a wet scrubber is installed may be reduced to approximately $\$ 0.26 / \mathrm{MWh}$.

Table 6.1-5 can be used to calculate the operating cost if lower levels of mercury removal are required. For example, if 70 percent reduction is required the sorbent injection rate is 0.31 $\mathrm{lb} / \mathrm{MMacf}(18 \mathrm{lb} / \mathrm{hr}$ ). If 80 percent reduction is required, the sorbent injection rate is $0.40 \mathrm{lb} / \mathrm{MMacf}$ (23 lb/hr). A mercury removal versus required sorbent injection rate table is provided in Table 6.1-5 below.

Table 6.1-5 Sorbent Consumption Rates as a function of Mercury Removal Level for Alstom's Mer-Cure ${ }^{\mathrm{TM}}$ Technology Implementation at PacifiCorp's Dave Johnston Unit \#3

\begin{tabular}{|c|c|c|}
\hline $\begin{array}{c}\text { \% Mercury } \\
\text { Removal }\end{array}$ & $\begin{array}{c}\text { Sorbent } \\
\text { (lb/MMacf) }\end{array}$ & $\begin{array}{c}\text { Sorbent } \\
\text { (lb/hr) }\end{array}$ \\
\hline 60 & 0.26 & 15 \\
\hline 70 & 0.31 & 18 \\
\hline 75 & 0.34 & 20 \\
\hline 80 & 0.40 & 23 \\
\hline 90 & 0.65 & 38 \\
\hline 95 & 1.07 & 63 \\
\hline
\end{tabular}

Sensitivity analysis with respect to the mercury removal level required and unit sorbent costs are shown in Figure 6.1-23. These calculations indicate that at a sorbent cost of $\$ 1.25 / \mathrm{lb}$, the operating cost for 90\% mercury control at PacifiCorp’s Dave Johnston Unit \#3 using Alstom's Mer-Cure ${ }^{\mathrm{TM}}$ technology is $\$ 0.30 / \mathrm{MWh}$. Corresponding operating cost for 75 percent control is $\$ 0.20 / \mathrm{MWh}$. If sorbent costs increase to $\$ 2.00 / \mathrm{lb}$, the Mer-Cure ${ }^{\mathrm{TM}}$ operating cost increases to $\$ 0.48$ and $\$ 0.32 / \mathrm{MWh}$ for 90 and 75 percent mercury control, respectively. 


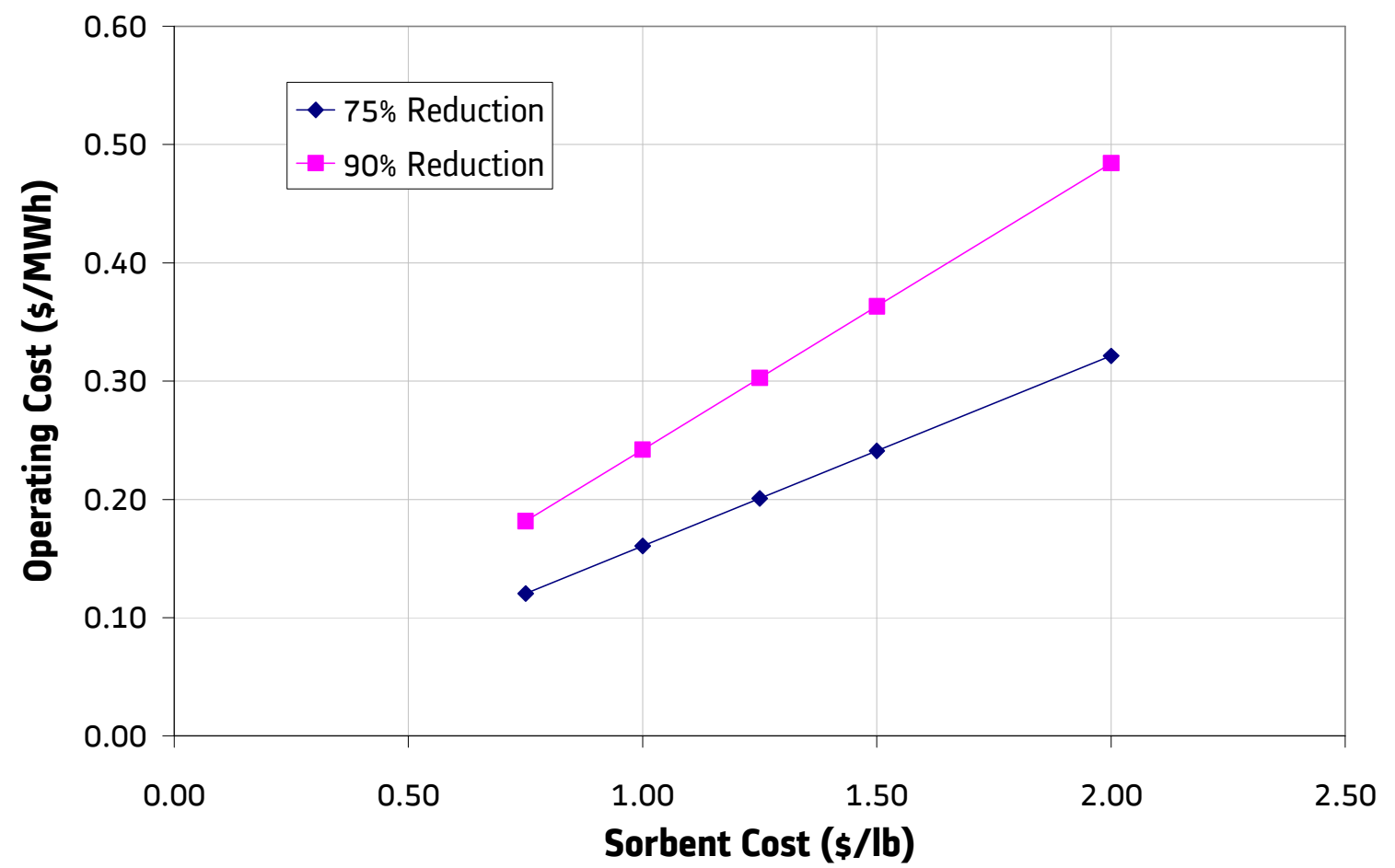

Figure 6.1-23 Effect of Sorbent Cost on Operating Cost of Mer-Cure ${ }^{\mathrm{TM}}$ System at DJ3

Figure 6.1-24 shows operating costs of a Mer-Cure ${ }^{\mathrm{TM}}$ system as a function of mercury removal rate at a constant sorbent cost of $\$ 1.25 / \mathrm{lb}$ for Dave Johnson Unit \#3. Even at $95 \%$ mercury removal rates, the operating costs of a Mer-Cure ${ }^{\mathrm{TM}}$ system are under $\$ 0.45 / \mathrm{MWh}$ for Dave Johnson Unit \#3

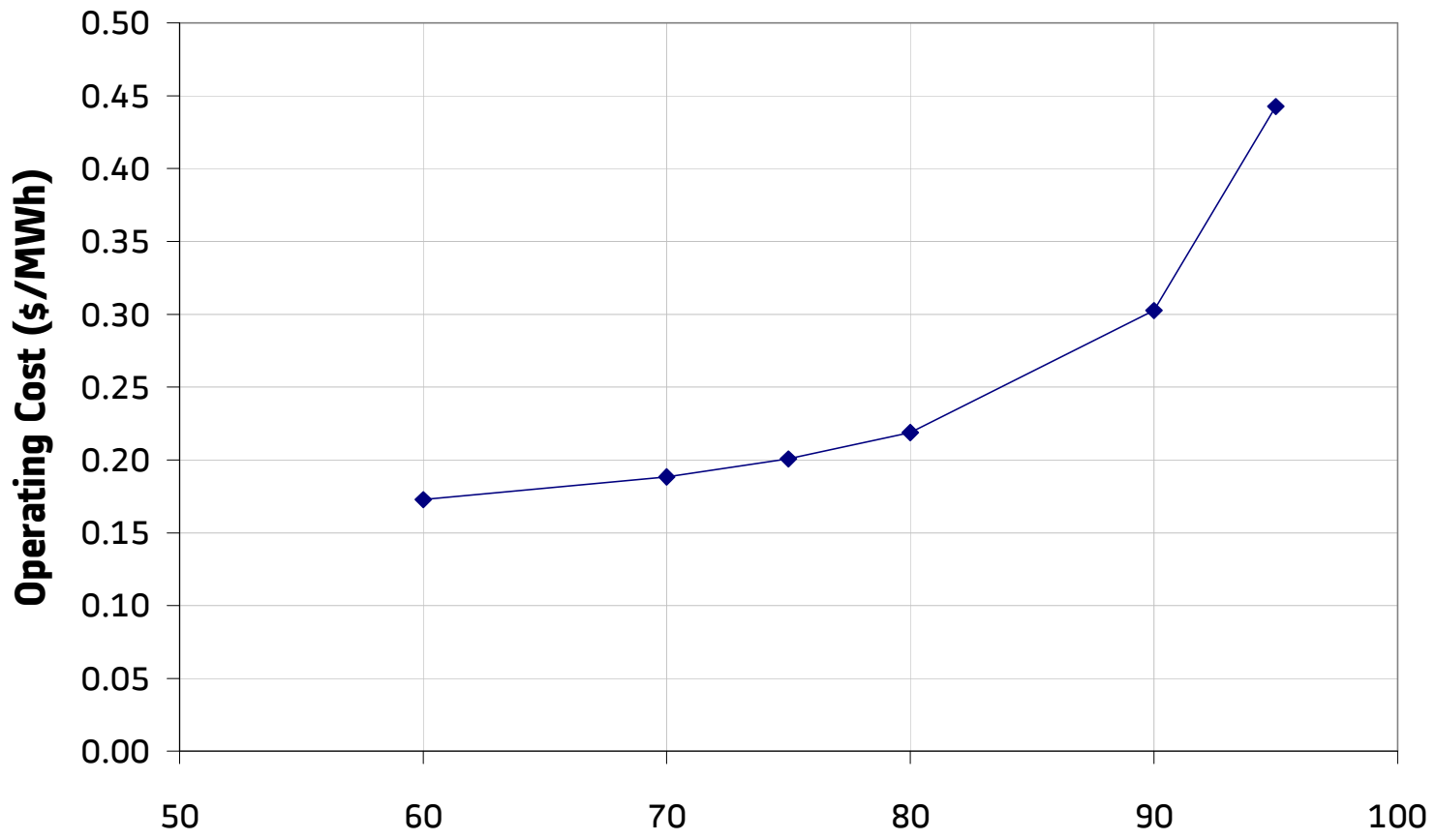

$\%$ Mercury Removal (based on uncontrolled emissions)

Figure 6.1-24 Effect of Mercury Control Level on Mer-Cure ${ }^{\mathrm{TM}}$ System Operating Cost at DJ3 ( $\$ 1.25 / \mathrm{lb}$ Sorbent Cost) 


\subsubsection{Conclusions}

Field demonstration of the Mer-Cure ${ }^{T M}$ system has been completed at PacifiCorp's Dave Johnson Unit \#3 (DJ3). Following is the summary of DJ3 test campaign:

\section{Performance:}

- An injection rate of $0.65 \mathrm{lb} / \mathrm{MMacf}$ achieved 90 percent removal of total gaseous mercury during long-term performance testing of the Mer-Cure ${ }^{T M}$ system at PacifiCorp's DJ3, as measured by both $\mathrm{OH}$ method and CMMs.

- An injection rate of $0.95 \mathrm{lb} / \mathrm{MMacf}$ achieved 95 percent removal of total gaseous mercury during long-term performance testing of the Mer-Cure ${ }^{T M}$ system at PacifiCorp's DJ3, as measured by both $\mathrm{OH}$ method and CMMs.

Mercury Speciation:

- The long-term performance data show that at the air heater inlet, mercury was mostly elemental mercury (95\% of total gaseous mercury on average); the mercury further oxidized at the back-pass to give a total of at least $50 \%$ of the mercury as elemental at the ESP outlet.

- During injection of the sorbent, the elemental form of the total gaseous mercury at the ESP outlet further decreased to $25-45 \%$, demonstrating the role of the sorbent as an oxidation catalyst.

- In addition to the above, a predominant portion of the total mercury was captured by the sorbent.

- For boilers with scrubbers, the scrubbers will further remove $50-90 \%$ of the oxidized mercury at the ESP outlet. As a result, even higher removal efficiency should be achieved. This increase in mercury capture due to wet scrubbing can sometimes be limited by re-emission of oxidized mercury from the scrubber.

Economics:

- Overall capital cost of the Mer-Cure ${ }^{\mathrm{TM}}$ system for Dave Johnson Unit \#3 is estimated to be about $\$ 1.8$ million or about $\$ 8 / \mathrm{kW}_{\mathrm{e}}$.

- The overall operating cost for DJ3 with Mer-Cure ${ }^{\mathrm{TM}}$ for 90 percent mercury control is $\$ 470,536$ or 0.30 mills $/ \mathrm{kWh}$ ( $\$ 2650 / \mathrm{lb} \mathrm{Hg}$ removed), with a delivered sorbent cost of $\$ 1.25$ per pound.

- If a wet scrubber is installed at DJ3, then a portion of the oxidized mercury that escapes the cold-side ESP can be removed in the wet scrubber. If a wet scrubber is installed, the operating cost with Mer-Cure ${ }^{\mathrm{TM}}$ for 90 percent mercury control may be reduced by about 25 percent or to 0.22 mills/kWh.

- Sensitivity analysis with respect to the mercury removal level required indicates that if only 75 percent control is required, then the Mer-Cure ${ }^{T M}$ operating cost is reduced to 0.20 mills $/ \mathrm{kWh}$ ( $\$ 1767 / \mathrm{lb} \mathrm{Hg}$ removed) with a sorbent cost of $\$ 1.25$ per pound. On the other hand, if sorbent costs increase to $\$ 2.00$ per pound, the Mer-Cure ${ }^{\mathrm{TM}}$ operating cost increases 
to 0.49 and 0.32 mills/kWh ( $\$ 4328$ and $\$ 2827 / \mathrm{lb} \mathrm{Hg}$ removed) for 90 and 75 percent mercury control respectively.

Balance of Plant Impacts:

- Observations throughout the long-term testing suggest that injection of Mer-Clean ${ }^{\mathrm{TM}}$ sorbent did not increase the stack opacity during long-term testing.

- Loss on ignition (LOI) was measured for bulk fly ash samples collected before and during long-term testing. The LOI showed a slight increase from a baseline of $0.95 \%$ to $1.03 \%$ with sorbent injection. After long-term testing, the LOI recovered to the baseline LOI level. The LOI increase of $0.08 \%$ percentage points is attributed to the injection of sorbent

- No change in air heater outlet temperatures was observed due to injection of sorbent upstream of the air heaters.

- No change in $\mathrm{NO}_{\mathrm{x}}$ and $\mathrm{SO}_{2}$ emissions levels was observed as a result of continuous sorbent injection.

Byproduct Evaluation:

- TCLP and SPLP were used to determine the leachable components in the sorbent-fly ash mixture collected in the ESP hoppers during long-term sorbent injection tests. The leaching data showed that the only leachable component detected was barium. The regulatory limit for barium is $100 \mathrm{mg} / \mathrm{l}$ (RCRA limit for a material defined as being hazardous waste). The barium values obtained in this testing were significantly lower than the regulatory limit. The barium values correspond to those from the native ash resulting from the combustion of PRB coal and without sorbent injection. 


\subsection{Leland Olds Unit \#1}

The goals for this Round 2 program, established by DOE/NETL under the original solicitation, were to reduce the uncontrolled mercury emissions by 50 to $70 \%$ at a cost 25 to $50 \%$ lower than the previous target of $\$ 60,000 / \mathrm{lb}$ mercury removed. Alstom's objective was to demonstrate greater than 90\% capture (in preparation for Mercury Round III), and Basin Electric's objective was to demonstrate greater than $75 \%$ capture of the gaseous mercury in the flue gas by injection of tailored sorbent at a feed rate significantly lower than standard (untreated) activated carbon.

\subsubsection{Site Description and Test Preparation}

Leland Olds Unit \#1 of Basin Electric is a $220 \mathrm{MW}_{\mathrm{e}}$ wall-fired, pulverized coal (PC) boiler firing North Dakota lignite and equipped with an ESP as a particulate emission control device. The specific collection area (SCA) of the ESP is $320 \mathrm{ft}^{2} / \mathrm{kacfm}$. Table 1.2-1 previously showed the unit configuration and coal and emissions data for Leland Olds Unit \#1.

The back-pass section of the unit has a transition section, following the economizer, with dropout hoppers that serve as mechanical collectors for large ash particle/deposits leaving the economizer or upstream sections. Downstream of the transition section are two Ljungstrom ${ }^{\mathrm{TM}}$ and one tubular air pre-heaters installed in parallel followed by a cold side electrostatic precipitator. Because of the ductwork configuration, it was not possible to treat only one portion of the flue gas and the gas path for one regenerative plus the tubular air heater had to be treated for mercury control. The temperature at the inlet of the air pre-heater was $800^{\circ} \mathrm{F}$, higher than normally expected for a typical pulverized coal-fired boiler. The air pre-heater outlet/ESP inlet temperature was $375^{\circ} \mathrm{F}$, also higher than typical operation. The loss-on-ignition (LOI) of the fly ash collected in the ESP hoppers varied between 1.3 to $1.5 \%$. The plant is fully equipped to provide the operational data including flue gas composition, stack opacity, and air heater flue gas temperatures.

Leland Olds Unit \#1 was chosen for this evaluation because it fires a North Dakota lignite and is equipped with an ESP. Low rank coals such as lignite and Powder River Basin (PRB) coals have been shown to be difficult to treat for mercury removal in past demonstration programs.

A coal-fired boiler firing low rank coals with a cold-side ESP has emerged as a preferred combination in the US utility industry for several reasons. Utilities are switching to these lower sulfur Western coals to lower $\mathrm{SO}_{2}$ emissions. Second, when the boilers are operated in a low- $\mathrm{NO}_{\mathrm{x}}$ configuration (air staging), very low emissions can be achieved with these coals (< $0.1 \mathrm{lb} / \mathrm{MMBtu})$, particularly with tangentially-fired boilers. Fuel cost, which is the predominant operating cost for coal-fired power plants, is also lower with the use of low rank coals. These coals are low cost because they are typically surface mined with low mining costs.

Previous tests at plants with PRB coal and a cold-side ESP using plain activated carbon sorbents indicated that the mercury removal was limited to about 70 percent. For example, in a Round 1 mercury control technology demonstration sponsored by US DOE, testing was conducted at We Energies Pleasant Prairie power plant, also a PRB-fired unit equipped with a cold-side ESP. The average mercury control efficiency ranged from 46 percent at an injection rate of $1.0 \mathrm{lb} / \mathrm{MMacf}$ to 
50-55 percent at an injection rate of $5.0 \mathrm{lb} / \mathrm{MMacf}$. Increasing the injection rate to $10 \mathrm{lb} / \mathrm{MMacf}$ increased mercury capture across the ESP to 60-65 percent. Almost no further increase was observed at higher injection rates. ${ }^{1,2}$

Several technical risks associated with the Mer-Cure ${ }^{\mathrm{TM}}$ technology would be addressed by the demonstration testing at LOS1. These included:

- Sorbent survivability and activity retention upon exposure to the high temperature flue gas upstream of the air heater

- Long-term and continuous operation of the sorbent processing, distribution and injection system

- Potential for increased opacity due to slip of the fine sorbent particles through the ESP

- Potential for increased air pre-heater fouling

In preparation for the design of the site-specific portion of the Mer-Cure ${ }^{\mathrm{TM}}$ system, site visits were made to Leland Olds Station. During the visits, more detailed information was collected such as that on the injection location (e.g., duct dimensions, turning vane arrangement), workspace, sampling port locations, trailer placement, equipment placement and the availability of utilities at work locations.

Extensive CFD studies were conducted to design the injection lances for the Mer-Cure ${ }^{\mathrm{TM}}$ system. The flue gas stream from LOS1 boiler is split into three streams (see Figure 6.2-6). Approximately $25 \%$ of the total flue gas flow is directed to the tubular primary air heater, and the rest is evenly split between the two Ljungstrom ${ }^{\mathrm{TM}}$ secondary air heaters. Based on the calculated flow distributions, the numbers of injection ports, injection lances and their nozzles were determined. In August 2005, Basin Electric completed installation of the injection ports.

Appropriate distribution of sorbent into the flue gas stream is critical for maximum contact between the sorbent and the mercury in the flue gas stream. Flow modeling studies using Fluent CFD package were conducted using specific boiler design data to better determine the location and the number of injection lances. As mentioned above, the flue gas ductwork at the LOS1 boiler exit to air heaters is currently designed to split the flow into three streams. Approximately $25 \%$ of the total flue gas flow is directed to a tubular primary air heater, and the rest is evenly split between two Ljungstrom $^{\mathrm{TM}}$ secondary air heaters. Mer-Cure ${ }^{\mathrm{TM}}$ technology requires injection of sorbent into a location upstream air heaters. In order for maximum in-flight capture of mercury, the mixing characteristics of sorbent with flue gas at the boiler exit have been carefully examined by CFD.

In Figure 6.2-1, the flow distribution of flue gases is shown at various cross-sections of the boiler outlet ducts. The figure indicates a wide variation of flow velocity as the flue gas makes several turns out of the boiler into the air heaters. The inlet to the Ljungstrom ${ }^{\mathrm{TM}}$ air heaters, for example, shows a large recirculation zone developed at the upper section of the horizontal inlet duct. On the other hand, the inlet to the primary air heater shows relatively uniform mixing.

Figure 6.2-2 shows a more detailed cross sectional view of the flue gas flow distribution at the Ljungstrom $^{\mathrm{TM}}$ air heater inlet. It clearly depicts that the flow is skewed towards the lower section of 


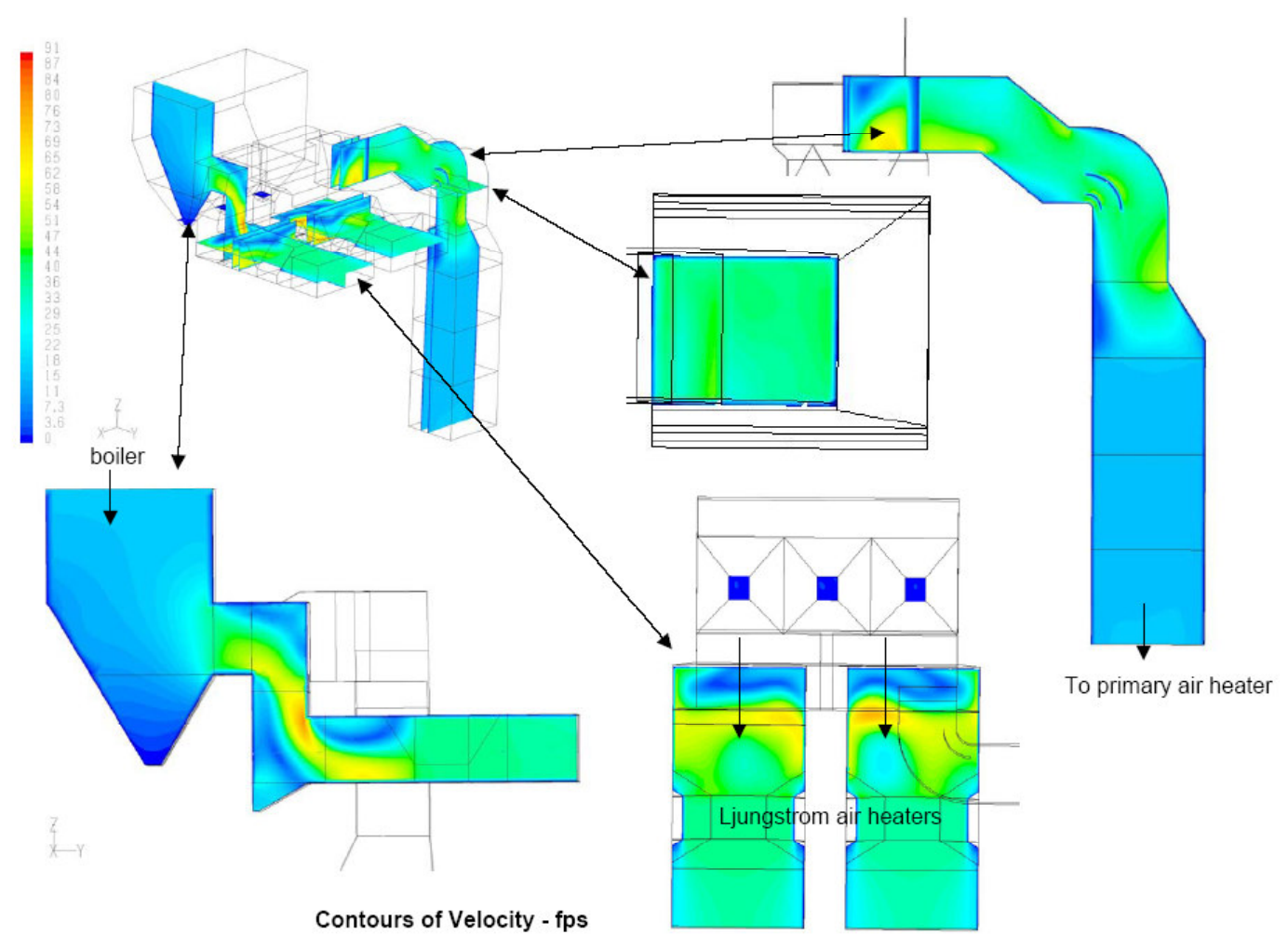

Figure 6.2-1 CFD Results for LOS1 Sorbent Injection Location

Equal Area: Mass Flow \%
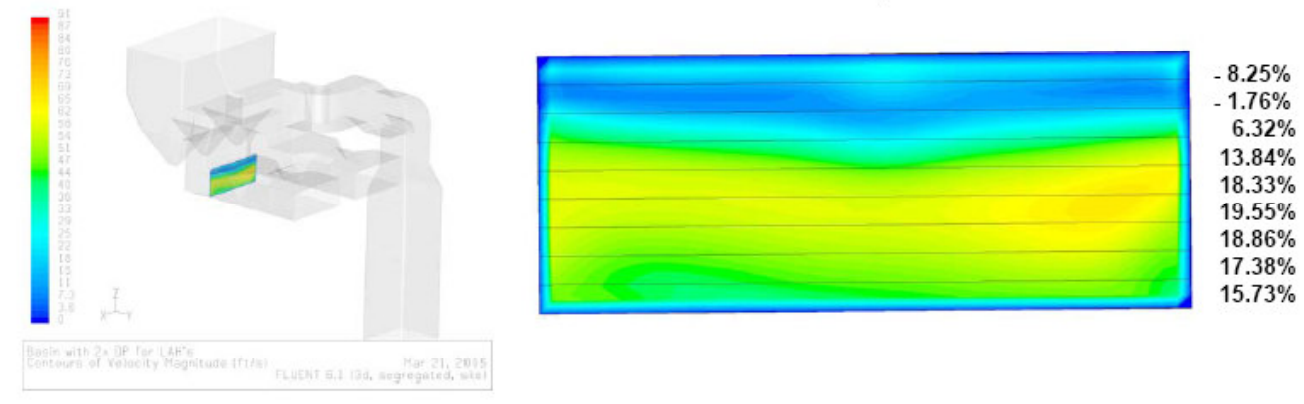

Section height above floor - $\mathrm{ft}$ :

Section Height adjusted for equal Mass flow:

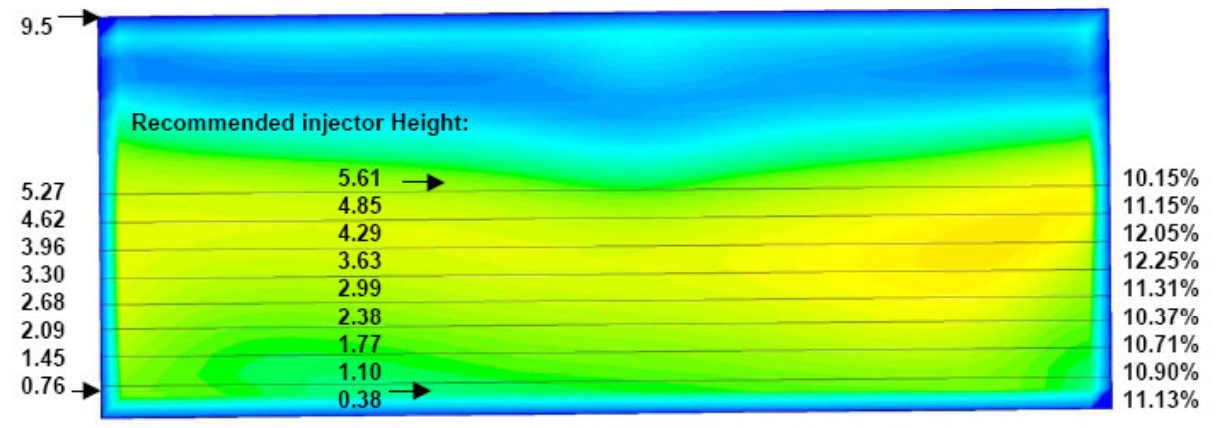

Figure 6.2-2 Flow Distribution Results for LOS1 Sorbent Injection Location

Alstom Power Inc. 
the area. In fact, the upper one-third of the total cross sectional area accounts for only $10 \%$ of the total mass flow. This maldistribution could significantly impact the design and arrangement of nozzles on injection lances for uniform distribution of sorbent particles in the flue gas stream.

In order to confirm this flow prediction, velocity measurements were conducted by EERC.

Measurements were made both at the boiler exit and the air heater inlet duct for velocity as well as temperature and oxygen. Results are shown in Figure 6.2-3 for velocities as measured along the vertical centerline of the cross-sectional area in Figure 6.2-2. The measured velocity distribution indicates that there is indeed reversal of flow directions at the upper section of the area. A varied distribution was also observed for temperature and oxygen at the measured location.

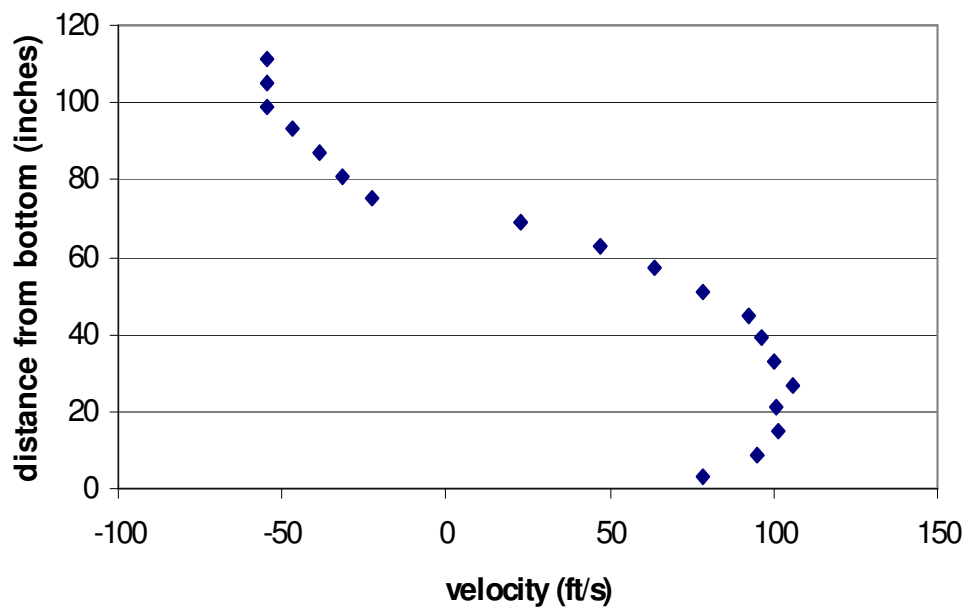

Figure 6.2-3 Vertical Flow Distribution Measured by a Pitot Tube at the Center of the Injection Location

Based on the CFD results and these flow distributions, a lance injection system was designed for LOS1 targeting proportional distribution of sorbent with the flue gas volumetric flow. The lance design parameters such as the number of lances, nozzle size, number and location for each of the lances were determined based on these studies to create immediate and uniform mixing of sorbent as it is introduced into the flue gas stream. Lances for the demonstration project were fabricated according to the final design. The completed mobile Mer-Cure ${ }^{\mathrm{TM}}$ demonstration trailer was shipped to Leland Olds Station in September 2005.

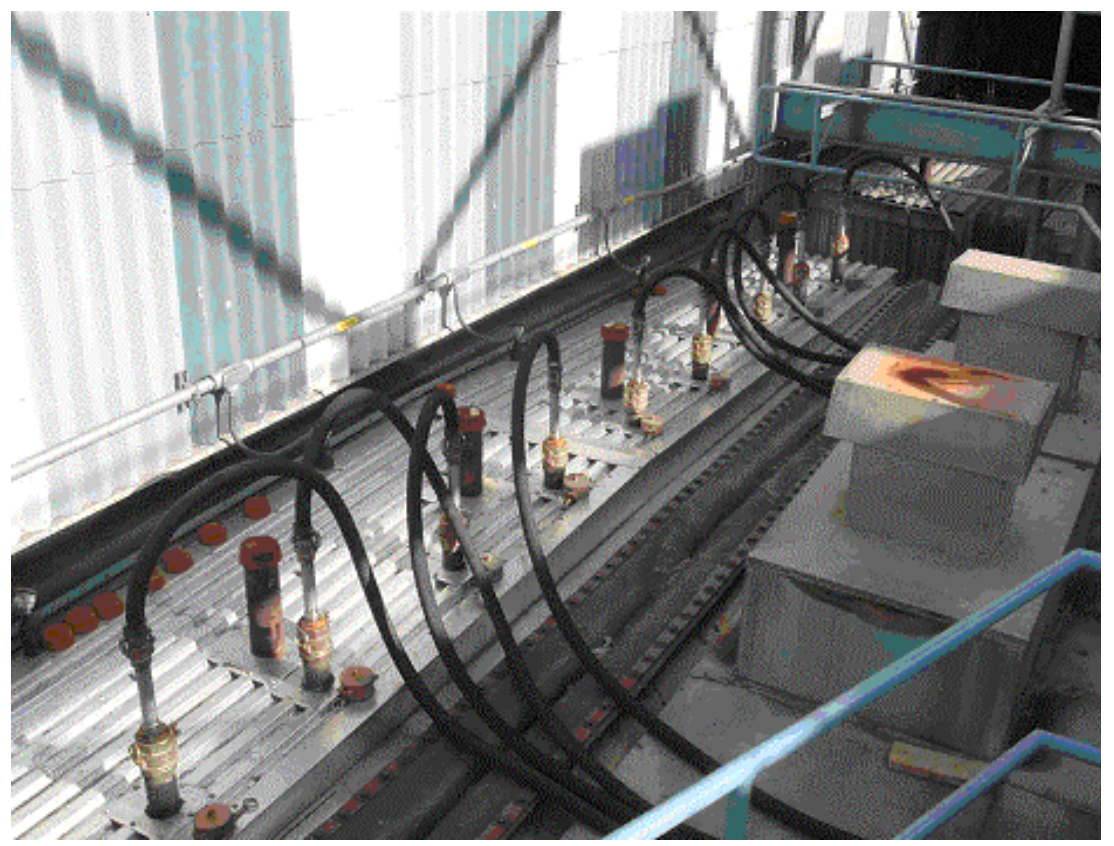

Figure 6.2-4 Sorbent Injection Lances Installed Upstream of the Air Heater 
The Mer-Cure ${ }^{\mathrm{TM}}$ system was placed on the east side of the LOS1 boiler. The sorbent storage and delivery system was assembled at the site; the sorbent processing system was placed close to the sorbent injection system and was connected to the storage system by 4 -inch flexible hoses. The sorbent injection lance system was installed at the injection location as shown in Figure 6.2-4, and connected to the delivery system by 4 -inch flexible hoses. The injection and distribution systems were secured to the boiler structure locally. Figure 6.2-5 shows the MerCure $^{\mathrm{TM}}$ system after installation at Leland Olds Station. Shakedown of the assembled system was carried out when installation was complete.

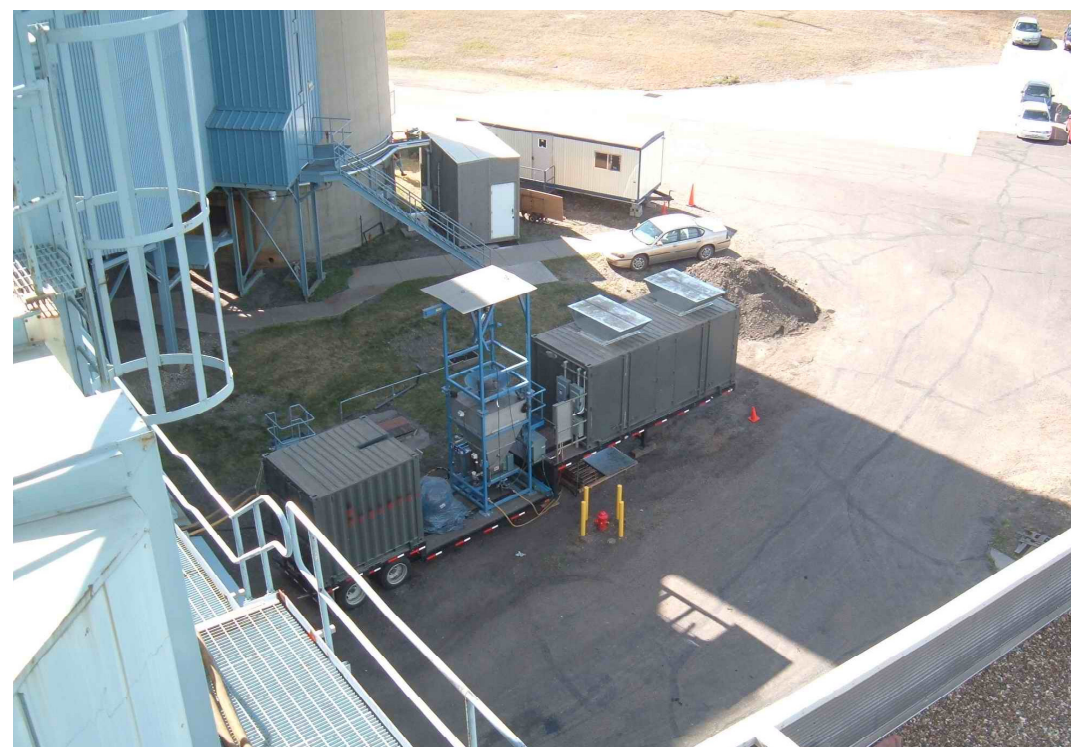

Figure 6.2-5 Mer-Cure $^{\mathrm{TM}}$ System After Installation

Figure 6.2-6 shows a schematic diagram of the LOS1 plant layout showing various sampling locations. The boiler has two Ljungstrom ${ }^{\mathrm{TM}}$ air heaters and one tubular air heater. Only a portion of the flue gas - flue gas through one Ljungstrom ${ }^{\mathrm{TM}}$ air heater and one tubular air heater, or about two thirds of the total flue gas flow coming out of the boiler - was treated by Mer-Cure ${ }^{\mathrm{TM}}$ system. (The shaded area shown in light blue in Figure 6.2-6 indicates the treated portion.) Coal samples were collected from the mills and composite samples prepared. Ash samples were collected from the ESP hoppers and the ash silo on a regular basis.

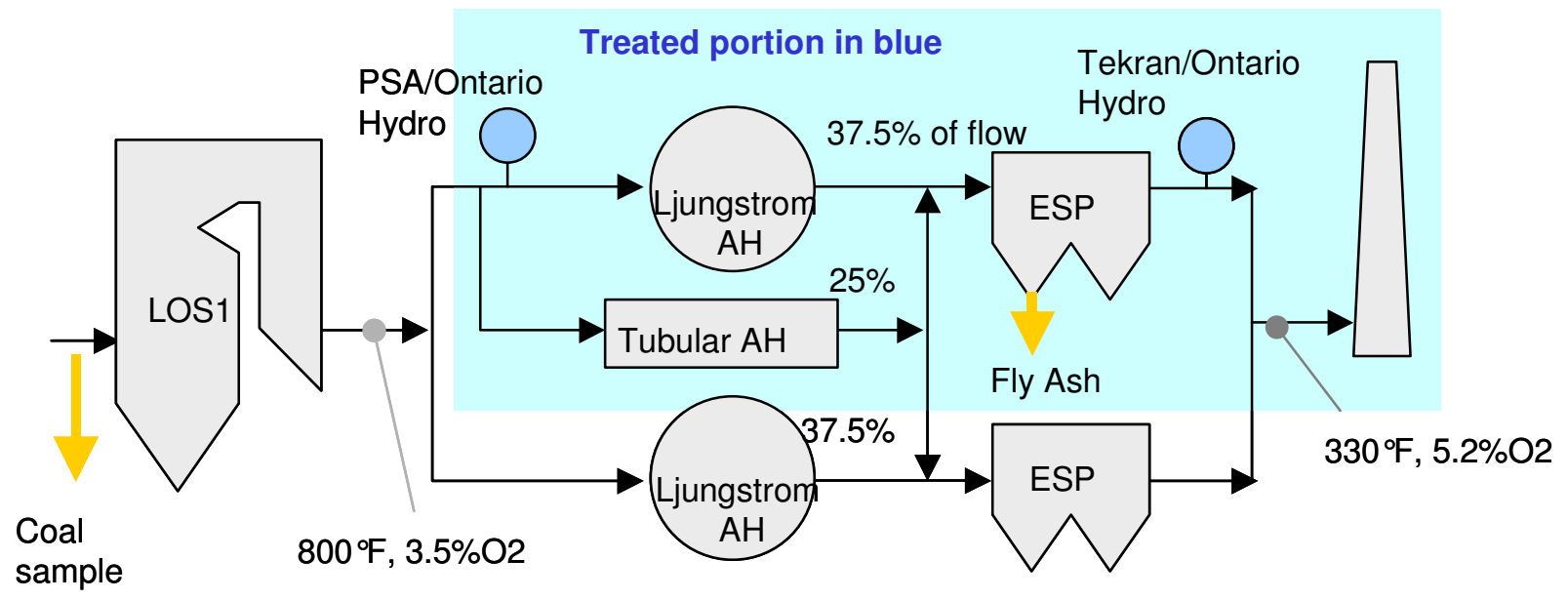

Figure 6.2-6 Sorbent Treatment and Sampling Locations, Leland Olds Unit \#1 
One of the unique aspects of Alstom's Mer-Cure ${ }^{\mathrm{TM}}$ technology is that the sorbent injection is performed between the economizer and the air heater. In typical utility boilers, temperatures at this location are around 600 to $800^{\circ} \mathrm{F}$. The sorbents used in the Mer-Cure ${ }^{\mathrm{TM}}$ technology are activated carbon-based. Different halogenated components are added to the activated carbon and the material processed to make the final sorbent. During this test program, four such formulations were tested (\# 2, 4, 6, and 8). These formulations differed from each other in terms of the added components, amounts of the added components, and manufacturing process conditions.

The coal fired at Leland Olds was a lignite coal from North Dakota. Table 6.2-1 lists the average coal properties determined by analysis of coal composite samples. A total of ten (10) composite coal samples were collected and prepared from the four mills of LOS1 during the test campaign. From these composite samples, the average mercury content of the coal and its standard deviation have been determined to be $0.054 \mu \mathrm{g} / \mathrm{g}$ dry coal, and $0.017 \mu \mathrm{g} / \mathrm{g}$ dry coal, respectively. The chlorine content of the coal was $46( \pm 25)$ ppm on a dry basis.

Table 6.2-1 Leland Olds Unit \#1 Average Coal Properties

\begin{tabular}{|l|c|c|}
\hline Proximate analysis & As received & Dry basis \\
\hline Total moisture (\%) & 36.59 & $\mathrm{~N} / \mathrm{A}$ \\
\hline Volatile matter (\%) & 24.64 & 38.87 \\
\hline Fixed Carbon (\%) & 30.92 & 48.76 \\
\hline Ash (\%) & 7.84 & 12.37 \\
\hline HHV (BTU/lb) & 6,654 & 10,494 \\
\hline Ultimate analysis & As received & Dry basis \\
\hline Moisture (\%) & 36.59 & $\mathrm{~N} / \mathrm{A}$ \\
\hline Carbon (\%) & 39.36 & 62.07 \\
\hline Hydrogen (\%) & 2.59 & 4.09 \\
\hline Oxygen (\%) & 12.41 & 19.56 \\
\hline Nitrogen (\%) & 0.61 & 0.96 \\
\hline Sulfur (\%) & 0.60 & 0.94 \\
\hline Chlorine (ppmw) & $28 \pm 15$ & $46 \pm 25$ \\
\hline Ash (\%) & 7.84 & 12.37 \\
\hline Total (\%) & 100.00 & 100.00 \\
\hline \hline Hg ( $\mu$ g/g dry coal) & $\mathrm{N} / \mathrm{A}$ & $0.054 \pm 0.017$ \\
\hline Hg (lb/TBTU) & $4.86 \pm 1.36$ & $4.86 \pm 1.36$ \\
\hline
\end{tabular}

The minimum and maximum mercury contents in the samples analyzed were $0.04 \mathrm{ppm}$ and 0.10 ppm, respectively, indicating a fairly wide variation in the quantity of mercury entering the boiler with the coal.

Table 6.2-2 lists the tasks carried out to complete the Basin Electric test campaign and their associated timeline. 
Table 6.2-2 Basin Electric Test Campaign Timeline

\begin{tabular}{|c|c|}
\hline Tasks & Timeline \\
\hline Baseline measurement & September 30 - October 4, 2005 \\
\hline Parametric Testing & October 5 - 14, 2005 \\
\hline Long-term testing & October 16 - November 14, 2005 \\
\hline System removal & November 15 - 18, 2005 \\
\hline
\end{tabular}

Baseline measurements of mercury concentration in the flue gas were performed at the air heater inlet (pre-sorbent injection) and precipitator outlet. Validation data using the $\mathrm{OH}$ method was also obtained for the baseline condition. Subsequent to the baseline testing, approximately ten days of parametric testing was conducted. Parametric tests included four enhanced activated carbon sorbents. In the parametric tests, Mer-Clean ${ }^{\mathrm{TM}} 8$ gave the best performance in terms of mercury removal versus sorbent injection rate. Mer-Clean ${ }^{\mathrm{TM}} 8$ was chosen for the long-term testing.

\subsubsection{Baseline Testing Results}

The Basin Electric testing at LOS1 started with a week of baseline mercury measurement using CMMs. Figure 6.2-7 shows the baseline mercury levels from LOS1 at the ESP outlet. A Tekran mercury system was employed by UND-EERC for the measurements. The reported concentrations are vapor phase mercury levels corrected to $68^{\circ} \mathrm{F}$ and $3 \% \mathrm{O}_{2}$. The average temperature and $\mathrm{O}_{2}$ concentrations measured at the ESP outlet by EERC were $334^{\circ} \mathrm{F}$ and $5.2 \%$, respectively.

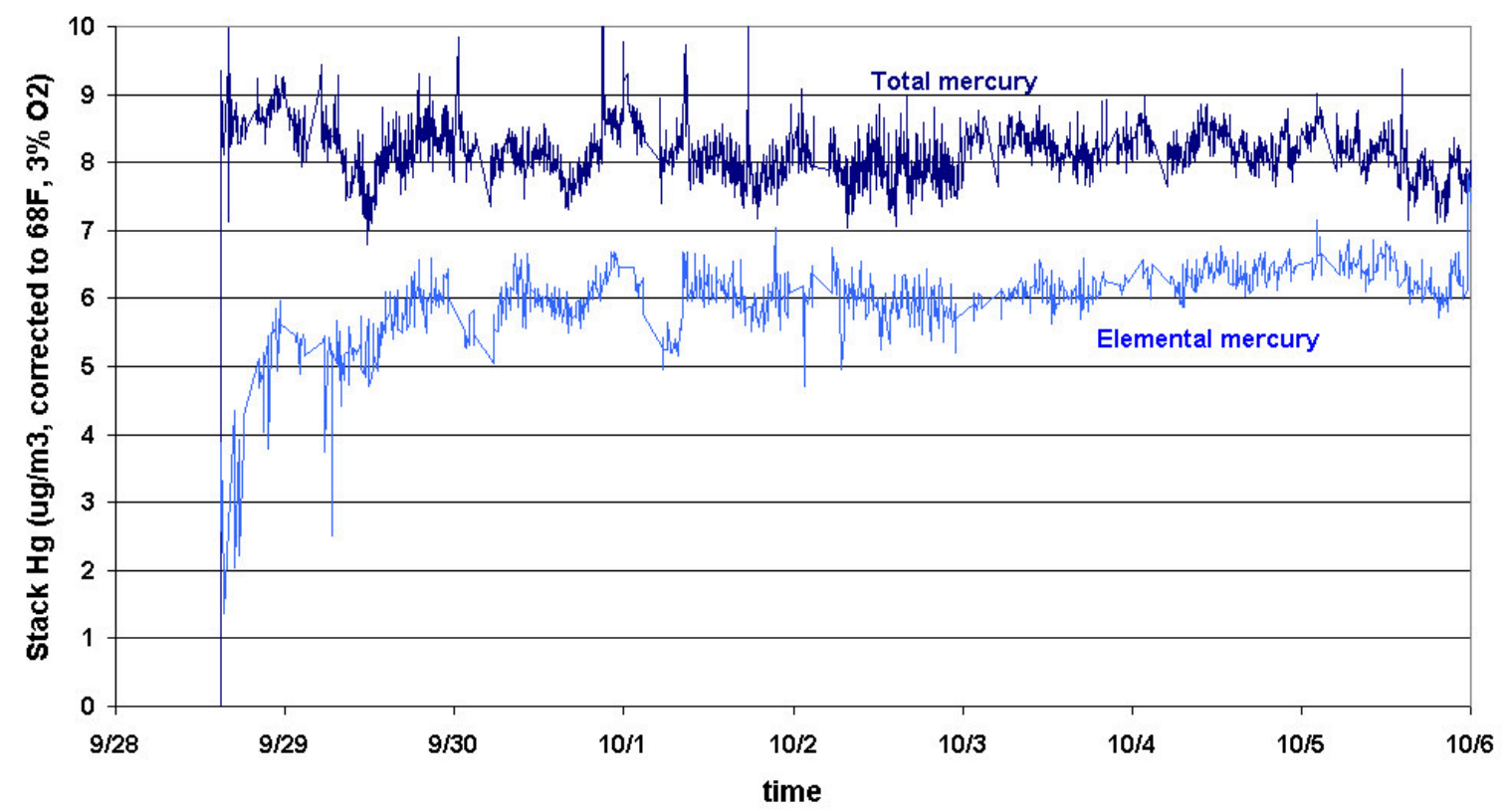

\section{Figure 6.2-7 Baseline Mercury Measurement at Leland Olds Unit \#1}

Some fluctuations in baseline levels were observed over time for both elemental and total mercury, which may be due to variation of mercury content in the coal fed. As shown in Figure 6.2-7, the 
total mercury varied between $7 \mu \mathrm{g} / \mathrm{m}^{3}$ and $9 \mu \mathrm{g} / \mathrm{m}^{3}$ during the baseline measurement period and averaged to be $7.3 \mu \mathrm{g} / \mathrm{m}^{3}$, with a standard deviation of $0.9 \mu \mathrm{g} / \mathrm{m}^{3}$. According to the CMM measurements, nearly $80 \%$ of the total gaseous mercury was in elemental form. This is not surprising in that the chlorine content of the coal was less than 50 ppm dry and no detectable bromine was found in the coal.

\subsubsection{Parametric Testing Results}

Figure 6.2-8 shows a typical response of the mercury levels from LOS1 when Mer-Clean ${ }^{\mathrm{TM}}$ sorbent is injected to the backend of the boiler during parametric testing. Before injection, the total mercury level was $7.5 \mu \mathrm{g} / \mathrm{m}^{3}$. At $10 \mathrm{AM}$ on October 6 , the Mer-Cure ${ }^{\mathrm{TM}}$ system was turned on and the MerClean $^{\mathrm{TM}}$ sorbent was injected at a constant rate. Within half an hour, the mercury level decreased from $7.5 \mathrm{~g} / \mathrm{m}^{3}$ to $3.5 \mu \mathrm{g} / \mathrm{m}^{3}$, followed by a slow decrease to $3.0 \mu \mathrm{g} / \mathrm{m}^{3}$ over 4 hour period. Further increase in sorbent injection rate decreased the mercury level to $1.5 \mu \mathrm{g} / \mathrm{m}^{3}$, followed by a slow decrease to approximately $0.8 \mu \mathrm{g} / \mathrm{m}^{3}$, resulting in $90 \%$ removal of uncontrolled stack mercury.

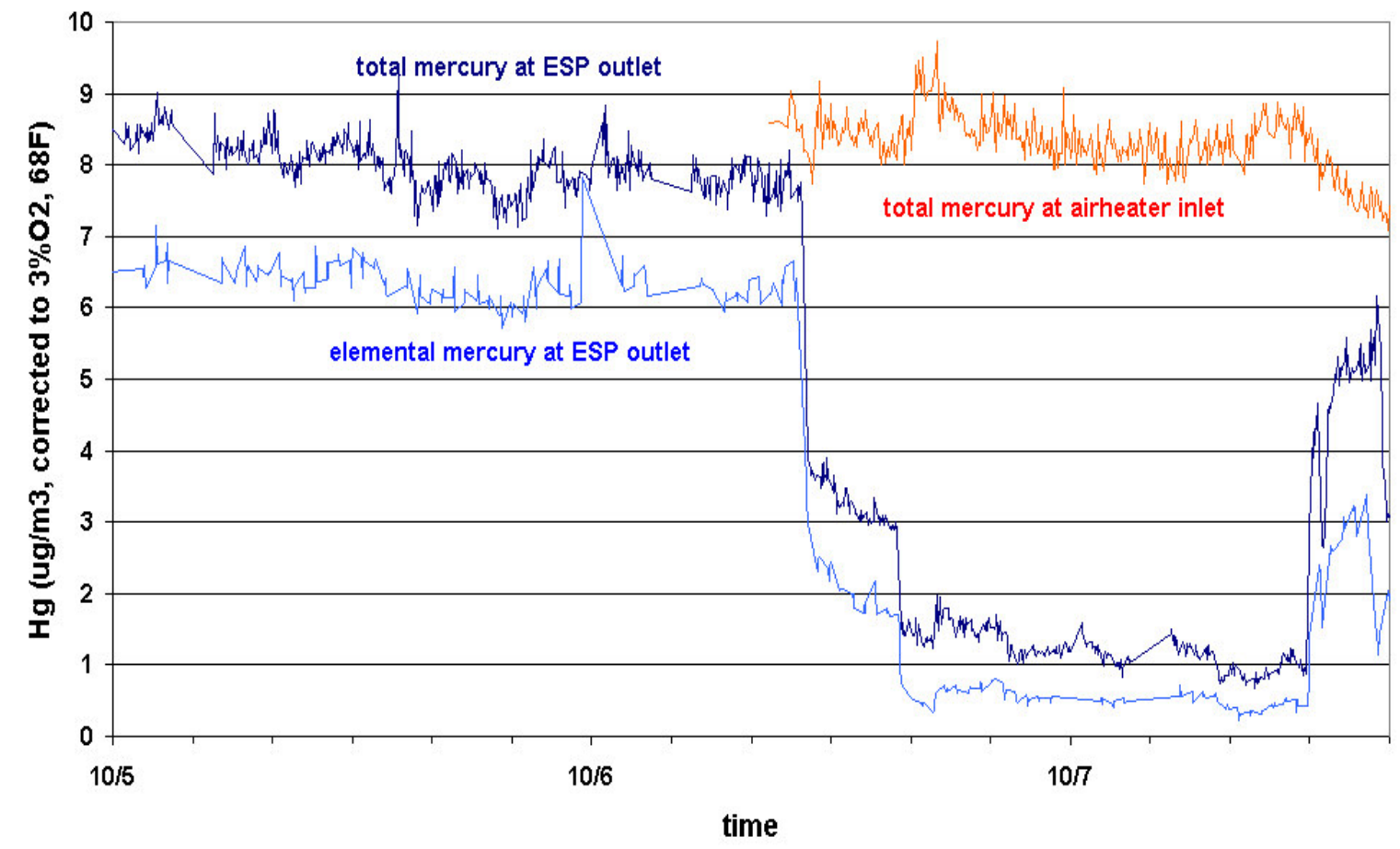

Figure 6.2-8 CMM Response to Mer-Cure ${ }^{T M}$ System On/Off Operation

At 12 PM on October 7, the Mer-Cure ${ }^{\mathrm{TM}}$ system was turned off, and the total mercury level at the ESP outlet recovered in two steps: initial immediate recovery over 30 minute period to $4 \mu \mathrm{g} / \mathrm{m}^{3}$; followed by a recovery at a slower rate. This recovery pattern has been observed for every test condition during parametric testing. In fact, this behavior has been observed in previous testing conducted in our laboratory scale experiments, as well as in other field testing conducted as part of our DOE-sponsored field demonstration program. 
The mercury speciation shows that without Mer-Clean ${ }^{\mathrm{TM}}$ injection, about $80 \%$ of the total mercury was in elemental form, whereas during injection, the elemental mercury level at the ESP outlet came down to less than $50 \%$ as observed. This demonstrates the role of Mer-Clean ${ }^{\mathrm{TM}}$ in the flue gas duct on speciation of gaseous mercury. Mer-Clean ${ }^{\mathrm{TM}}$ particles provide surface area for catalytic oxidation of elemental mercury. The elemental mercury level was about $50 \%$ even after the injection was stopped. This may be due to the residual Mer-Clean ${ }^{\mathrm{TM}}$ sorbent still in the ductwork contributing to the oxidation.

These two-step reduction and recovery patterns may be explained by how sorbent particles would behave differently as they are injected into the flue gas stream. As sorbent particles are injected, they are entrained by flue gas and travel through various devices (air heaters, SCRs, ductwork, scrubbers, etc.) until collected by particulate control devices (an electrostatic precipitator in case of LOS1). Some of these "in-flight" particles, however, are deposited onto internal surfaces (air heater elements, turning vanes, duct surfaces, regions of high turbulence, etc,) even before they arrive at the electrostatic precipitators. The residence time of "in-flight" sorbent particles in the ductwork is on the order of a second, whereas that of the wall-deposited particles may be orders of magnitude longer.

As the Mer-Cure ${ }^{T M}$ system is turned on, sorbent particles interact with mercury in the flue gas and reduce the mercury level from roughly $8 \mu \mathrm{g} / \mathrm{m}^{3}$ to $4 \mu \mathrm{g} / \mathrm{m}^{3}$. Some of these injected sorbent particles start "coating" most of the internal surfaces, providing additional mercury adsorption surface area. Depending on the duct design, sorbent particle size distribution, degree of turbulence, etc., it may take time for the internal surfaces to be completely covered by some of these in-flight particles. This is observed in the slow decrease of stack mercury level over a two-hour period.

The in-flight and wall effects may be decoupled as the recovery pattern is further analyzed. During injection (10:00 on 10/06 through 12:00 on 10/07 in Figure 6.2-8), mercury reduction is achieved both by the in-flight particles and by the wall particles. A relatively constant population of in-flight particles will be maintained between the injection point and the electrostatic precipitators. As soon as the injection system has been turned off, the in-flight sorbent particles quickly disappear, leaving only the wall-deposited particles in the back-pass for mercury capture. The immediate recovery to 4 $\mu \mathrm{g} / \mathrm{m}^{3}$ is mainly attributed to the absence of the in-flight particles. Those wall-deposited particles continue to adsorb mercury until their adsorption capacity is depleted or they are covered by incoming fly ash particles. This is observed in an asymptotic recovery pattern towards the baseline mercury level.

This simple analysis of the recovery pattern shows that the in-flight contributions to the overall mercury capture, i.e., immediate recovery, are approximately $40 \%$. Nearly $60 \%$ of the total mercury capture is, in other words, due to the wall effect. This further emphasizes the significance of injecting sorbent particles as far upstream of the particulate collection devices as possible, maximizing conversion of internally available surface area into reactive surfaces. This is achieved in a Mer-Cure ${ }^{\mathrm{TM}}$ system by selecting the air heater inlet as the sorbent injection point. 
Figure 6.2-9 shows the performance of Mer-Cure ${ }^{T M}$ system at Leland Olds Station during parametric testing. In the figure, the mercury removal efficiency is reported for various sorbents (Mer-Clean ${ }^{\mathrm{TM}}$ sorbents 2, 4, 6, and 8) as a function of the sorbent feed rate in lb/MMacf (or pounds per million actual cubic feet, where the "actual" condition refers to the actual ESP outlet condition, i.e., $330^{\circ} \mathrm{F}$ and $5.2 \% \mathrm{O}_{2}$ ). The reported removal efficiency was calculated based on the uncontrolled (or baseline) ESP outlet concentrations of gaseous mercury measured before parametric testing.

Among the Mer-Clean ${ }^{\mathrm{TM}}$ sorbents, Mer-Clean ${ }^{\mathrm{TM}} 8$ demonstrated the best performance, exhibiting $80 \%$ reduction at $1 \mathrm{lb} /$ MMacf (or $29 \mathrm{lb} / \mathrm{hr}$ ), and 90\% reduction at $1.5 \mathrm{lb} / \mathrm{MMacf}$. Ninety five percent removal was achieved at $2.2 \mathrm{lb} / \mathrm{MMacf}$. The performance of Mer-Clean ${ }^{\mathrm{TM}} 8$ was significantly deteriorated, however, when the processor of the Mer-Cure ${ }^{\mathrm{TM}}$ system was turned off (8 (off) in Figure 6.2-9). At a feed rate of $1 \mathrm{lb} / \mathrm{MMacf}$, the removal efficiency decreased from $80 \%$ mercury reduction to only $55 \%$ reduction.

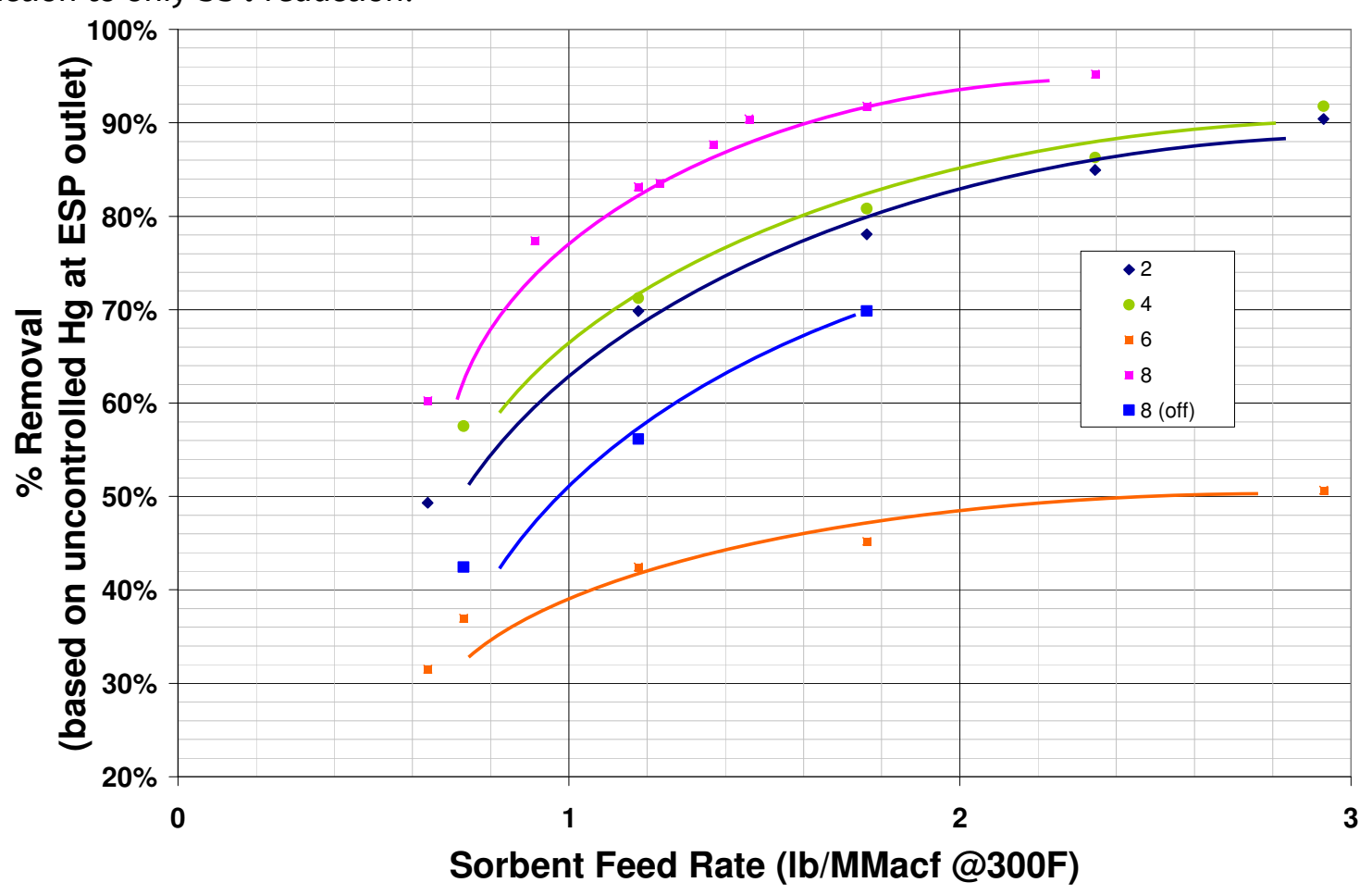

Figure 6.2-9 Mer-Cure ${ }^{\mathrm{TM}}$ Performance Curve from Parametric Testing at Leland Olds Unit \#1

From the viewpoint of sorbent consumption, the role of the processor in the Mer-Cure ${ }^{\mathrm{TM}}$ system is significant. For the same removal target, the sorbent consumption rate for the Mer-Cure ${ }^{\mathrm{TM}}$ system with its processor turned on was only half of that with it turned off. For example, for $60 \%$ removal, the Mer-Cure ${ }^{\mathrm{TM}}$ system in processor-off mode requires $1.2 \mathrm{lb} / \mathrm{MMacf}$, whereas in processor-on mode it requires only $0.6 \mathrm{lb} / \mathrm{MMacf}$.

The effect of the processor of the Mer-Cure ${ }^{\mathrm{TM}}$ system is also shown in Figure 6.2-10. At 13:30, the sorbent feed rate was increased to $1.2 \mathrm{lb} /$ MMacf bringing the ESP outlet mercury level down to 3.2 $\mu \mathrm{g} / \mathrm{m}^{3}$. During this time, the Mer-Cure ${ }^{\mathrm{TM}}$ system was operated with its processor turned off. At 16:05, the processor was turned on while keeping the sorbent feed rate constant. This led to a step 
decrease in ESP outlet mercury level to $1.5 \mu \mathrm{g} / \mathrm{m}^{3}$, clearly demonstrating significant improvement of the sorbent performance by the processor. The role of the processor has been reproduced several times in the test program.

Figure 6.2-10 also shows a typical recovery pattern of the outlet gaseous mercury observed at the Leland Olds Unit \#1 as a function of sorbent injection rate. Under this test condition, an immediate recovery to $5 \mu \mathrm{g} / \mathrm{m}^{3}$ was observed as soon as the Mer-Cure ${ }^{\mathrm{TM}}$ system was turned off (18:00). This was followed by a slow, steady recovery to its baseline mercury level of $7.4 \mu \mathrm{g} / \mathrm{m}^{3}$ over a 12 -hour period. The step increase in mercury level demonstrates the effect of in-flight sorbent particles on mercury capture, whereas the subsequent slow recovery shows that of residual sorbent at the boiler back pass.

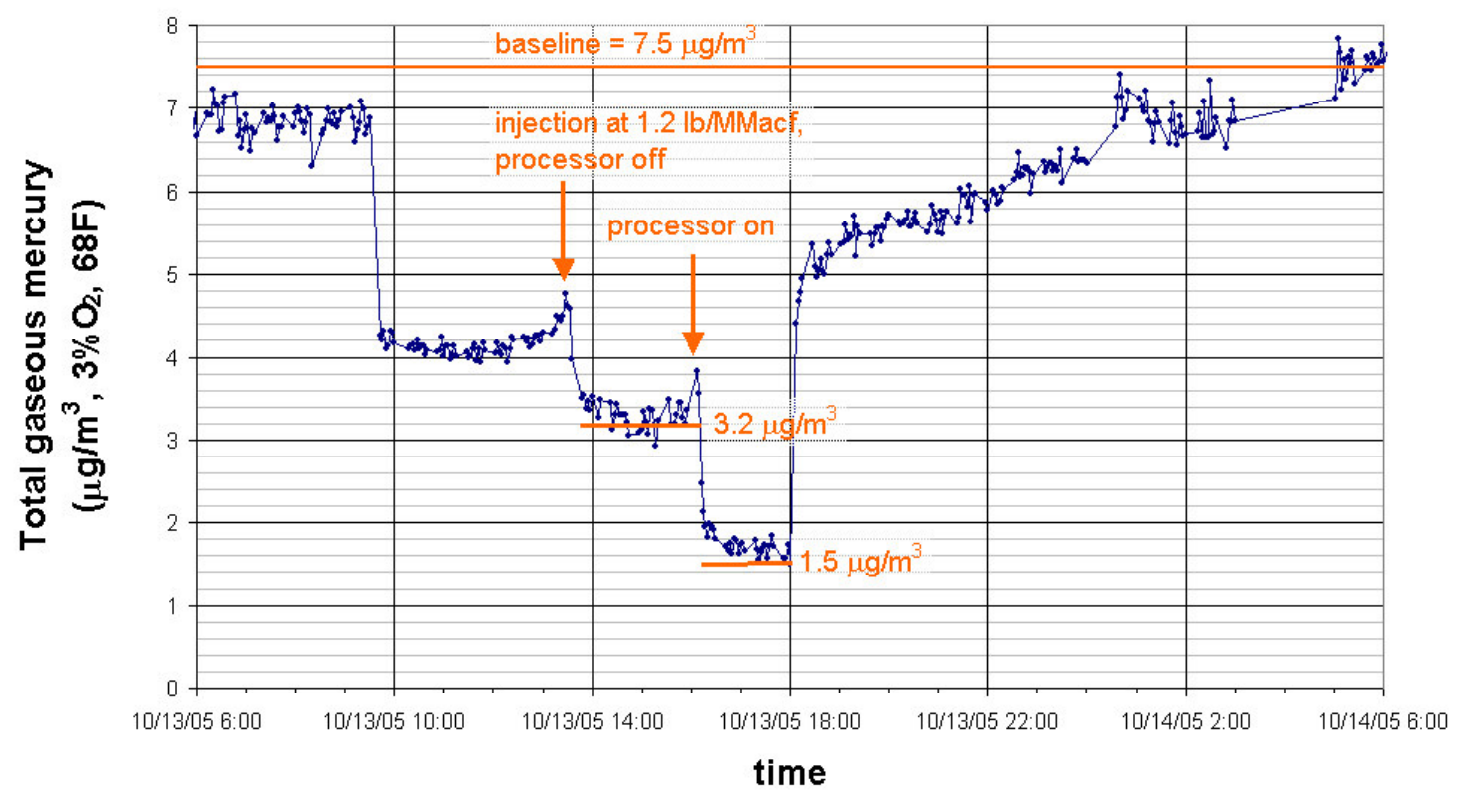

Figure 6.2-10 Effect of Processor Operation on Sorbent Performance at Leland Olds Station

(Orange line = typical baseline (untreated) stack mercury emissions rate)

(Blue line $=$ measured stack mercury emissions rate when treated with Mer-Cure ${ }^{\mathrm{TM}}$ )

Although this excellent performance may be partly attributed to the size of the electrostatic precipitator and the relatively long ductwork leading to the electrostatic precipitator, it is mostly due to the three-pronged approach being taken in the Mer-Cure ${ }^{\mathrm{TM}}$ system, i.e., (1) uniform dispersion of sorbent particles in the flue gas stream, (2) process chemistry enhancement from carefully selected injection location, and (3) use of proprietary sorbent additives.

\subsubsection{Long-Term Testing Results}

Figure 6.2-11 shows the gaseous mercury levels measured at the ESP outlet by a Tekran continuous monitor over the entire 30-day long-term demonstration period of the Mer-Cure ${ }^{\mathrm{TM}}$ system. The reported mercury levels are total gaseous mercury, i.e., both elemental and oxidized, corrected to $3 \%$ $\mathrm{O}_{2}$ and reported in micrograms per dry standard cubic meter. As shown, the baseline total mercury levels measured before and after injection are $7.48 \mu \mathrm{g} / \mathrm{m}^{3}$ and $7.59 \mu \mathrm{g} / \mathrm{m}^{3}$, respectively. 


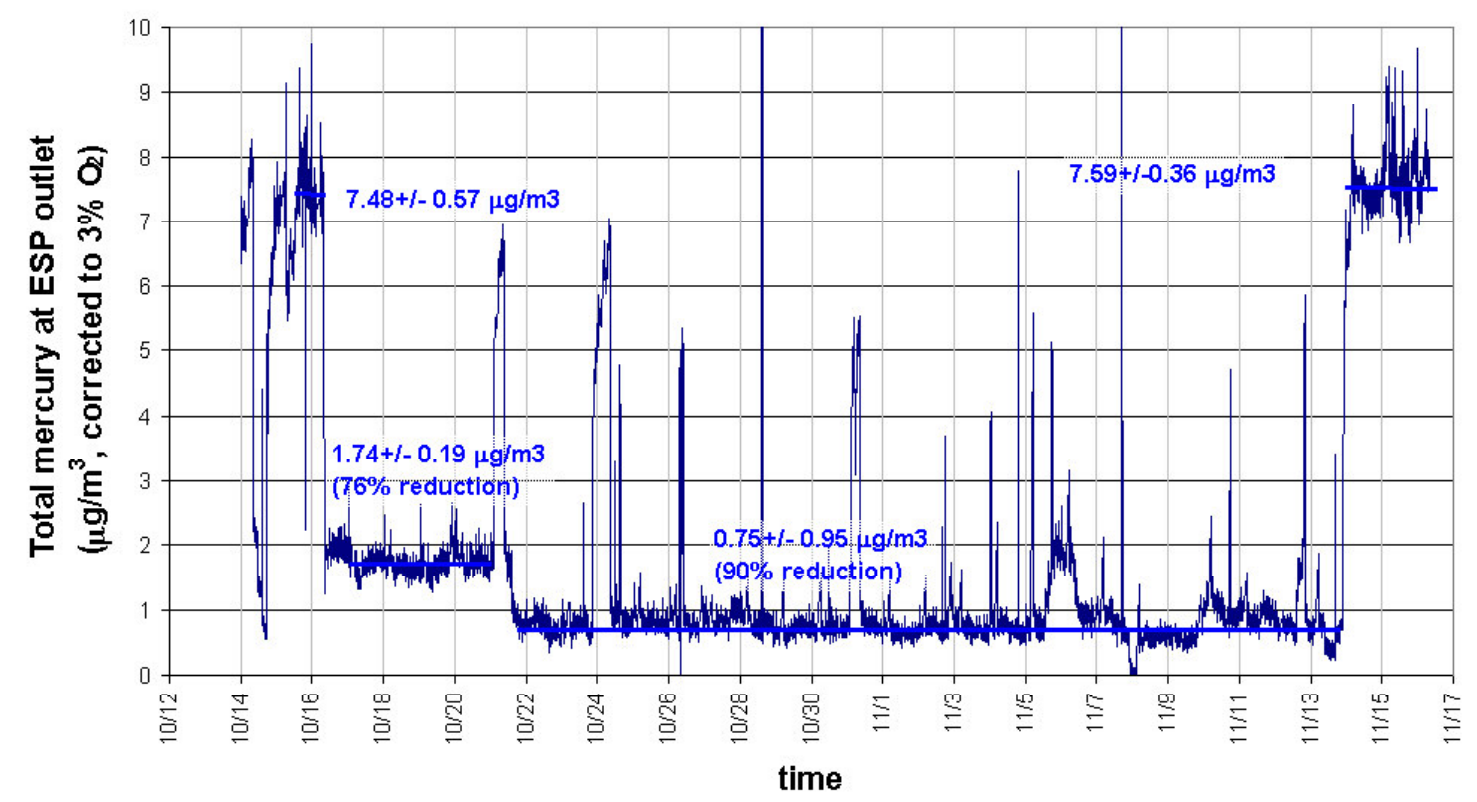

Figure 6.2-11 Mercury Capture and Stack Mercury Emission Results from CMMs During Long-Term Demonstration

The long-term demonstration program was broken into two test periods. Upon request from Basin Electric, testing for the first five days was conducted with the Mer-Cure ${ }^{\mathrm{TM}}$ system mercury removal target set at approximately $75 \%$. This goal was achieved with an average emissions rate of 1.74 $\mu \mathrm{g} / \mathrm{m}^{3}$ at the sorbent injection rate of $0.9 \mathrm{lb} / \mathrm{MMacf}$. This testing was then followed by operation at the target removal rate of approximately $90 \%$. This goal was achieved with an average emissions rate of $0.75 \mu \mathrm{g} / \mathrm{m}^{3}$ by continuous injection of sorbent at $1.4 \mathrm{lb} / \mathrm{MMacf}$. It was clearly demonstrated that $90 \%$ mercury removal could be achieved on a long term basis at Basin Electric's Leland Olds Station.

The CMM measurement of the long-term performance of the Mer-Cure ${ }^{\mathrm{TM}}$ system has been verified by another measurement method; this validation is shown in Figure 6.2-12. The reported mercury levels are the total gaseous mercury levels measured by University of North Dakota Energy and Environmental Research Center (UND EERC) throughout the long-term testing by employing the $\mathrm{OH}$ method. The mercury levels are corrected to $3 \% \mathrm{O}_{2}$ and reported in micrograms per dry standard cubic meter $(\mu \mathrm{g} / \mathrm{dscm})$. In contrast, the $\mathrm{CMM}$ values are $\mu \mathrm{g} / \mathrm{m}^{3}$ on a wet basis.

According to the $\mathrm{OH}$ measurements during the long-term test period, the air heater inlet level varied from $7.8 \mu \mathrm{g} / \mathrm{dscm}$ to $10.6 \mu \mathrm{g} / \mathrm{dscm}$ with its mean of $9.3 \pm 1.0 \mu \mathrm{g} / \mathrm{dscm}$. When corrected to a wet basis, as for CMM readings, this mercury level is a mean of $7.9 \pm 0.85 \mu \mathrm{g} / \mathrm{m}^{3}$ at the air heater inlet. The mercury removal efficiency calculated based on the air heater inlet was $80 \%$ for the initial test period, and $92 \%$ for the rest of the test period, confirming the performance of the Mer-Cure ${ }^{\mathrm{TM}}$ system as measured by CMMs. 


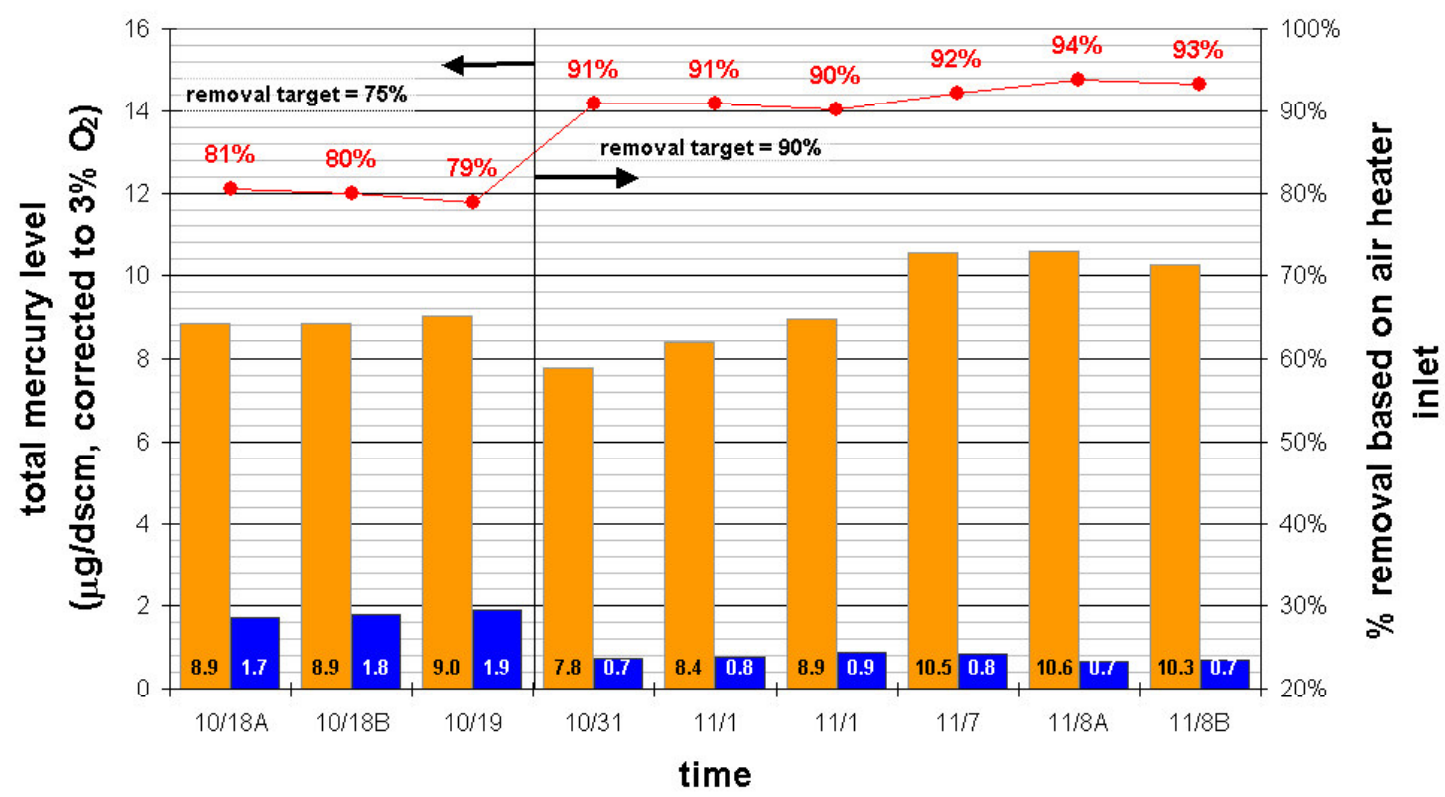

Figure 6.2-12 Mercury Capture and Stack Emission Results from Ontario Hydro Tests During Long-Term Demonstration

Figure 6.2-13 shows a comparison between the $\mathrm{CMM}$ readings and $\mathrm{OH}$ measurements during longterm test period for readings taken at the air heater. For the air heater inlet comparison, a paired $\mathrm{t}$ test for the 7 sets of air heater data have been carried out. The paired t-test gave a p-value of 0.14 , indicating that we cannot conclude with $95 \%$ confidence that the two measurements differ from each other.

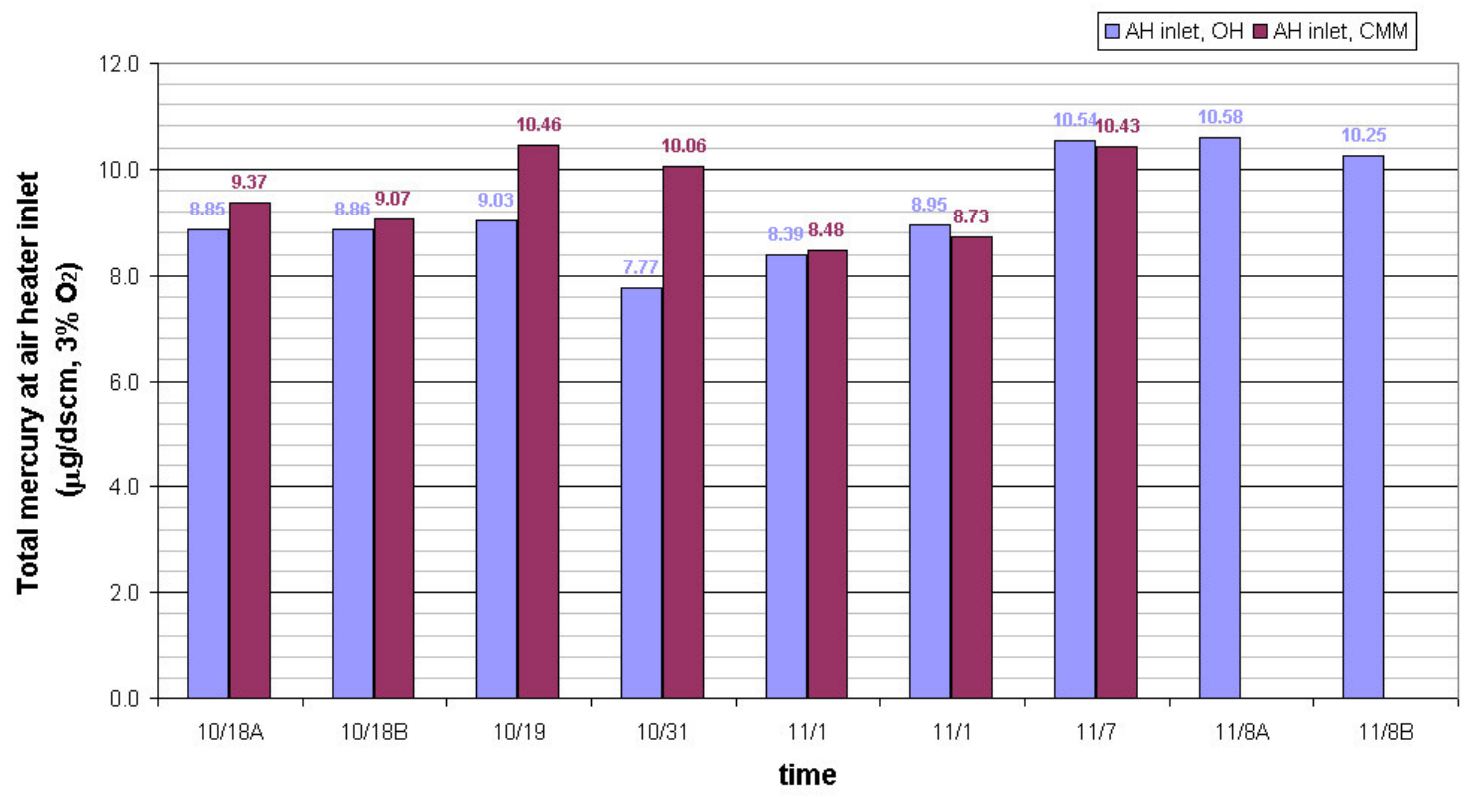

Figure 6.2-13 Comparison of CMM Measurements with Ontario Hydro Measurements at the Air Heater Inlet 
Figure 6.2-14 shows a comparison between the CMM readings and $\mathrm{OH}$ measurements during longterm test period for readings taken at the ESP outlet. For the ESP outlet comparison, a paired t-test for the 9 sets of ESP outlet data have been carried out. The paired t-test for the 9 sets of data during long-term injection gave a p-value of 0.1 , indicating that we cannot conclude with $95 \%$ confidence that the two measurements differ from each other.

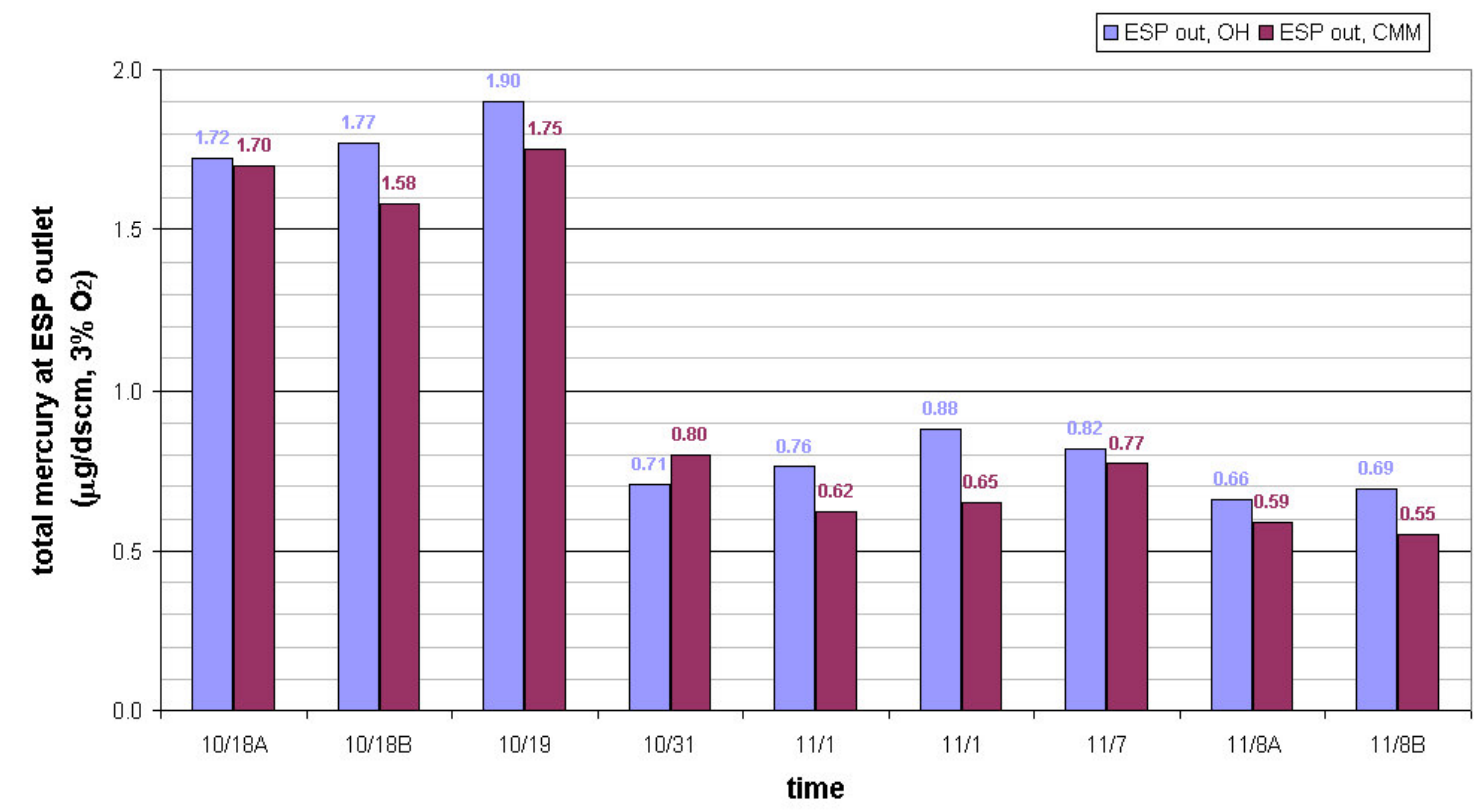

Figure 6.2-14 Comparison of CMM Measurements with Ontario Hydro Measurements at the ESP Outlet

Figure 6.2-15 shows the change of mercury speciation between air heater inlet and ESP outlet. At the air heater inlet, most of the gaseous mercury was in the elemental form. Only $3 \%$ of the total gaseous mercury was in oxidized form. Some of the gaseous mercury oxidizes at the back pass; at the ESP outlet, $23 \%$ of the gaseous mercury was in the oxidized form before sorbent injection. However, the oxidized portion of the gaseous mercury further increased to $37 \%$ during sorbent injection, suggesting that further oxidation takes place due to the presence of sorbent in the flue gas. 


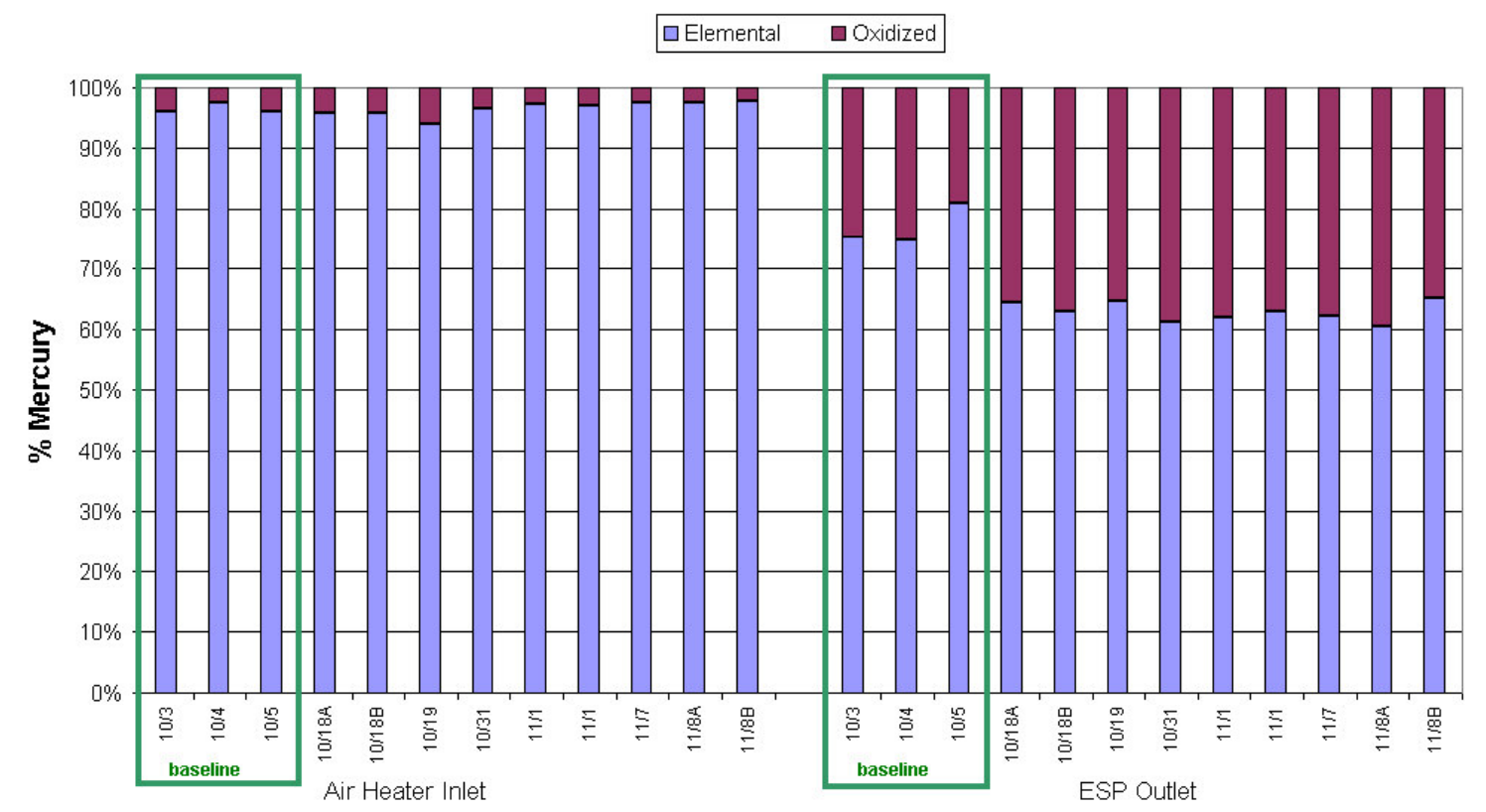

Figure 6.2-15 Mercury Speciation at the Air Heater linlet and the ESP Outlet

\subsubsection{Balance of Plant Impacts}

In the previous section, performance data have been presented to demonstrate that Mer-Cure ${ }^{\text {TM }}$ technology offers a solution to effectively control mercury emissions from coal-fired boilers. Sorbent injection into the economizer outlet, however, may be of technical and operational concern to boiler operators. In this section, the impact of sorbent injection on opacity and fly ash unburned carbon levels is discussed.

Figure 6.2-16 shows opacity measured before and during long-term sorbent injection testing. Before injection testing, the stack opacity was in the range of $2-4 \%$. When injection of the Mer-Clean ${ }^{\text {TM }}$ sorbent started on October 6 , the stack opacity actually decreased slightly to $1.5 \%$. With sorbent injection the opacity was in the range of 1.5-4\%. On October 14-16, sorbent injection was stopped to allow for two days of unit recovery between parametric and long-term Mer-Cure ${ }^{\mathrm{TM}}$ testing. Opacity actually increased from $2 \%$ to $3 \%$ over that time. The figure shows that there was no appreciable increase in opacity with sorbent injection. The load curve shows the unit was operating at or near full load throughout the test period.

Observations throughout the long-term testing suggest that injection of Mer-Clean ${ }^{\mathrm{TM}}$ sorbent did not increase the stack opacity during long-term testing. If anything, sorbent injection decreased the opacity slightly, although the data set is too limited to draw a meaningful conclusion on opacity reduction with sorbent injection. 


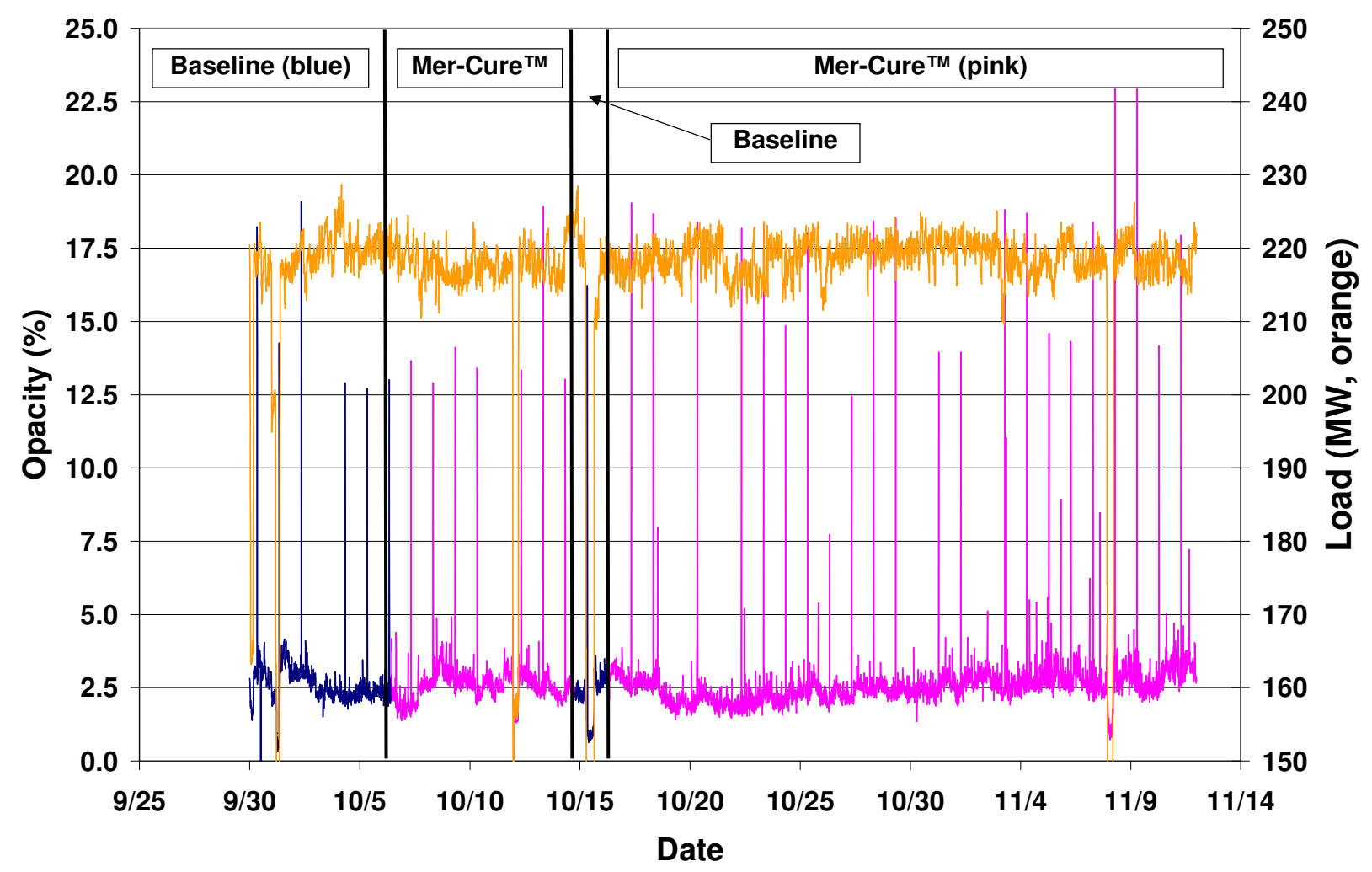

\section{Figure 6.2-16 Opacity Change During Long-Term Testing at LOS1}

Figure 6.2-17 shows unburned carbon levels measured for ESP hopper fly ash samples collected during long-term testing. Separate samples were collected from the four rows of ESP hoppers. The unburned carbon showed a slight increase from $0.58 \%$ without sorbent injection to $0.87 \%$ with sorbent injection on average. The unburned carbon increase of $0.29 \%$ points is attributed to the injection of sorbent. 


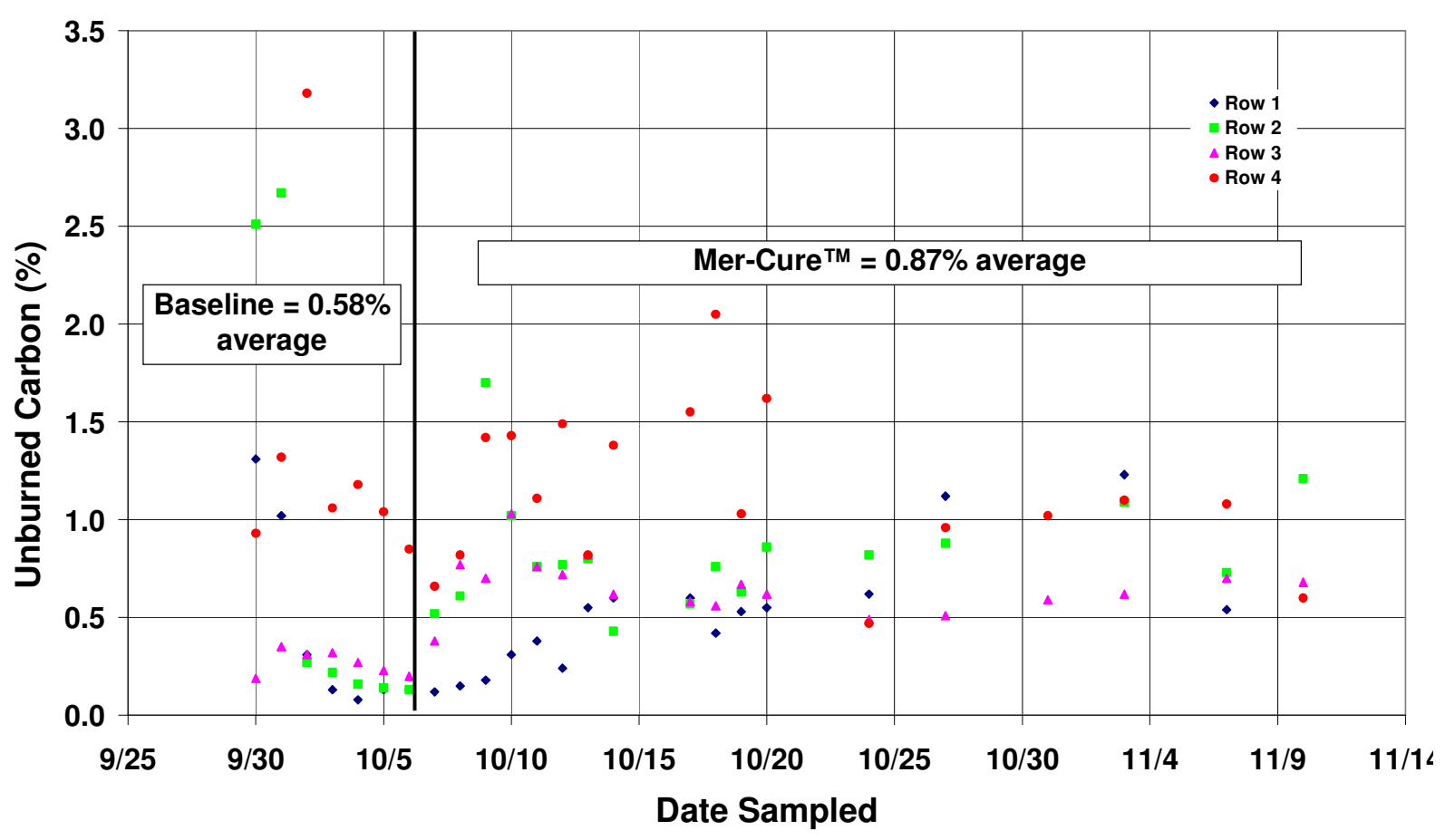

Figure 6.2-17 Change in Unburned Carbon of Bulk Fly Ash Samples During Long-Term Testing at LOS1

A related concern is fly ash salability for concrete applications with use of Mer-Cure ${ }^{\mathrm{TM}}$ technology. Fly ash with low unburned carbon content is often sold as a replacement for Portland cement in ready-mix concrete. However, fly ashes with elevated levels of carbon are unsuitable for concrete mixtures, because concrete mixtures containing such ashes require increased amounts of costly airentraining agents (AEA) to achieve a given level of air entrainment. ${ }^{7}$

For fly ash with added carbon from active carbon injection, the absolute level of unburned carbon in the ash is not as important as its effect on air entrainment for ash salability. The Foam Index Test is a rapid means that is widely used to determine the relative levels of AEA needed for concrete containing fly ash and to measure the degree of interaction between AEA and fly ash or carbon. ${ }^{8,9}$

Fly ash containing less than $1 \%$ carbon is well within the specification for use as a concrete additive, but a Foam Index Test (or other air entrainment measure) would be needed on the specific ash from Leland Olds Unit \#1 to determine if ash containing the tested level of Mer-Clean ${ }^{\text {TM }}$ sorbent is suitable for concrete applications. Basin Electric sells their ash for mine reclamation, and the ash carbon levels documented in this project do not affect use of fly ash for that purpose.

\subsubsection{Economics}

Capital and operating costs for the installation and operation of a Mer-Cure ${ }^{\mathrm{TM}}$ system for Leland Olds Unit \#1 are presented below in Table 6.2-3. Capital costs include those for sorbent storage, sorbent processing and injection equipment, and were determined from vendor quotes. Equipment costs, including all piping, materials and controls, are estimated to be $\$ 1.1$ million. Installation, including 
site integration, is estimated around $\$ 500,000$. Adding in start-up support and a contingency of 10 percent of capital costs, the overall capital cost of the Mer-Cure ${ }^{T M}$ system is estimated to be about $\$ 1.8$ million or about $\$ 8.20 / \mathrm{kW}_{\mathrm{e}}$.

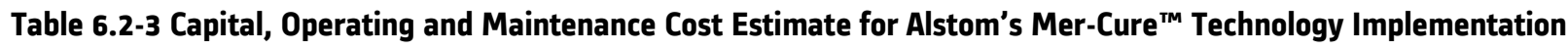
at Leland Olds Unit \#1 for 90 Percent Mercury Reduction

\begin{tabular}{|l|r|}
\hline \multicolumn{2}{|c|}{ Capital Costs Summary } \\
\hline Equipment & $\$ 1,110,000$ \\
\hline Installation including site integration (materials and labor) & $\$ 518,000$ \\
\hline Start-up support & $\$ 18,000$ \\
\hline Contingency & $\$ 163,000$ \\
\hline Total Capital Required (2006) & $\$ 1,799,000$ \\
\hline \$/kW (220 MWe gross) & 8.18 \\
\hline \multicolumn{2}{|c|}{ Operating and Maintenance Costs Summary } \\
\hline Sorbent (\$1.25/lb, 90\% reduction, 79 lb/h, 7,500 hrs) & $\$ 740,625$ \\
\hline Power, Labor and Maintenance & $\$ 115,000$ \\
\hline Waste Disposal & $\$ 0$ \\
\hline Annual O\&M (2006 costs) & $\$ 855,625$ \\
\hline Levelized - 20 year 0\&M Cost (\$/kW) & 5.32 \\
\hline \$MWh & 0.52 \\
\hline
\end{tabular}

Notes:
a) 90 percent mercury removal target
b) Unit is assumed to be base loaded
c) Ash is not utilized or still available for use after carbon injection
d) Installation is with union labor
e) Contingency is calculated at 10 percent of capital cost
f) Levelized costs are calculated assuming 3\% increase per year
g) $220 \mathrm{MW}_{\mathrm{e}}$ gross capacity with 7500 hours operation per year

The predominant component of the operating cost is the sorbent cost. Costs were estimated based on a long-term custom-enhanced activated carbon injection rate conservatively assumed to be 1.58 $\mathrm{lbs} / \mathrm{MMacf}$ or $79 \mathrm{lbs} / \mathrm{hr}$. Unit operation is assumed at 85 percent capacity factor. With these assumptions, the annual sorbent costs are $\$ 740,625$, assuming a delivered sorbent cost of $\$ 1.25 / \mathrm{lb}$. There is a significant uncertainty in the cost for the sorbent because of anti-dumping tariffs being imposed on imported (Chinese) activated carbon and because of anticipated increased demand for activated carbon. The tariff amounts are expected to be around $\$ 0.25$ to $\$ 0.30 / \mathrm{lb}$. This almost doubles the cost of imported Chinese activated carbon which is currently around $\$ 0.30-0.40 / \mathrm{lb}$. The tariffs and increased demand for active carbon may both lead to an increase in the custom-enhanced sorbent costs, even for carbon produced domestically. 
The other component of the operating cost is parasitic power, labor and maintenance and this is estimated to be $\$ 115,000$ annually. The overall operating cost for LOS1 for 90 percent mercury control is $\$ 855,625$ or 0.52 mills $/ \mathrm{kWh}$.

Table 6.2-4 can be used to calculate the operating cost if lower levels of mercury removal are required. For example, if 70 percent reduction is required the sorbent injection rate is 0.77 $\mathrm{lbs} / \mathrm{MMacf}(38.5 \mathrm{lb} / \mathrm{hr})$. If 80 percent reduction is required, the sorbent injection rate is 1.0 $\mathrm{lbs} / \mathrm{MMacf}$ ( $50 \mathrm{lb} / \mathrm{hr})$. A mercury removal versus required sorbent injection rate table is provided in Table 6.2-4 below.

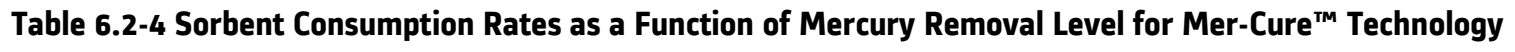
Implementation at Leland Olds Unit \#1

\begin{tabular}{|c|c|c|}
\hline $\begin{array}{c}\text { \% Mercury } \\
\text { Removal }\end{array}$ & $\begin{array}{c}\text { Sorbent } \\
\text { (lb/MMacf) }\end{array}$ & $\begin{array}{c}\text { Sorbent } \\
\text { (lb/hr) }\end{array}$ \\
\hline 60 & 0.64 & 32 \\
\hline 70 & 0.77 & 38.5 \\
\hline 75 & 0.86 & 43 \\
\hline 80 & 1.0 & 50 \\
\hline 90 & 1.58 & 79 \\
\hline 95 & 2.38 & 119 \\
\hline
\end{tabular}

Sensitivity analysis with respect to the mercury removal level required and unit sorbent costs are shown in Figure 6.2-18. These calculations indicate that at a sorbent cost of $\$ 1.25 / \mathrm{lb}$, the operating cost for $90 \%$ mercury control at Basin Electric's Leland Olds Station Unit \#1 using Mer-Cure ${ }^{\mathrm{TM}}$ technology is 0.52 mills/kWh. Corresponding operating cost for 75 percent control is 0.31 mills $/ \mathrm{kWh}$. If sorbent costs increase to $\$ 2.00 / \mathrm{lb}$, the Mer-Cure ${ }^{\mathrm{TM}}$ operating cost increases to $\$ 0.83$ and 0.5 mills/kWh for 90 and 75 percent mercury control respectively.

If a wet scrubber is installed at LOS1, then a portion of the oxidized mercury that escapes the coldside ESP can be removed in the wet scrubber. It is estimated that about 35 percent of the mercury leaving the ESP is in the oxidized form. Assuming a range of 50 to 90 percent removal of the oxidized mercury in the scrubber, we can use Figure 6.2-18 to estimate the amount of reduction that we can expect in the sorbent needed if removal occurs both in the ESP and the wet scrubber. This is estimated to be about 10 to 15 percent. This implies that the overall operating cost if a wet scrubber is installed may be reduced by about 10 percent or to 0.47 mills $/ \mathrm{kWh}$. 


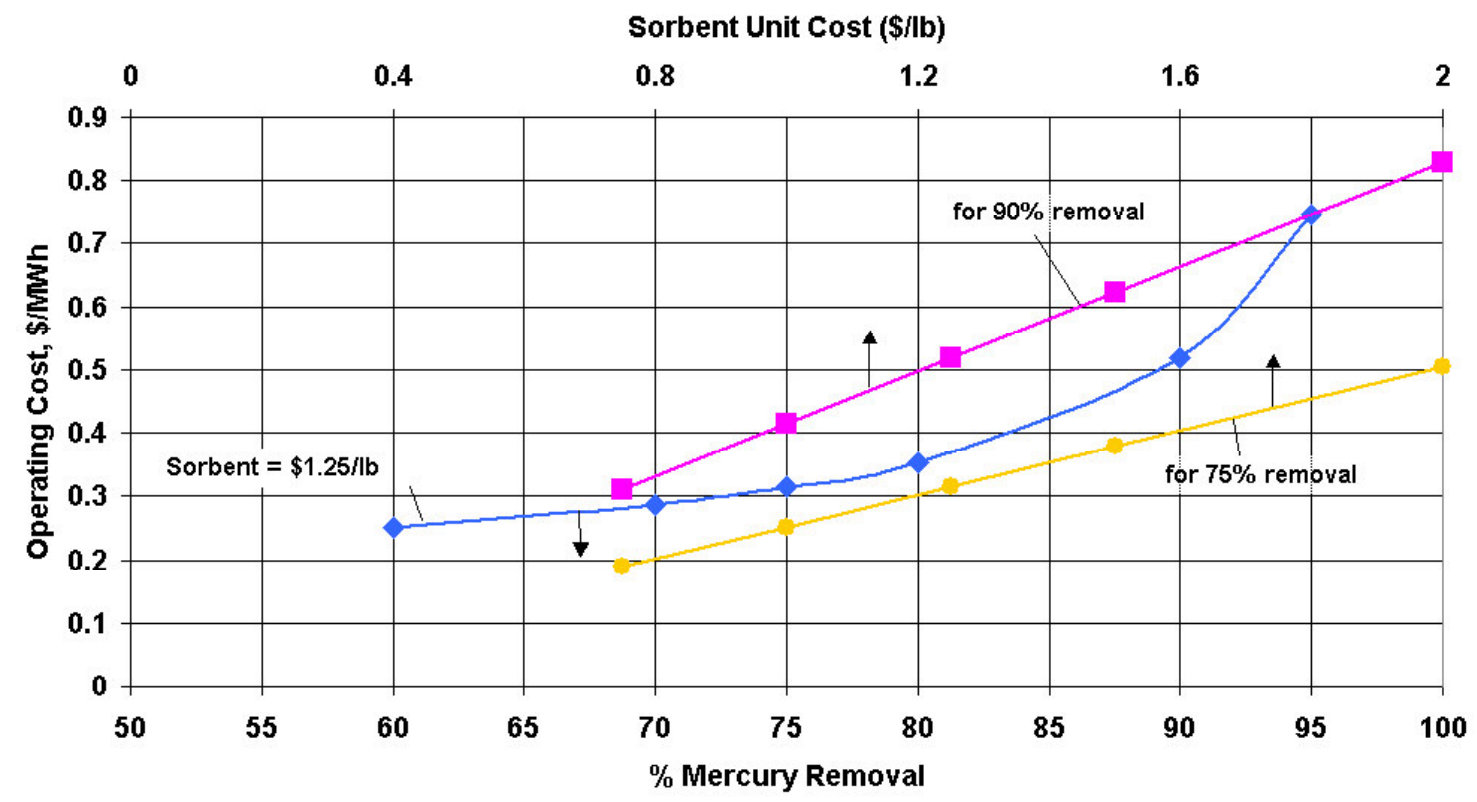

Figure 6.2-18 Sensitivity analysis: Effect of Sorbent Unit Cost and Mercury Removal Required on Operating Cost for Mercury Control for Basin Electric Leland Olds Unit \#1 using Mer-Cure ${ }^{\mathrm{TM}}$ technology $^{-1}$

\subsubsection{Conclusions}

Field demonstration of the Mer-Cure ${ }^{\mathrm{TM}}$ system has been completed at Basin Electric's LOS1. Following is the summary of LOS1 test campaign:

\section{Performance:}

- The long-term performance of Mer-Cure ${ }^{T M}$ system at Basin Electric's LOS1, as measured by both $\mathrm{OH}$ method and CMMs, shows that at an injection rate of $1.4-1.6 \mathrm{lb} / \mathrm{MMacf}, 90$ percent removal of total gaseous mercury was achieved with Mer-Cure ${ }^{\mathrm{TM}}$ system.

\section{Mercury Speciation:}

- The long-term performance data show that at the air heater inlet, mercury was mostly elemental mercury ( 97 percent of total gaseous mercury); the mercury further oxidized at the back-pass to give a total of 77 percent of the mercury as elemental at the ESP outlet.

- During injection of the sorbent, the elemental form of the total gaseous mercury at the ESP outlet further decreased to 63 percent, demonstrating the role of the sorbent as an oxidation catalyst.

- In addition to the above, a predominant portion of the total mercury was captured by the sorbent.

- For boilers with scrubbers, the scrubbers will further remove most of the oxidized mercury at the ESP outlet. As a result, even higher removal efficiency will be achieved. This increase in 
mercury capture due to wet scrubbing can sometimes be limited by re-emission of oxidized mercury from the scrubber.

\section{Economics}

- Overall capital cost of the Mer-Cure ${ }^{\top M}$ system for Leland Olds Unit \#1 is estimated to be about $\$ 1.8$ million or about $\$ 8.2 / \mathrm{kW}_{\mathrm{e}}$.

- The overall operating cost for LOS1 with Mer-Cure ${ }^{\mathrm{TM}}$ for 90 percent mercury control is $\$ 855,625$ or 0.52 mills $/ \mathrm{kWh}$ ( $\$ 8680 / \mathrm{lb} \mathrm{Hg}$ removed), with a delivered sorbent cost of $\$ 1.25$ per pound.

- Sensitivity analysis with respect to the mercury removal level required indicates that if only 75 percent control is required, then the Mer-Cure ${ }^{\mathrm{TM}}$ operating cost is reduced to 0.31 mills $/ \mathrm{kWh}$ ( $\$ 6200 / \mathrm{lb} \mathrm{Hg}$ removed) with a sorbent cost of $\$ 1.25$ per pound. On the other hand, if sorbent costs increase to $\$ 2.00$ per pound, the Mer-Cure ${ }^{\mathrm{TM}}$ operating cost increases to 0.83 and 0.50 mills/kWh ( $\$ 13,860 / \mathrm{lb}$ and $\$ 10,000 / \mathrm{lb} \mathrm{Hg}$ removed) for 90 and 75 percent mercury control respectively.

- If a wet scrubber is installed at LOS1, then a portion of the oxidized mercury that escapes the cold-side ESP can be removed in the wet scrubber. If a wet scrubber is installed, the operating cost with Mer-Cure ${ }^{\mathrm{TM}}$ for 90 percent mercury control may be reduced by about 10 percent or to $0.47 \mathrm{mills} / \mathrm{kWh}$.

Balance of Plant Impacts:

- Observations throughout the long-term testing suggest that injection of Mer-Clean ${ }^{\mathrm{TM}}$ sorbent did not increase the stack opacity during long-term testing.

- Unburned carbon (UBC) was measured for individual ESP hopper fly ash samples collected before and during long-term testing. The UBC showed a slight increase from a baseline of $0.58 \%$ to $0.87 \%$ with sorbent injection. The UBC increase of $0.29 \%$ percentage points is attributed to the injection of sorbent 


\subsection{Portland Unit \#1}

The goals for this Round 2 program, established by DOE/NETL under the original solicitation, were to reduce the uncontrolled mercury emissions by 50 to $70 \%$ at a cost 25 to $50 \%$ lower than the previous target of $\$ 60,000 / \mathrm{lb}$ mercury removed. The enhanced performance objective desired by Reliant Energy and Alstom was to demonstrate greater than 90\% capture of the gaseous mercury in the flue gas by injection of tailored sorbent at a feed rate significantly lower than standard (untreated) activated carbon.

\subsubsection{Site Description and Test Preparation}

Portland Unit \#1 of Reliant Energy is a $172 \mathrm{MW}_{\mathrm{e}}$ wall-fired, pulverized coal (PC) boiler firing medium sulfur eastern bituminous coal and equipped with an ESP as a particulate emission control device. The specific collection area (SCA) of the ESP is $284 \mathrm{ft}^{2} / \mathrm{kacfm}$. Table 1.2-1 previously showed the unit configuration and coal and emissions data for Port1.

The temperatures at the inlet of the air pre-heater ranged between 600 and $640^{\circ} \mathrm{F}$, somewhat lower than normally expected for a typical pulverized coal-fired boiler. The air pre-heater outlet/ESP inlet temperatures ranged from $250^{\circ} \mathrm{F}$ at half load to $280^{\circ} \mathrm{F}$ at full load, also lower than typical operation. The loss-on-ignition (LOI) of the fly ash collected in the ESP hoppers varied between 10 to $12 \%$. The plant is fully equipped to provide the operational data including flue gas composition, stack opacity, and air heater flue gas temperatures.

Portland Unit \#1 was chosen for this evaluation because it fires an eastern bituminous coal and is configured with a cold-side ESP that is somewhat smaller than desirable. The Reliant Energy test program was unique and challenging in that it is a cycling unit operating between a half load (75 $\mathrm{MW}_{\mathrm{e}}$, typically from midnight to 6 am during weekdays and all day during weekends) and a full load (170 $\mathrm{MW}_{\mathrm{e}}$ ) depending on the market demand. The unit was firing eastern bituminous coals from two different mines containing varying amounts of mercury. The unit was also operated in two different firing modes in order to meet seasonal $\mathrm{NO}_{\mathrm{x}}$ emissions requirements - ozone season mode and non-ozone season mode. These plant-specific variations were taken into account in executing the demonstration program.

Several technical risks associated with the Mer-Cure ${ }^{T M}$ technology would be addressed by the demonstration testing at Port1. These include:

- Sorbent effectiveness with high flue gas $\mathrm{SO}_{3}$ levels.

- Sorbent survivability and activity retention upon exposure to the high temperature flue gas upstream of the air heater

- Long-term and continuous operation of the sorbent processing, distribution and injection system

- Potential for increased opacity due to slip of the fine sorbent particles through the ESP

- Potential for increased air pre-heater fouling 
The test campaign was also conducted taking the targets of mercury regulation in Pennsylvania into consideration. The regulation calls for a two-phase reduction: Phase 1 starting January 1, 2010, and Phase 2 starting January 1, 2015. The removal targets are specified either in terms of (i) the amount of mercury per electricity generated or (ii) the percentage removal based on the amount of mercury input. According to the regulation, the Phase 1 limit for existing PC-fired units is $0.024 \mathrm{lb} / \mathrm{GWh}$, or $80 \%$ as measured from the mercury content in the coal; the Phase 2 limit is $0.012 \mathrm{lb} / \mathrm{GWh}$, or $90 \%$ as measured from the mercury content in coal. Converted to the volume concentration in the flue gas, the Phase 1 limit of $0.024 \mathrm{lb} / \mathrm{GWh}$ is approximately $3.2 \mu \mathrm{g} / \mathrm{m}^{3}$ at Portland Station, and the Phase 2 limit of $0.012 \mathrm{lb} / \mathrm{GWh}$ is $1.6 \mu \mathrm{g} / \mathrm{m}^{3}$.

In preparation for the design of the site-specific portion of the Mer-Cure ${ }^{\mathrm{TM}}$ system, site visits were made to Portland Station. During the visits, more detailed information was collected such as that on the injection location (e.g., duct dimensions, turning vane arrangement), workspace, sampling port locations, trailer placement, equipment placement and the availability of utilities at work locations.

Extensive CFD studies were conducted to design the injection lances for the Mer-Cure ${ }^{\mathrm{TM}}$ system. The flue gas stream from the Portland Unit \#1 boiler is split into two streams. Based on the calculated flow distributions, the numbers of injection ports, injection lances and their nozzles were determined. In March 2006, Reliant Energy completed installation of the injection ports.

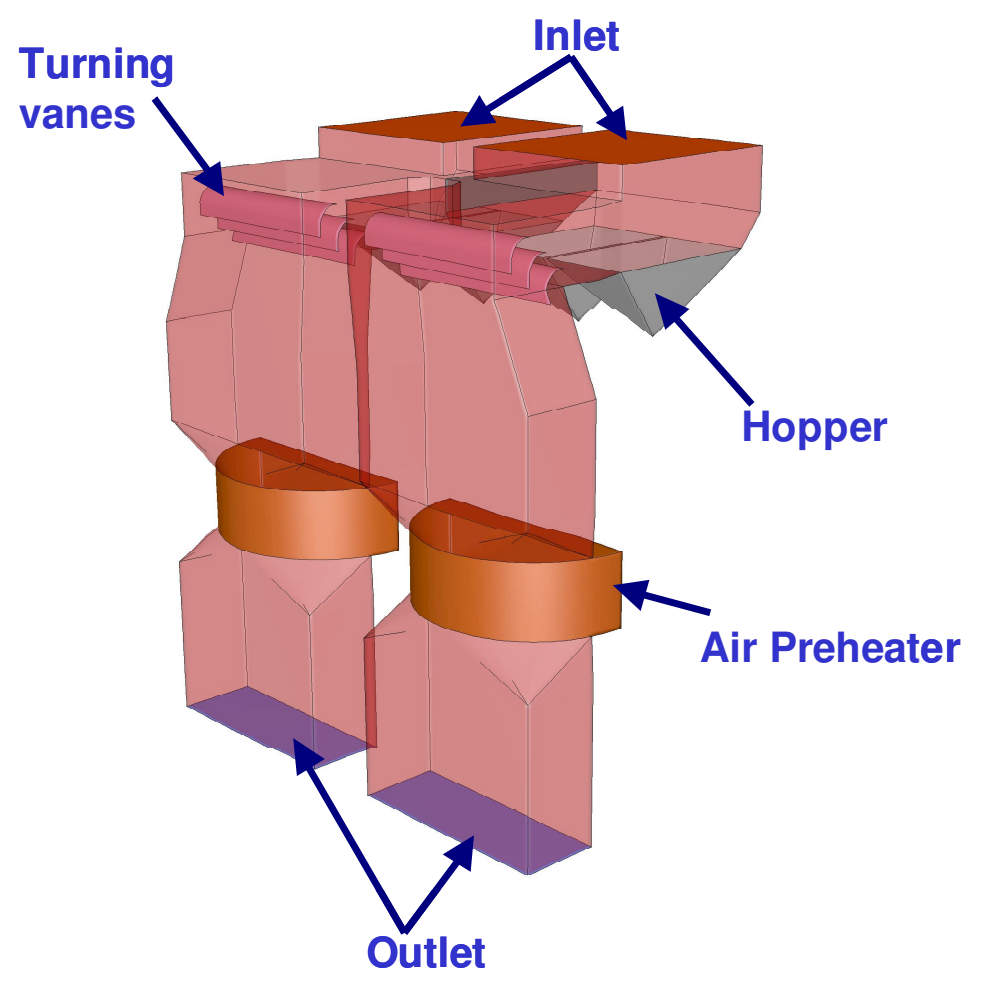

Figure 6.3-1 Modeled Injection Region for Portland Unit \#1

Appropriate distribution of sorbent into the flue gas stream is critical for maximum contact between the sorbent and the mercury in the flue gas stream. Flow modeling studies using Fluent CFD package were conducted using specific boiler design data to better determine the location and the 
number of injection lances. Mer-Cure ${ }^{T M}$ technology requires injection of sorbent into a location upstream air heaters. In order for maximum in-flight capture of mercury, the mixing characteristics of sorbent with flue gas at the boiler exit have been carefully examined by CFD.

Figure 6.3-1 shows the modeled flue gas flow region for Portland Unit \#1, from the economizer inlet plane ("Inlet" in the figure) through the air heater outlet plane ("Outlet" in the figure). The geometric representation of the air heater and ductwork also models flow disturbances in the flue gas flow path, including turning vanes and the economizer hopper.

Figure 6.3-2 shows a CFD output of the flue gas flow distribution from the economizer inlet through the air heater outlet. It clearly depicts that the flow is skewed towards the lower section of the duct after the economizer hopper. In fact, the upper one-third of the total cross sectional area accounts for only $10 \%$ of the total mass flow. The turning vanes were installed to attempt to distribute the flue gas flow more evenly in the vertical duct to the air heater inlet. The turning vanes do distribute the flue gas more evenly, but the flow is still concentrated in rear of the vertical duct going to the air heater. This maldistribution could significantly impact the design and arrangement of nozzles on injection lances for uniform distribution of sorbent particles in the flue gas stream.
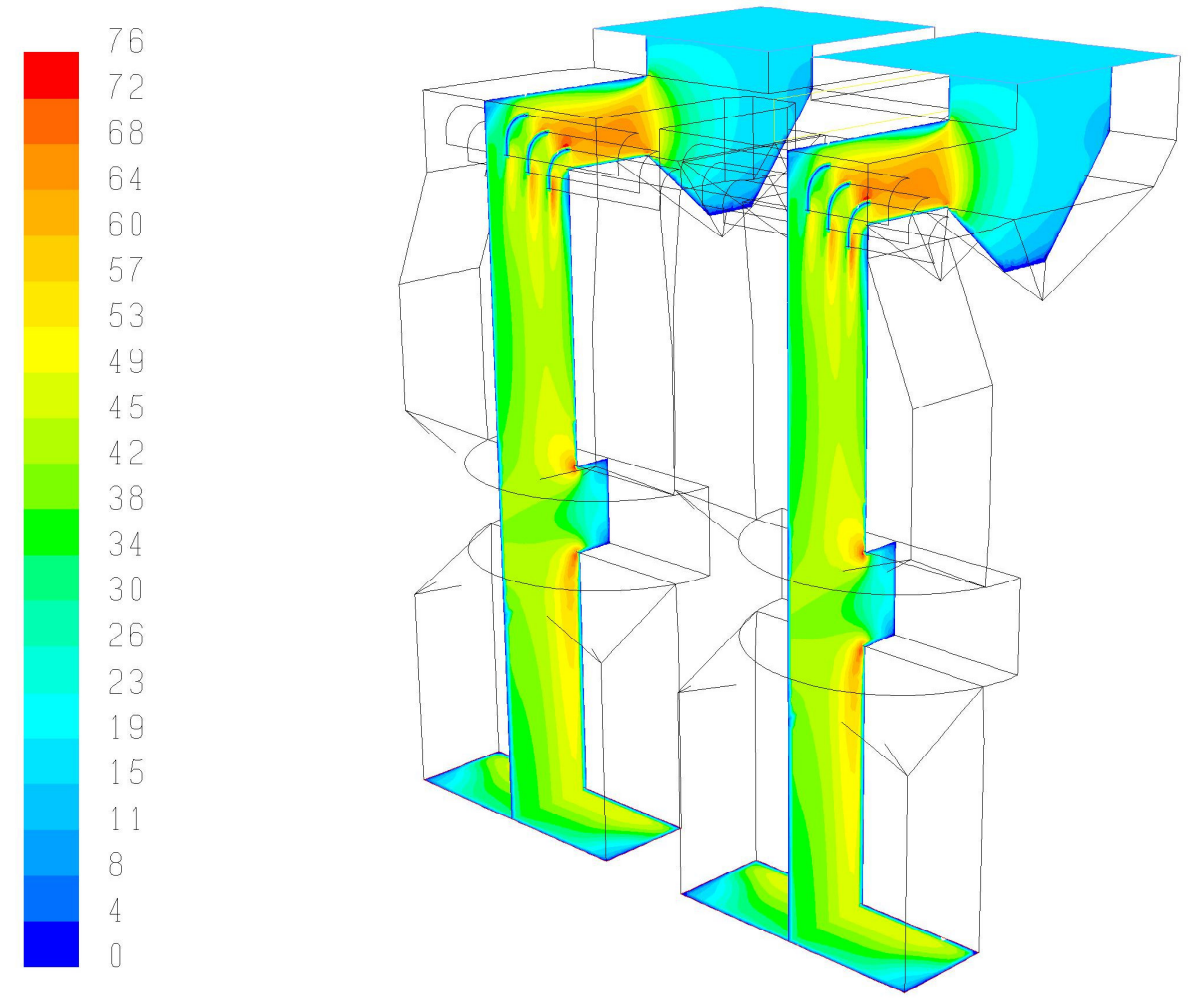

Figure 6.3-2 Flow Distribution Results for Portland Unit \#1 Sorbent Injection Location

Based on this flow distribution, a lance injection system was designed for Portland Unit \#1 targeting proportional distribution of sorbent with the flue gas volumetric flow. The lance design parameters such as the number of lances, nozzle size, number and location for each of the lances were 
determined based on these studies to create immediate and uniform mixing of sorbent as it is introduced into the flue gas stream. Lances for the demonstration project were fabricated according to the final design.

The completed mobile MerCure $^{\mathrm{TM}}$ demonstration trailer was shipped to Portland Station in March 2006. The Mer-Cure ${ }^{\mathrm{TM}}$ system was placed on the east side of the Port1 ID fans. The sorbent storage and delivery system was assembled at the site, the sorbent processing system was placed close to the sorbent injection system and was connected to the storage system by 4 -inch

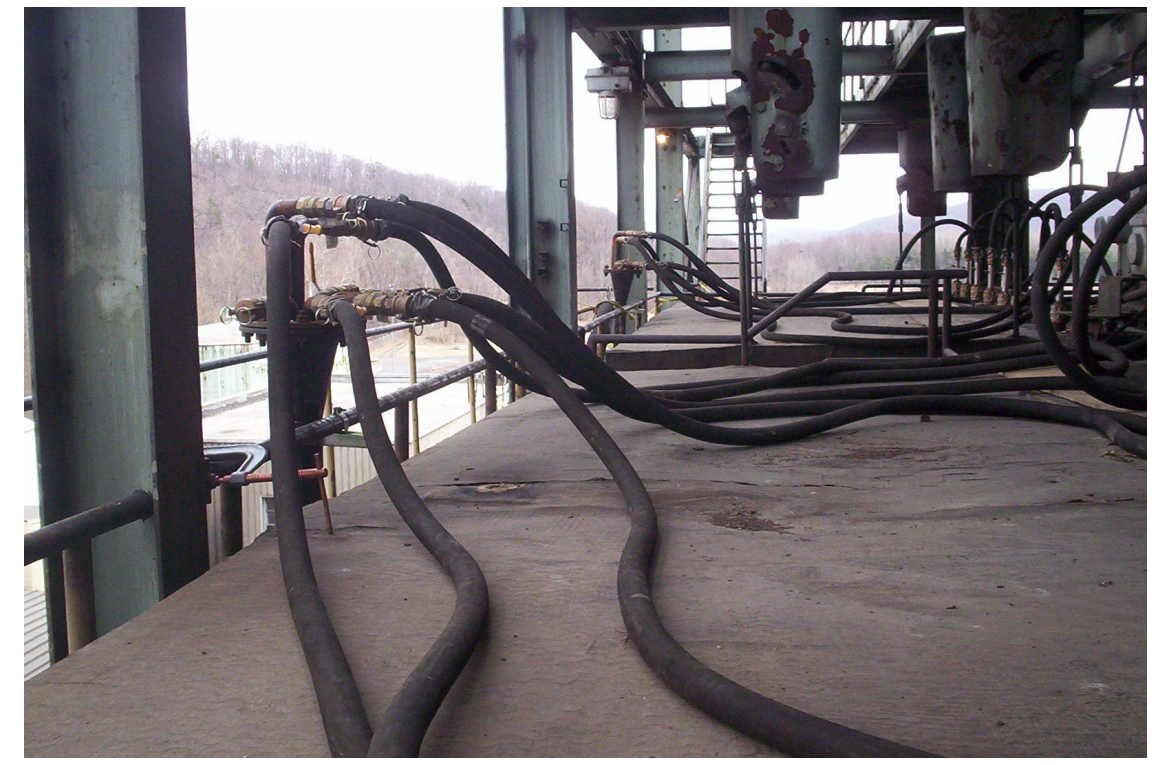
flexible hoses.

Figure 6.3-3 Sorbent Distribution and Injection System at the Economizer Outlet

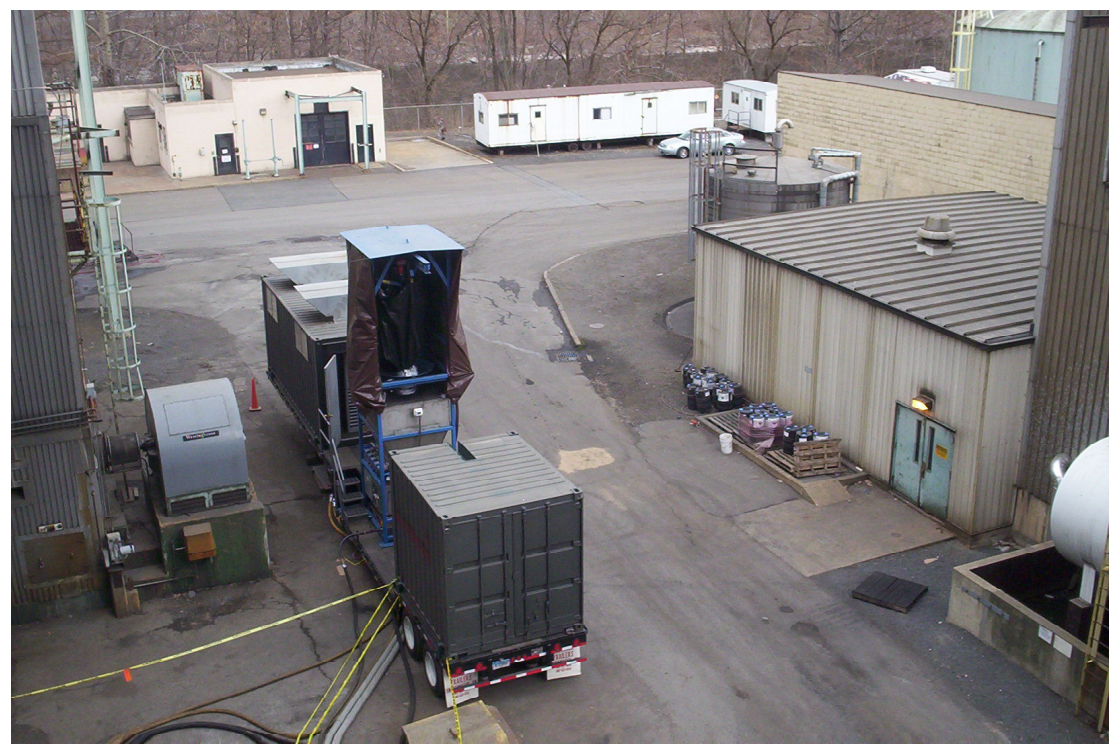

The sorbent distribution system and injection lances were installed at the injection location as shown in Figure 6.3-3, and connected to the delivery system by 4 -inch flexible hoses. The injection and distribution systems were secured to the boiler structure. Figure 6.3-4 shows the MerCure $^{\mathrm{TM}}$ delivery system after installation at Portland Station.

Figure 6.3-4 Mer-Cure ${ }^{\mathrm{TM}}$ System After Installation

Figure 6.3-5 shows a schematic layout of the Portland Station showing various testing locations. The boiler has two Ljungstrom ${ }^{\mathrm{TM}}$ air heaters connected to an ESP. All of the flue gas coming out of the boiler was treated by Mer-Cure ${ }^{\mathrm{TM}}$ system with its sorbent injection at the economizer outlet. 


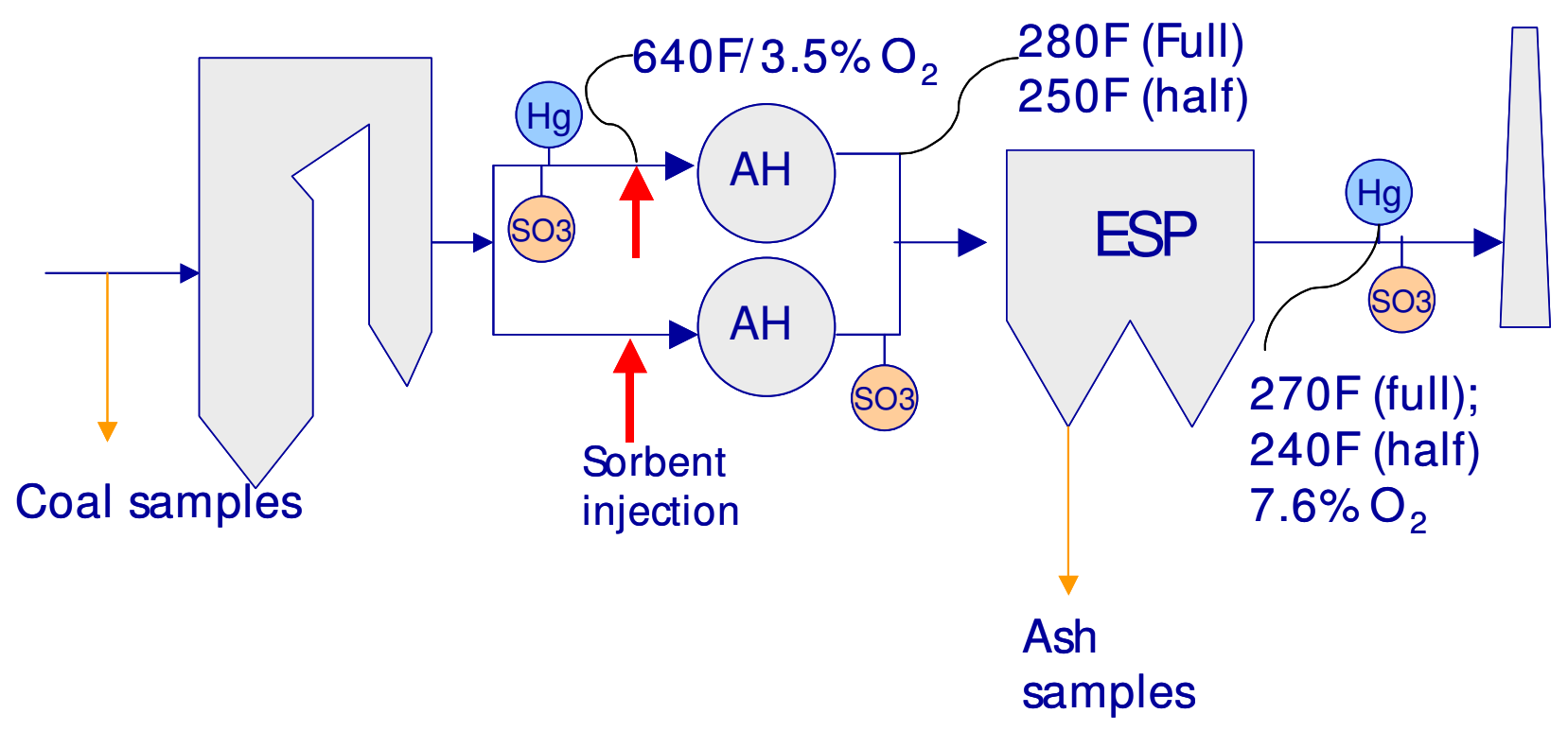

\section{Figure 6.3-5 Sorbent Treatment and Sampling Locations, Portland Unit \#1}

One of the unique aspects of Alstom's Mer-Cure ${ }^{\mathrm{TM}}$ technology is that the sorbent injection is performed between the economizer and the air heater. In typical utility boilers, temperatures at this location are around 600 to $800^{\circ} \mathrm{F}$. The sorbents used in the Mer-Cure ${ }^{\mathrm{TM}}$ technology are activated carbon-based. Different halogenated components are added to the activated carbon and the material processed to make the final sorbent. During this test program, several such formulations were tested (Mer-Clean 2, 4, 6, and three variations of 8). These formulations differed from each other in terms of the added components, amounts of the added components, and manufacturing process conditions.

Figure 6.3-6 shows the variation of sulfur and mercury contents from composite daily coal samples obtained over the test period. Analysis results show that the mercury content in the fuel varied widely from sample to sample (9.01 $\pm 3.00 \mathrm{lb} / \mathrm{TBtu})$ and also varied much more than the sulfur content (3.04 $\pm 0.22 \mathrm{lb} / \mathrm{MMBtu}$ ). The coefficients of variation for mercury and sulfur content were $25.9 \%$ and $7.2 \%$, respectively. This variation comes from the fact that Portland Station fuels are shipped from two different mines - Federal \#2 and Bailey. The variation of coal mercury content possible between these two mines is seen dramatically in the consecutive coal samples on March 24 (Federal \# 2 with $10.1 \mathrm{lb} / \mathrm{TBtu}$ ) and on March 25 (Bailey with $3.7 \mathrm{lb} / \mathrm{TBtu}$ ).

Table 6.3-1 lists the average coal properties determined by analysis of coal composite samples. A total of 52 composite coal samples were collected and analyzed from the four mills of Portland Station Unit \#1 during the test campaign. The average mercury content of the coal and its standard deviation have been determined to be $0.125 \mu \mathrm{g} / \mathrm{g}$ dry coal, and $0.041 \mu \mathrm{g} / \mathrm{g}$ dry coal, respectively. The average chlorine content of the coal was 1,085 ( \pm 169$)$ ppm on a dry basis. 


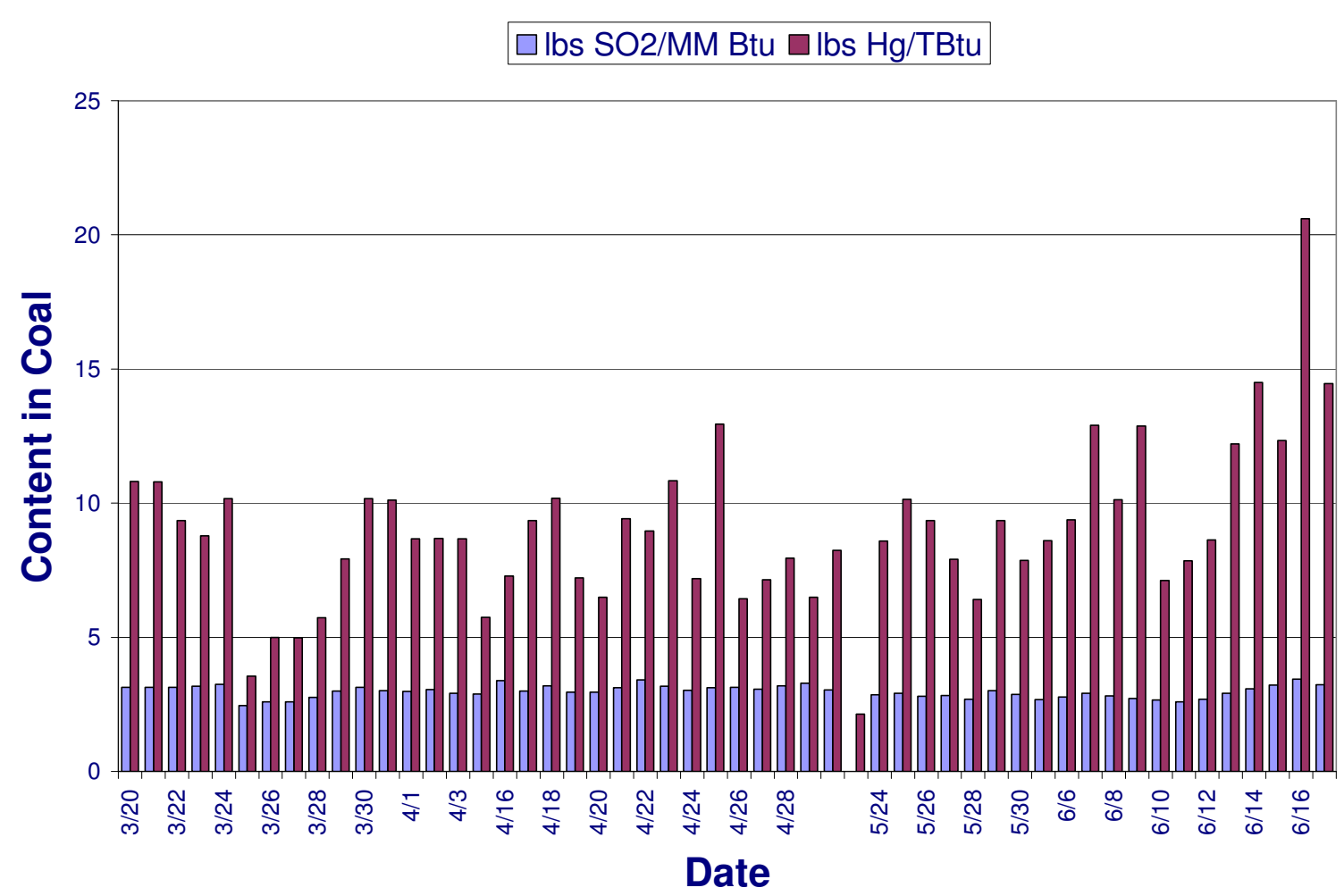

Figure 6.3-6 Daily Composite Sample Variation in Mercury and Sulfur Content in Coal from Portland Unit \#1

Table 6.3-1 Reliant Energy Fuel Properties (Average)

\begin{tabular}{|l|c|c|}
\hline Proximate analysis & As received & Dry basis \\
\hline Total moisture (\%) & 6.22 & $\mathrm{~N} / \mathrm{A}$ \\
\hline Volatile matter (\%) & 31.85 & 33.97 \\
\hline Fixed Carbon (\%) & 54.44 & 58.05 \\
\hline Ash (\%) & 7.48 & 7.98 \\
\hline HHV (BTU/lb) & 13,002 & 13,864 \\
\hline Ultimate analysis & As received & Dry basis \\
\hline Moisture (\%) & 6.22 & $\mathrm{~N} / \mathrm{A}$ \\
\hline Carbon (\%) & 70.79 & 75.49 \\
\hline Hydrogen (\%) & 4.89 & 5.21 \\
\hline Oxygen (\%) & 7.23 & 7.43 \\
\hline Nitrogen (\%) & 1.41 & 1.51 \\
\hline Sulfur (\%) & 1.98 & 2.11 \\
\hline Chlorine (ppmw) & $1,016 \pm 158$ & $1,085 \pm 169$ \\
\hline Ash (\%) & 7.48 & 7.98 \\
\hline Total (\%) & 100.00 & 100.00 \\
\hline Hg ( $\mu$ g/g dry coal) & N/A & $0.125 \pm 0.041$ \\
\hline Hg (lb/TBTU) & $9.01 \pm 3.00$ & $9.01 \pm 3.00$ \\
\hline
\end{tabular}


Table 6.3-2 lists the tasks carried out to complete the Reliant Energy test campaign and their associated timeline. As listed, the long-term testing was conducted over two consecutive test periods: non-ozone season testing and ozone season testing. At the Portland Station, ozone season starts on May 1 and ends on September 30. During ozone season, the boiler is operated with deeper air staging in order to more aggressively control $\mathrm{NO}_{\mathrm{x}}$ emissions. This change in boiler operating condition could affect mercury emission level by changing the unburned carbon content in the ash. In order to investigate its effect, the long-term testing period was broken down into two periods, covering both non-ozone season and ozone season. During each of the test periods, the Mer-Cure ${ }^{\mathrm{TM}}$ system was continuously operated except during outages.

The non-ozone season testing was further broken into two test periods: (i) April 13 through April 22 for sorbent trap method evaluation and (ii) April 23 through April 28 for Mer-Cure ${ }^{\mathrm{TM}}$ system evaluation. The first non-ozone season test period was dedicated mostly for a test program designed to compare the sorbent trap method against CMMs and $\mathrm{OH}$ methods. During the period, the Mer-Cure ${ }^{\mathrm{TM}}$ system was operated at varying injection rates to achieve moderate ( 2 to $3 \mu \mathrm{g} / \mathrm{m}^{3}$ ) and relatively high ( 8 to $10 \mu \mathrm{g} / \mathrm{m}^{3}$ ) concentrations of total mercury. (The low concentration test series was conducted during the ozone-season long-term test period.) The piggyback test program, conducted by the UND EERC, was organized by Reliant Energy with additional financial support by the DOE/NETL and EPRI. The results have been presented elsewhere. ${ }^{12}$

Table 6.3-2 Reliant Energy Test Campaign Timeline

\begin{tabular}{|c|c|}
\hline Tasks & Timeline \\
\hline Baseline measurement & March 20 - March 24, 2006 \\
\hline Parametric Testing & March 25 - April 3, 2006 \\
\hline Long-term testing (non-ozone, sorbent trap) & April 13 - April 22, 2006 \\
\hline Long-term testing (non-ozone, Mer-Cure ${ }^{\mathrm{TM}}$ ) & April 23 - April 28, 2006 \\
\hline Scheduled outage & May 12 - May 24, 2006 \\
\hline Long-term testing (ozone, $1^{\text {st }}$ half, LT1) & May 25 - June 1, 2006 \\
\hline Forced outage & June 1 - June 4, 2006 \\
\hline Long-term testing (ozone, $2^{\text {nd }}$ half, LT2) & June 5 - June 12, 2006 \\
\hline System removal & June 13 - June 17, 2006 \\
\hline
\end{tabular}

Baseline measurements of mercury concentration in the flue gas were performed at the air heater inlet (pre-sorbent injection) and precipitator outlet. Validation data using the $\mathrm{OH}$ method was also obtained for the baseline condition. Subsequent to the baseline testing, approximately ten days of parametric testing was conducted. Tests included eight enhanced activated carbon sorbents.

In the parametric tests, Mer-Clean ${ }^{\mathrm{TM}} 8$ gave the best performance in terms of mercury removal versus sorbent injection rate. Mer-Clean ${ }^{\mathrm{TM}} 8$ was chosen for the long-term testing.

Following the baseline and parametric testing in March and April, the long-term testing was scheduled to begin in April and extended through June because of both a scheduled and a forced outage. With these delays, the four-week field demonstration was completed in early June. 
During the long-term demonstration, the boiler load varied between a half load and a full load depending on the power demand. The control algorithm of the Mer-Cure ${ }^{\mathrm{TM}}$ system was designed to adjust the sorbent injection rate based on the boiler load signal from the control room. This maintained a constant sorbent concentration in the flue gas.

\subsubsection{Baseline Testing Results}

The Reliant Energy testing at Portland Unit \#1 started with a week of baseline mercury measurement using CMMs. Figure 6.3-7 shows the gaseous total mercury levels measured by CMMs at the air heater inlet and the ESP outlet measured during the baseline test period. Also presented are the gaseous mercury levels calculated from the mercury content of the coal (green horizontal bars) and the $\mathrm{OH}$ measurements at the air heater inlet (open squares) and ESP outlet (open circles) during the period.

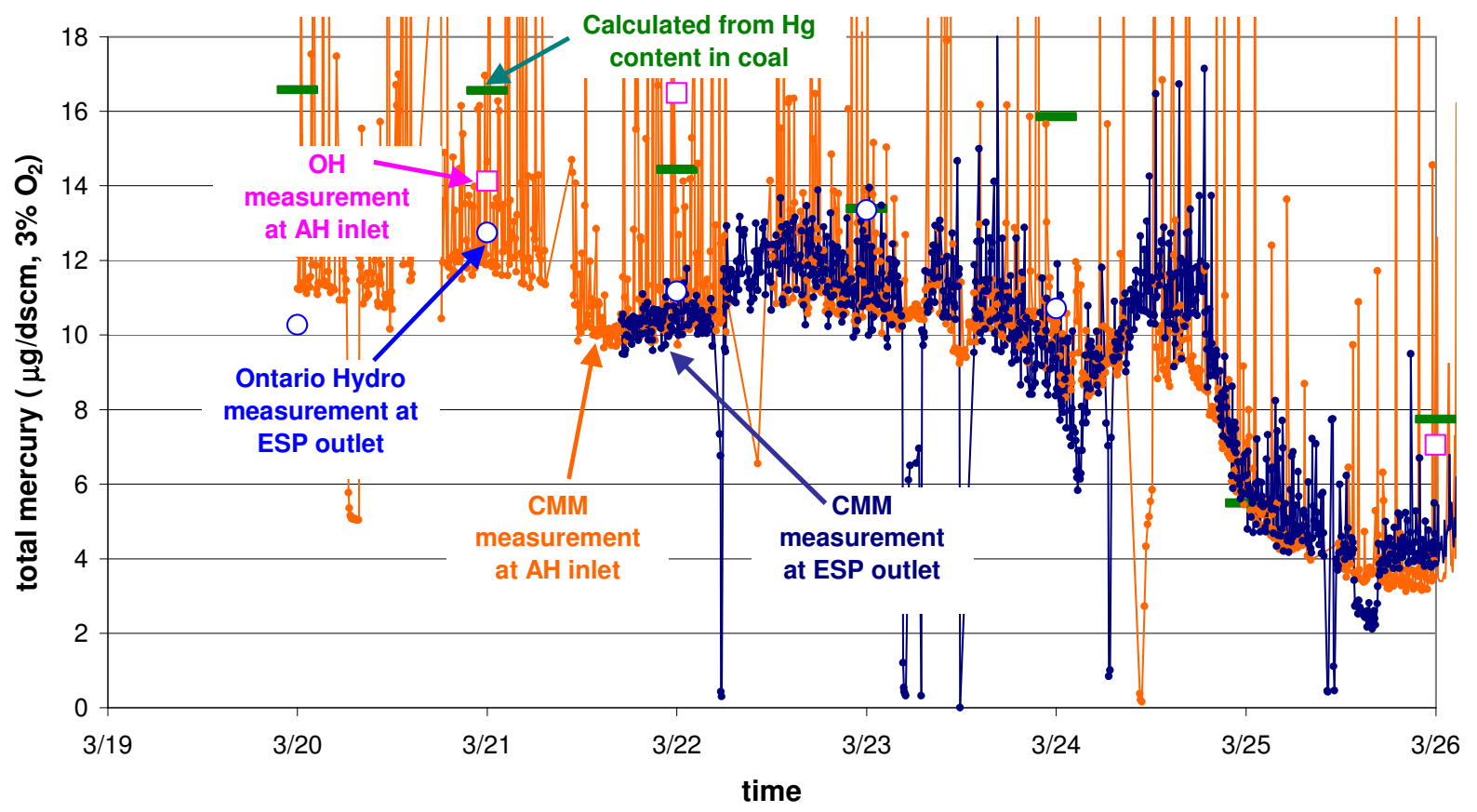

Figure 6.3-7 Gaseous Mercury Measurements at the ESP Outlet (navy blue) and Air Heater Inlet (orange)

Comparison of the coal data with the $\mathrm{OH}$ data shows that there is no native capture between the boiler and the air heater inlet. The CMM measurement at the air heater inlet is $25 \%$ lower than the $\mathrm{OH}$ measurement. The CMM measurement at the ESP outlet, however, agrees with the $\mathrm{OH}$ measurement. During the period, the baseline gaseous mercury levels varied widely also ranging from $3 \mu \mathrm{g} / \mathrm{m}^{3}$ to $16 \mu \mathrm{g} / \mathrm{m}^{3}$. The reported concentrations are vapor phase mercury levels corrected to $68^{\circ} \mathrm{F}$ and $3 \% \mathrm{O}_{2}$.

The wide fluctuation observed during baseline measurement suggested that an average mercury level calculated over the baseline measurement period is not an appropriate basis for calculation of mercury removal efficiency during parametric testing of the Mer-Cure ${ }^{T M}$ technology. As shown in Figure 6.3-7, however, the agreement between the air heater inlet and ESP outlet CMM 
measurements indicates that, for the purpose of evaluating the mercury removal performance, the air heater inlet CMM measurement could be used as a substitute for the uncontrolled baseline mercury emission level at the ESP outlet.

\subsubsection{Parametric Testing Results}

Figure 6.3-8 shows a snapshot of changes in gaseous mercury levels at the air heater inlet and the ESP outlet during parametric testing at Portland Station. The ESP outlet measurements show that approximately one third of the total gaseous mercury was in elemental form throughout the parametric testing period. Before injection (between 0:00 and 08:00 on 3/26), the CMM readings for total mercury at the air heater inlet and the ESP outlet were approximately the same. At around 9:30, the Mer-Cure ${ }^{T M}$ system was turned on and Mer-Clean ${ }^{T M} 8$ was injected at $6.6 \mathrm{lb} / \mathrm{MMacf}$ (test condition 1). After 4 hours of continuous injection, the total mercury level at the ESP outlet leveled off at $1 \mu \mathrm{g} / \mathrm{m}^{3}$, giving $75 \%$ reduction. The injection rate was then reduced to $2.8 \mathrm{lb} / \mathrm{MMacf}$ (test condition 2) at 19:30, and the ESP outlet reading increased to $1.6 \mu \mathrm{g} / \mathrm{m}^{3}$ giving $55 \%$ reduction. The parametric testing was continued in this fashion with various sorbents (Mer-Clean ${ }^{\mathrm{TM}}$ 2, 4, 6, 9 and variations of 8 ) at a range of sorbent feed rates and under non-ozone season operations.

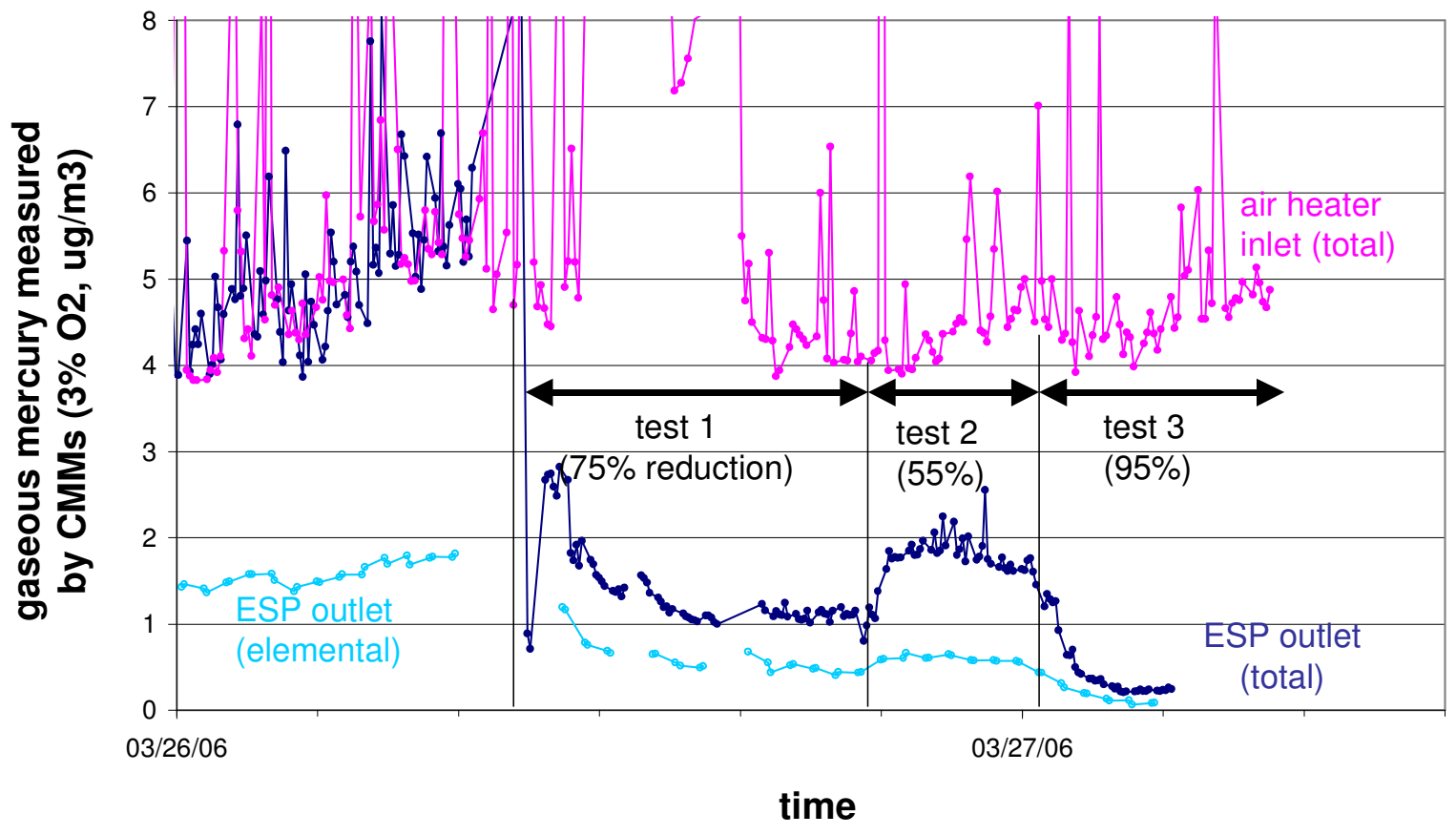

Figure 6.3-8 CMM Measurements at the Air Heater Inlet and ESP Outlet During Parametric Testing

The parametric test performance results are summarized in Figure 6.3-9. In the figure, mercury removal efficiency is shown as a function of the sorbent feed rate (in lb/MMacf, or pounds per million actual cubic feet, where the "actual" condition refers to the actual ESP outlet condition, i.e., $270^{\circ} \mathrm{F}$ and $7.6 \% \mathrm{O}_{2}$ ). The reported removal efficiency was calculated with the air heater inlet CMM concentration of gaseous mercury as the basis for uncontrolled emissions. The graph was constructed based on data collected while the boiler was operated at a full load. 


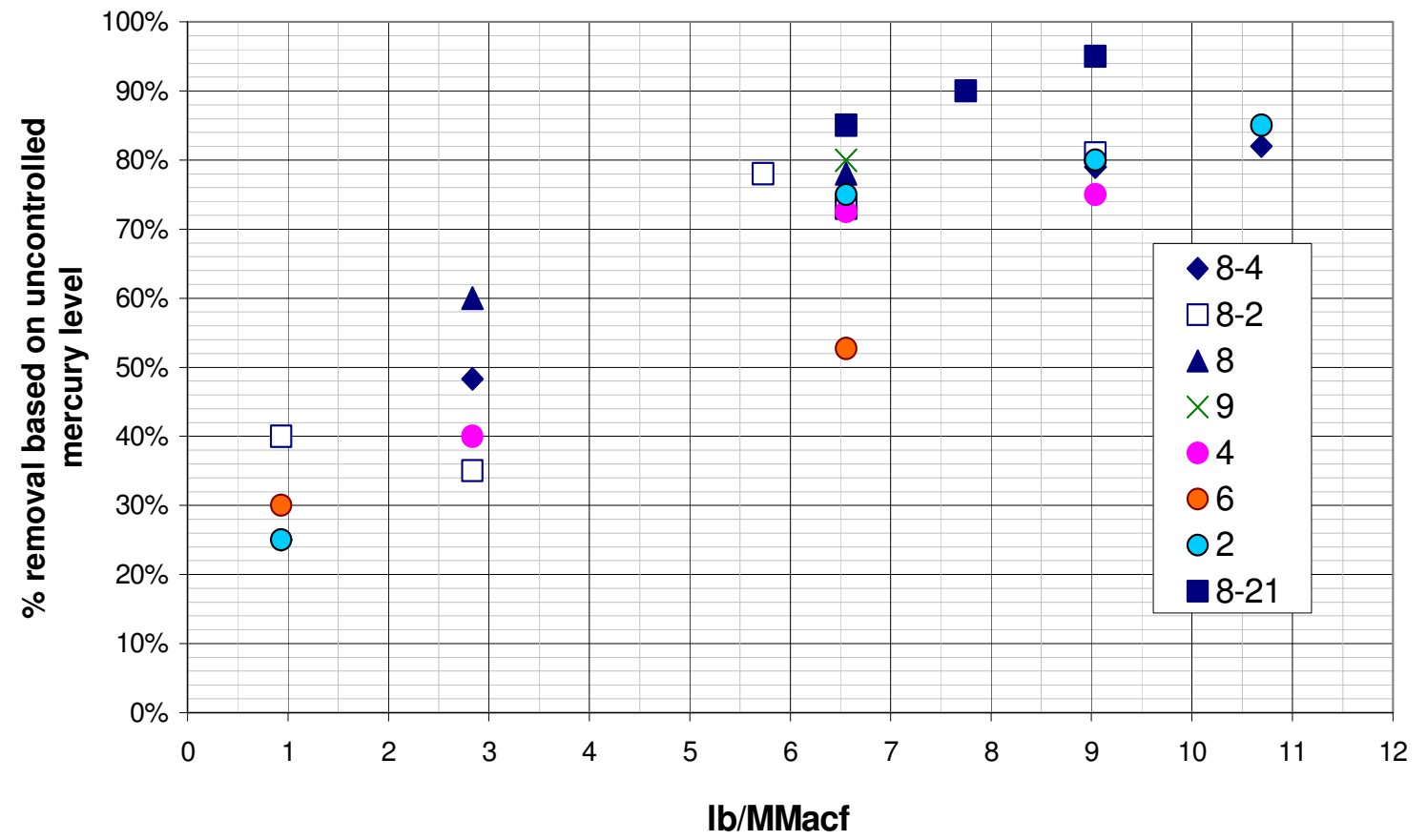

Figure 6.3-9 Full Load Parametric Test Summary of Mer-Cure ${ }^{\mathrm{TM}}$ System with Various Mer-Clean ${ }^{\text {TM }}$ Sorbents

Among the Mer-Clean ${ }^{T M}$ sorbents tested, Mer-Clean ${ }^{T M}$ 8-21 demonstrated the best performance, exhibiting $90 \%$ reduction at $7.7 \mathrm{lb} / \mathrm{MMacf}$. This is a higher injection rate than was necessary at the previous two sites, which is believed to be due to $\mathrm{SO}_{3}$ in the flue gas. $\mathrm{SO}_{3}$ molecules compete with $\mathrm{Hg}$ for active sites on sorbent particles, inhibiting $\mathrm{Hg}$ capture. Measurement of $\mathrm{SO}_{3}$ was carried out during the long-term test period to understand the impact of $\mathrm{SO}_{3}$ on the Mer-Cure ${ }^{\mathrm{TM}}$ system performance.

\subsubsection{Long-Term Testing Results}

The long-term demonstration program was broken into two test periods. Upon request from Reliant Energy, the long-term testing was conducted over two consecutive test periods: non-ozone season testing and ozone season testing. At the Portland Station, ozone season starts on May 1 and ends on September 30. During ozone season, the boiler is operated with deeper air staging in order to more aggressively control $\mathrm{NO}_{\mathrm{x}}$ emissions. This change in boiler operating condition could affect mercury emission level by changing the unburned carbon content in the ash. In order to investigate its effect, the long-term testing period was broken down into two periods, covering both non-ozone season and ozone season. During each of the test periods, the Mer-Cure ${ }^{\mathrm{TM}}$ system was continuously operated except during outages.

The non-ozone season testing was further broken into two test periods:

- April 13 through April 22 for sorbent trap method evaluation, and

- April 23 through April 28 for Mer-Cure ${ }^{T M}$ system evaluation. 
The first non-ozone season test period was dedicated mostly for a test program designed to compare the sorbent trap method against CMMs and $\mathrm{OH}$ methods. During the period, the Mer-Cure ${ }^{\mathrm{TM}}$ system was operated at varying injection rates to achieve moderate $\left(2\right.$ to $3 \mu \mathrm{g} / \mathrm{m}^{3}$ ) and relatively high (8 to $10 \mu \mathrm{g} / \mathrm{m}^{3}$ ) concentrations of total mercury. An addition test series with low concentration of total mercury was conducted during the ozone-season long-term test period. Reliant Energy organized the piggyback test program, conducted by the UND EERC, with additional financial support by the DOE/NETL and EPRI. The results evaluated the use of sorbent traps as a mercury reference test method and have been presented elsewhere. ${ }^{13}$

Figure 6.3-10 shows the gaseous mercury (total) levels continuously measured at the air heater inlet and ESP outlet during non-ozone, long-term Mer-Cure ${ }^{T M}$ demonstration period. Also shown in the figure are the mercury levels calculated assuming all of the mercury in the coal were to stay in the flue gas as gas phase mercury. The mercury level thus calculated from daily coal samples varied from $10 \mu \mathrm{g} / \mathrm{m}^{3}$ to $21 \mu \mathrm{g} / \mathrm{m}^{3}$. As a result, the air heater inlet mercury (total) levels varied widely between $5 \mu \mathrm{g} / \mathrm{m}^{3}$ and $14 \mu \mathrm{g} / \mathrm{m}^{3}$. These levels indicate that up to $30 \%$ of the total mercury in the coal was captured between the boiler and the air heater inlet during this period.

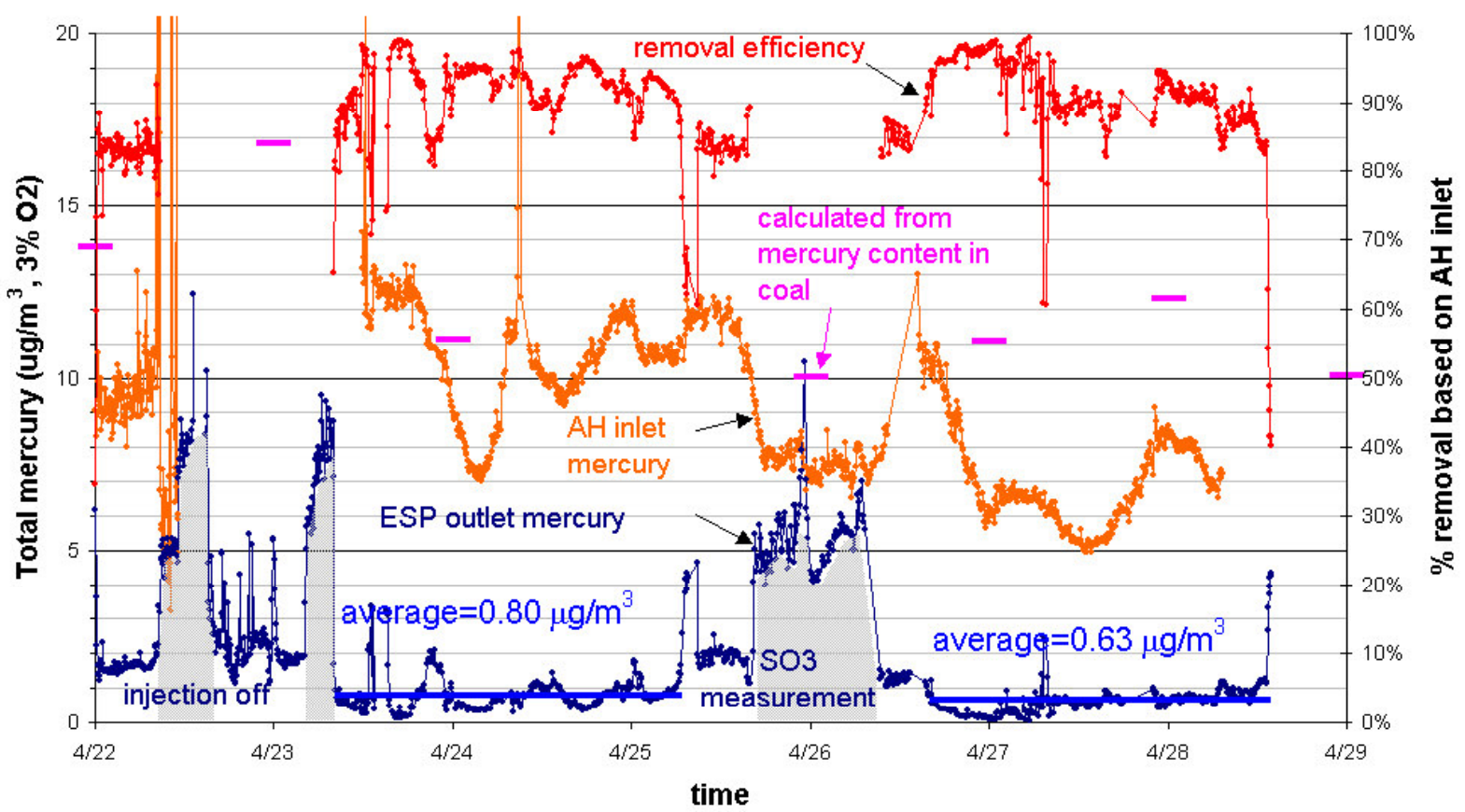

Figure 6.3-10 Long-term Demonstration Performance of Mer-Cure ${ }^{\mathrm{TM}}$ with Non-Ozone Season Operation

During the demonstration, the boiler load varied between half load and full load depending on the power demand. The control algorithm of the Mer-Cure ${ }^{\mathrm{TM}}$ system was designed to adjust the sorbent injection rate based on the boiler load signal from the control room. This maintained a constant sorbent concentration in the flue gas. 
Except for the time intervals when operation of the Mer-Cure ${ }^{T M}$ system was briefly interrupted (shown in grey blocks in Figure 6.3-10), the Mer-Cure ${ }^{\mathrm{TM}}$ system was operated at approximately 8.5 $\mathrm{lb} / \mathrm{MMacf}$ and was able to control the ESP outlet mercury level below $1.6 \mu \mathrm{g} / \mathrm{m}^{3}$, or below 0.012 $\mathrm{lb} / \mathrm{GWh}$. In fact, the average gaseous mercury level was $0.8 \mu \mathrm{g} / \mathrm{m}^{3}$ from April 23 through April 25, and $0.63 \mu \mathrm{g} / \mathrm{m}^{3}$ from April 26 through April 28. This level corresponds to over $90 \%$ of the air heater inlet mercury (total gaseous) as shown in Figure 6.3-10. Based on the mercury content of the coal, the removal efficiency is well above $90 \%$. The test performance in this period demonstrates that the Mer-Cure ${ }^{\mathrm{TM}}$ system can meet and exceed both of the removal targets specified in the utility boiler mercury regulation from the Pennsylvania Department of Environmental Protection.

With the Mer-Cure ${ }^{T M}$ system, the project team could successfully achieve all of the proposed removal targets at Portland Station 1. The sorbent injection rate required to achieve the target of $90 \%$ reduction - about $7.7 \mathrm{lb} / \mathrm{MMacf}$ from parametric testing - was, however, significantly higher than that in the previous two test campaigns. Field data as well as laboratory data from other test programs suggest that there is a strong correlation between $\mathrm{SO}_{3}$ concentration in the flue gas stream and mercury sorbent performance. The presence of $\mathrm{SO}_{3}$ tends to deteriorate performance of sorbent injection-based mercury control technologies. The sorbent active sites are believed to be bound more preferably by $\mathrm{SO}_{3}$ than by mercury. Also, $\mathrm{SO}_{3}$ is believed to displace previously adsorbed mercury from active sites, resulting in re-release of mercury into the flue gas stream.

Measurements were made using the controlled condensation technique for $\mathrm{SO}_{3}$ during the test period at two locations: the air heater outlet and the ESP outlet. As shown in Figure 6.3-11, the mercury levels at the air heater outlet and the ESP outlet were $4.3 \mathrm{ppm}$ and $2.6 \mathrm{ppm}$ (both at 3\% $\mathrm{O}_{2}$ ), respectively. Measurements were also made while injecting sorbent for mercury control. The measured levels at the air heater inlet and the ESP outlet were $1.9 \mathrm{ppm}$ and $0.2 \mathrm{ppm}$, respectively. Most of the $\mathrm{SO}_{3}$ was adsorbed by the sorbent, which dramatically reduced the $\mathrm{SO}_{3}$ level at the ESP outlet presumably at the expense of the active sites for potential mercury capture.

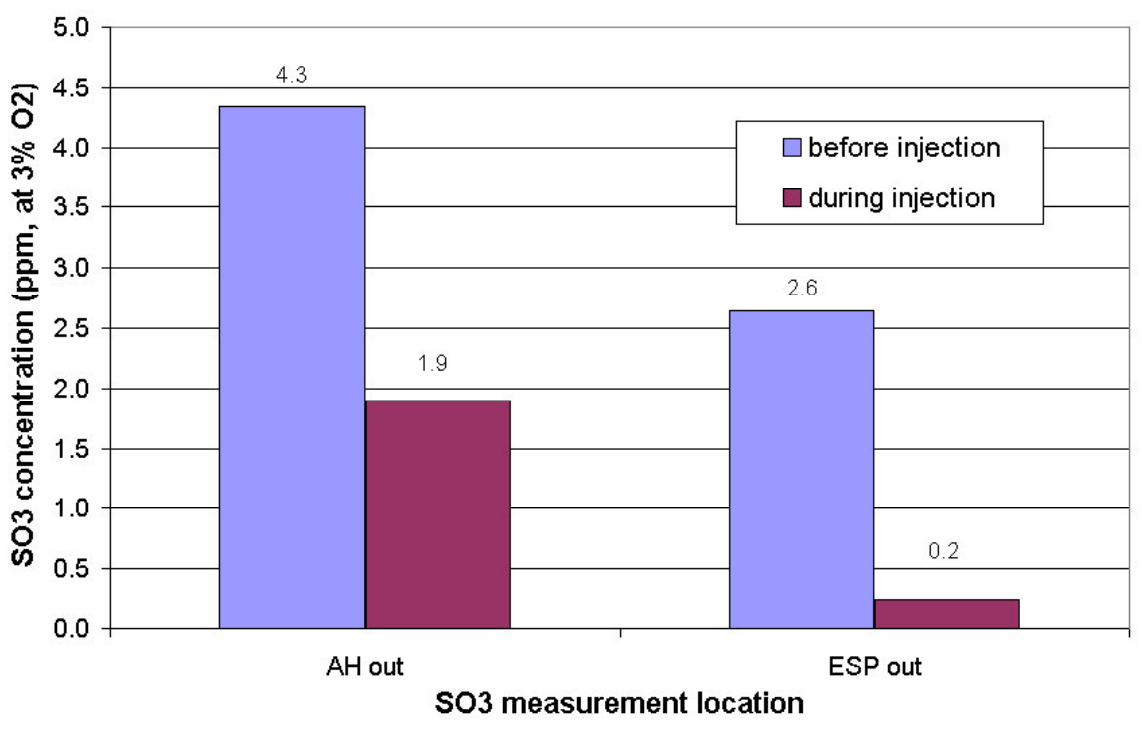

Figure 6.3-11 SO $\mathrm{S}_{3}$ Concentrations at the Air Heater Outlet and ESP Outlet with Non-Ozone Season Operation 
The plant had a scheduled outage from May 12 through May 24 for ozone season tuning. During the outage, the settings of the boiler firing system - burner settings, over-fire air tilts, etc. - were adjusted to meet the required $\mathrm{NO}_{\mathrm{x}}$ emissions level for the season. With non-ozone season operation, unburned carbon levels were $6 \%$ to $9 \%$; during ozone season operation, unburned carbon levels were between $10 \%$ and $17 \%$.

Figure 6.3-12 shows the CMM measurements during the ozone-season, long-term demonstration period. The Mer-Cure ${ }^{\mathrm{TM}}$ system was turned on at 8:00 am, May $26^{\text {th }}$, and was left on until a forced outage on June 1. The injection rate was approximately $8.5 \mathrm{lb} /$ MMacf. During this long-term test period (LT1), the mercury concentration at the ESP outlet stayed between $0.12 \mu \mathrm{g} / \mathrm{m}^{3}$ and $1 \mu \mathrm{g} / \mathrm{m}^{3}$, with its average of $0.47 \mu \mathrm{g} / \mathrm{m}^{3}$. As shown in the figure, the removal efficiency calculated based on the mercury level at the air heater inlet varied between $90 \%$ and $98 \%$. The test performance in this period demonstrates that the Mer-Cure ${ }^{\mathrm{TM}}$ system can exceed the mercury removal limits specified in utility boiler regulations from the Pennsylvania Department of Environmental Protection.

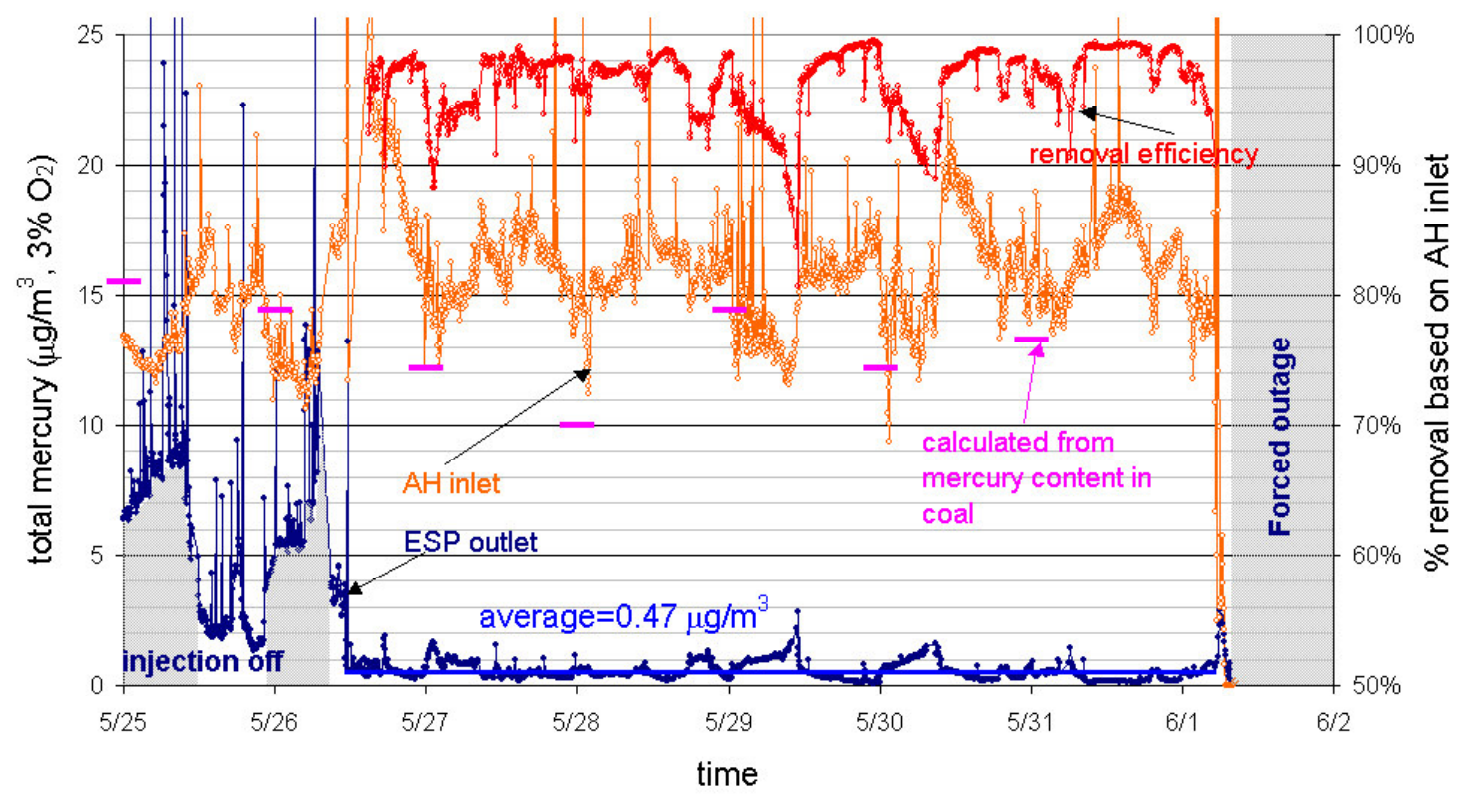

Figure 6.3-12 Long-term Demonstration Performance of Mer-Cure $^{\mathrm{TM}}$ with Ozone Season Operation (LT1)

A week into the ozone-season long-term testing, the plant had another outage due to tube leaks in the boiler. The boiler was brought on line after three days. Figure 6.3-13 shows the long-term performance data after the forced outage. (The grey area in the figure shows the test intervals during which the Mer-Cure ${ }^{\mathrm{TM}}$ system was turned off.)

During the second ozone-season testing (LT2), the ESP outlet mercury level was further decreased to a level below $1 \mu \mathrm{g} / \mathrm{m}^{3}$ with its average of $0.16 \mu \mathrm{g} / \mathrm{m}^{3}$, again below $1.6 \mu \mathrm{g} / \mathrm{m}^{3}$, or $0.012 \mathrm{lb} / \mathrm{GWh}$. The mercury level calculated from the mercury content in daily coal samples continued to show a wide variation between 11 and $22 \mu \mathrm{g} / \mathrm{m}^{3}$ with its average of $18 \mu \mathrm{g} / \mathrm{m}^{3}$. The average mercury at the air heater inlet was $14 \mu \mathrm{g} / \mathrm{m}^{3}$; and that at the ESP outlet during the last three days of the test period 
was $6.5 \mu \mathrm{g} / \mathrm{m}^{3}$. The calculated mercury capture efficiencies based on these three different baseline mercury levels were $99 \%, 99 \%$, and $98 \%$, respectively.

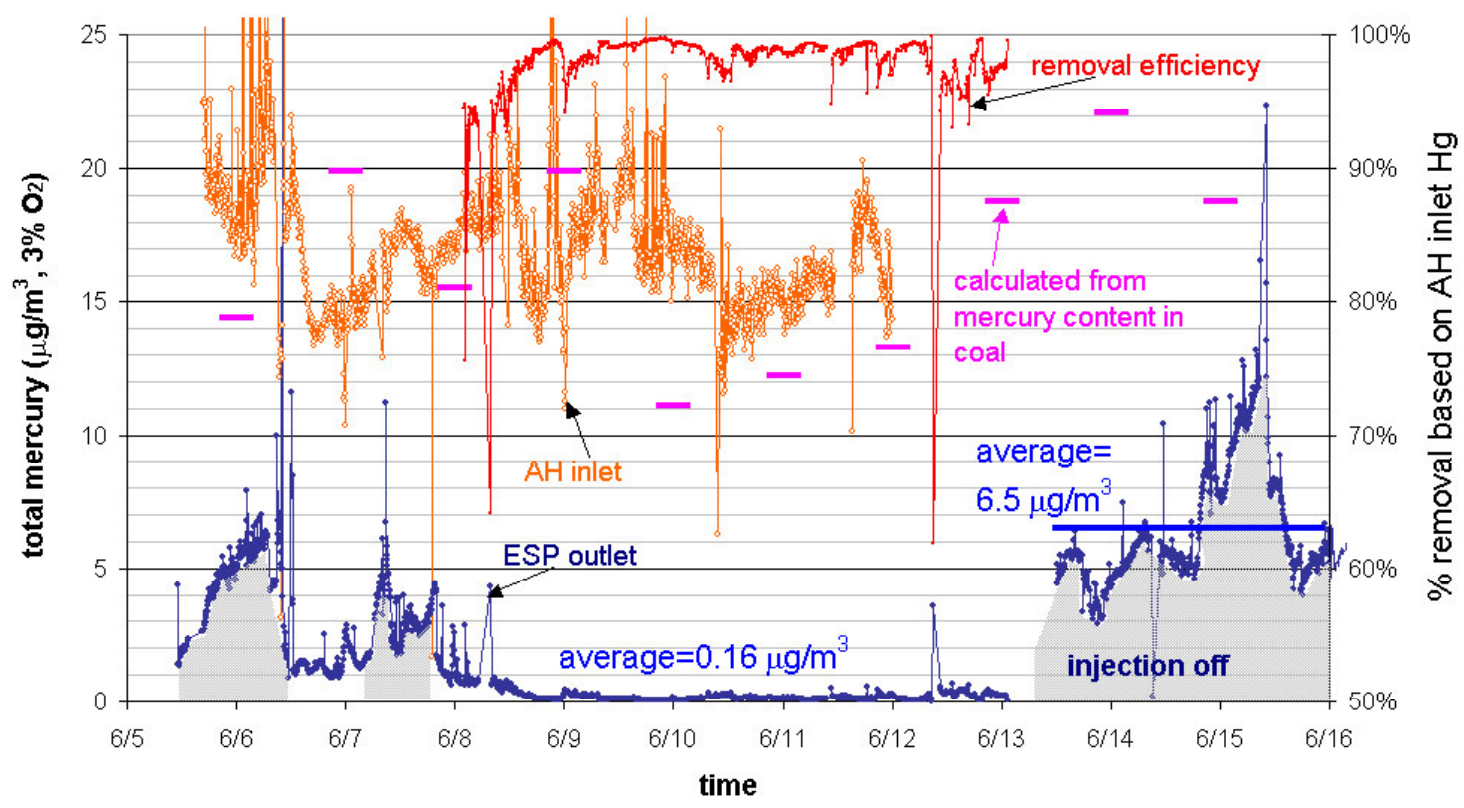

Figure 6.3-13 Long-term Demonstration Performance of Mer-Cure ${ }^{\mathrm{TM}}$ with Ozone Season Operation (LT2)

The CMM measurements during the long-term demonstration (shown in Figure 6.3-10, Figure 6.3-12 and Figure 6.3-13) were verified by $\mathrm{OH}$ measurements conducted by UND EERC. Figure 6.3-14 shows the $\mathrm{OH}$ measurement results conducted over the entire test campaign.

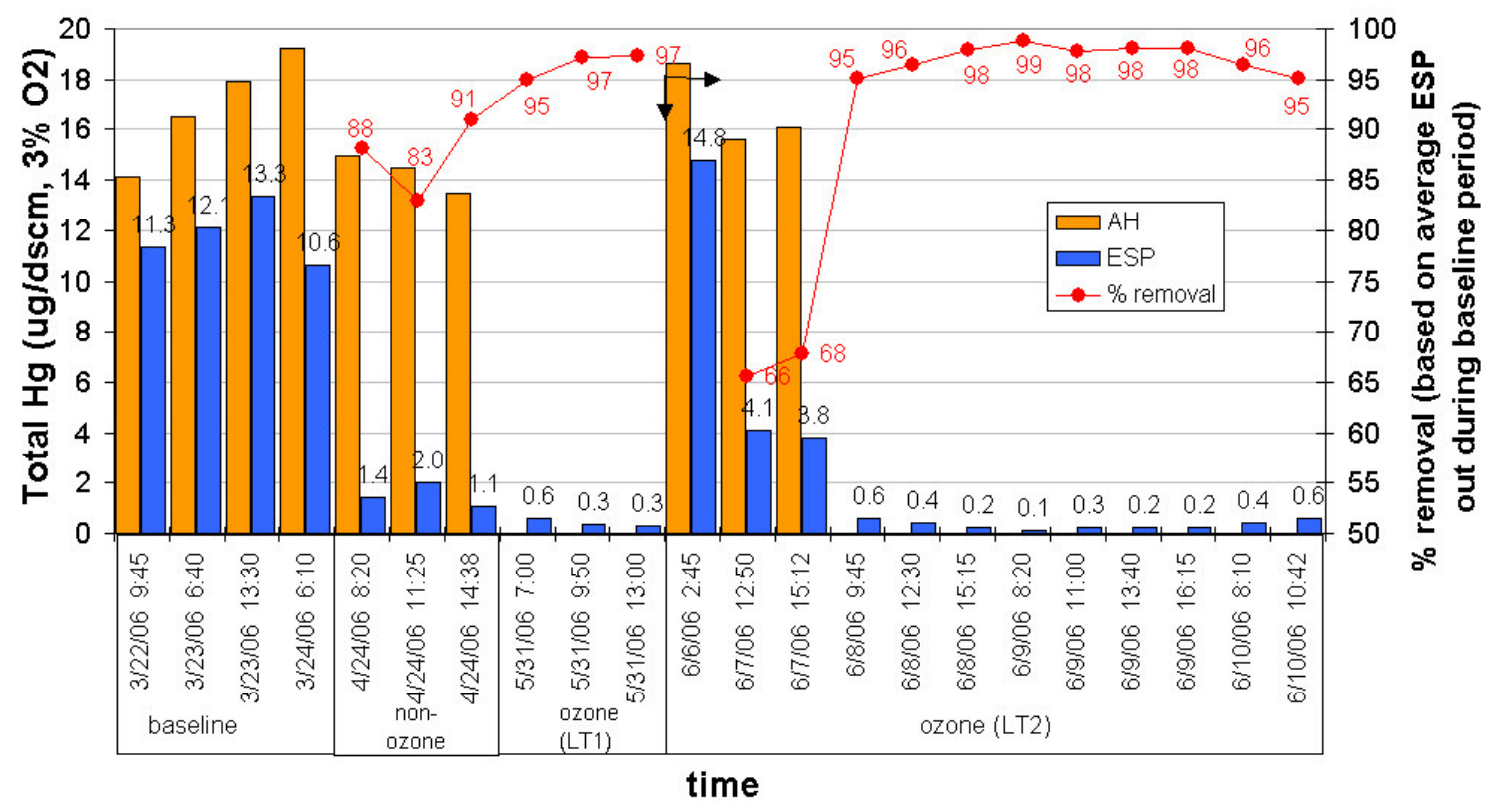

Figure 6.3-14 Validation of Long-Term Performance of Mer-Cure ${ }^{\mathrm{TM}}$ System by Ontario Hydro Method 
The mercury levels were corrected to $3 \% \mathrm{O}_{2}$ and reported in micrograms per dry standard cubic meter $(\mu \mathrm{g} / \mathrm{dscm})$. During the baseline measurement period, the measured total mercury at the air heater inlet varied from $14.1 \mu \mathrm{g} / \mathrm{m}^{3}$ to $19.2 \mu \mathrm{g} / \mathrm{m}^{3}$ while the ESP outlet mercury varied from $10.5 \mu \mathrm{g} / \mathrm{m}^{3}$ to $13.5 \mu \mathrm{g} / \mathrm{m}^{3}$.

According to these measurements, about $29 \%$ of the air heater inlet mercury was inherently captured in the boiler backend system of the Portland Unit \#1. Measurements over the long-term test periods verify the findings from the CMM measurements. For example, the highest removal efficiency achieved during non-ozone testing was $91 \%$. Throughout the ozone season testing, the mercury removal was greater than $95 \%$. In both operating modes of the boiler, the Mer-Cure ${ }^{\mathrm{TM}}$ system could consistently achieve greater than $90 \%$ of the baseline mercury.

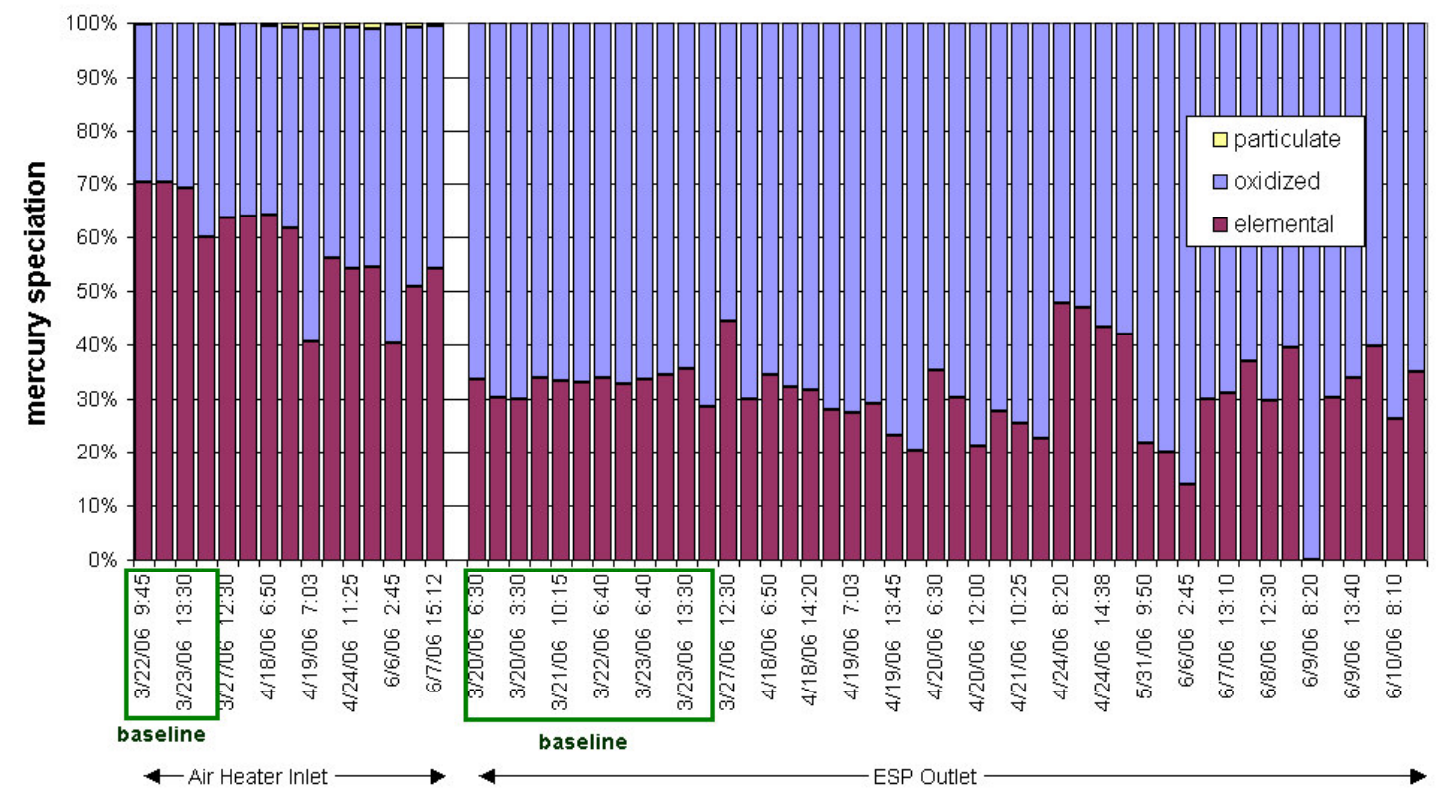

Figure 6.3-15 Mercury Speciation at the Air Heater Inlet and ESP Outlet

Figure 6.3-15 shows the mercury speciation at the air heater inlet and the ESP outlet at Portland Unit \#1. At the air heater inlet, about $45 \%$ of the gaseous mercury was oxidized. Some of the elemental gaseous mercury was further oxidized downstream the air heaters to result in $70 \%$ of the total gaseous mercury as oxidized mercury at the ESP outlet. Long-term data, however, show that sorbent injection did not change the speciation at the ESP outlet. A typical bituminous coal- fired unit with a flue gas desulfurization (FGD) device such as a wet FGD or a dry scrubber would be able to further remove this oxidized portion of the emitted mercury ( $70 \%$ of the total mercury), potentially increasing the total mercury removal efficiency.

\subsubsection{Balance of Plant Impacts}

In the previous section, performance data have been presented to demonstrate that Mer-Cure ${ }^{\mathrm{TM}}$ technology offers a solution to effectively control mercury emissions from coal-fired boilers. Sorbent injection into the economizer outlet, however, may be of technical and operational concern to boiler 
operators. In this section, the impact of sorbent injection on stack opacity and fly ash carbon levels is discussed.

Figure 6.3-16 shows the stack opacity data from the plant for the last two days of the long-term test period (LT2). The plant load is also reported in the figure since the stack opacity is a function of the plant load. As indicated, sorbent injection by the Mer-Cure ${ }^{\mathrm{TM}}$ system was continued until the end of June 12. The system was shut off on June 13.

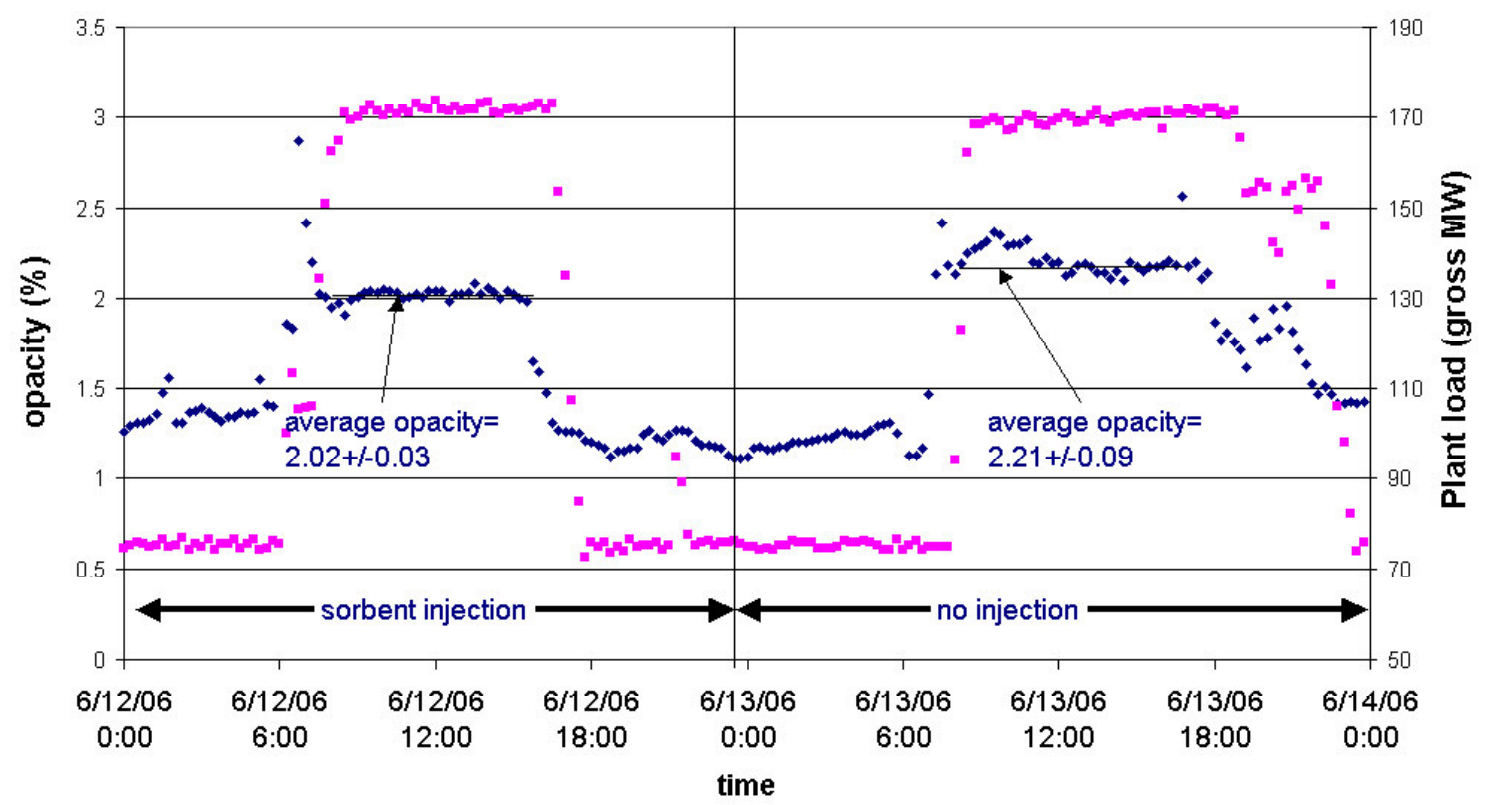

Figure 6.3-16 Stack Opacity Change During Sorbent Injection

At Portland Unit \#1, the stack opacity varied between $1 \%$ and $2.5 \%$. As expected, the opacity was lower at a low load than at a full load. During sorbent injection, the reported stack opacity at a full load was $2.02 \pm 0.03 \%$ whereas after the Mer-Cure ${ }^{T M}$ system was shut off, the stack opacity at a full load was $2.21 \pm 0.09 \%$. The stack opacity with sorbent injection was not higher than that with no injection.

This finding has been verified from independent measurements by Air Hygiene International, Inc. conducted as part of the Reliant test program. The particulate matter (PM) emission testing was conducted at the stack at the end of the ozone-season testing (LT2). The objective of the PM testing was to ensure that operation of the Mer-Cure ${ }^{T M}$ system does not cause increase in particulate emissions beyond the permit level. Measurements and analysis were carried out by employing the EPA Method 5 and Method 202 for the test conditions with and without injection of sorbent. Results are listed in Table 6.3-3. The reported data are averages of three measurement runs. 
Table 6.3-3 Summary of Portland Unit \#1 Particulate Matter Testing

\begin{tabular}{|l|c|c|}
\hline \multicolumn{1}{|c|}{ Parameters } & Baseline (no sorbent injection) & With sorbent injection \\
\hline \hline Test date & June 13, 2006 & June 12, 2006 \\
\hline Load & 169.4 & 171.6 \\
\hline PM filter carbon content (\%) & 6.5 & 6.9 \\
\hline Stack exhaust flow (scfh) & $21,149,078$ & $20,957,004$ \\
\hline Total PM (gr/dscf) & 0.022 & 0.017 \\
\hline Total PM (lb/h) & 68.0 & 50.2 \\
\hline Total PM (lb/MMBtu) & $\mathbf{0 . 0 4 6}$ & $\mathbf{0 . 0 3 4}$ \\
\hline Front half PM (gr/dscf) & 0.008 & 0.006 \\
\hline Front half PM (lb/h) & 24.0 & 18.6 \\
\hline Front half PM (lb/MMBtu) & 0.016 & 0.013 \\
\hline Back half PM (gr/dscf) & 0.015 & 0.011 \\
\hline Back half PM (lb/h) & 44.0 & 31.6 \\
\hline Back half PM (lb/MMBtu) & 0.030 & 0.022 \\
\hline O2 (\%) & 6.6 & 6.6 \\
\hline
\end{tabular}

* Permit limit for Portland Unit \#1 is $0.10 \mathrm{lb} / \mathrm{MMBtu}$

As listed in Table 6.3-3, the total PM measured was $0.046 \mathrm{lb} / \mathrm{MMBtu}$ during normal boiler operation. The total PM while the Mer-Cure ${ }^{T M}$ system was running was $0.034 \mathrm{lb} / \mathrm{MMBtu}$. In both cases, the measured total PM was less than the permit limit of $0.10 \mathrm{lb} / \mathrm{MMBtu}$.

Figure 6.3-17 shows unburned carbon levels measured for ESP hopper fly ash samples collected during long-term testing. Separate samples were collected from the four rows of ESP hoppers, and the composite unburned carbon level determined for each sample. A total of 31 samples were analyzed. Testing was done at four conditions:

- Baseline (no sorbent injection and unit operated in unstaged, non-ozone season firing mode),

- Parametric tests (sorbent injection at various rates and unit operated in unstaged, non-ozone season firing mode),

- Long-term non-ozone tests (sorbent injection at constant rate and unit operated in unstaged, non-ozone season firing mode), and

- Long-term ozone tests (sorbent injection at constant rate and unit operated in staged, ozone season firing mode).

The unburned carbon showed an increase from $6.2 \%$ without sorbent injection to $9.0 \%$ and $8.3 \%$ under non-ozone season operation and with sorbent injection on average. The unburned carbon increase of $2.1 \%$ points between baseline and long term non-ozone tests is attributed to the injection of sorbent. Parametric tests included operation at both higher and lower sorbent injection rates than the long term tests. Under long term ozone tests, fly ash unburned carbon further increased to 
$13.4 \%$ on average. The increase of $5.1 \%$ from long term non-ozone to long term ozone tests is attributed to ozone season operation, where combustion is staged to reduce $\mathrm{NO}_{\mathrm{x}}$ emissions.

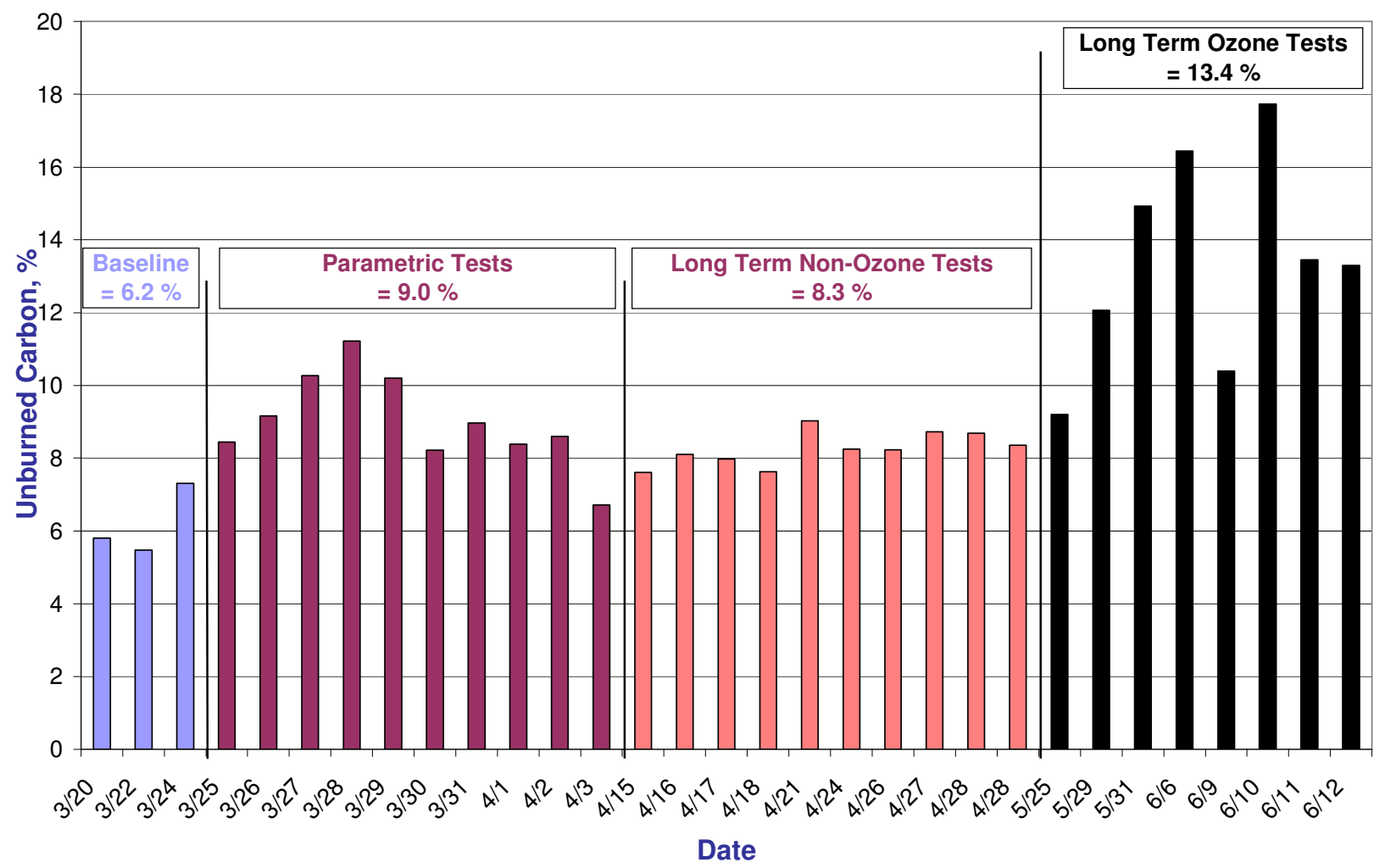

Figure 6.3-17 Change in Unburned Carbon of Bulk Fly Ash Samples at Portland Unit \#1

The increase in fly ash carbon levels from ozone season operation is much larger than the increase due to sorbent injection. In any event, the baseline carbon levels are such that all of the fly ash from Portland Unit \#1 is landfilled or otherwise disposed, and none of it is suitable for sale or recycling.

\subsubsection{Economics}

The performance of several Mer-Clean ${ }^{T M}$ sorbents with the Mer-Cure ${ }^{T M}$ system has been determined in this demonstration project. In our economic analysis, the mercury removal data of Mer-Clean ${ }^{\mathrm{TM}} 8$ sorbent at Portland Unit \#1 firing Eastern bituminous coal was used to calculate the operating costs for a typical $170-\mathrm{MW}_{\mathrm{e}}$ boiler. For example, if 70 percent mercury reduction is required, the sorbent injection rate is $7.77 \mathrm{lb} / \mathrm{MMacf}$ (302 lb/hr). If 90 percent reduction is required, the sorbent injection rate is $0.84 \mathrm{lb} / \mathrm{MMacf}$ ( $92 \mathrm{lb} / \mathrm{hr}$ ). Mercury removal versus sorbent injection rate data is provided in Table 6.3-4 below. 


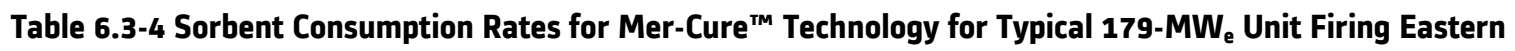
Bituminous Coal

\begin{tabular}{|c|c|c|}
\hline $\begin{array}{c}\text { \% Mercury } \\
\text { Removal }\end{array}$ & $\begin{array}{c}\text { Sorbent } \\
\text { (lb/MMacf) }\end{array}$ & $\begin{array}{c}\text { Sorbent } \\
\text { (lb/hr) }\end{array}$ \\
\hline 50 & 1.78 & 69 \\
\hline 70 & 4.15 & 161 \\
\hline 75 & 4.93 & 192 \\
\hline 80 & 5.80 & 225 \\
\hline 90 & 7.77 & 302 \\
\hline 95 & 8.89 & 346 \\
\hline
\end{tabular}

\section{Costs and Economics}

Capital and operating costs for the installation and operation of a Mer-Cure ${ }^{\mathrm{TM}}$ system for a typical 170-MWe boiler firing Eastern bituminous coal are presented below (Table 6.3-5) along with assumptions. Capital costs include those for sorbent storage, sorbent processing and injection equipment, and were determined from vendor quotes. Equipment costs including all piping, materials and controls are estimated to be $\$ 1.32$ million. Installation, including site integration, is estimated around $\$ 518,000$. Adding in start-up support and a contingency of 10 percent of capital costs, the overall capital cost of the Mer-Cure ${ }^{\mathrm{TM}}$ system is estimated to be about $\$ 2.04$ million or about $\$ 12.01 / \mathrm{kW}_{\mathrm{e}}$.

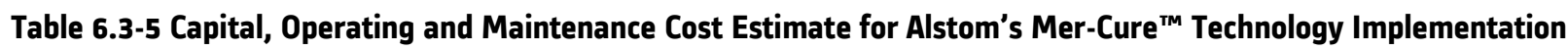
(90 percent mercury reduction)

\begin{tabular}{|l|r|}
\hline \multicolumn{2}{|c|}{ Capital Costs Summary } \\
\hline Equipment & $\$ 1,320,000$ \\
\hline Installation including site integration (materials and labor) & $\$ 518,000$ \\
\hline Start-up support & $\$ 18,000$ \\
\hline Contingency & $\$ 185,000$ \\
\hline Total Capital Required & $\$ 2,041,000$ \\
\hline \$/kW (170 MW gross) & 12.01 \\
\hline \multicolumn{2}{|c|}{ Operating and Maintenance Costs Summary } \\
\hline Sorbent (\$1.25/lb, 90\% reduction, 302 lb/h, 7,500 hrs) & $\$ 2,831,250$ \\
\hline Power, Labor and Maintenance & $\$ 115,000$ \\
\hline Waste Disposal & $\$ 0$ \\
\hline Annual 0\&M & $\$ 2,946,250$ \\
\hline Levelized - 20 year 0\&M Cost (\$/kW) & 8.61 \\
\hline
\end{tabular}

Notes:
a) 90 percent mercury removal target
b) Unit is assumed to be base loaded 
c) Ash is not utilized or still available for use after carbon injection

d) Installation is with union labor

e) Contingency is calculated at 10 percent of capital cost

f) Levelized costs are calculated assuming $3 \%$ increase per year

g) $170 \mathrm{MW}_{\mathrm{e}}$ gross capacity with 7500 hours operation per year

The predominant component of the operating cost is the sorbent cost. Costs were estimated based on a long-term Mer-Clean ${ }^{\mathrm{TM}} 8$ sorbent injection rate conservatively assumed to be $7.77 \mathrm{lb} / \mathrm{MMacf}$ or $302 \mathrm{lb} / \mathrm{hr}$. Unit operation is assumed at 85 percent capacity factor. With these assumptions, the annual sorbent costs are $\$ 2,831,250$, assuming a delivered sorbent cost of $\$ 1.25 / \mathrm{lb}$. There is a significant uncertainty in sorbent cost because of various factors: e.g., anticipated demand increase for mercury control in utility industry and anti-dumping tariffs being imposed on Chinese activated carbon. This may increase sorbent costs by a large amount.

The other component of the operating cost is parasitic power, labor and maintenance and this is estimated to be $\$ 115,000$ annually. The overall operating cost for 90 percent mercury control is $\$ 2,946,250$ or $\$ 2.28 / \mathrm{MWh}$.

Sensitivity analysis results with respect to the mercury removal level required and unit sorbent costs are shown in Figure 6.3-18. These calculations indicate that at a sorbent cost of $\$ 1.25 / \mathrm{lb}$, the

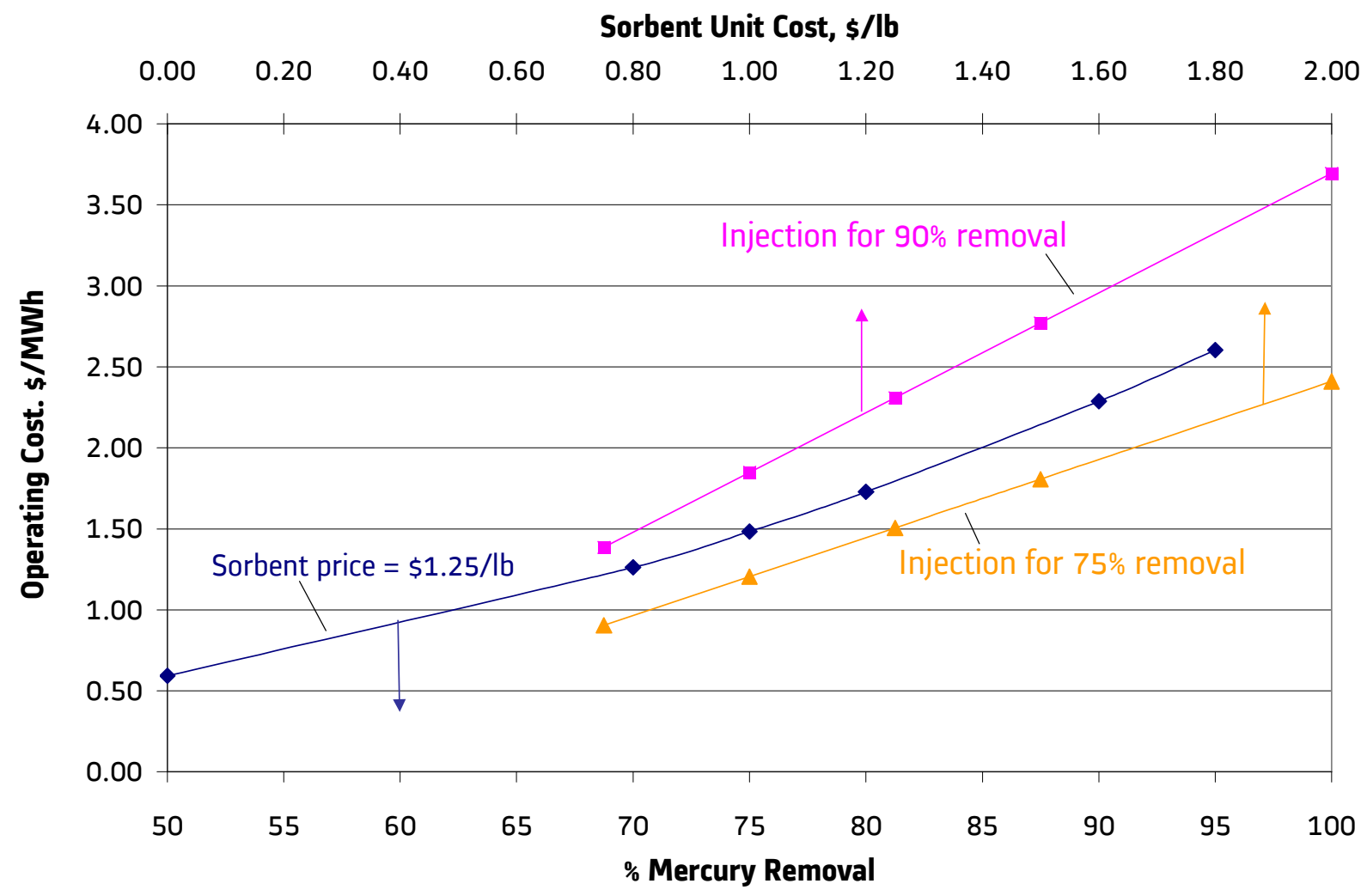

Figure 6.3-18 Sensitivity analysis: Effect of Sorbent Unit Cost and Mercury Removal Required on Operating Cost for Mercury Control for Typical 170-MW e Unit Firing Eastern Bituminous Coal Using Mer-Cure ${ }^{\mathrm{TM}}$ Technology 
operating cost for $90 \%$ mercury control using Alstom's Mer-Cure ${ }^{T M}$ technology is $\$ 2.28 / \mathrm{MWh}$. Corresponding operating cost for 75 percent control is $\$ 1.48 / \mathrm{MWh}$. If sorbent costs increase to $\$ 2.00 / \mathrm{lb}$, the Mer-Cure $\mathrm{TM}^{\mathrm{TM}}$ operating cost increases to $\$ 3.60 / \mathrm{MWh}$ and $\$ 2.32 / \mathrm{MWh}$ for 90 and 75 percent mercury control, respectively.

\subsubsection{Conclusions}

Field demonstration of the Mer-Cure ${ }^{\mathrm{TM}}$ system has been completed at Reliant Energy's Portland Station Unit \#1. Following is the summary of Port1 test campaign:

\section{Performance:}

- The long-term performance of the Mer-Cure ${ }^{\mathrm{TM}}$ system at Portland Station 1 during nonozone season showed that at an injection rate of approximately $8.5 \mathrm{lb} / \mathrm{MMacf}$, the mercury removal rate was greater than $90 \%$ based on the uncontrolled mercury level at the stack.

- The long-term performance during ozone season showed that at the same injection rate, the mercury removal rate was greater than $95 \%$ based on the uncontrolled mercury level at the stack.

- The mercury content of the fuels fired at Portland Station 1 varied widely on a daily basis, with an average of $8.23 \pm 2.13 \mathrm{lb} \mathrm{Hg} / \mathrm{TBtu}$. The sulfur content, on the other hand, did not vary as much, with an average of $3.04 \pm 0.22 \mathrm{lb} \mathrm{SO} / \mathrm{MMBtu}$. This variation was due to the station alternating fuels from two different coal mines.

- As a result, baseline gaseous mercury levels varied widely, ranging from $3 \mu \mathrm{g} / \mathrm{m}^{3}$ to 16 $\mu \mathrm{g} / \mathrm{m}^{3}$.

Mercury Speciation:

- According to the $\mathrm{OH}$ measurements, the oxidized mercury was approximately $45 \%$ of the total mercury upstream the air heaters and $70 \%$ at the ESP outlet. The mercury speciation did not change during sorbent injection.

- During non-ozone season, injection of sorbent significantly decreased the $\mathrm{SO}_{3}$ at the ESP outlet.

Economics:

- Overall capital cost of the Mer-Cure ${ }^{\mathrm{TM}}$ system for a typical 170-MWe unit firing Eastern bituminous coal is estimated to be about $\$ 2.04$ million or about $\$ 12 / \mathrm{kW}_{\mathrm{e}}$.

- The overall operating cost for a typical $170-\mathrm{MW}_{\mathrm{e}}$ unit firing Eastern bituminous coal with Mer-Cure ${ }^{\mathrm{TM}}$ for 90 percent mercury control is $\$ 2,946,250$ or $\$ 2.28 / \mathrm{MWh}(\$ 28,540 / \mathrm{lb} \mathrm{Hg}$ removed), with a delivered sorbent cost of $\$ 1.25$ per pound.

- Sensitivity analysis with respect to the mercury removal level required indicates that if only 75 percent control is required, then the Mer-Cure ${ }^{T M}$ operating cost is reduced to $\$ 1.48 / \mathrm{MWh}$ $(\$ 22,230 / \mathrm{lb} \mathrm{Hg}$ removed), with a sorbent cost of $\$ 1.25$ per pound. On the other hand, if sorbent costs increase to $\$ 2.00$ per pound, the Mer-Cure ${ }^{\mathrm{TM}}$ operating cost increases to $\$ 3.60$ 
and $\$ 2.32 / \mathrm{MWh}$ ( $\$ 45,065$ to $\$ 34,850 / \mathrm{lb} \mathrm{Hg}$ removed) for 90 and 75 percent mercury control, respectively.

- If a wet scrubber is installed at Port1, then a portion of the oxidized mercury that escapes the cold-side ESP can be removed in the wet scrubber. If a wet scrubber is installed, the operating cost with Mer-Cure ${ }^{\mathrm{TM}}$ for 90 percent mercury control may be reduced by about 25 percent or to $\$ 1.71 / \mathrm{MWh}(\$ 21,400 / \mathrm{lb} \mathrm{Hg}$ removed).

Balance of Plant Impacts:

- Both stack opacity measurement and the particulate emissions rate measurement indicate that sorbent injection did not increase particulate emission levels at the stack.

- Unburned carbon (UBC) was measured for bulk fly ash samples collected before and during long-term testing. The UBC showed an increase from a baseline of $6.2 \%$ to $8.3 \%$ with a constant sorbent injection rate and under non-ozone season firing conditions. The UBC increase of $2.1 \%$ percentage points is attributed to the injection of sorbent.

- The UBC showed an increase from $8.3 \%$ with a constant sorbent injection rate and under non-ozone season firing conditions to $13.4 \%$ with a constant sorbent injection rate and under ozone season (staged) firing conditions. The UBC increase of $5.1 \%$ percentage points is attributed combustion staging for ozone season (low $\mathrm{NO}_{\mathrm{x}}$ ) operation.

- The increase in fly ash carbon levels from ozone season operation is much larger than the increase due to sorbent injection. In any event, the baseline carbon levels are such that all of the fly ash is landfilled or otherwise disposed, and none of it is suitable for sale or recycling. 


\section{Commercialization of Mer-Cure ${ }^{T M}$ Process}

The timing of commercialization for mercury capture technology is driven largely by mercury reduction regulations. Regulations have consisted of proposed federal regulations plus a variety of proposed and enacted state regulations. On February 8, 2008, the DC Circuit Court of Appeals struck down two EPA rules in response to an appeal by 18 states and several environmental groups. The petitioners questioned EPA's decision to delist coal and oil-fired power plants from the list of sources that produce hazardous air pollutants (including mercury). The court agreed, finding that EPA did not go through the proper process before delisting. As a result, mercury emissions trading is illegal; instead mercury will be subject to yet-to-be-specified command-and-control regulations.

The effective result is that state regulations are now driving the near-term commercialization of mercury capture technology. For utilities with units currently under state regulation, there is an understanding that new federal regulations are forthcoming, but they are required to implement solutions to meet the current state regulations.

\subsection{Commercial Mer-Cure ${ }^{\mathrm{TM}}$ System Design}

Alstom's Mer-Cure ${ }^{\mathrm{TM}}$ technology employs a sorbent preparation and injection system consisting of four (4) major subsystems as follows:

- Bulk Storage and Feed

- Transport

- Processing

- Distribution and Injection

The bulk storage and feed system receives PAC sorbent delivered by tank trucks. Sorbent is conveyed pneumatically from the truck into a fabricated storage silo. The sorbent is fed into a hopper where it is temporarily stored until fed into the drop tube by the variable speed screw feeder and into an eductor inlet.

Motive air, supplied from air compressors, passes through the eductor nozzle and creates a vacuum in the eductor inlet, resulting in the sorbent being drawn into the mixing zone and exiting the transport system. Sorbent is conveyed via conventional piping to the sorbent processor where highpressure air from the compressors is used to process the sorbent before it enters the distributors and the injection lances.

Additional motive air from the compressors is added downstream of the sorbent processor in order to ensure that the processed sorbent continues to be entrained and enters the distribution at the correct velocity. Distribution is achieved via splitters that divide the sorbent flow between the flue gas ducts (typically, two) and additional splitters that direct the sorbent flow to the different injection lances.

Overall system operation is controlled via programmable logic controllers for the silo and feed system, and Alstom-supplied control logic for the overall control system, which can be programmed into the plant's existing Distributed Control System (DCS). 
All components integrated into an assembled Mer-Cure ${ }^{T M}$ system are commercially available for systems of various sizes and capacities, with one exception. The injection lances and nozzles are designed and fabricated specifically for each site.

\subsection{Status of Mer-Cure ${ }^{\mathrm{TM}}$ Commercialization Efforts}

Since completion of the field tests for this DOE project, Alstom has conducted multiple commercial demonstrations at electric utility boilers for several generating companies. One of the demonstrations has resulted in the first large commercial installation contract for Mer-Cure ${ }^{\mathrm{TM}}$ technology. At least one other multiple unit installation of Mer-Cure ${ }^{\mathrm{TM}}$ is under consideration by a second utility.

Alstom and Reliant Energy, Inc., one of the largest independent power producers in the United States, have announced the contract signing for the purchase of Alstom's advanced mercury removal system, Mer-Cure ${ }^{\mathrm{TM}}$. $^{13}$ The deal follows the successful launch of Alstom's Mer-Cure ${ }^{\mathrm{TM}}$ product line in 2007, marking Alstom's entry into this new market. Mer-Cure ${ }^{\mathrm{TM}}$ delivers reductions in flue gas mercury emissions of up to $90 \%$ and more, at low sorbent consumption rates, thus trimming operation and maintenance costs.

The system will be installed at Reliant's Shawville, Conemaugh, Titus, Portland and New Castle power stations in Pennsylvania. Delivery is scheduled for early 2009. This is in response to Pennsylvania's mercury capture regulations, Phase I of which take effect on January 1, 2010. 


\section{Summary of Demonstration Program Results}

Different sorbent formulations were evaluated at each test site. Different halogenated components are added to the activated carbon and the material processed to make the final sorbent. The detailed parametric results presented previously are summarized in this section. Economic results presented previously for each site are also summarized. Finally, the balance of plant impacts and future mercury capture research needs are discussed.

\subsection{Mercury Capture Performance}

The mercury capture results for the low rank coal sites are shown in Figure 8.1-1. DJ3 fired a PRB coal and LOS1 fired lignite, accounting for the difference in performance between the two sites. At these two test sites, four Mer-Clean ${ }^{\mathrm{TM}}$ formulations were tested (\# 2, 4, 6, and 8). These formulations differed from each other in terms of the added halogen compound, amounts of the added halogen, and manufacturing process.

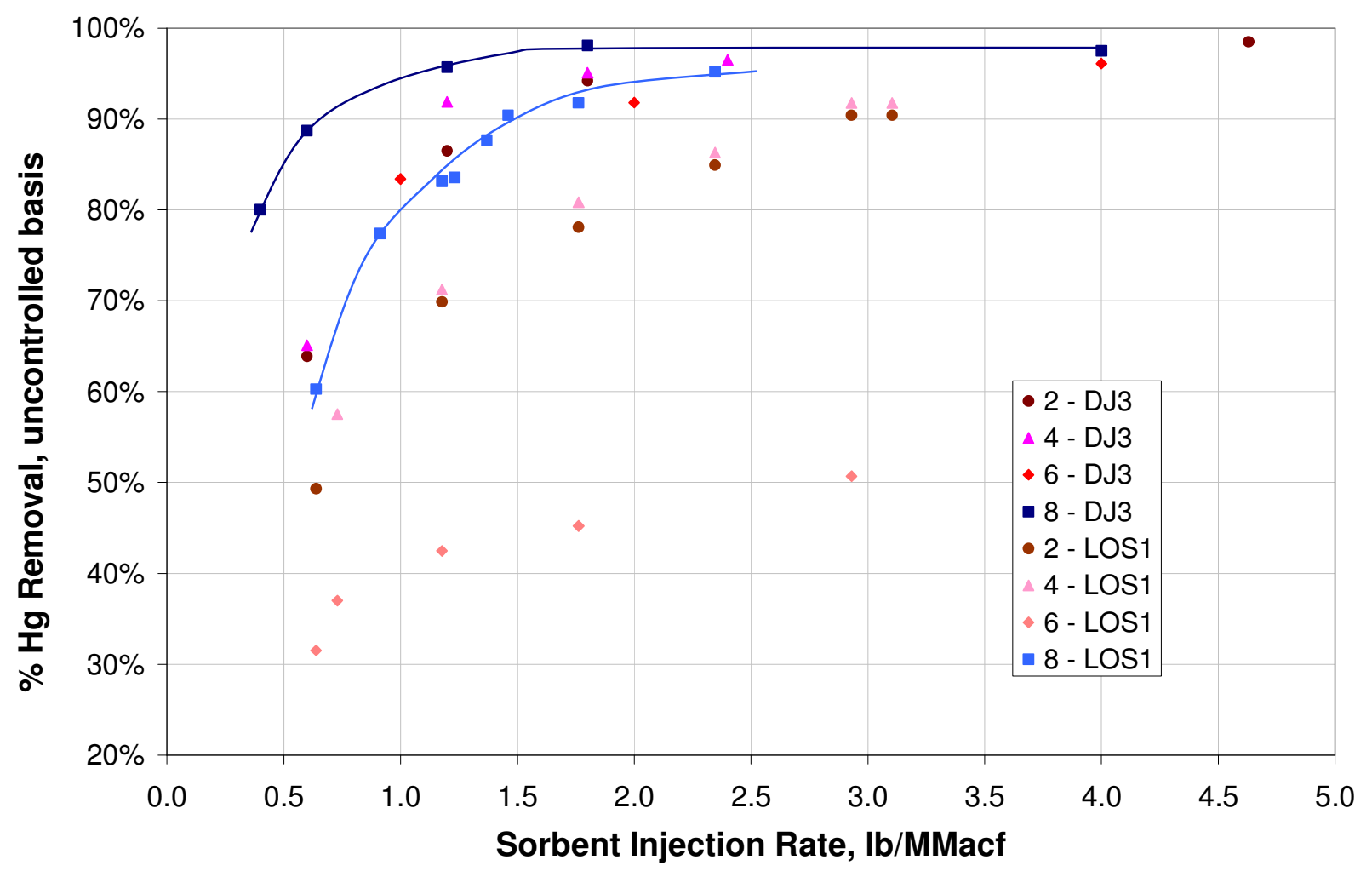

Figure 8.1-1 Mercury Capture Results for Low Rank Coal Sites

Mer-Clean ${ }^{\mathrm{TM}} 8$ showed the best mercury capture results in both cases, and it was chosen for the long term testing portion of the demonstration program. Long term tests were conducted at DJ3 injecting Mer-Clean ${ }^{\mathrm{TM}} 8$ at $52 \mathrm{lb} / \mathrm{h}$ (or $0.94 \mathrm{lb} / \mathrm{MMacf}$ ) to achieve $94 \%$ removal of baseline stack mercury based on CMM readings. The sorbent injection rate was then decreased to $35 \mathrm{lb} / \mathrm{h}$ (or 0.63 $\mathrm{lb} / \mathrm{MMacf})$ to achieve $90 \%$ mercury removal. Mer-Clean ${ }^{\mathrm{TM}} 2$ was then injected at $59 \mathrm{lb} / \mathrm{h}(1.06$ $\mathrm{lb} / \mathrm{MMacf}$ ) for the rest of the test program to achieve $90 \%$ mercury removal. 
Long term tests were conducted at LOS1 injecting Mer-Clean ${ }^{\mathrm{TM}} 8$ at $26 \mathrm{lb} / \mathrm{h}$ (or $0.9 \mathrm{lb} / \mathrm{MMacf}$ ) for the first five days to achieve $75 \%$ mercury removal. This testing was then followed injection of MerClean $^{T M} 8$ at $40 \mathrm{lb} / \mathrm{h}$ (or $1.4 \mathrm{lb} / \mathrm{MMacf}$ ) for the remainder of long term testing to achieve $90 \%$ mercury removal.

The mercury capture parametric test results for the eastern bituminous coal site (Port1) is shown in Figure 8.1-2. At this test sites, five Mer-Clean ${ }^{\mathrm{TM}}$ formulations were tested (\# 2, 4, 6, 8 and 9), including slight variations of Mer-Clean ${ }^{\mathrm{TM}} 8$. Again, these formulations differed from each other in terms of the added halogen compound, amounts of the added halogen, and manufacturing process. The four variations of Mer-Clean ${ }^{\mathrm{TM}} 8$ differed only in manufacturing process preparation temperatures.

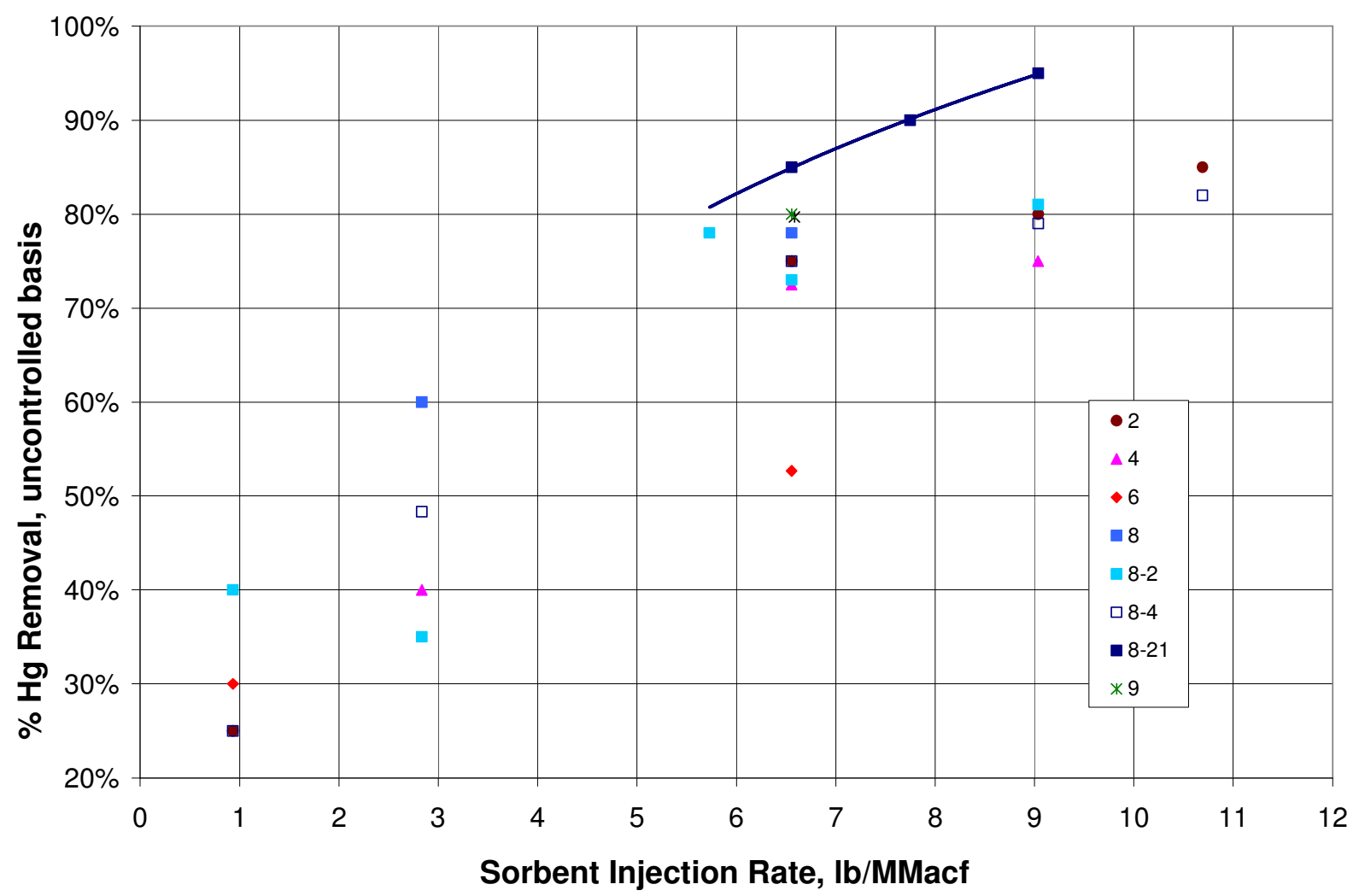

Figure 8.1-2 Mercury Capture Results for Bituminous Coal Site

At Portland Unit \#1, Mer-Clean ${ }^{\mathrm{TM}}$ 8-21 (a processing temperature variation of Mer-Clean ${ }^{\mathrm{TM}} 8$ ) showed the best mercury capture results, and it was chosen for the long term testing portion of the demonstration program. During ozone season long term tests, the sorbent injection rate was 330 $\mathrm{lb} / \mathrm{hr}$ (approximately $8.5 \mathrm{lb} / \mathrm{MMacf}$ ) to achieve $90 \%$ mercury removal at minimum.

\subsection{Economic Analysis}

The goals for this Round 2 program, established by DOE/NETL in the original solicitation, were to reduce the uncontrolled mercury emissions by 50 to $70 \%$ at a cost 25 to $50 \%$ lower than the previous target of $\$ 60,000 / \mathrm{lb}$ mercury removed. The mercury removal costs in $\$ / \mathrm{lb} \mathrm{Hg}$ removed are 
summarized for all three test sites in Figure 8.2-1. This figures shows that the goals of the test program were met or exceeded at all three sites. Mercury reduction rates of $75 \%$ and $90 \%$ were demonstrated at all three host sites. Mercury removal costs were below the goal at both DJ3 and LOS1. At Port1, mercury removal costs were at or below the goal with one exception. The removal cost at a $90 \%$ reduction rate $\$ 45,065 / \mathrm{lb} \mathrm{Hg}$ removed, which was just above the minimum goal of a $25 \%$ reduction in removal cost.

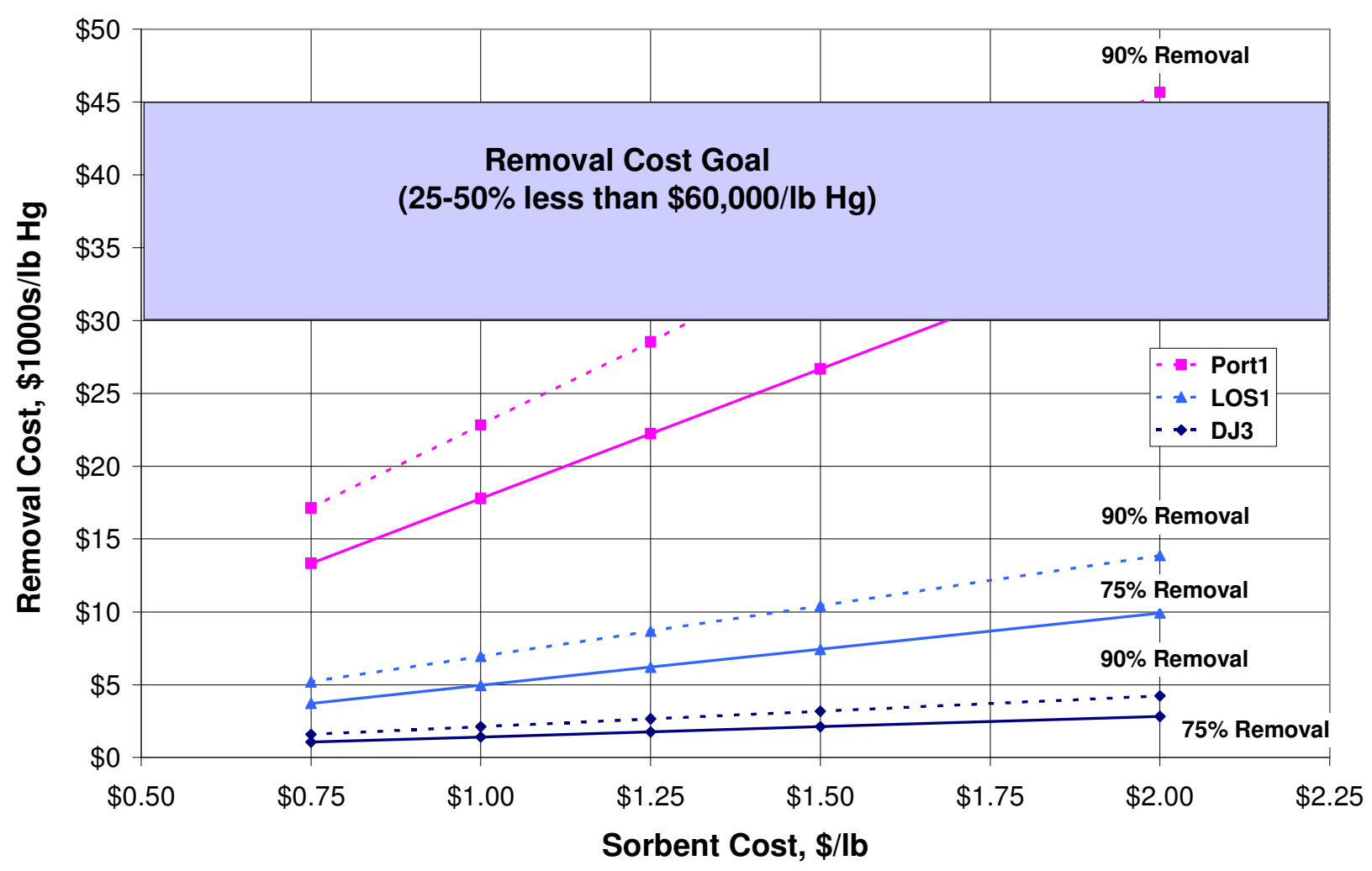

Figure 8.2-1 Mercury Removal Costs for Demonstration Project Host Sites

The levelized annual operating costs (in $\$ / M W h$ ) are summarized for all three test sites in Figure 8.2-2. This figures shows that annualized operating costs were well under $\$ 1 / M W h$ at both DJ3 and LOS1, the low rank coat test sites. (Note that the 75\% removal cost line for Leland Olds Unit \#1 and the 90\% removal cost line for Dave Johnson Unit \#3 are nearly identical.) At Port1, annualized operating costs were $\$ 0.90-3.75 / \mathrm{MWh}$ because of the higher sorbent injection rates required with medium sulfur bituminous coal. 


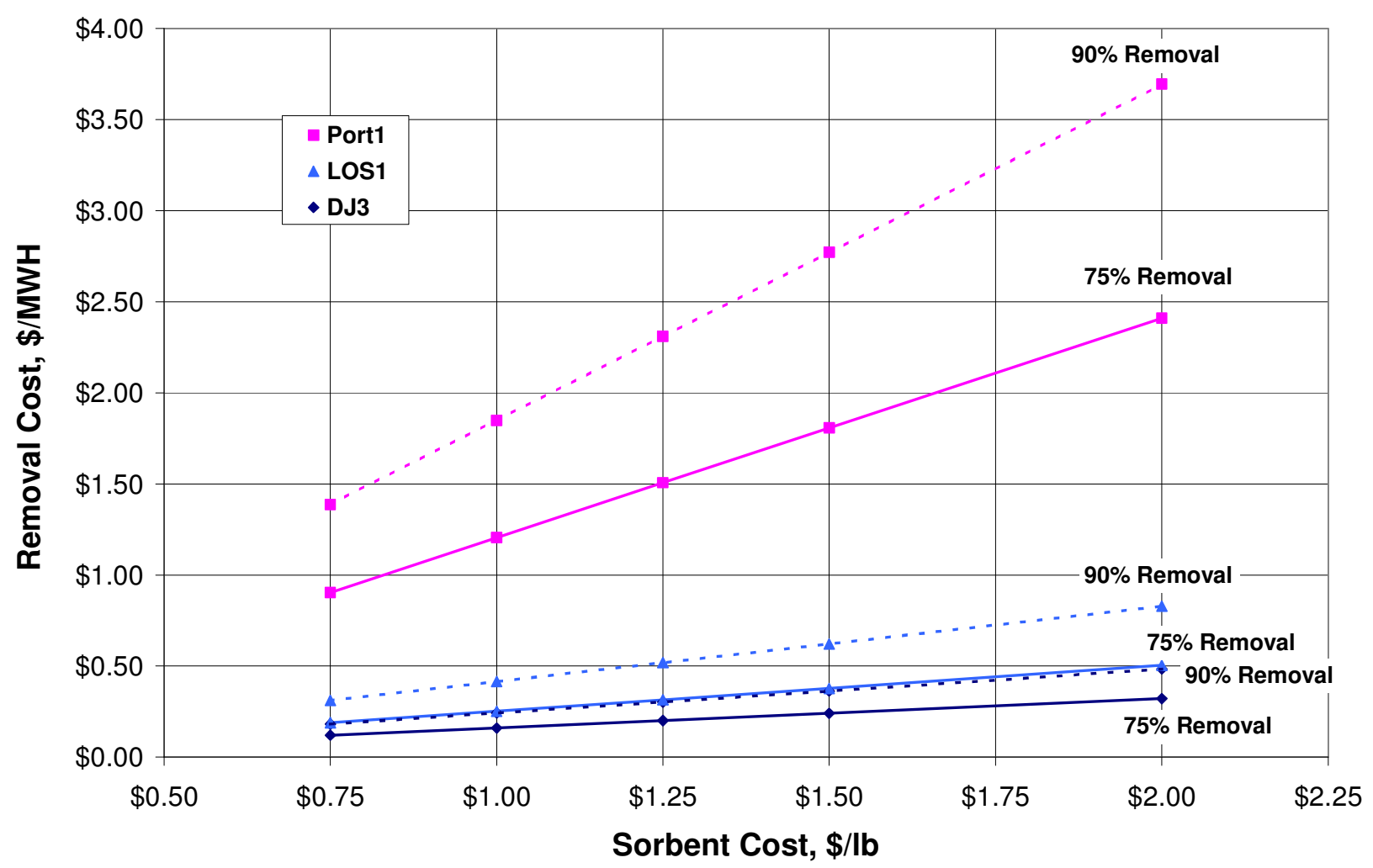

Figure 8.2-2 Levelized Annual Operating Costs for Demonstration Project Host Sites

\subsection{Balance of Plant Impacts}

Performance data have been presented to demonstrate that Mer-Cure ${ }^{\mathrm{TM}}$ technology offers a solution to effectively control mercury emissions from coal-fired boilers. Sorbent injection into the economizer outlet, however, may be of technical and operational concern to boiler operators. In this section, the impact of sorbent injection on boiler operation, such as emissions/opacity and fly ash unburned carbon levels, is discussed.

Observations throughout the long-term testing suggest that injection of Mer-Clean ${ }^{\mathrm{TM}}$ sorbent did not increase the stack opacity during long-term testing. Opacity is directly related to flue gas temperature entering the ESP (air heater gas outlet temperature). As expected, the air heater gas outlet temperatures varied with the unit load change. No change was observed due to injection of sorbent upstream of the air heaters.

$\mathrm{NO}_{\mathrm{x}}$ and $\mathrm{SO}_{2}$ emissions were documented during mercury sorbent injection. As expected, no change in $\mathrm{NO}_{\mathrm{x}}$ and $\mathrm{SO}_{2}$ emissions levels was observed as a result of continuous sorbent injection. Particulate emissions rates were also documented at Portland Unit \#1. At Port1, the total PM measured was $0.046 \mathrm{lb} / \mathrm{MMBtu}$ during normal boiler operation. The total PM while the Mer-Cure ${ }^{\mathrm{TM}}$ system was running was $0.034 \mathrm{lb} / \mathrm{MMBtu}$. In both cases, the measured total PM was less than the permit limit of $0.10 \mathrm{lb} / \mathrm{MMBtu}$, and did not increase with sorbent injection. 
The unburned carbon in the fly ash increased at all three test sites, and the increase was related to the amount of sorbent injected. The unburned carbon showed a slight increase from $0.95 \%$ to $1.03 \%$ at DJ3. After testing, the unburned carbon recovered the baseline level. The unburned carbon increase of $0.08 \%$ points at DJ3 is attributed to the injection of sorbent. The unburned carbon showed a slight increase from $0.58 \%$ without sorbent injection to $0.87 \%$ with sorbent injection on average at LOS1. The unburned carbon increase of $0.29 \%$ points at LOS1 is attributed to the injection of sorbent. Both of these low rank coal sites had low sorbent feed rates (35-52 lb/hr).

At Port1, the unburned carbon showed an increase from $6.2 \%$ without sorbent injection to $9.0 \%$ (parametric tests) and 8.3\% (long term tests) under non-ozone season operation and with sorbent injection on average. The unburned carbon increase of $2.1 \%$ points between baseline and long term non-ozone tests is attributed to the injection of sorbent. This increase was higher than the other two sites because of the higher sorbent feed rates required with bituminous coal (302-330 lb/hr). Note that parametric tests included operation at both higher and lower sorbent injection rates than the long term tests. Under long term ozone tests, fly ash unburned carbon further increased to $13.4 \%$ on average. The increase of $5.1 \%$ from long term non-ozone to long term ozone tests (both with sorbent injection) is attributed to ozone season operation, where combustion is staged to reduce $\mathrm{NO}_{x}$ emissions.

Mercury content of the fly ash was documented during the long term tests. Comparing mercury content distributions, a clear difference is observed for ash samples from the last 2-3 ESP hoppers. Baseline ash samples from these hoppers do not contain as much mercury as those collected during injection testing. Mercury is more effectively captured by ash collected in the last two hoppers during injection testing. This may be due to the very fine sorbent particles being collected mostly in the last two hoppers during continuous injection testing. The ash samples with high specific mercury content all have d50 of approximately $2 \mathrm{~mm}$ and d90 of less than $7 \mathrm{~mm}$, indicating the importance of the particle size on mercury control. Previous studies have also shown that the mercury captured on activated carbon has very low leachability, and this was confirmed with TCLP testing at DJ3.

Another concern would be the impact on the fly ash saleability for concrete applications due to sorbent injection with the Mer-Cure ${ }^{\mathrm{TM}}$ technology. Fly ash with low unburned carbon content is often sold as a replacement for Portland cement in ready-mix concrete. However, fly ashes with elevated levels of carbon are unsuitable for concrete mixtures. One of the reasons given is that concrete mixtures containing such ashes require increased amounts of costly air-entraining agents (AEA) to achieve a given level of air entrainment. ${ }^{5}$

It has been suggested that the reason for an increase in the AEA requirement is due to AEA adsorption by the unburned carbon. ${ }^{6,7}$ The Foam Index Test is a rapid means to determine the relative levels of AEA needed for concrete containing fly ash and other materials that affect air entrainment in concrete. Because of the presumed influence of unburned carbon on AEA adsorption, the Foam Index Test has also been used as a measure of the degree of interaction between an AEA and fly ash or carbon. ${ }^{6,7}$ 
Fly ash containing less than $1 \%$ carbon is well within the specification for use as a concrete additive, but a Foam Index Test (or other air entrainment measure) would be needed on the specific ash from a given unit to determine if ash containing the tested level of Mer-Clean ${ }^{\mathrm{TM}}$ sorbent is suitable for concrete applications. Basin Electric sells ash from LOS1 for mine reclamation, and the ash carbon levels documented in this project do not affect use of fly ash for that purpose.

We could expect the ash (with the sorbent) in the ESP would be unsuitable for concrete applications, due to interaction of the carbonaceous sorbent and the air-entraining additives. Most of the ash (greater than 75 percent) from coal-fired boilers in the US is currently land-filled, and, in this case, would not be expected to be impacted by carbonaceous sorbent that is added in small amounts to the flue gas with our technology.

\subsection{Future Research Needs}

Long term mercury capture performance has been fairly well documented for sorbent injection. Areas where further experience would be of interest are:

1. Investigation and mitigation of $\mathrm{SO}_{3}$ effects on sorbent performance, and

2. Investigation and mitigation of sorbent impacts on ash utilization for concrete applications. 


\section{References}

1. Feeley, T., Brickett, L.A., O’Palko, B.A., and Murphy, J.T., DOE/NETL Mercury R\&D Program Review, May 2005; http://www.netl.doe.gov/technologies/coalpower/ewr/pubs/mercuryR\%26D-v4-0505.pdf

2. Feeley, T., Overview of DOE/NETL's Mercury R\&D Program, July 2005 http://www.netl.doe.gov/publications/proceedings/05/Mercury/pdf/Feeley-071205-am.pdf

3. Dombrowski, K.; 2006 Mercury Control Technology Conference, Pittsburgh, PA, 2006.

4. Dunham, G.; Hill-Brandt, K.; Olson, E.; Pavlish, J.; The Proceedings of the 31st International Technical Conference on Coal Utilization and Fuel Systems, Clearwater, FL, 2006.

5. Sjostrom, S.; 2006 Mercury Control Technology Conference, Pittsburgh, PA, 2006.

6. http://www.power.alstom.com/ looks/alstomV2/frontofficeScripts/index.php?languageld= EN\&docld=36673\&dir=/home/equipment___systems/ecs/power/mercury_control/pilot_pl ant/knx/ (accessed Jul 2008)

7. Gebler, S. H.; Klieger, P. Publication No. RD085.01T, Portland Cement Association (1983).

8. Gao, Y.-M.; Shim, H.-S.; Hurt, R. H.; Suuberg, E. M. Energy Fuels 1997, 11, 457-462.

9. Freeman, E.; Gao, Y.-M.; Hurt, R.; Suuberg, E. Fuel 1997, 76, 761-765.

10. Senior, C., Baldrey, K., Starns, T., Durham, M., Paper \# 87, Mega Symposium 2003

11. Pavlish, J., Sondreal, E.A., Mann, M.D., Olson, E.S., Galbreath, K.C., Laudal, D.L. and Benson, S.A., Fuel Processing Technology, 82 (2003) pp. 89-165

12. Laudal, D., 2006 Mercury Control Technology Conference, Pittsburgh, PA, 2006, http://www.netl.doe.gov/publications/proceedings/06/mercury/presentations/Laudal_pres entation_121306.pdf

13. Projects and Contracts, Power Engineering, July 2008 p. 34 